\title{
The renin-angiotensin system and arteriolar growth : consequences of vascular architecture for the development of hypertension
}

Citation for published version (APA):

le Noble, F. A. C. (1996). The renin-angiotensin system and arteriolar growth : consequences of vascular architecture for the development of hypertension. [Doctoral Thesis, Maastricht University]. Universiteit Maastricht. https://doi.org/10.26481/dis.19970124fn

Document status and date:

Published: 01/01/1996

DOI:

10.26481/dis.19970124fn

Document Version:

Publisher's PDF, also known as Version of record

Please check the document version of this publication:

- A submitted manuscript is the version of the article upon submission and before peer-review. There can be important differences between the submitted version and the official published version of record.

People interested in the research are advised to contact the author for the final version of the publication, or visit the DOI to the publisher's website.

- The final author version and the galley proof are versions of the publication after peer review.

- The final published version features the final layout of the paper including the volume, issue and page numbers.

Link to publication

\footnotetext{
General rights rights.

- You may freely distribute the URL identifying the publication in the public portal. please follow below link for the End User Agreement:

www.umlib.nl/taverne-license

Take down policy

If you believe that this document breaches copyright please contact us at:

repository@maastrichtuniversity.nl

providing details and we will investigate your claim.
}

Copyright and moral rights for the publications made accessible in the public portal are retained by the authors and/or other copyright owners and it is a condition of accessing publications that users recognise and abide by the legal requirements associated with these

- Users may download and print one copy of any publication from the public portal for the purpose of private study or research.

- You may not further distribute the material or use it for any profit-making activity or commercial gain

If the publication is distributed under the terms of Article 25fa of the Dutch Copyright Act, indicated by the "Taverne" license above, 


\section{The renin-angiotensin system and arteriolar growth}

Consequences of vascular architecture for the development of hypertension 


\section{The renin-angiotensin system and arteriolar growth}

\section{Consequences of vascular architecture for the development of hypertension}

\section{Copyright (C) 1996}

Niets uit deze uitgave mag worden verveelvoudigd en/of openbaar gemaakt worden door middel van druk, fotokopie, microfilm of op enige andere wijze, noch opgeslagen in een retrieval-systeem noch vertaald in welke taal dan ook, zonder voorafgaande schriftelijke toestemming van de auteur. No part of this book may be reproduced or transmitted in any form or by other means, electronic, mechanical, photocopying, recording or otherwise, without written permission from the author.

Printed and bound in The Netherlands

ISBN 90-9010258-2

Grafische vormgeving: Mady Reliëf, Landgraaf

Druk: Van Hooren, drukkerij en repro bv 


\section{The renin-angiotensin system and arteriolar growth}

\section{Consequences of vascular architecture for the development of hypertension}

\section{Proefschrift}

ter verkrijging van de graad van doctor

aan de Universiteit Maastricht te Maastricht,

op gezag van Rector Magnificus, Prof. Mr. M.J. Cohen

volgens het besluit van het College van Dekanen,

in het openbaar te verdedigen

op vrijdag 24 januari 1997 om 14.00 uur

door:

Ferdinand Anton Charles le Noble

geboren te Heerlen 1 september 1968 
Promotor:

Prof. dr. H.A.J. Struijker Boudier

Co-promotor:

Dr. D.W. Slaaf

Beoordelingscommissie:

Prof. dr. C.E. Blanco, voorzitter

Prof. dr. A.R. Pries, Freie Universität Berlin, Berlin Germany

Prof. dr. R.S. Reneman

Prof. dr. M.A.D. H. Schalekamp, Erasmus Universiteit Rotterdam

Dr. H.M.W. van Straaten

The research presented in this thesis was supported by a grant from the Netherlands Heart Foundation.

Financial support by the Netherlands Heart Foundation for the publication of the thesis is gratefully acknowledged.

For financial support of the publication of this thesis we thank:

- M.S.D. The Netherlands

- Servier The Netherlands 
For my mother

In memory of my father

The author wishes to thank all colleagues and friends who contributed to the work presented in this thesis. 


\section{Table of Contents}

\section{Chapter 1}

General introduction on Hypertension

and Vascular Development

p. 7

\section{Chapter 2}

Evidence for a novel angiotensin-II receptor

involved in neovascularization

in the chick embryo chorioallantoic membrane

p. 37

\section{Chapter 3}

The role of angiotensin-II and prostaglandins

in arcade formation

in a developing microvascular network

p. 51

\section{Chapter 4}

Localization and expression of the chick embryo angiotensin receptor in the developing vasculature of the chorio-allantoic membrane

p. 69

\section{Chapter 5}

Effects of angiotensin-II on isolated

endothelial cells in culture

\section{Chapter 6}

Angiogenic properties

of WKY and SHR rat serum

p. 99

\section{Chapter 7}

Vascular growth in the chick embryo

chorio-allantoic membrane: towards an integrative

approach for analyzing vascular architecture

p. 109

\section{Chapter 8}

General Discussion

p. 161

Summary

p. 175

Samenvatting

p. 177

List of publications

p. 180

Curriculum vitae

p. 182 
Chapter 1

General Introduction on Hypertension and Vascular development 


\section{Introduction}

Hypertension is an important risk factor for heart failure, atherosclerosis, and cerebrovascular accidents'. Hypertension may be divided into primary and secondary forms. Secondary forms include coarctation of the aorta, primary aldosteronism, glomerulonephritis, pheochromocytoma and renovascular hypertension ${ }^{153}$. Essential hypertension refers to the unknown cause of the disease. The etiology of essential hypertension suggests that it is a multifactorial disease. It has been hypothesized that a genetic predisposition and environmental factors may underly the development of

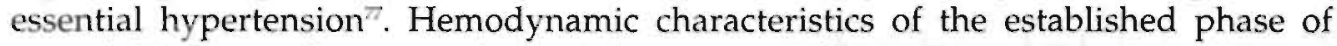
essential hypertension are an increased mean arterial pressure, a normal cardiac output, and an increased peripheral resistance ${ }^{43,104,150}$. The increase in peripheral resistance as the possible cause of the ensuing high blood pressure in hypertension has been the subject of many investigations. It has been postulated that reduced lumen diameters in the small arterioles and reduction in the available cross-sectional area for flow, both contribute to an increase in resistance. Recent evidence suggests that the latter may be due to attenuated growth of the microvasculature $e^{1496,100,156}$. This stresses the need for understanding the cellular and molecular events that control vascular development and their possible consequences for the hemodynamics.

\subsection{Blood pressure regulation}

In higher vertebrates, blood is pumped through a closed fluid circuit, the vascular system. Based on functional morphology, the vascular system can be divided in the arterial, the capillary, and the venular system ${ }^{6.5}$. The arterial system can be divided in three compartments based on function and vessel dimensions: the conduit vessels, the resistance sized vessels, and the microcirculation ${ }^{65.161}$. Blood pressure within the arterial vascular system varies during the heart cycle. The static pressure within the arterial system, the mean arterial blood pressure, depends on cardiac output and peripheral vascular resistance. Cardiac output is a function of heart rate and stroke volume ${ }^{65}$. Peripheral vascular resistance is influenced by blood viscosity, vessel diameter, and vessel length, according to Poiseuille's law ${ }^{5,124}$. Cardiac output $(\mathrm{CO})$ and mean arterial pressure (MAP) can be measured directly. Peripheral vascular resistance is calculated from the ratio of MAP and CO.

The resistance sized vessels and the microcirculation contribute to the peripheral vascular resistance. For a single vessel, resistance can be calculated according to Poiseuille's law (Table 1) ) $^{5.124}$ Vessels are part of a vascular network. The vascular architecture, the interconnection of single vessils (parallel coupling of vessels, arcades), also contributes to total vascular resistance. Any factor altering lumen diameter, vessel length, blood viscosity, or network geometry may influence peripheral resistance.

Since diameter stands to the power $t$ in Poiscuille's law, lumen diameter is considered to be an important determinant of resistance. Diameter control can be exerted by either acute or long-term adaptations. 
Acute diameter control includes nervous mechanisms, myogenic response, flow dependent dilation, metabolic regulation, direct propagation of vasodilator response, and vasomotion $32,5,5,5,60,72,73,145,149$. Long-term regulation of lumen diameter can be divided in a structural and a functional component. Structural changes include changes in vascular wall mass and structure ${ }^{24.31 .66}$. Structural changes in the vascular wall can alter lumen diameter directly by narrowing the lumen due to smooth muscle cell hypertrophy or hyperplasia, remodeling or increase in lumen diameter due to radial growth ${ }^{3,315,127}$. Long-term functional changes include alterations in the regulation of vascular tone for example by changes in sensitivity for circulating vasoactive hormones or alterations in nervous innervation ${ }^{229,255}$. Changes in network geometry, due to formation or regression of vessels, are also regarded as a long-term control mechanisms ${ }^{12}$. Theoretically, length and viscosity can influence resistance but experimental evidence supporting the idea that dynamic changes in either parameter influences resistance is scanty.

Although alteration of resistance is the subject of many investigations, resistance itself can not be sensed by the vasculature. It is a calculated parameter that determines flow to the target tissue given a certain pressure drop along a vascular segment or network. Changes in resistance that occur during development of disease should be related to their hemodynamic determinants. If perfusion of an organ remains constant, delivery of nutrients and oxygen, and removal of metabolites seems to prevail. The resulting change in prcsisure may be just the consequence and not the cause of the resistance change.

Several theories exist with regard to the genesis of the increase in peripheral resistance in essential hypertension.

\section{The Kidney}

The classic theory on renal mechanisms of primary hypertension was formulated by Borst \& Borst-De Geus and extended by Guyton ${ }^{21.64}$. A primary defect in the kidney results in a shift in the pressure-diuresis curve to a higher pressure level. This means that normal volume excretion is obtained at a higher pressure. The improper volume handling by the kidney results in an increase of cardiac output ${ }^{13104.150}$. This increase in cardiac output may result in overperfusion of the organs. In order to prevent overperfusion, the peripheral organs display an autoregulatory response, resulting in a reduced lumen diameters. This implies an increased resistance. During the established phase of hypertension, cardiac output is normalized but mean arterial pressure increased $^{104}$. Hence, normal tissue perfusion, flow, may be obtained but at the cost of a larger driving pressure. 


\section{The Vascular Wall}

A second line of reasoning has been championed by Folkow, Mulvany, and Korner ${ }^{50.51 .53}$ 55,92,93:112-116. These authors have proposed a role for changes in the vascular wall of small arteries and arterioles. They have proposed that due to vascular smooth muscle cell hypertrophy or remodeling, lumen diameter might be reduced directly. Indirectly; changes in smooth muscle cell mass can influence contractile force or sensitivity for vaso-active substances making the vessel hyperresponsive. Other mechanisms that are recognized to play an important role in resistance control at this level of the arterial tree are reduced endothelium dependent relaxation and hyperinnervation of sympathetic nerves. The functional and structural abnormalities may have a genetic cause. However, it has also been suggested that small increases in blood pressure cause small structural changes ${ }^{100}$. This implies that small blood pressure increases are continuously reinforced, ultimately leading to a substantial increase in blood pressure.

Small reductions in diameter of the resistance-sized vessels have a pronounced effect on resistance. Current treatment of hypertension is therefore targeted at antagonizing circulating vasoconstrictor substances or interfering with the intracellular second messenger release of calcium in order to obtain vasodilation.

This has resulted in administration of vasodilator drugs like $\mathrm{Ca}^{2+}$-antagonists, $\alpha$ adrenergic antagonists, angiotensin-converting enzyme inhibitors and recently, angiotensin-II receptor antagonists $58,100,164,160$. Although these drugs have been proven to be very useful in the treatment of hypertension, they may not treat the cause of hypertension $^{159}$.

\section{Architecture of the Microcirculation}

Recently, more emphasis has been put on the role of the microcirculation in the regulation of peripheral resistance in essential hypertension ${ }^{\prime \prime}$. The commonly used experimental model to study essential hypertension is the spontaneously hypertensive rat (SHR). In the established phase of hypertension, the SHR shows normal cardiac output, increased mean arterial pressure, and, hence, increased peripheral resistance ${ }^{43,150}$. Comparing SHR with normotensive Wistar Kyoto (WKY) control shows that the input pressure for skeletal muscle at the level of the microcirculation is elevated in SHR ${ }^{1930}$. However, capillary pressures during resting conditions are almost comparable ${ }^{19}$. Given an equal cardiac output for SHR and WKY, this implies, for unaltered flow distribution, a higher resistance of the microcirculation in SHR compared to WKY $Y^{930}$. This relative increase in resistance in the microcirculation may be achieved through a reduction of vessel lumen diameter according to Poiseuille's law. However, it has also been suggested that a reduction in the number of microvessels available to carry flow, i.e., rarefaction, may play a role in the resistance increase ${ }^{23,7899}$. Computer simulation studies have shown that both reduced lumen diameters in the microcirculation and a reduction in the flow transporting capacity due to regression of vessels (rarefaction) may contribute significantly to the elevated resistance ${ }^{63}$. 
Experimental evidence showing that lumen diameters are indeed reduced in the microcirculation is inconsistent. Reduced lumen diameters have been reported mainly in kidney, brain, and cutaneous maximus muscle microcirculation ${ }^{59,70,59,96,172}$. In rat cremaster muscle, both diameter reduction and diameter increase have been report$\mathrm{ed}^{20,7899,135,136}$. No differences were found in the spinotrapezius muscle ${ }^{62.140}$. In human essential hypertension, diameters of the conjunctival microcirculation were shown not to be different from normotensive controls ${ }^{69}$. In human borderline hypertension, conjunctival diameters were even shown to be increased compared to normotensive controls $^{162}$. The lack of consistent observations on diameter reductions in essential hypertension differs strongly from the observations in the microcirculation during secondary forms of hypertension in which diameter reduction (ranging from 15 to $40 \%$ ) seems to be a general phenomenon ${ }^{156}$.

Numerous studies support an important role for network architecture alterations in hypertension ${ }^{18,23,69,71,78,99,266}$. In general, the number of perfused arterioles and capillaries is reduced in several vascular beds, both in human essential hypertension and in SHR. These changes in vascular network architecture are referred to as rarefaction and are already found during early developmental stages and might precede the increase in mean arterial pressure in SHR (for review of. reference ${ }^{135.15 \% 155}$ ), which implies that rarefaction is not the consequence but the cause of hemodynamic alterations.

The nature of rarefaction in essential hypertension is unclear. It has been proposed that arterioles in the microcirculation display an enhanced tone, which results in lumen reduction and eventually lumen occlusion ${ }^{127}$. These vessels are not perfused during resting conditions but administration of the vasodilator adenosine may cause these vessels to open. The stage in which vessels are anatomically present in the tissue but not available for flow during resting conditions is referred to as functional rarefaction $^{127}$. It has been proposed that, eventually, these non-perfused vessels will regress. This stage is referred to as structural rarefaction ${ }^{127}$. Although the concept of functional and structural rarefaction may be an attractive hypothesis to explain rarefaction during secondary forms of hypertension, it may prove to be different in essential hypertension. First, arteriolar diameters are generally not decreased in essential hypertension. Furthermore, during early development ( 6 weeks) vessel recruitment after complete vasodilation is already reduced in spontaneous hypertension in rats, which implies that the total number of vessels is reduced ${ }^{\text {s. }}$. Structural rarefaction implies active degradation of vessels and the formation of ghost arterioles ${ }^{t s}$; these are vessels that are anatomically present, but not connected to the existing vascular tree. However, active removal or the presence of ghost arterioles has not yet been observed in essential hypertension.

The origin of rarefaction in essential hypertension might be understood from the following observations on peripheral resistance changes in SHR and WKY rats during early development. In the period between 6 and 12 weeks, peripheral resistance of WKY decreases, whereas peripheral resistance of SHR shows a slight increase ${ }^{43}$. 
At 6 weeks, peripheral resistance is not different between SHR and WKY. However, the significant difference between WKY and SHR at 12 weeks is caused by the substantial decrease in resistance in WKY rather than the slight increase in SHR ${ }^{43}$. This implies that the available cross-sectional area for flow is increased in WKY. This may be achieved by an increase in arteriolar diameter or by making more parallel coupled vessels available for flow.

Since, in general, vessel diameters in the microcirculation of SHR and WKY were shown not to be different, the decrease in peripheral resistance in WKY might be due to an increase in the number of parallel coupled vessels. This suggests that in SHR attenuated growth of arterioles resulting in a diminished number of parallel coupled vessels, underlies the relative increase in resistance. Taken together, microvascular rarefaction in primary hypertension might be related to a growth disorder of the vascular system $^{156}$. Indeed, epidemiological studies in humans have shown a relationship between attenuated intra-uterine growth and development of hypertension at the adult stage ${ }^{i, 96}$. A similar relationship was found in $\mathrm{SHR}^{5,4,142}$. It was therefore postulated that somatic growth and blood pressure have a functional correlation ${ }^{16}$.

The aim of this thesis is to get more insight in the processes that contribute to proper outgrowth of the vascular system and to estimate hemodynamic consequences. An attractive, clinically useful new approach for treatment of essential hypertension would be administration of microvascular grow th factors that restore normal architecture by increasing the number of parallel coupled vessels and, hence, lowering resistance, and consequently reduce the high blood pressure in essential hypertension.

\subsection{Vascular Growth}

To understand the process of vascular growth, a distinction should be made depending on the instant at which vascular growth is investigated, i.e., embryonic versus adult; the condition of the examined tissue, i.e., physiologic versus pathologic growth; and the origin of the effector, i.e., chemical versus hemodynamic factors ${ }^{327,49,76,127,133.173}$ (for overview, figure 1).

\subsubsection{Vascular growth during embryonic development}

During embryonic development, endothelial precursor cells can be detected along with primitive blood cells, (hem)angioblasts ${ }^{133.175}$. They are located in discrete zones referred to as blood islands. Subsequent fusion of blood islands is the first evidence for a primitive vasculature. The formation of these earliest blood vessels is called vasculogenesis ${ }^{133}$. Morphogenetically, vasculogenesis can be divided in vasculogenesis type 1 and type 2. Type 1 refers to angioblasts that arise in the place were the vessel is formed, for example the dorsal aorta, whereas type 2 refers to angioblasts that migrate to the site of vessel formation, for example the posterior cardinal veins ${ }^{125}$. 
These primitive blood vessels do not carry flow. Angiogenesis is defined as the formation of new blood vessels as outgrowths of pre-existing vessels ${ }^{119.133}$. The origin of endothelial cells and vascular smooth muscle cells is still under investigation.

It has been suggested that during vasculogenesis, blood vessels arise from in situ, both intra- and extraembryonic, differentiating endothelial cells ${ }^{119}$. This may require endoderm-mesoderm interaction ${ }^{119,133}$. Vasculogenesis has been found to be operative in the vascularization of endodermal organs (lung). Other organs (kidney, brain) may depend on angiogenesis ${ }^{133}$. Growth of new vessels into developing organs may results from invaginations of primitive arteries and veins into the organ. Using corrosion cast techniques this can be visualized as blind-ending tributaries of existing arteries and veins $^{3.5}$. These developing organs may also possess endothelial precursor cells that do not yet form a lumen ${ }^{35}$.

During development these endothelial cells can adhere to the invading vessels and become incorporated into the vascular wall. It has been shown that outgrow'th of the vascular system might be partly due to the incorporation of these pre-existing endothelial cells located in the organ into the vascular wall of already existing and expanding vessels ${ }^{25}$. Outgrowth of existing vessels, angiogenesis, into endothelial precursor-free mesenchyme was not observed ${ }^{35}$. It has also been shown in quail embryos that endothelial cells from the dorsal aorta and pharyngeal arch arteries develop from the same splanchnic plexus as the pulmonary arteries and the ventral pharyngeal reins, implicating a common endothelial precursor".

Thus, endothelial cells used for vessel formation may arise from in situ differentiation in the organ, from sprouting of existing vessels into the organ, or originate from a preexisting plexus located elsewhere and through migration contribute to the development of the organ vasculature.

Vascular smooth muscle cells seem to originate from the ventrolateral mesoderm and mesectodermal-derived neural crest cells ${ }^{0.187}$. During the process of vasculogenesis presumptive smooth muscle cells may be recruited from mesenchyme surrounding the developing blood vessels ${ }^{87}$. Although research regarding the origin of vascular smooth muscle cells is not conclusive, it is suggested that vascular smooth muscle cells in the tunica media of large arteries arise from neural crest cells"1. Development of the media of umbilical vein and artery seems to be independent of neural crest cells. Finally, it has been postulated that vascular smooth muscle cells may arise from fibroblasts ${ }^{22}$.

The factors controlling the final three-dimensional architecture of a vascular bed characteristic for a given organ are poorly understood. Recently, a set of genes has been identified, homeobox genes, that might be important in the regulation of organ development and, perhaps, vascular architecture . Among factors that might also determine architecture are local remodeling, apoptosis, flow, and pressure. However, the ontogeneity of organ characteristic features of endothelium, vascular smooth cells, and vascular architecture remains speculative. 


\subsubsection{Post embryonic vascular development}

During the post-natal period, the vasculature expands with tissue growth. This involves outgrowth of the existing vasculature, both in length and diameter, formation of arterioles and venules, and growth of capillaries ${ }^{76}$. Literature reviewing vascular development usually addresses these processes with a single term, angiogenesis. However, they may involve distinctive cellular control mechanisms. Therefore, for clarity, a distinction may be made between arteriolar and venular growth, capillary growth or true angiogenesis, and adaptitive processes in already exisiting vessels.

\section{The capillarization process}

Post-embryonic capillary growth, or true angiogenesis, follows a set program ${ }^{10.27 .76}$ (fig. 2a). The first event involve's disruption of the basement-membrane surrounding the endothelial layer. This is associated with production of digestive enzymes, such as collagenases and plasminogen activator by the endothelial cell. The second event is migration of the endothelial cell towards the angiogenic stimulus. This is followed by proliferation of the endothelial cell. Finally, the new sprouts form a lumen, fuse with nascent tubes, and become surrounded by a basement membrane. It was postulated that during normal development angiogenesis takes place at the venular side of the capillary bed ${ }^{7}$. Although angiogenesis in general is associated with endothelial cell proliferation, this is not essential as has been shown in a rabbit eye angiogenesis assay ${ }^{1+8}$. In mature adult tissues, the turnover of endothelial cells is very low, angiogenesis is rarely observed, and the vasculature is in a quiescent stage ${ }^{27}$. One exception is the female reproductive tract ${ }^{132137}$. During the menstrual cyle, vascular growth is observed in the endometrium. Furthermore, angiogenesis is necessary for normal development of the corpus luteum ${ }^{132,137}$.

\section{Development of arterioles and venules}

Surprisingly little experimental evidence is available dealing with the aspects of arteriolar and venular growth (fig. $2 \mathrm{~b}$ ). It has been postulated that arterioles grow by investing of capillary tubes with circular layers of smooth muscle cells, and not by sprouting ${ }^{128}$. It was suggested that at the transition of a terminal arteriole and a capillary, vascular smooth muscle cells, which most likely originate from the arteriole, migrate towards the capillary tube, and subsequently surround the capillary tube and form a circular layer ${ }^{128}$. Although the nature of the process that controls arteriolization is not known, it may involve several distinct events. Assuming that the vascular smooth muscle cells used for the upgrading arise from an existing terminal arteriole, it may involve proliferation of vascular smooth muscle in the vascular wall of the arteriole, and migration towards the capillary tube. Growth of the vascular smooth muscle cell may be controlled by local autocrine and paracrine growth and anti-growth factors s.1.123.143.14. $^{3}$. 
Enabling migration towards the capillary tube may involve the creation of a pathway in the surrounding extracellular matrix ${ }^{86}$. This would involve the activation of digestive enzymes, metalloproteinases, that actively degrade the extracellular matrix ${ }^{81.56,111}$.

It furthermore requires a direction of movement. This may involve the establishment of a chemical gradient towards the capillary tube. Although the origin of this gradient remains speculative, it may involve the release of chemoattractants by the capillary endothelium. Based on these theoretical considerations, the extracellular matrix may play an important role in the arteriolization process ${ }^{106,138}$. The extracellular matrix consists of collagens, adhesive glycoproteins, and proteoglycans ${ }^{106,138.167}$. Cells in the vascular wall express receptors for the extracellular matrix, integrins ${ }^{\circ 0}$. Interactions between the extracellular matrix and integrins influence cell behaviour by altering cell differentiation, proliferation, and signal transduction ${ }^{70,80}$. The extracellular matrix is furthermore involved in binding of growth factors which may regulate cell growth, and facilitate cell-cell interactions ${ }^{134}$. During embryonic development, the extracellular matrix is an important determinant of organ morphogenesis ${ }^{103}$.

The vascular smooth muscle cells used for upgrading capillaries do not necessarily have to originate from the existing arteriole. Capillary tubes are sometimes accompanied by pericytes ${ }^{i t}$. These cells, which contain contractile proteins, are localized inbetween the basal membrane and the endothelial cell layer, and are thought to play a role in capillary growth ${ }^{17.1+6 .}$. However, it has also been speculated that pericytes can differentiate into vascular smooth cells and possibly contribute to the arteriolization process $^{146}$. Finally, the arteriolization process may involve other cells, for example mast-cells, capable of releasing substances that can either alter growth (histamine), or act as a chemoattractant 19 .

Experimental studies specifically addressing the question how venules grow, are lacking. This may be due to the fact that venules are generally not considered to play a role in arterial pressure regulation. Theoretically, venular growth may involve the same events as the arteriolization process but at the venular part of the circulation. Although the events in arteriolar and venular growth may be comparable, the regulation of their grow th seems to be quite different. In pathological conditions like hypertension, arteriolar densities tend to be decreased, rarefaction, whereas venular densities tend to be increased ${ }^{78}$. This may be due to the fact that venules are not exposed to changes in central hemodynamics. Their growth is probably more likely controlled by local conditions like interstitial pressure. For the understanding of the process of vascular development in general, and especially of venular changes in pathology, more emphasis should be put on clarifying the differences in grow th regulation of arterioles and venules. 


\subsubsection{Physiological growth}

It is recognized that the main function of the capillary network is to provide an exchange organ for oxygen and nutrients, and removal of metabolites ${ }^{3,76}$. To ensure metabolic homeostasis, the capillary network would have to meet organ requirements. Indeed, the number of capillaries in an organ is related to the metabolic status ${ }^{3}$. Skeletal muscles with a high aerobic metabolism, red muscles, have a more dense capillary network than white muscles with a glycolytic metabolism ${ }^{75,76}$. Physical training, excercise, has been shown to result in higher capillary densities in heart and skeletal muscles $^{76}$. Similar results were obtained with chronically electrically stimulated muscles. It has also been shown that immobilization of skeletal muscle may lead to a decrease of capillary density ${ }^{76}$. Furthermore, growing of chick embryos under low oxygen tension led to an increase of the vascular density of the chorio-allantoic membrane (CAM) and an increased vascular volume of the embryo proper. A metabolite resulting from a low oxygen tension, adenosine, can induce angiogenesis in the CAM assay. Growing chick embryos under high oxygen tension will result in lower vascular density of the CAM vasculature as compared to growing under normoxic conditions. These observations led to the hypothesis that angiogenesis, at least during physiological conditions, is tightly controlled by the metabolic demand of the tissue?.

\subsubsection{Pathological growth}

Although angiogenesis is rare during adult life, certain pathological conditions are associated with extensive vascular proliferation. These pathological conditions include tumor growth, diabetic retinopathy, retrolental fibroplasia, psoriasis, and wound healing ${ }^{7.679,99}$. Diabetic retinopathy and retrolental fibroplasia are characterized by excessive capillary proliferation, eventually occluding the retina and impairing normal vision. Folkman ${ }^{+7}$ showed that tumor growth is dependent on the formation of a supportive vascular network near the growing tumor. Without induction of a vascular network, tumors will not grow beyond a few millimeters ( $10^{6}$ cells). In order to establish a supportive vascular network, tumors may release a chemical substance that can evoke an angiogenic response. Extensive research during the last two decades showed the existence of numerous (tumor) angiogenic factors ${ }^{4,449121}$ (Table 2). Angiogenic factors might influence the angiogenic process directly by stimulating endothelial cell proliferation, migration, or lumen formation, or indirectly by activating host cells, for example mast-cells, to release angiogenic substances. On the other hand, the activity of angiogenic factors has been shown to be counterbalanced by endogenous inhibitors of angiogenesis". Extensive reviews dealing with molecular and cellular mechanisms of action of growth and anti-growth factors can be found in

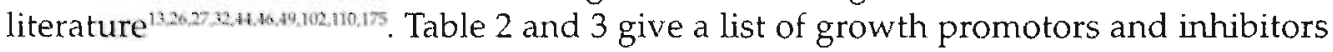
currently studied. 
Changes in the morphology of microvascular networks and alterations in the structure of the vessel wall of arterioles and arteries during pathological conditions like essential hypertension and secondary hypertension, have led to the suggestion that, besides chemical factors, hemodynamic factors such as flow and pressure may also influence vascular development ${ }^{127}$. The effects of hemodynamics on vascular development will be discussed in section 1.5.

Literature reviewing the process of angiogenesis usually discerns between "physiologic" and "pathologic" or tumor growth. However, the two processes of angiogenesis have not been shown to be different ${ }^{175}$. In fact, tumor associated angiogenesis might also be governed by the metabolic demand of the extensively growing tumor cells, whereas excercise induced angiogenesis is highly correlated with the expression of vascular endothelial growth factor ${ }^{67}$; this in its turn is also associated with tumor growth. The difference between physiologic and pathologic growth may be found in the resulting architecture of the vascular networks ${ }^{33}$. Tumor associated networks can be described as having a chaotic appearance, with pronounced dilation of feeding arterioles and tortuousity of capillaries ${ }^{33,171}$. At the capillary level, the basement membrane does not have to be continuous and gaps between endothelial cells can be present, enabling spread of tumor cells through the blood ${ }^{101}$. The origin of this abberant pattern and the hemodynamic consequences are still subject for investigations. It is therefore of great importance to recognize that angiogenesis should not be looked upon as the simple result of an imbalance of growth factors but that it also incorporates architectural design.

\subsection{The renin-angiotensin system and angiogenesis}

The first experimental evidence showing that angiotensin-II, the active substance of the renin-angiotensin system, could play a role in angiogenesis was put forward by Fernandez et $\mathrm{al}^{45}$. They showed that Ang-II could induce angiogenesis in the rabbit cornea angiogenesis assay. A polyacrylamide gel containing $5 \mu \mathrm{g}$ of angiotensin-II was implanted into a surgically created pocket in the cornea. In the period following surgery, they observed that small capillaries, coming from the limbal circulation, crossed the corneal-limbal junction and penetrated the cornea, which, normally does not contain blood vessels. Subsequently, these capillaries increased in length, and diameter, and started to branch off. Growth proceded towards the cornea pocket. The changes in vascular growth were assessed semi-quantitatively by comparing the treated eye with the untreated contralateral eye, and scoring vascular growth on a fourpoint ordinal scale ( 0 , no new vessel formation; 3 , prominent vessel growth). The peak in the development of corneal vascularity was obtained after 2-3 weeks, after which vessels would slowly regress and disappear. Positive neovascularization was present in $85 \%$ of the total number of corneas implanted with angiotensin-II. The authors concluded that angiotensin-II has angiogenic properties, and may stimulate the capillarization process in vivo. 
Involvement of the renin-angiotensin system in vascular growth was put forward by two studies of Wang \& Prewitt ${ }^{168,169}$. In the first study the authors showed that treatment of normotensive Wistar rats and one-kidney one-clip hypertensive rats with the angiotensin converting enzyme inhibitor captopril attenuated microvascular development in the rat cremaster muscle. They observed that captopril, given in a dose of 100 $\mathrm{mg} / \mathrm{kg} /$ day during four weeks, decreased the small arteriolar density by $37 \%$ in the hypertensive, and by $20 \%$ in the control rats. Furthermore, captopril treatment resulted in an increase in wall-to-lumen ratio of the first order arterioles of both hypertensive and normotensive rats, and a decrease in cross-sectional wall area of these vessels of $37 \%$ in hypertensive rats and of $20 \%$ in normotensive treated rats, which may suggest a structural reduction in arteriolar diameter. In the second study, they examined the longitudinal effect of captopril treatment, in a dose of $100 \mathrm{mg} / \mathrm{kg} /$ day, on arteriolar development in normotensive rats. They showed that after captopril arteriolar density (of vessels with a diameter ranging from $15-150 \mu \mathrm{m}$ ) in the rat cremaster muscle was decreased $17 \%$ at 4 weeks, and $13 \%$ at 8 weeks. From these studies, it may be concluded that chronic treatment with captopril attenuates arteriolar growth, resulting in both a reduction in number of vessels and a structural lumen reduction.

Long-term (4 weeks) peripheral ischemia in spontaeously hypertensive rats is associated with vascular growth, expressed as an increase in capillary-to-fibre ratio in the soleus muscle ${ }^{118}$. Chronic treatment with the angiotensin-converting enzyme inhibitor captopril in a dose of $0.5 \mathrm{mg} / \mathrm{kg} / \mathrm{h}$, abolished the increase in capillary-to-fibre ratio.

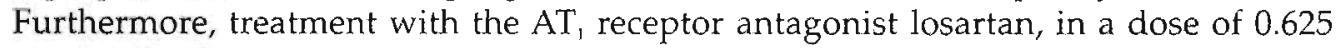
$\mathrm{mg} / \mathrm{kg} / \mathrm{h}$, also prevents an increase in capillary-to-fibre ratio. These data suggest that angiotensin-II, most likely through activation of the $\mathrm{AT}_{1}$ receptor, may influence capillary growth in the rat soleus muscle during ischemia.

Unger et $\mathrm{al}^{165}$ observed that chronic oral treatment, starting in utero and subsequently up to 20 weeks of age, with the ACE-inhibitor ramipril in dose of $0.01 \mathrm{mg} / \mathrm{kg}$ day and $1 \mathrm{mg} / \mathrm{kg}$ day, induced myocardial capillary growth in the spontaneously hypertensive rats. Capillary growth was assessed stereologically. The effect of ramipril on capillary growth was independ of the antihypertensive action. Further studies by the same group showed that angiotensin-II can inhibit rat coronary endothelial cell growth in vitro $^{i 52}$. This growth-inhibitory effect of angiotensin-II was mediated through the $\mathrm{AT}_{2}$ receptor ${ }^{152}$.

From the in vivo experimental studies, it may be concluded that angiotensin-II can stimulate the arteriolization process and enhance capillary growth. However, less is known about the potential sites of interaction of angiotensin-II with the mechanisms of both growth processes. Enhancement of the arteriolization process may involve growth and/or migration of vascular smooth muscle cells. Furthermore, since the arteriolization process may result from upgrading of capillaries, vascular smooth muscle cells have to be directed towards the terminal part of the circulation, the capillaries. Substantial experimental evidence shows that angiotensin-Il can stimulate growth of vascular smooth muscle, both hyperplasia and hypertrophy $y^{16,17,74,88,122,139,170}$. 
It has furthermore been shown that angiotensin-II is capable of activating signal transduction pathways and inducing expression of genes involved in the regulation of cell growth ${ }^{2,99,105,13}$. It has also been shown that angiotensin-II can stimulate vascular smooth muscle cell migration ${ }^{15}$. However, evidence showing that angiotensin-II can actually direct migration (towards capillaries) is lacking. Theoretically this process may involve two events. First, vascular smooth muscle cells in the arteriolar wall are attached to and surrounded by the extracellular matrix. To allow migration, a pathway enabling movement has to be created. This may involve activation of enzymes that degrade the extracellular matrix. Second, the created pathway has to direct the vascular smooth muscle cell towards the capillaries. This may involve the establishment of a chemical gradient through the release of chemo-attractants by the endothelial cells of the capillary plexus. However, the extracellular matrix exerts tensile forces on the vascular smooth muscle cell, which may also help to direct the movement of the vascular smooth muscle cell.

Capillary growth is a multi-step process including basement membrane degradation, endothelial cell proliferation and migration, lumen formation, and fusion of developing sprouts. Based on the in vivo results of Fernandez et al ${ }^{15}$, angiotensin-II may interfere with any of these processes. In vitro studies have provided evidence that angiotensin-II may induce endothelial cell growth. Less attention has been paid to other events in the capillarization process. It may, however, be speculated that, similar to the arteriolization process, angiotensin-II can trigger the release of enzymes that digest the basement membrane and the extracellular matrix, thereby allowing endothelial cells to migrate. A possible role of angiotensin-II in lumen formation and sprout fusion remains speculative since the nature of these processes is largerly unknown. Based on the available experimental evidence, both in vivo and in vitro, and theoretical considerations on the potential sites of interaction with the mechanisms of vascular growth, the renin-angiotensin system (RAS) may be regarded as an important candidate to play a role in vascular development.

Table 1 . Definitions of Resistance, Shear stress and Circumferential wall stress.

Resistance for a vessel segment according to Poisseuille law
$R=$
$8 \mathrm{Ln}$
$L$, vessel length; $n$, viscosity; $r$, radius
Unit: Pam's
$\pi r^{4}$

Shear Stress for a vessel segment

$\tau=\frac{4 n Q}{\pi r^{3}} \quad \begin{aligned} & Q, \text { flow; } n, \text { viscosity; } r \text {, radius } \\ & \text { Unit: } N / m^{2}\end{aligned}$

Circumferential wall stress for a vessel segment (Laplace)

$\sigma=\frac{\operatorname{Pr}}{W} \quad \begin{aligned} & \text { P, pressure; } r \text {, radius; } W \text {, wall thickness } \\ & \text { Unit: } N / \mathrm{m}^{2}\end{aligned}$


Table 2. Angiogenic factors.

Fibroblast growth factor (FGF), acid-FGF, basic-FGF

Vascular endothelial growth factor (VEGF)

Platelet derived growth factor (PDGF)

Transforming growth factor- $\alpha$ (TGF- $\alpha$ )

Transforming growth factor- $\beta$ (TGF- $\beta$ )

Tumor necrosis factor- $\alpha$ (TNF- $\alpha$ or cachetin)

Angiogenin

Insulin-like growth factor (IGF-I)

Granulocyte-macrophage colony stimulating factor

Interleukin 1 (IL-1)

Interleukin 6 (IL-6)

Interleukin 8 (IL-8)

Endothelial cell angiogenesis factor (ESAF)

Substance P

Prostaglandins (PGE1, PGE2)

Adenosine

Angiotensin-II (Ang-II)

Tible 3. Angiogenesis inhibitors

Angiostatin

Angioinhibin (AGM-1470/TNP470)

Interferon- $\alpha$

Thrombospondin

Platelet factor 4

angiostatic steroids

cartilage-derived inhibitor

Thalidomide

Carboxyaminoimidazole

anti-proleolytic agents 


\subsection{Hemodynamics, flow and pressure, with regard to vascular growth}

The first study of the role of hemodynamic factors in the regulation of vascular growth was initiated by Thoma during the previous century ${ }^{163}$ Looking at the microcirculation of the chick-embryo vitelline membrane, he postulated a relationship between flow and growth of vessels. He observed that vessels with a high flow widen whereas vessels with low flow regress or disappear. Although Thoma was unable to measure flow and pressure, he was the first to postulate that hemodynamics may influence vascular development.

It is currently suggested that vessels may adapt their dimensions to match changes in flow and pressure according to shear stress and circumferential wall stress adaptation

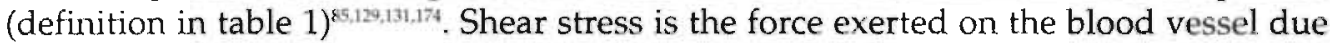
to shear of the flowing blood along the vascular wall ${ }^{174}$. Circumferential wall stress is related to the force distending the blood vessel, i.e., the intra-luminal pressure ${ }^{35}$. To evaluate the effects of shear stress and circumferential wall stress adaptations on vascular development, a distinction has to be made between acute and long-term effects and, between effects on a single vessel and the vascular network. Furthermore, the effects may be dependent on the developmental stage, i.e., embryonic versus adult, of the vascular bed examined.

For single vessels, adaptation to shear stress implies that an acute reduction in flow is counteracted by a lumen reduction, whereas an increment in flow is counteracted by a lumen increase $e^{60.8595,174}$. Both experimental and theoretical studies support the idea that, in adult tissues, shear stress is rather constant throughout the circulation with values in the arteriolar tree ranging from $1.04-2.6 \mathrm{~N} / \mathrm{m}^{2}(05.107,147)$. This may imply that vessels strive for an optimal shear stress value. Experimental studies have shown that longterm increments in tissue flow, during exercise ${ }^{4.75}$ or treatment with vasodilatory drugs $^{30,13}$, may cause radial outgrowth of arterioles, implying a structural lumen increase. It is interesting to notice that the flow-induced vasodilatory response, which during the acute phase is partly mediated by local release by the endothelium of vasodilator substances like nitric oxide ${ }^{109}$ and prostacyclin, in the long-term phase may result in a structural adaptation of the vascular wall. Although the nature of this switch from functional to structural adaptation is not known, it may involve growth or rearrangements of vascular smooth muscle cells and endothelial cells in the vascular wall ${ }^{114,115}$. Experimental studies have furthermore shown that long-term increment in flow during exercise result in an increase of the number of arterioles", hence, increase of the arteriolization process, and the number of capillaries" ${ }^{\% 4}$, hence, enhancement of the capillarization process ${ }^{55,76}$. In vitro studies with isolated endothelial cells have shown a proliferative response to shear stress ${ }^{636}$. It has furthermore been proposed that flow-mediated dilation may cause endothelial cells and vascular smooth muscle cells in arterioles to stretch. 
This may act as a proliferative stimulus ${ }^{3}$. Computer modeling studies have suggested that adaptation to shear stress alone is not enough to explain the maintainance of a stable vascular network $k^{66}$. Vessels preferential for carrying flow were predicted to increase lumen diameter, whereas vessels perpedicular to the preferential flow direction, were predicted to regress. Eventually, this process leads to regression of almost all arterioles, venules, and capillaries, and finally to the formation of $\mathrm{A}-\mathrm{V}$ shunts ${ }^{66}$. Since in vivo this is not a general phenomenon, adaptation to shear stress alone can not explain the formation of stable vascular network. Thus, although shear stress seems to be controlled within a rather narrow range, it does not seem to be the primary regulated variable.

Vessels may also adapt to changes in intra-luminal pressure according wall stress adaptation $^{11,127}$ (definition in table 1). Wall stress adaptation suggests that changes in vessel diameter or wall thickness may compensate for changes in pressure. Experimental evidence indeed shows a close correlation between the level of systolic blood pressure and wall thickness ${ }^{115}$. Mulvany ${ }^{115}$ postulated that in essential hypertension, structural changes in the vascular wall resulting in an increased media to lumen ratio, hence, lumen reduction and increase in average media thickness, are adaptive mechanisms induced by increased pressure. This process may either involve growth of vascular smooth muscle cells, or rearrangement of vascular smooth muscle cells around a more narrow lumen, i.e., remodeling

Beside effects on the structure of single vessel, pressure may also have profound effects on the microvascular network architecture. In experimental secondary forms of hypertension it has been shown that an increase of arteriolar pressure is accompanied by a decrease in number of perfused arterioles and capillaries, both structural and functional rarefaction ${ }^{127,156}$. Regions protected from rises in central blood pressure showed attentuated rarefaction ${ }^{15}$. Recently, computer simulation studies suggested that increases in pressure may explain rarefaction by adaptation to circumferential wall stress ${ }^{129}$. However, a similar study showed that adaptation to circumferential wall stress could explain upgrading of capillaries into arterioles resulting in arteriolar-arteriolar arcade formation, hence a stimulation of the arteriolization process ${ }^{120}$. Finally, it has been shown that modeling according to circumferential wall stress alone can also not explain the maintainance of stable vascular networks"...

Taken together, both experimental and computer simulation studies suggest that changes in hemodynamics may influence vascular development through shear stress and circumferential wall stress adaptation. Little attention has been paid to the mechanisms that may control the shift of acute (functional) towards long-term (structural) regulation. Furthermore, shear stress or circumferential wall stress alone are not sufficient to explain the maintainance of a vascular bed. This may imply that for the maintainance of a vascular bed, a combination of shear stress, wall stress, and perhaps other regulatory mechanisms, for example metabolic demand ${ }^{3}$, is required. 
Furthermore, the studies mentioned, describe alterations in an already existing, quiescent vascular bed. In a growing vascular bed, as during embryogenesis, the influences may be different, since the abilitiy of the vascular wall to sense shear and circumferential wall stress may involve the local release of vaso-active substances, intracellular coupling between membrane receptors and the contractile apparatus, and the release of growth hormones, which do not necessarily have to be present. Literature addressing the question how hemodynamics influence vascular growth during early developmental stages is lacking. Since it has been postulated that essential hypertension may be due to a growth disorder of the vascular system ${ }^{156}$ during early development, more emphasis should be put on understanding the mechanisms that govern growth control especially during this period.

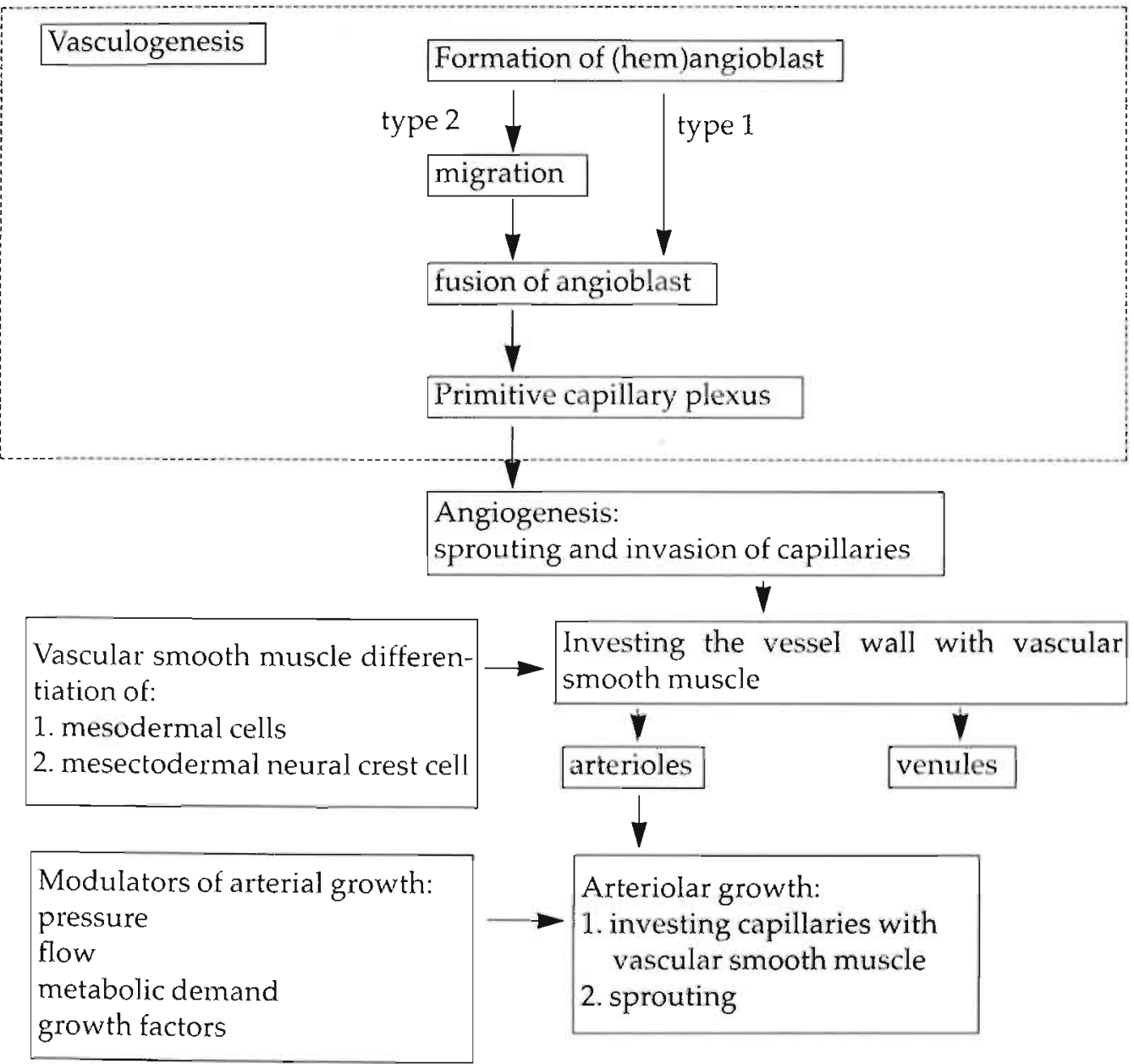

Figure 1. Schematic representation of the process of vascular development. 
Angiogenesis:

1. degradation of the basement membrane surrounding the endothelial layer

2. migration of the endothelial cell towards the angiogenic stimulus

3. proliferation of endothelial cells

4. lumen formation and fusion with nascent sprouts

5. formation of the basement membrane

Fig. 2a. Schematic representation of the five events involved in capillary growth or angiogenesis (section 1.2.2.2).

Arteriolar Growth:

I: based on upgrading of capillaries into arterioles:

1. proliferation of vascular smooth muscle cells

2. migration of vascular smooth muscle towards the capillary plexus

3. alignment of vascular smooth muscle cells around the capillary tube

4. modulation of the extracellular matrix

II: based on sprouting of arterioles:

1. no experimental evidence available indicating sprouting

Fig. $2 b$. Schematic representation of the events that may take place during development of arterioles (section 1.2.2.2). 


\section{Assays for angiogenesis}

To study angiogenesis, several in vivo and in vitro models have been developed. The model used in this thesis, the chick embryo chorioallantoic membrane, is discussed below. Extensive reviews dealing with angiogenesis assays and models can be found in literature $e^{826}$.

\section{Chick-embryo chorioallantoic membrane assay}

The chick-embryo chorioallantoic membrane assay is a technique used by embryologists that involves analysis of the developmental potential of grafts transplanted onto the chorioallantoic membrane $(\mathrm{CAM})^{20,09}$. Because the chick-embryo lacks a complete immune system, xenografts from mammalian species become established and grow. Vascularization of these grafts is rapid. Folkman used this model to test his hypothesis that tumortissue can evoke an angiogenic response ${ }^{10.12 .48}$. For this purpose, fertile eggs were incubated for three days. At day 3, a rectangular window was made in the eggshell and some albumen was withdrawn from the egg. The CAM vasculature becomes established around day 5 of embryonic development. Subsequently, the tumortissue was placed on the CAM and the angiogenic response was evaluated 3-4 days later. Typically, a tumorgraft would evoke a spoke-wheel type arrangement of vessels directed towards the graft ${ }^{390}$. The growth response was evaluated semi-quantitatively by scoring on a graded scale ( 0 , no vessel growth; 4 pronounced vessel growth). In subsequent studies, Folkman incorporated substances extracted from tumortissue, slow releasing polymers (Elvax) ${ }^{94}$. The polymers were put onto the CAM and the possible growth response was evaluated similar to the graft studies.

The elaborate work by Folkman has led to the identification of numerous stimulators and inhibitors of angiogenesis $\mathrm{s}^{\text {s.4. }}$. In fact, almost all substances known to influence (tumor) angiogenesis have been tested in the CAM assay ${ }^{49}$. This is an important observation since the isolated (anti) growth factors originate from mammalian species. This may imply that vascular growth in various species may be governed by similar control mechanisms.

To allow a more quantitative assessment of vascular grow th in the CAM, stereological techniques have been introduced ${ }^{3540,154}$. This technique involves counting the number of intersections of blood vessels with a counting grid ${ }^{\text {it }}$. The number of intersections with the grid is linearly related to the vascular density ${ }^{14}$. Vascular density is comprised of both vessel length and vessel number. However, it does not contain information about the spatial distribution of vessels. Scoring on an ordinal scale seems to be quite useful for evaluating large changes in vascular growth usually elicited by tumor growth factors, but is compromised by the resolution of the human eye and prone to interpretation errors by the observer. It furthermore does not allow to make a distinction between changes in arteriolar, venular, or capillary growth. The stereogical technique involves the use of a microscope and may allow to quantify even subtle changes in growth of small arterioles, venules and capillaries. However, it is more time consuming than scoring with the eye. 
Currently, the chick embyo chorioallantoic membrane assay can also be carried out on explanted chick embryos ${ }^{826}$. In this assay, the egg content is transferred into a petridish or a plastic cup. Under these conditions, the CAM develops on top as a flat membrane, reaching to the edge of the petri-dish or plastic cup, to provide a two-dimensional monolayer on which substances with a potential angiogenic capacity can be tested. This technique has the advantage that the entire CAM is visible, which may allow the continuous observation of the developing CAM vasculature. It furthermore allows the use of multiple sites on the CAM, hence, the test substance and the control substance may be evaluated in the same individual, thus decreasing inter-individual variability. However, this technique is compromised by a decreased viability compared to the window technique. This is due to the fact that the embryo or the membrane are more likely to become damaged during the explanting procedure.

Although the CAM has proven to be quite useful in the identification of angiogenic substances, it may have some limitations. First, the CAM serves as functional lung tissue for the developing embryo. This implies that the oxygen tension in arterioles is smaller compared to venules. Since oxygen tension has been implicated in vascular growth, it may have a differential role in the modulation of arteriolar and venular growth. Furthermore, the CAM is a rapidly expanding tissue during the period day 510, whereas after day 10, the CAM ceases to grow ${ }^{51}$. It may therefore be difficult to distinguish between true angiogenesis or neovascularization associated with tissue growth. Application of drugs in elvax polymers or other vehicles may induce a false positive response due to irritation or inflammatory responses ${ }^{84}$. Finally, growth in the CAM may be prone to changes in environmental factors like gas content $\left(\mathrm{pO}_{2}, \mathrm{pCO}\right)$ or $\mathrm{pH}$. However, the CAM is a model that allows (1) continuous observation of the vascular growth process in time and (2) repetitive local administration of drugs that may interfere with growth. This makes the CAM a very suitable model for pharmacological intervention studies.

\subsection{Summary}

The process of postembryonic vascular growth may be divided in: (1) angiogenesis, which takes place at capillary level, and (2) the arteriolization process.

In the process of angiogenesis 5 critical events take place, basement membrane degradation, endothelial cell migration, endothelial cell proliferation, tube formation and fusion of growing sprouts, and formation of a new basement membrane. The process of arteriolization involves upgrading of capillaries into arterioles by investing capillary tubes with vascular smooth muscle cells. Vascular growth can be influenced by several (anti) growth factors that can have specific effects on the mentioned events. Beside the growth factors, the growth response may be controlled by a complex interplay of endothelial cells, vascular smooth muscle cells, pericytes and other cells like mast cells. Since vessels grow within a certain tissue frame-work, composition of the extracellular matrix, controlled by proteolytic enzymes and fibroblast activity, has got to be taken into account as well. 
Since vessels are part of the circulation, changes in hemodynamics may influence growth according to shear stress and circumferential wall stress adaptations. Finally, the orchestration of vascular growth might be controlled by a genetic super control mechanism involving homeobox genes. The result of the mentioned interactions between growth factors, cells, and extracellular matrix is a vascular bed. This vascular bed has to perform a certain physiological function. To understand vascular growth, it may not be regarded upon as the mere complex interaction of cells and growth factors, but as a process thriving from the organs need for homeostasis.

\subsection{Present Thesis}

The aim of this thesis is to evaluate the role of the renin-angiotensin system in vascular development, both the arteriolization and the capillarization process. Furthermore, we applied a computer model with in vivo observations to determine the effects of changes in vascular architecture on distribution of flow and development of resistance.

The first experimental study, chapter 2, focusses on the role of angiotensin-II and specific AT receptor antagonists on vascular development in the chick embryo chorioallantoic membrane. This was investigated both in vivo looking at angiogenic responses and by ligand-binding studies.

Chapter 3 focusses on the architectural changes after angiotensin-II induced vascular growth. Pharmacological induction of vascular growth in the CAM resulted in an aberrant arteriolar developmental pattern. Insight in factors that control arteriolar growth might be important to understand pathological processes in which arteriolar development is impaired, for example arteriolar rarefaction. The study evaluates parameters used for quantifying arteriolar development and, by means of pharmacological intervention, tries to gain insight in the mechanism that controls the arteriolization process.

To understand the mechanism of action of angiotensin-II in the angiogenic process, we wanted to localize the AT receptors in the vasculature. Chapter 4 describes the autoradiography study that was performed to localize angiotensin-II receptors in the CAM. Chapter 5 describes the effects of angiotensin-II on isolated endothelial cells in vitro. Since endothelial cells are the main effector cells in the process of angiogenesis, it was investigated whether Ang-II could alter endothelial cell grow th.

It has been postulated that genetic hypertension and attenuated vascular development are linked. Chapter 6 describes a study in which differences in the angiogenic capacity of normotensive Wistar Kyoto rats and Spontaneously Hypertensive rats were investigated. 
Finally, chapter 7 describes a study in which the growth of an arteriolar tree was followed during embryonic development. The consequences of vascular growth for resistance control and flow distribution were investigated. It was furthermore investigated whether the pattern of growth could be explained from topological growth models. Finally, it was assessed whether adaptations to shear or wall stress could explain the pattern of growth. This was done by comparison with computer models.

The thesis ends with a general discussion integrating the observations regarding the role of angiotensin-II in vascular development. The relation between vascular growth, network architecture and hypertension is also discussed in the final chapter. 


\section{References}

1. 1988 Joint National Committee. The 1988 report of the joint national committee on detection, evaluation, and treatment of high blood pressure. Arch Int Med. 148, 1023-1037, 1988.

2. Abboud FM. The sympathetic system in hypertension. Hypertension. 4 (suppl. II), ilz208-1:225, 1982.

3. Adair TH, Gay WJ, Montani J. Growth regulation of the vascular system: evidence for a metabolic hypothesis. Am I Physiol. 259. R393-R404, 1990.

4. Adair TH, Hang J, Wells ML, Magee FD, Montani JP. Long.term electrical stimulation of rabbit skeletal muscle increases growth of paired arteries and veins. Am I Physial. 269, H717-H724, 1995.

5. Aguilar E, Rodriguez L, Bellido C, de la Fuente M, Pinilla,L. Changes in growth hormone secretion in spontaneously hypertensive rats. Neuroendocrin. 5?, 337-341, 1990.

6. Ando J, Nomura H. Kamiya A. The effect of fluid shear stress on the migration and proliferation of cultured endothelial cells. Microvasc Res. 33, 62-70, 1987.

7. Arnold F, West DC. Angiogenesis in wound healing. Pharmac Ther. 52, 407.422, 1991.

8. Auerbach R. Auerbach W, Polakowski. Assays for angiogenesis: a review. Pharmac Ther. 51, 1-11, 1991.

9. Auerbach W, Auerbach R. Angiogenesis inhibition: a review. Pharmac Ther. 63, 265-311, 1994.

10. Ausprunk DH, Folkman J. Migration and proliferation of endothelial cells in preformed and newly formed blood vessels dur ing tumor angiogenesis. Microvasc Res. 14, 53-65, 1977.

11. Ausprunk DH, Knighton DR, Folkman I. Differentiation of vascular endothelium in the chick charioallantois: a structural and auturadiographic study. Dev Biol. 38, 237-248, 1974.

12. Ausprunk DH, Knighton DR, Folkman I. Vascularization of normal and neoplastic tissues grafted to the chick chorioallantrois. Am I Pathol.. 79, 597-611, 1975.

13. Baillie CT, Winslet MC, Bradley N\}. Tumour vasculature - a potential therapeutic target. Br I Cancer. 72, 257-267, 1995.

14. Barker DJP, Bull AR, Osmond C, Simmonds SJ. Fetal and placental size and risk of hypertension in adult life. BM]. 301, 259. $262,1990$.

15. Bell L, Madri JA. Influence of the angiotensin system on endothelial and smooth muskle cell migration. Am J Pathol. 137. 7 . 12,1990 .

16. Berk BC, Rao GN. Angiotensin-II induced vascular smooth muscle cell hypertrophy: POGF.A chain mediates the increase in cell size. J Cell Physiol. 154, 746-754, 1993 .

17. Berk BC, Vekhstein V, Gordon HM, Tsuda T. Angiotensin-II stimulated protein synthesis in cultured vascuiar smoath muscle cells. Hypertension, 13, 305-314, 1989.

18. Bohlen HG. Intestinal microvascular adaptation during maturation of SHR. Hypertension. $5,739 \cdot 745,1983$.

19. Bohlen HG. The microcirculation in hypertension. I Hypertens. 7 (Suppl. 4), S117-S124. 1989.

20. Bohlen $\mathrm{HG}$, Lobach $\mathrm{D}$. In vivo study of microvascular wall characteristics and resting control in young and mature sponta. neously hypertensive rats. Blood Vessels. 15, 322-330, 1978.

21. Borst IGG, Borst-de Geus A. Hypertension explained by starling's theory of circulatory homeostasis. The Lancet. 1, $677 \cdot 682$, 1963.

22. Campbell GR, Campbell JH: Development of the vessel wall: overview, in Schwartz SM, Mecham RP (eds): The vascular smooth muscle cell: molecular and biological responses to the exiracellular matrix. San Diego, Academic Press, 1995. P 1

23. Chen IIH, Prewitt RL, Dowell RF, Microvascular rarefaction in spontaneously hypertensive rat cremaster muscle. Am I Physiol. 241.(Heart Circ. Physiol. 10), H306-H310, 1981.

24. Cho AC, Courtman DW, Langille BL. Apoptosis (programmed cell deathì in arteries of the neonata: lamb. Circ Res. 76,168 . $175,1995$.

25. Christ B, Poelmann RE, Mentink MM, Gittenberger-de Groot AC. Vascular endothelial cells migrate centripetally within embryonic arteries. Anat Embryol. 181 (4), 333-339, 1990.

26. Cockerill GW, Gamble IR, Vadas MA. Angiogenesis: models and modulators. Int rev cytol. 159, 113-160, 1995. 
27. D'Amore PA, Thompson RW. Mechanisms of angiogenesis. Ann Rev Physiol. 49* 453-454. 1987.

28. Davis MJ: Myogenic response gradient in an arteriolar network, in Mulvany MI), Aalkjeai C, Heagerty AM, Nyborg NCB, Strandgaard S (eds): Resistance arteries: structure and function. Amsterdam, Elsevier, 1991, p 51.

29. DeChamplain 1. Pre- and postsynaptic adrenergic dysfunctions in hypertension. J Hypertens. 8 (Suppl.), S77-585, 1990.

30. DeLano FA, Schmid-Schonbein GW, Skalak TC, Zweifach BW. Penetration of the Systemic Blood Pressure into the Microvasculature of Rat Skeletal Muscie. Microvasc Res. 41, 92-110, 1991.

31. DeMey JGR: Smooth muscle cell proliferation in hypertension: possible contribution to arterial remodeling, in Schwartz SM, Mecham RP (eds): The vascular smooth muscle cell: molecular and biological responses to the extracellular matrix. San Diego, Academic Press, 1995. p 361

32. Denekamp 1. Angiogenesis, neovascular proliferation and vascular pathophysiology as targets for cancer therapy. British J Radiol, 66 (783), 181-196, 1993.

33. De Robertis EM, Oliver G, Wright CVE. Homeobox genes and the vertebrate body plan. Sci Am., 26-32, 1990.

34. DeRuiter MC: Development of the vascular system in the embryo: a concept of the origin of systemic-pulmonary collateral arteries [Dissertation]. University of Leiden, The Netherlands, 1992

35. DeRuiter MC, Hogers B, Poelmann RE, Vaniperen L, Gittenbenger-de Groot. The development of the vascular system in quail embryos: a combination of microvascular corrosion casts and immunohistochemical identification. Scanning Micr. 5. 1082-1090, 1992.

36. Dewey CF, Bussolari SR, Gimbrone MA, Davies PF. The dynamic response of vascular endothelial cells to fluid shear stress. Journal of Biomechanical Engineering. 103, 177-185, 1981.

37. Duncan JC, Brown FI, McKinnon A, Long WF, Williamson FB, Thompson WD. Patterns of angiogenic response to mast cell granule constituents. Int J Microcirc: Clin Exp. 11, 21-33, 1992.

38. Dusseau IW. Hutchins PM. Hypoxia-induced angiogenesis in chick chorio-allantoic membranes: a role for adenosine. Respiratory Physiology. 71, 33-44, 1988.

39. Dusseau J, Hutchins PM. Calcium entry blockers stimulate vasoproliferation on the chick chorioallantoic membrane. Int ! Microcirc: Clin Exp. 13, 219-231, 1993.

40. Dusseau IW, Hutchins PM, Malbassa DS. Stimulation of angiogenesis by adenosine on the chick chorio-allantoic membrane. Circ Res. 59. 163-170, 1986.

41. Erkadius JDI, Lucente F, Bramich C, Morgan T, Nicolantonio RD. Role of uterine factors in the development of hypertenion in SHR. Clin Exp Pharmacol Physiol. 21, 239-242, 1994.

42. Esler $M$, Lambert $G$, Jennings $G$. Increased regional sympathetic nervous activity in human hypertension: causes and consequences. J Hypertens. 8 (Suppl.). S53-S57, 1990.

43. Evenwel RT, Kasbergen CM, Struyker Boudier HAl. Central and regional hemodynamics and plasma volume distribution during the development of spontaneous hypertension in rats. Clin and Exper Hypertension. A5, 1511-1536, 1983.

44. Fan TD. Jaggar R. Bicknell R. Controlling the vasculature: angiogenesis, anti-angiogenesis and vascular targeting of gene therapy. TIPS. $16,57-66,1995$.

45. Fernandez LA, Twickler I, Mead A. Neovascularization produced by angiotensin-ll. The journal of Laboratory and Clinical Medicine. 105, 141-145, 1985,

46. Flamme I, Risau W. Mechanismen der neubildung von blutgefässen. Ann Anat. 177, 493-502, 1995.

47. Folkman I. What is the evidence that tumors are angiogenesis dependent? Joumal of the National Cancer institute. 82, 4-6. 1990.

48. Folkman J. Haudenschild CC, Zetter BR. Longterm culture of capillary endothelial cells. Proc Natl Acad Sci USA. 76. 5217$5221,1979$.

49. Folkman I. Klagsbrun M. Angiogenic factors. Science. 235, 442-447, 1987.

50. Folkow B. Cardiovascular structural adaptation: its role in the initiation and maintenance of primary hypertension. Clin Sci. 55 (Suppl. 4), \$3.522, 1978.

51. Folkow B. Physiological aspects of primary hypertension. Physiological reviews. $62,347 \cdot 504.1982$. 
52. Folkow B. Brief historical background and principle nature of proceșs. Hypertension. 6 (Suppl. III), 1-3, 1984.

53. Folkow B. "Structural Factor" in primaiy and secondary hypertension. Hypertension. 16, 89-101, 1990.

54. Folkow B, Grimby G. Thulesius O. Adaptive structural changes of the vascular walls in hypertension and their relation to the control of peripheral resistance. Acta Physiol Scan. 44, 255-272, 1958.

55. Folkow B. Karlstrim G. Altered relationships between design, transmural pressure, distensibility and contractility in hypertensive vessels. Prog appl Microcirc. 8, 82-95, 1985 .

56. Fung YC: Biodynamics. New York, Springer-Verlag, 1984.

57. Funk W, Endrich B, Messmer K, Intaglietta M. Spontaneous arteriolar vasomotion as a determinant of peripheral vascular resistance. Int J Microcirc: Clin Exp. 2, 11-25, 1983.

58. Fyhrquist F. Clinical pharmacology of the ACE inhibitors. Drugs. 32 (Suppl. 5). 33*39, 1986.

59. Gebremedhin D, Fenoy FJ, Harder DR, Roman RI. Enhanced vascular tone in the renal vascuiature of sponteously hyperten. sive rats. Hypertension, $16,648-654,1990$.

6o. Gerova M, Gero J, Barta E, Dolezel S. Smiesko V, Levicky V. Neurogenic and myogenic control of conduit coronary arteries: a possible interference. Basic Res Cardiol. 76, 503-507, 1981.

61. Gittenberger-de Groot AC, Slomp J, DeRuiter MC. Poelmann RE: Smooth muscle cell differentiation during early development and during intimal thickening formation in the ductus arteriosus, in Schwartz SM, Mecham RP (eds): The vascular smooth mus. cle cell: molecular and cellular responses to the extracellular matrix. San Diego, Acadernic Press, 1995, p 17

62. Gray SD. Muscle Capillaries in Hypertension. Microvasc Res. 27, 39-49, 1984.

63. Greene AS, Tonellato PI, Lui J, Lombard JH, Cowley AWJ. Microvascular rarefaction and tissue vascular resistance in hypertension. Am J Physiol. 256.(Heart Circ. Physiol. 25), H126-H131, 1989.

64. Guyton AC, Granger JH, Coleman TG. Autoregulation of the total systemic circulation and its relation to control of cardiac output and arterial pressure. Circ Res. 28 (Suppl. 1), 93-97, 1971.

65. Guyton AC, Hall JE: Textbook of medical physiology(ed 9). Philadelphia, W.B. Saunders Company, 1996.

66. Hacking WIG, VanBavel E, Spaan JAE. Shear stress is not sufficient to control growth of vascular networks: a model study. Am J Physiol. 270, $\mathrm{H}_{364}-\mathrm{H}_{375}, 1996$.

67. Hang J, Kong L, Gu JW, Adair TH. VEGF gene expression is upregulated in electrically stimulated rat skeletal muscle. Am J Physiol. 269, H1827-H1831, 1995.

68. Hansen-Smith F, Greene AS, Cowley AW, Lombard JH. Structural changes during microvascular rarefaction in chronic hypertension. Hypertension. $15.922 \cdot 928,1990$.

69. Harper RN, Moore MA, Marr MC, Watts LE, Hutchins PM. Arteriolar rarefaction in the conjunctiva of human essential hypertensives. Microvasc Res. $16,369 \cdot 372,1978$.

70. Harper SL, Bohlen HG. Microvascular adaptation in the cerebral cortex of adult spontaneously hypertensive rats. Hypertension. 6, 408-419, 1984 .

71. Henrich HA, Romen W, Heimgärtner W, Hartung W, Bäumer F. Capillary rarefaction characteristic of the skeletal muscle of hypertensive patients. Klin Wochenstr. 66, 54-60, 1988.

72. Hintze TH, Vatner SF. Reactive dilation of large coronary arteries in conscious dogs. Circ Res. 54, 50.57. 1984.

73. Hirst GDS. Edwards FR. Sympthetic neuroeffector transmission in arteries and arterioles. Physiologicat reviews. $69.546-$ 604. 1989.

74. Holycross BJ, Peach MI, Owens GK. Angiotensin-II stimulates increased protein synthesis, not increased DNA synthesis, in intact rat aortic segments in vitro. J Vasc Res. 30, 80-86, 1993.

75. Hudlicka O, Brown M, Egginton S. Angiogenesis in skeletal and cardiac muscle. Physiological reviews. 72, 369-417. 1992.

76. Hudlicka O, Tyler KR: Angiogenesis: the growth of the vascular system(ed 1). London, Academic Press, 1986.

77. Hunt SC, Williams RR: Genetic factors in human hypertension, in Swales JD (ed): Textbook of Hypertension. London, Blackwell scientific publications, 1994, p 519.

78. Huichins PM, Darnell AE. Observation of a decreased number of small arterioles in spontaneously hypertensive rats. Circ: Res. $34 / 35$ (Suppl. 1), 1611-165. 1974. 
79. Ingber DE. Extracellular matrix and cell shape: potential control points for inhibition of angiogenesis. I. Cell Biochem. 47, 236-241, 1991.

8o. Ingber DE. Integrins as mechanochemical transducers. Curr. Opin. Cell. Biol. 3, 841-848, 1991.

81. Iruela-Arispe ML, Diglio A, Sage EH. Modulation of Extracellular Matrix Proteins by Endothelial Cells Undergoing: Angiogenesis in Vitro. Arteriosclerosis and Thrombosis. 11 (Suppl. 4), 805-815, 1991.

82. Itoh H, Mukoyama M, Pratt RE, Gibbons GH, Dzau V]. Muttiple autocrine growth factors modulate vascular smooth muscle growth response to angiotensin-II. I Clin Invest. 91, 2268-2274. 1993.

83. Jain RK. Determinants of tumor blood flow: a review. Cancer Res، 48, 2641-2658, 1988.

84. Jakob W, Jentzsch KD, Mauersberger B, Heder G. The chick embryo chorioallantoic membrane as bioassay for angiogenesis factors: reactions induced by carrier materials. Exp Path Bd. 15, 241-249, 1978.

85. Kamiya A, Bukhari R, Togawa T. Adaptive regulation of wall shear stress optimizing vascular tree function. Bulletin Mathematics in Biology. 46, 127-137, 1984.

86. Karelina TV, Goldberg Gl, Eisen AZ. Matrix metalloproteinases in blood vessel development in human fetal skin and in cutaneous tumors. I linvest Dermatol. 105, 411-417, 1995.

87. Katoh Y. Periasamy' M. Growth and differentiation of smooth muscle cells during vascular development. TCM. 6, 100-106, 1996.

88. Katz. Angiotensin-11: hemodynamic regulator or growth factor? Mol Cell Cardiol. 22, 739-747, 1990.

89. Kimura K, Tojo A, Matusoka H, Sugimoto T. Renal arteriolar diameters in spontaneously hypertensive rats. Hypertension. 18. 101-110, 1991.

90. Knighton DR, Fiegel VD, Phillips GDP. The assay of angiogenesis. Clin Exp Appr Derm Epiderm Rep., 291-299, 1991.

91. Koibuchi Y, Lee WS, Gibbons GH. Pratt RE. Role of the transforming growth factor-beta1 in the cellular repons to angiotensin-1I. Hypertension. 21, 1046-1050, 1993.

92. Korner PI, Angus JA. Structural determinants of vascular resistance properties in hypertension. JVascRes. 29, $293 \cdot 312,1992$.

93. Korner PI, Bobik A, Jennings GL, Angus, JA, Anderson WP. Significance of cardiovascular hypertrophy in the development and maintenance of hypertension. I Cardiovasc: Pharmacol. 17 (Suppl. 2), S25-S32, 1991.

94.Langer R, Folkman l. Polymers for the sustained release of proteins and other macromolecules. Naiture. 263, 797-800, 1976.

95.Langille BL, Brownlee RD, Adamson SL. Perinatal aortic growth in lambs: relation to blood flow changes at birth. Am I Physiol. 259. H1247-H1253, 1990.

96. Law CM, Barker DJP. Bull AR, Osmond C. Maternat and fetal influences on blood pressure. Arch Dis Childhood. 66, 12911295. 19991.

97.Leibovich.5.J. Wiseman.D.M. Macrophages, wound repair and angiogenests. Biol Clin !mpl., 131-145, 2988.

98. Le Noble JLML. Smith TL, Hutchins PM, Struyker-Boudier HAJ. Microvascular alterations in adult conscious spontaneously hypertensive rats. Hypertension. 15. 415-419, 1990.

99. Le Noble ILML, Tangẹdẹ Gj, Slaạf DW, Vạn Essen H, Reneman RS, Struyker-Boutier. A functional morphometric study of the cremaster muscle microcirculation in young spontaneously hypertensive rats. J Hypertens. 8, 741-74:3, 1990.

100. Lever AF, Harrap SB. Essential hypertension: a disorder of growth with origins in childhood? I Hypertens. 10, 101-120, 1992. 101. Liotta L, Steeg PS, Stetler-Stevensen WG. Cancer metastasis and angiogenesis: an imbalance of positive and negative regulation. Cell. 64, 327-336, 1991.

202. Liotta LA, Steeg PS, Stetler-Stevenson WG. Cancer metastasis and angiogenesis: an imbalance of positive and negative regulation. Cell. $6 \hat{4}_{\mathbf{4}}, 327-336,1991$.

103. Little CD, Rongish B1. The extracellular matrix during heart development. Experientia. 51, 873-883. 1995.

104. Lund Johanson P: Haemodynamics of essential hypertension, in Swales JD (ed): Textbook of hypertension. London. Blackwell scientific publications, 1994, p 61.

105. Lyall F, Dornan ES, McQueen J, Boswell F, Kelly M. Angiotensin-ll increases proto-oncogene expression and phosphoinositide turnover in vascular smooth muscle cells via the angiotensin-II type I receptor. I Hypertens. 10, 1463-1469. i992. 
106. Madri JA, Pratt BM. Endothelial cell-matrix interactions: in vitro models of angiogenesis. J Histochem Cytochem. $34,85 \cdot 91$, 1986.

107. Mayrovitz HN, Roy J. Microvascular blood flow: evidence indicating a cubic dependence on arteriolar diameter. Ann J Physiol. 245, H1031-H1038, 1983.

108. Mecham RF, Stenmark KR, Parks WC. Connective tissue production by vascular smooth muscle in development and disease. CHEST. 99 (3) (Supplement). 435-47S, 1991.

109. Moncada S, Higgs EA. Endogenous nitrit oxide: physiology, pathology and clinical relevance. Eur J Clin Invest. 21, 361.374, 1991.

110. Montesano.R. Regulation of angiogenesis in vitro. Eur f Clin Invest. 22, 504-5,15, 1992.

111. Moscatelli D, Rifkin DB. Membrane and matrix localization proteinases: a common theme in tumor cell invasion and angiogenesis. Biochimica Biophysica Acta. 948,67-85, 1988.

112. Mulvany M]. Do resistance vessel abnormalities contribute to the elevated blood pressure of spontaneously hypertensive rats? Blood Vessels. 20, 1-22, 1983.

113. Mulvany MJ. Are vascular abnormalities a primary cause of a secondary consequence of hypertension? Hypertension. 18 (Suppl. 1), 152-157, 1991.

114. Mulvany M). The development and Regression of Vascular Hypertrophy. ) Cardiovasc Pharmacol. 19 (Suppl. 2), 522-5z7. 1992.

115. Mulvany MI: Resistance vesseis in hypertension. in Swales JD (ed): Textbook of hypertension. London, Blackwell scientific publications, 1994 , p 103.

116. Mulvany MJ, Aalkjaer C. Structure and function of small arteries. Physiological reviews. 70, 921-961, 1990.

127. Nehls V, Denzer K. Drenckhahn D. Pericyte involvement in capillary sprouting during angiogenesis in situ. Cell Tissue Res $270,469-474,1992$.

118. Nelissen-Vrancken MHJ, Struyker-Boudier HAJ, Daemen MJAP, Smits IFM. Antihypertensive therapy and adaptive mecha. nisms in peripheral ischemia. Hypertension. 22, 780-788, 1993.

119. Noden Drew.M. Embryonic Origins and Assembly of Blood Vessels. Am Rev Respir Dis. 140, 1097-1103, 1989.

120. Norrby K, Jakobsson A, Sörbo I. Mast-celi secretion and angiogenesis, a quantitative study in rats and mice. Virchows, Archiv B Cell Pathol. 57, 251-256, 1989.

121. Odedra R, Weiss JB. Low molecular weight angiogenesis factors. Pharmac Ther. 49. 131-124, 1991.

122. Owens GK. Control of hypertrophic versus hyperplastic growth of vascular smooth muscle cells. Am J Physiol. 257. Hi755. $\mathrm{H}_{1765}, 1989$

123. Owens GK. Regulation of differentiation of vascular smooth muscle cells. Physiological reviews, $75,487-517,1995$.

124. Pappenheimer JR: Contributions to microvascular research of Jean Leonard Marie Poiseuille, in Genest I, Ruchel $O$. Hamet $F$. Cantin M (eds): Handbook of Physiology, section 2(vol 4 (1)). Bethesda, USA, American Physiological Society, $1984_{3}, p 3$

125. Poole T], Coffin JD: Morphogenetic mechanisms in avian vascular development, in Feinberg RN, Sherer GK, Auerbach R (eds): Issues in Biomedicine: The development of the vascular system(vol 24). Basel, Karger, $1991, p 25$

126. Prewitt RL, Chen H. Dowell R. Development of microvascular rarefaction in the spontaneously hypertensive rat. Am I Physiol. 243, H243-H251, 1982.

127. Prewitt RL, Wang DH, Nakamura T, Smith EG: Growth and modification in number of resistance vessels; in Bevan JA (ed): The resistance vasculature., Humana Press, 1991, P 127

128. Price RI, Owens GK. Skalak TC. Immunohistochemical identification of arteriolar development using markers of smooth muscle differentiation: evidence that capillary arterialization proceeds from terminal arterioles. Circ Res. 75. 520-527, 1994.

129. Price RJ, Skalak TC. Circumferential wall stress as a mechanism for arteriolar rarefaction and proliferation in a network model. Microvasc Res. 47, 188-202, 1994.

130. Price RI. Skalak TC. A circumferential stress-growth rule predicts arcade arteriole formation in a network model.

Microcirculation. 2, 41-51, 1995.

131. Pries AR, Secomb TW, Gaehtgens P. Design principles of vascular beds. Circ Res. $77,1017-102 \overline{3}, 1995$. 
132. Reynolds LP, Killilea SD, Redmer DA. Angiogenesis in the female reproductive system. FASEB J. 6, 886-892, 1992.

133. Risau W: Vasculogenesis, angiogenesis and endothelial cell differentiation during embryonic development, in Feinberger RN, Sherer GK, Auerbach R (eds): The development of the vascular system(ed Issues Biomedicine, vol 14). Basel, Karger, 1991, p 58 .

134. Rogers TB, Lokuta A). Angiotensin II signal transduction pathways in the cardiovascular system. TCM. 4, 110-116, 1994.

135. Roy JW, Mayrovitz HN. Microvascular pressure, flow and resistance in spontaneously hypertensive rats. Hypertension. 6 , $877-886,1984$.

136. Roy RW, Mayrovitz HN. Microvascular blood flow in the normotensive and spontaneously hypertensive rat. Hypertension. 4. $264 \cdot 271,1982$.

137. Ryan KJ, Makris A. Significance of angiogenic and growth factors in ovarian foilicular development. Adv Exp Med Biol. 2 19. 203-209, 1987.

138. Sage EH, Vernon RB. Regulation of angiogenesis by extracellular matrix: the growth and the glue. I Hyper: 12 (Suppl. 10), S145-S152, 1994.

139. Schelling P, Fischer H, Ganten D. Angiotensin and cell growth: a link to cardiovascular hypertrophy? | Hypertens. 9, 3-15. 1991.

140. Schmid-Schînbein GW, Zweifach BW. Delano FA, Chen P. Microvascular tone in a skeletal muscle of spontaneously hypertensive rats. Hypertension. 9, 164-171, 1987.

141. Schmid-Schoenbein GW. Zweifach BW, Kovalcheck S. The application of stereological principles to morphometry of the microcirculation in different tissues. Microvasc Res. 14, 303-317, 1977.

142. Schork N], Jokelainen P, Grant El. Schork MA, Weder AB. Relationship of growth and blood pressure in inbred rats. Am J Physiol. 266, R702-R708, 1994.

143. Schwartz SM, DeBlois D, O'Brein ERM. The Intima: soil for atherosclerosis and restenosis. Circ Res. 77, 445-465, 1995.

144. Schwartz SM, Heimark RL, Majesky MW. Developmental mechanisms underlying pathology of arteries. Physiological reviews. $70(4), 1177 \cdot 1209,1990$.

145. Segal 55. Duling B. Propagation of Vasodilation in Resistance Vessels of the Hamster: Development and Review of a Working Hypothesis. Circ Res. 61 (Suppl. I1), II-20--11-25, 1987.

146. Shepro D, Morel N. Pericyte physiology. FASEB ]. 7, 1031-1038, 1993.

147. Sherman TE, On connecting large vessels to smail. I Gen Physiol. 78, 431-453, 1981.

148. Sholley MM, Ferguson GP, Seibel HR, Montour IL, Wilson IK. Mechanisms of neovascularization: vascular sprouting can occur without proliferation of endothelial cells. Lab Inv. 51, 624.632, 1984.

149. Slaaf DW, Tangelder GJ, Teirlinck HC, Reneman R5. Arteriolar vasomotion and arterial pressure reduction in rabbit tenuissimus muscle. Microvasc Res. 33, 71-80, 1987.

150. Smith TL, Hutchins PM. Central hemodynamics in the developmental stage of spontaneous hypertension in the unanesthetized rat. Hypertension. 1, 508-517, 1979.

151. Stacy DL. Prewirt RL. Attenuated microvascular alterations in coarctation hypertension. Am J Physiol. 256.(Heart Circ. Physiol. 25), H213·H221, 1989.

152. Stoll M, Steckelings M, Paul M, Bottari SP, Metzger R, Unger T. The angiotensin AT2-receptor mediates inhibition of cell proliferation in coronary endothelial cells. J Clin Invest. 95, 651-657, 1995.

153. Streeten DHP, Anderson GH. Secondary hypertension: an overview of its causes and management. Drugs. 43(6), 805-819. 1992.

154. Strick DM, Waycaster RL, Montani IP, Gay WI, Adair TH. Morphometric measurements of chorioallantoic membrane vascularity: effects of hypoxia and hyperoxia. Am I Physiol. 260, $\mathrm{H}_{1385} \cdot \mathrm{H} 1389,1991$.

155. Struijker Boudier HAJ, Le Noble ILML, Messing MWJ, Hijberts MSP, Le Noble FAC, Van Essen H. The microcirculation and hypertension.) Hyper. 10 (Suppl. 7), S147-S157, 1992.

156. Struyker-Boudier HA): Vascular growth and hypertension, in Swales ID (ed): Textbook of Hypertension. London. Blackwell Scientific Publications, 1994, p 200. 
157. Struyker Boudier HA). Bortel van LMAB, De Mey JGR. Remodeling of the vascular tree in hpertension: drug effects. TiPS. 11, $240-245,1990$.

158. Struyker-Boudier HAJ, Noble le J.L.M.L, Noble le F.A.C, Messing MW], Essen van H. Hypertension, The Microcirculation and Seretonin. Clin Physiol Biochem. 8 (Suppl. 3), 28-39, 1990.

159. Struyker-Boudier HAJ, Smits IFM, DeMey JGR. Pharmacology of cardiac and vascular remodeling. Ann Rev Pharmacol Toxicol. 35. 509-539, 1995 .

160. Struyker-Boudier HAJ, Smits JFM, Mey de J.G.R. The Pharmacology of Calcium Antagonist: A Review. I Cardiovasc. Pharmacol. 15 (Suppl. 4). S1.S10, 2990.

161. Struyker Boudier HAl, Van Bortel LMAB, De Mey JGR. Remodeling of the vascular tree in hypertension: drug effects. TiPS. $11,240 \cdot 245,1990$.

162. Sullivan JM, Prewitt RL, Josephs JA. Attenuation of the microcirculation in young patients with high-output borderline hypertension. Hypertension. 5, 844-851, 1983 .

163. Thoma R: Untersuchungen Über die Histogenesis und Histomechanik des Gefäss systems (German). Stuttgart, Enke, 1893

164. Timmermans PBMWM, Wong PC, Chiu AT, Herblin WF, Benfield P, Carini DJ, Lee RJ, Wexler RR, Saye IAM, Smith RD. Angiotensin-II receptors and angiotensin-ll receptor antagonists. Pharmacological Reviews. 45, 205-251, 1993.

165. Unger T. Mattfeldt T, Lamberty V, Bock P, Mall G, Linz W, Scholkens BA, Göhlke P. Effect of early onset angiotensin convert. ing enzyme inhibition on myocardial capillaries. Hypertension. 20(4), 478-482, 1992.

166. VanZwieten PA. Drugs interacting with alpha adrenoceptors. Cardiovasc Drugs Ther. 3, 121-133, 1989.

167. Vernon RB, Sage HE. Between molecules and morphology: extracellular matrix and creation of vascular form. American Journal of Pathology. 147, 873-883, 1995.

168. Wang DH, Prewitt RL. Captopril reduces aortic and microvascular growth in hypertensive and normotensive rats. Hypertension. $15,68 \cdot 77,1990$.

169. Wang DH, Prewitt RL. Longitudinal effect of captopril on aortic and arteriolar development in normotensive rats. Am J Physiol. 260, H195?-H1965, 1991.

170. Weber H, Taylor DS, Molloy CJ. Angiotensin II induces delayed mitogenesis and cellular proliferation in rat aortic smooth muscle cells: correlation with the expression of specific endogenous growth factors and reversai by suramin. J Clin Invest. 93 $788.798,1994$.

171. Weidner N, Semple JP, Welch WR, Folkman I. Tumor angiogenesis and metastasis: a correlation in invasive breast carcino. ma. N Eng I Med. 324, 1.8, 1991.

172. Yang ST, Mayhan WG, Faraci FM, Heistad DD. Endothelium-dependent responses of cerebral blood vessels during chronic hypertension. Hypertension. 17, 612-618, 1991.

173. Yuan XQ, Smith TL, Prough DS, De Witt DS. Dusseau JW, Lynch CD, Fulton IM, Hutchins PM. Longaterm effects of nimodipine on pial microvasculature and systemic circulation in conscious rats. Am J Physiol. 258, H1395-H1401, 1990.

174. Zamir $M$. Shear forces and blood vessel radii in the cardiovascular system. J Gen Physiol. 69, 449.461, 1977.

175. Zetter Bruce.R. Angiogenesis. CHEST. 93/3 (Suppl. y). 1595-166S, 1988. 


\section{Chapter 2}

Evidence for a novel angiotensin-II receptor involved in neovascularization in the chick embryo chorioallantoic membrane 


\subsection{Introduction}

Angiotensin-II is an oligopeptide that is involved in several processes including vascular smooth muscle contraction, steroidgenesis, and renal electrolyte transport ${ }^{\mathrm{B}}$ More recently, a role for angiotensin-II has been implied in growth processes in the heart and vasculature ${ }^{925}$. It can induce DNA and protein synthesis in isolated vascular smooth muscle cells. In vivo, it may act as a mediator of cell hypertrophy and hyperplasia in the heart and blood vessels after ischemic or mechanical challenges of these tissues $^{25,33}$.

Angiotensin-II induced angiogenesis represents a special form of vascular growth. Thus administration of angiotensin-II to the rabbit cornea ${ }^{\text {I }}$ or chick embryo chorioallantoic membrane $(\mathrm{CAM})^{19}$ induced pronounced neovascularization. Furthermore, angiotensin-II can stimulate the development of collateral vessels to the kidney after aortic stenosis ${ }^{10}$. Blocking of the renin-angiotensin system using the angiotensin-I converting enzyme (ACE)-inhibitor captopril reduces outgrowth of microvessels in the cremaster muscle of renal hypertensive as well as normotensive rats ${ }^{24}$. Angiotensin-II induced neovascularization may represent an important long-term mechanism of blood pressure control, since the number of in series and parallel coupled vessels is one of the microvascular parameters determining vascular resistance ${ }^{18}$. A decreased number of microvessels available to carry flow, so-called rarefaction, is a common feature of various microvascular beds in several forms of hypertension n.1.18. $^{1.1}$. Microvasscular rarefaction may explain up to $50 \%$ of the pressure increase observed in hypertension ${ }^{12}$.

The cardiovascular actions of angiotensin-II are mediated via specific receptors. The existence of at least two types of angiotensin-II receptors is suggested by ligand binding studies ${ }^{622}$, isolated organ experiments ${ }^{2331}$, and complementary DNA cloning ${ }^{15,2124}$. Two types, the angiotensin type $1\left(\mathrm{AT}_{1}\right)$ and type $2\left(\mathrm{AT}_{2}\right)$ binding sites exist in different quantities in various organs. Currently, all acute physiological effects of angiotensinII are attributed to the $\mathrm{AT}_{1}$ receptor ${ }^{31}$. The aim of the present study was to define the nature of the AT receptor mediating angiotensin-II induced vascular growth, in the chick embryo CAM. Both functional and biochemical approaches were used to identify the receptor.

\subsection{Materials and Methods}

\section{Surgical preparations}

Fertile eggs of Lohman-selected White Leghorns were incubated for 3 days at $37^{\circ} \mathrm{C}$, $55 \%$ relative air humidity and rotated hourly (see Ref. 19 for details). At day 3 , a rectangular window $(1 \mathrm{~cm} \times 1.5 \mathrm{~cm})$ was made in the eggshell using a little saw. Two milliliters of albumen was withdrawn by a needle through the large blunt edge of the egg. The window and the hole were covered with Scotch tape to prevent evaporation. The eggs were placed back in the incubator, without rotation. 
At day 7 , a silastic ring (diam. $10 \mathrm{~mm}$, weight $17 \mathrm{mg}$ ) was placed on the CAM to allow local drug administration within the ring. Drugs, dissolved in sterile saline $(0.9 \% \mathrm{NaCl})$ were applied once daily in aliquots of $65 \mu \mathrm{l}$ from day 7 through day 14 within the ring. At day 14 the CAM was fixed using $4 \%$ buffered formaldehyde, excised, and mounted on a glass slide. To avoid bacterial contamination, all solutions were filtered through a $0.22 \mu \mathrm{m}$ Millipore filter and administered to the egg within a laminar flow hood.

\section{Drug studies}

Angiotensin-II was added alone or in the presence of the selective nonpeptidergic $\Lambda T$, antagonist 2-n-butyl-4-chloro-5-(hydroxymethyl)-1-\{[2'-C1-H-tetrazol-5-yl) bipheny]4-yl]methyl\}-imidazole potassium (losartan), nonpeptidergic AT2 antagonist (S)-1-\{[4(dimethylamino)-3-methylphenyl]methyl]-5-(diphenylacetyl)- $4,5,6,7$,-tetrahydro- $1 \mathrm{H}$ imida $/ 0[4,5,-c]$ pyridine-6-carboxylic acid (PD123319), or the peptidergic $\mathrm{AT}_{2}$ antagonist nicotine-Tyr-(N"-benzyl-oxycarbonyl-Arg)Lys-His-Pro-lle-OH (CG,P42112d).

Angiotensin-II was administered is a dose of 670ng once daily (this corresponds to $65 \mu \mathrm{l}$ of a $10^{5} \mathrm{M}$ solution). The concentrations of the antagonists were $1.0 \times 10^{\circ} \mathrm{M}$ for losartan, 1.0 and $3.0 \times 10^{-6} \mathrm{M}$ for PD123319, and 2.1 and $6.3 \times 10^{-6} \mathrm{M}$ for CGP42112a. These concentrations were based on the ligand binding studies. To avoid seasonal variations in hatching viability, a separate saline $(0.9 \% \mathrm{NaCl})$ control was included in each experimental group.

\section{Stereology}

The angiogenic response was quantified by standard stereological techniques. Microvascular density index (VDI) values were obtained by counting the number of blood vessels intersections with an eye-piece rectangular line grid projected on the preparation. The grid constant $d$ was $62 \mu \mathrm{m}$ and the total grid length was $12.4 \mathrm{~mm}$, both with respect to the microcirculation. The number of intersections has a linear relationship with the vascular density. For each CAM, four nonoverlapping areas were counted four times each with a 16x objective (numerical aperture $0.35 \mu \mathrm{m}$ ), allowing vessels with a diameter as small as $5 \mu \mathrm{m}$ to be seen. The vessels counted predominantly represented precapillary vessels with diameters of $5-40 \mu \mathrm{m}$. The average of four areas was taken as the microvascular density index for each CAM. Counting was done without knowledge of the experimental group. 


\section{Ligand binding study}

For the ligand binding experiments, CAM's from 13-day-old fertilized Lohman selected White Leghorn eggs were excised and frozen immediately in liquid nitrogen. The membranes were prepared for binding experiments according to previously described methods ${ }^{823}$. Briefly, the tissue was minced with scissors and homogenates $(20 \%$ wit/vol) were prepared in $20 \mathrm{mM}$ sodium bicarbonate with a Polytron $(3 \times 10 \mathrm{~s})$ at setting 8 and centrifuged at $600 \mathrm{~g}$ for $20 \mathrm{~min}$; the pellet was treated similarly once more. The combined supernatants were centrifuged at $30,000 \mathrm{~g}$ for $30 \mathrm{~min}$ and the pellet resuspended in $50 \mathrm{mM}$ Tris. $\mathrm{HCl}$, $\mathrm{pH} 7.4$, containing (in $\mathrm{mM}$ ) $125 \mathrm{NaCl}$ and $6.5 \mathrm{MgCl}_{2}$. All steps were performed at $0-4^{\circ} \mathrm{C}$. Protein was determined as described ${ }^{4}$ using bovine serum albumen (BSA) as standard. The binding experiments were performed using $5 \mu \mathrm{g}$ membrane protein as described ${ }^{23}$ with the exception that $118 \mathrm{mM} \mathrm{NaCl}$ was included in the incubation buffer and that the equilibrium binding studies were performed for $60 \mathrm{~min}$. The binding experiments were performed using ${ }^{125}$ I-labeled angiotensin-II $(2,200 \mathrm{Ci} / \mathrm{mmol})$ as radioactive ligand. Control experiments showed that under these conditions equilibrium was reached and the binding was linear to the amoung of protein used. Bound and free ligand were separated by addition of $4 \mathrm{ml}$ of ice-cold $\mathrm{pH} 7.5$ Tris and subsequent rapid filtration through Whatman GF/F filters presoaked in $0.1 \%$ BSA. This was followed by three additional washes with $4 \mathrm{ml}$ of the same buffer, and radioactivity trapped on the filter was then measured in a gamma-counter (Pharmacia LKB, Uppsala, Sweden) at $80 \%$ efficiency. Nonspecific binding was determined in the presence of $10 \mu \mathrm{M}$ unlabeled fowl [Val']angiotensin-II (Peninsula labs, Belmont, CA). The binding data were analyzed by nonlinear regression analysis and logistic doseresponse methods described previously ${ }^{23}$. The data were obtained from four to eight binding experiments per ligand each performed in duplicate.

\section{Statistics}

The statistical analyses of the angiogenesis experiments was performed using Student's t-test for comparison of angiotensin-II and saline; analysis of variance (ANOVA) within the CGP42112a and PD123319 group to test for dose related effects and additional post hoc least-square difference tests (LSD) for testing significance of antagonist effects were performed. A p $<0.05$ was accepted as statistically significant.

\subsection{Results \\ Effects of angiotensin-ll on vascular growth}

Angiotensin- II administration caused an increase in vascular density in the CAM. In each of the three experiments, angiotensin-II caused a 30-40\% increase in microvascular density, compared with saline control. This response could not be blocked by the $\mathrm{AT}_{1}$ antagonist losartan (Fig 1a). The response to angiotensin-II also could not be blocked significantly with the nonpeptidergic AT: antagonist PD123319 (Fig 1c), although the vascular density had the tendency to decrcase. 
Simultaneous addition of the peptidergic $\mathrm{AT}_{2}$ antagonist CGP42112a (Fig 1b), however, led to a dose-dependent decrease of the angiotensin-Il evoked response $(\mathrm{p}<0.01$ in ANOVA). The post hoc LSD test showed a statistically significant reduction in the $2.1 \mu \mathrm{M}$ CGP42112a group of $69 \%(\mathrm{p}<0.05)$ and in the $6.3 \mu \mathrm{M}$ CGP $42112 \mathrm{a}$ group of $91 \%$ $(p<0.001)$. Addition of only the antagonists, without angiotensin-II, did not affect the microvascular density when compared with control (data not shown).
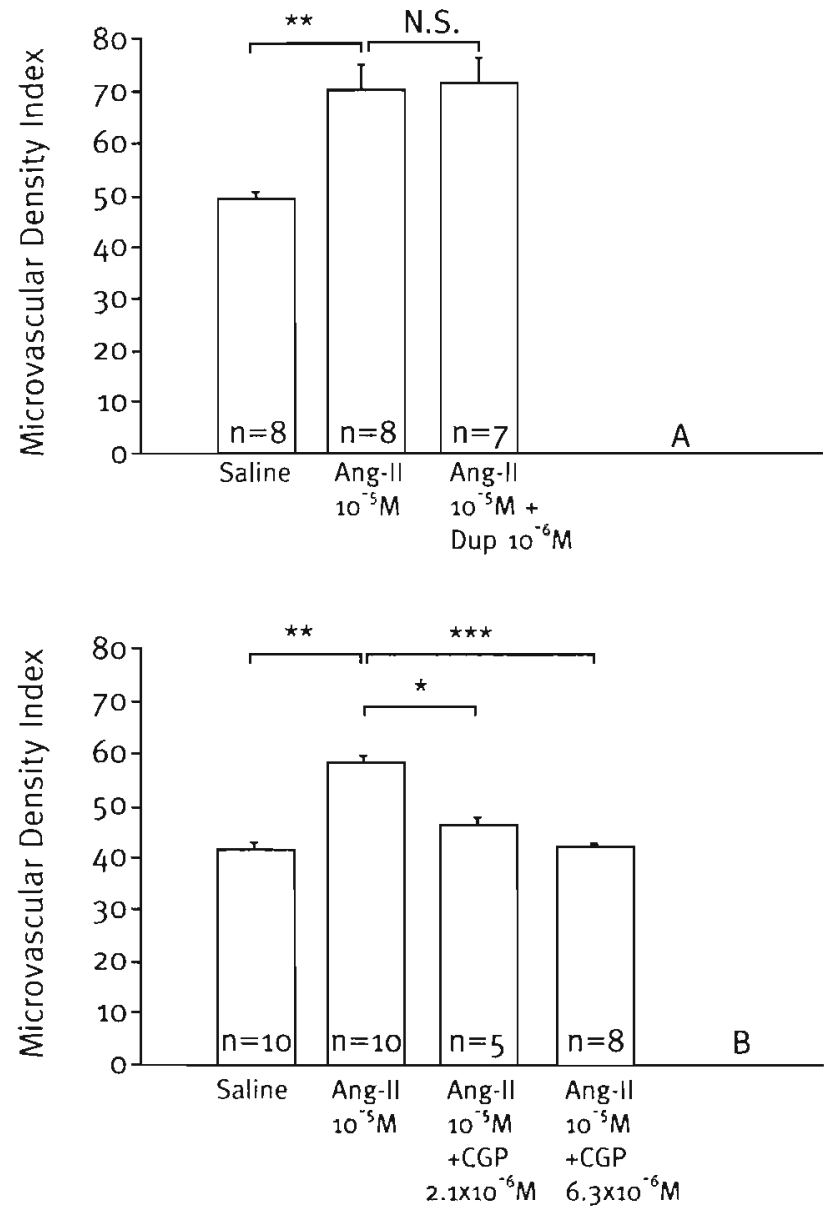

Figure $1 a, 1 b$. Quantitative representation of the angiogenic response to angiotensin-II (Ang-II) without and with the addition of the antagonists losartan (DuP753; top) and CGP42112A (bottom). Data are means and standard error. NS, not significant; ${ }^{*} p<0.05$; ${ }^{* *} \mathrm{p}<0.01 ;{ }^{* * *} \mathrm{p}<0.001$ compared to Ang-II. The number of CAM's (n) studied is indicated. Note that CGP but not losartan blocks the Ang-II induced angiogenic response. 


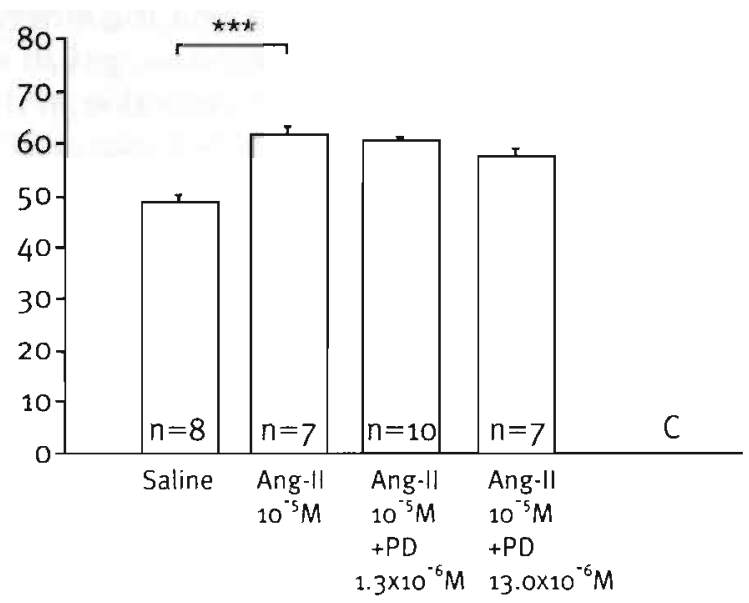

Figure 1 C. Quantitative representation of the angiogenic response to angiotensin-II (Ang-II) without and with the addition of the antagonist PD123319. Data are means and standard error. ${ }^{* * *} \mathrm{p}<0.001$ compared to Ang-II. Note that PD123319 does not block the Ang-II induced angiogenic response.

\section{Ligand binding studies}

Nonlinear regression of the angiotensin-II binding data in a Scatchard plot shows the presence in the CAM of a single class of angiotensin-II receptors with a Kd (affinity constant) for angiotensin-II of $2.7 \mathrm{nM}(\mathrm{n}=8$; range 1.7-4.4) and a Bmax (total number of binding sites) of $1,190 \mathrm{fmol} / \mathrm{mg}$ protein $(n=8$; range $912-1,424)$. The specificity of the angiotensin-II binding was corroborated in competition binding experiments (Table 1 , Fig. 2). A number of non-angiotensin-II like vasoactive peptides, somatostatin, neurotensin, glucagon, and luteinizing hormone-releasing factor showed no affinity, whereas angiotensin-II displaced $12 \mathrm{I}$-angiotensin-II monophasically with an IC $\mathrm{C}_{50}$ (drug concentration causing 50\% inhibition of ${ }^{125}$-angiotensin-II binding) of $3.1 \mathrm{nM}$. Human and fowl angiotensin-I displaced the ${ }^{125} \mathrm{I}$-angiotensin-II binding with relatively high affinity. This also occurred in the presence of the angiotensin-I converting enzyme inhibitor enalaprilat. The angiotensin-II peptide fragments 1-5 and 1-6 had no affinity for the receptor, whereas angiotensin 1-7 bound with an $\mathrm{IC}_{50}$ of $4,739 \mathrm{nM}$. AngiotensinII displaced ${ }^{12} \mathrm{I}$-angiotensin-II binding with an $\mathrm{IC}_{50}$ of $178 \mathrm{nM}$.

We used four AT receptor antagonists in the ligand binding studies. The peptidergic nonselective antagonist with partial acitivity, $\mathrm{Sar}^{1}, \mathrm{ll}^{\varepsilon}$ angiotensin-II (a saralasin analogue), had a high affinity for the CAM AT receptor with an $\mathrm{IC}_{50}$ of $23 \mathrm{nM}$. The peptidergic $\mathrm{AT}_{2}$ antagonist CGP42112a had a moderate affinity $\left(\mathrm{IC}_{-:}: 724 \mathrm{nM}\right)$, whereas the nonpeptidergic $\mathrm{AT}_{1}$ antagonist losartan $\left(\mathrm{IC}_{\mathrm{sa}}: 59,000 \mathrm{nM}\right)$ and the $\mathrm{AT}_{2}$ antagonist PD123319 (IC 50 : $>100,000 \mathrm{nM}$ ) showed only a very low affinity. 
Table 1. Inhibition of specific binding of ${ }^{125}$ I-labeled angiotensin-II with various ligands to chorioallantoic membranes of the chick embryo.

Ligand

Angiotensin-II

CGP'-42112

Losartan (DuP753)

PD123319

Sar',Ile ${ }^{8}$ Angiotensin-II

Angiotensin-I (human)

Angiotensin-I (human)

+ enalaprilat $(10 \mu \mathrm{M})$

Angiotensin- $\mathrm{I}$ (fowl)

Angiotensin-I (fowl)

+ enalaprilat $(10 \mu \mathrm{M})$

Enalaprilat

Angiotensin-IJI

Angiotensin-II (1-7)

Angiotensin-II (1-6)

Angiotensin-II (1-5)

AVP

Somatostatin

Neurotensin

Glucagon

LH-RH n

$\mathrm{IC}_{50}$

724

59,000

$>100,000$

23

104

193

33

63

$>100,000$

178

4,739

$>100,000$

$>100,000$

$>100,000$

$>100,000$

$>100,000$

$>100,000$

$>100,000$
Range

$2.2-4.8$

560-880

43,000-98,000

$18-28$

$52-210$

130-630

13-92

22-200

$58-440$

$3,100-8,700$

Data represent geometric means and the range; $n$, no. of experiments each performed in duplicate. $\mathrm{IC}_{50}$, drug concentration causing $50 \%$ inhibition; AVP, arginine vasopressin, LH-RH, luteinizing hormone-releasing factor. 


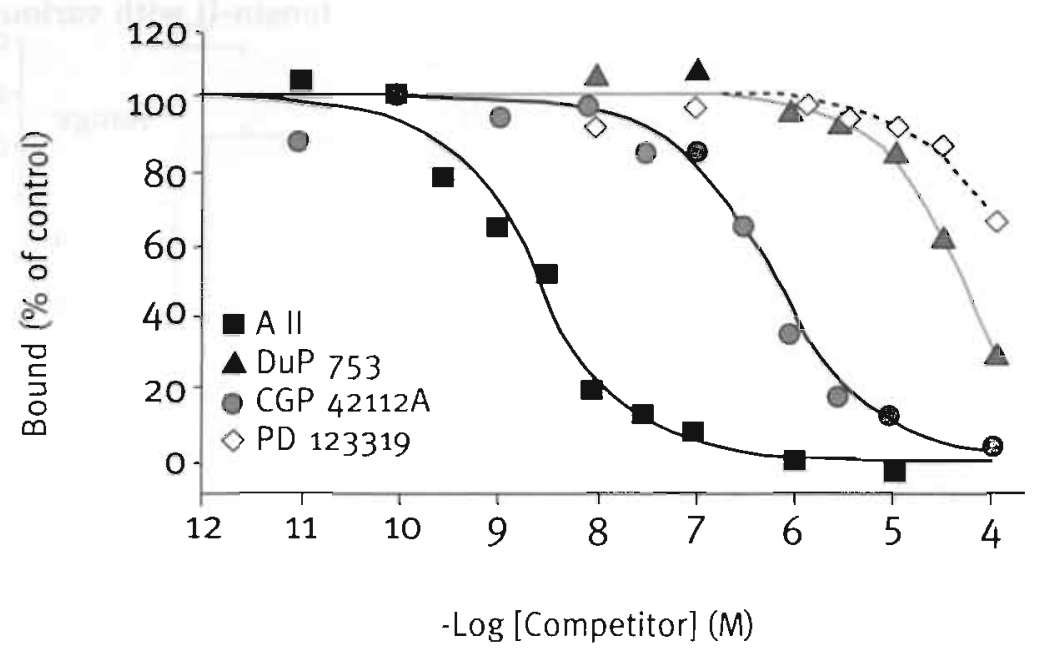

Figure 2. Inhibition of ${ }^{12} \mathrm{I}$-labeled angiotensin-II binding, by angiotensin-II ( $\left.\mathbf{\square}\right)$, CGP42112A ( $(\bullet)$, PD123319 $(\diamond)$, and DuP753 (losartan, $\mathbf{A})$ to homogenates of the CAM of the chick embryo. The data given represent the means of 4-8 binding experiments per ligand, each performed in duplicate.

\subsection{Discussion}

This study shows a pronounced effect of angiotensin-II on the microvascular density in the CAM of the chick embryo. In addition, both the angiogenic and ligand binding studies suggest the involvement of an angiotensin receptor different from the $\mathrm{AT}_{1}$ and $\mathrm{AT}_{2}$ receptors described so far.

\section{Angiotensin-ll as an angiogenic factor}

In addition to its classical role as a vasoconstrictor, angiotensin-II has been implied in growth processes in the heart and vasculature" . Angiotensin-II induced neovascularization represents a special form of vascular growth. Fernandez and co-workers ${ }^{10}$ were the first to suggest a role for angiotensin-II as an angiogenic substance in a study in which they showed that angiotensin-II infusion during ischemia of the rat kidney promotes the formation of collateral vessels. More direct evidence for an angiogenic effect of angiotensin-II was obtained in the rabbit cornea assay". We have used the CAM of the chick embryo, which is a standard model to study angiogenic substances in vivo ${ }^{\top}$. The stereological technique used provides an excellent means to quantitate even subthe microvascular responses induced by drugs $^{27}$. Such quantitation is necessary for studies on drug antagonism. 
In this study we found that once-daily administration of 670ng angiotensin-II is effective in stimulating new vessel formation in the CAM. In a previous study we reported that a daily dose of even $67 \mathrm{ng}$ is effective, although the increase in microvascular density index after that dose is not enough for quantitative antagonist studies ${ }^{19}$. It is difficult to relate once-daily applications of a substance onto the CAM to actual concentrations at the receptor level because of dilution, tissue uptake, and degradation of the drug. Recent in vivo studies in different mammalian species show an endogenous rate of production of angiotensin-II in several organs on the order of magnitude of nanograms per minute ${ }^{1,20}$. We therefore believe that a once-daily administration of angiotensin-II in the nanogram range does not represent excessive amounts.

The mechanisms underlying angiotensin-II induced blood vessel growth are still unknown. The possibility that angiotensin-II may affect cell replication was first suggested by Kharairallah et al. ${ }^{17}$ when they demonstrated increased DNA content in atria, ventricles, and adrenals of rats after intravenous infusion of angiotensin-II. This observation has been confirmed in the mean time in many different tissues and species (cf. 25), including the chick embryo ${ }^{2}$. Angiotensin-II has been shown to stimulate the expression of platelet-derived growth factor as well as growth related oncogenes in cultured smooth muscle cells ${ }^{330}$. In a study on cultured human mesangial cells, Ray et al. ${ }^{2}$ suggested that the mitogenic activity of angiotensin-II is more pronounced in fetal than in adult cells. This increased activity is though to be related to a higher number of angiotensin-II receptors during the fetal phenotype. In the same study Ray et al. showed that the mitogenic effect of angiotensin-II requires proliferative cofactors. This is consistent with the suggestion that angiotensin-II acts as a competence factor ${ }^{2225}$.

Further studies are required to determine the molecular mechanisms whereby angiotensin-II causes blood vessel growth. It may modulate growth directly or through the expression of other growth factors or protooncogenes. To identify these molecular mechanisms, it is necessary to define the nature of the receptor to which angiotensin-II binds and which transmembrane signals are linked to this binding. The CAM of the chick embryo may provide a tool to define these molecular mechanisms. 


\section{The nature of the angiotensin receptor involved}

\section{in neovascularization in the CAM}

The combined functional and biochemical studies provide a first analysis of the nature of the receptor involved in angiotensin-II induced neovascularization. This receptor seems different from those described thus far. First, the lack of effect of losartan in both functional and biochemical studies makes the involvement of an $\mathrm{AT}_{1}$ receptor highly unlikely. Losartan is known to effectively antagonize most of the classical actions of angiotensin-II, such as vasoconstriction, steroidgenesis, and renal electrolyte transport (cf. 31). The losartan-sensitive receptor has been cloned ${ }^{152.24}$ and its existence has been demonstrated in many tissues of different, especially adult, mammalian species ${ }^{5.68}$. The low affinity of the heptapeptide angiotensin-II fragment 1-7 makes it also unlikely that the receptor is identical with angiotensin-II 1-7 receptor recently proposed to exist in the rat hypothalamo-neurohypophysical system $^{26}$ and human astrocytes ${ }^{29}$. This receptor has been suggested to cause release of prostaglandins independent of an increase of intracellular calcium. CGP42112a, in contrast to losartan, was shown to effectively block the angiotensin-II 1-7 and 1-8 induced prostaglandin production ${ }^{29}$. Despite the similar antagonist profile in our study, we believe that the $>1,000$-fold difference in angiotensin-II 1-8 and 1-7 affinities makes the involvement of an angiotensin-II 1-7 receptor in neovascularization in the CAM unlikely.

The third possibility would be the involvement of an $\mathrm{AT}_{2}$ receptor. The functional role of this receptor has thus far not been identified. It has been recognized as an angiotensin-II binding site in a number of mammalian tissues on the basis of selective displacement of angiotensin-II binding by CGP4211a, PD123177, PD123319, and WL$19^{6,8,2335}$. In our studies, we did not find affinity for PD123319. Although both functional and biochemical studies showed antagonism by CGP42112a, the affinity of this antagonist was several orders of amgnitude lower when compared with mammalian $\mathrm{AT}_{2}$ receptors ${ }^{23}$.

The only comparable profile of binding data reported thus far was published recently by Ji et $\mathrm{al}^{16}$. In Xenopus leavis oocytes they found an angiotensin-II receptor coupled to the generation of inositol 1,4,5-triphosphate-induced calcium mobilization. This effect could be blocked by saralasin $\left(\mathrm{IC}_{50}=25 \mathrm{nM}\right)$ and CGP42112a $\left(\mathrm{IC}_{50}=400 \mathrm{nM}\right)$, whereas losartan and PD123177 both had an $\mathrm{IC}_{50}$ of $>10 \mu \mathrm{M}$. These relative potencies show remarkable similarities with ours. Ji et al. ${ }^{16}$ interpreted their data to indicate that the amphibian angiotensin-II receptor is pharmacologically distinct from the mammalian $\mathrm{AT}_{1}$ and $\mathrm{AT}$ : receptor. Along the same lines, the angiotensin receptor in the CAM of the chick embryo may also represent a nonmammalian type of angiotensin receptor. 
In addition to mammalian vs. nonmammalian species differences in angiotensin receptor expression, there may be important developmental differences. $\mathrm{AT}_{1}$ and $\mathrm{AT}_{2}$ binding sites are found widespread in various adult mammalian tissues ${ }^{623.35}$. Tsutsumi et al..$^{32}$ have recently reported a relatively high concentration of CGP42112a-sensitive angiotensin-II binding sites in fetal rat brain. Similarly, Tallant et al. ${ }^{28}$ found a predominance of CGP42112a-sensitive angiotensin-II binding sites in differentiated NG108-15 neurally derived clonal cell line. Both groups interpreted their data as evidence for a dominant role of $\mathrm{AT}_{2}$ receptor in embryonic development. However, both groups did not use a full range of antagonists to define the nature of the receptor involved. The picture that emerges form previous work ${ }^{1628,32}$ as well as our research indicates the existence of a special type of angiotensin-II receptor associated with cell growth and embryonic development. However, a full range of antagonist studies has to be performed before such a conclusion can be drawn more definitively.

\section{Perspectives}

This study supports the view that angiotensin-II is an angiogenic substance. In addition, it defines the existence of a novel AT receptor that mediates the vascular growth effect of angiotensin-II. Thus this study provides a basis for a more selective pharmacological, and perhaps ultimaltely therapeutic, approach toward the possible angiogenic role of the renin-angiotensin system. Hypertension treatment is thus far primarily based on the use of drugs that lower cardiac output or increase diameter of resistance vessels. This type of treatment needs to be continued throughout life. A future alternative approach may be to develop drugs that selectively target the structure of the vascular tree, making more vessels available for blood flow and thus lowering resistance on a structural basis. Our results suggest future research in this area to concentrate on AT receptor subtypes. 


\section{References}

1. Admiraal, P..J., A.H.). Danser, F.H.M. Derkx, and M.A.D.H. Schalekamp. Angiotensin-1l production in different vascular beds in hypertensive subjects. J. Hypertens. 9. Suppl. 6: S208-S209, 1991.

2. Baker, K.M., and J.F. Aceto. Angiotensin-ll stimulation of protein synthesis and cell growth in chick heart cells. Am. J. Physiol. 259 (Heart Circ. Physicl. 28): H610-H618, 1990.

3. Bobik, A., S. Grinpukel, P.J. Little, A. Grooms, and G. Jackman. Angiotensin-II and noradrenaline increase PDGF-BB receptors and potentiated PDGF-BB stimulated DNA synthesis in vascular smooth muscle. Biochem. Biophys. Res. Commun. $166: 580-$ $588,1990$.

4. Bradford, M.M. A rapid and sensitive method for the quantitation of microgram quantities of protein utilizing the principle of protein-dye binding. Anal. Biochem. 72: 248-254, 1976.

5. Bumpus, F.M., K.J. Catt, A.T. Chiu, M. DeGasparo, T. Goodfriend, A. Husain, M.J. Peach, D.G. Taylor, and P.B.M.W.M.

Timmermans. Nomenclature for angiotensin receptors. Hypertension Dallas 17: 720-721, 1991.

6. Chiu, T.A., W.F. Herblin, D.E. McCall, R.J. Ardecky, D.J. Carini, J.V. Duncai, L.J. Pease, P.C. Wong. R.R. Wexler, A.L. Johnson, and P.B.M.W.M. Timmermans. Identification of angiotensin-1/ receptor subtypes. Biochem. Biophys. Res. Commun. 165: 196-203, 1989.

7. D'Amore, P.A., and R.W. Thompson. Mechanisms of angiogenesis. Annu. Rev. Physiol. 49: 453-464, 1987.

8. Dudley, D.T., R.L. Panek. T.C. Major, G.H. Lu, R.F. Bruns, B.A. Klinkefus, I.C. Hodges, and R.E. Weishaar. Subclasses of angiotensin-11 binding sites and their functional significance. Mol. Pharmacol. 38: 370-377, 1990.

9. Dzau, V.J. Multiple pathways of angiotensin production in the blood vessel wall: evidence, possibilities and hypotheses. J. Hypertens. 7: $933 \cdot 936,1982$.

10. Fernandez, L.A., V.J. Casride, I. Twicklei, and R.E. Galardy. Renin-angiotensin system and development of collateral circulation after renal ischemia. Am. I. Physiol. 243 (Heart Circ. Physiol. 12): H869-H875, 1982.

11. Fernandez, L.A., J. Twickler, and A. Mead. Neovascularization produced by angiotensin-II. J. Lab. Clin. Med. 105: 141-145, 1985 .

12. Greene, A.S., P.J. Tonellato. I. Lui, J.H. Lombard, and A.W. Cowley. Microvascular rarefaction and tissue vascular resistaince in hypertension. Am. J. Physiol. 256 (Heart Circ. Physiol. 25): H126-H131, 1989.

13. Hall, J.E., H.L. Mizelle, and L. Woods. The renin-angiotensin system and long-term regulation of arterial pressure. I. Hypertens. $4: 387-397,1986$.

14. Hutchins, P.M., and A.E. Darnell. Observations of a decreased number of arterioles in spontaneously hypertensive rats. Circ. Res. 34, Suppl. I: $1161-1165,1974$.

15. Iwai, I., Y. Yamano, S. Chaki, F. Konishi, S. Bardhan, C. Tibbets, K. Sasaki, M. Hasegawa, and T. Inagami. Rat angiotensin-II receptor: CDNA sequence and regulation of the gene expression. Biochem. Biophys. Res. Commun. 177: 299-304, 1991.

16. Ji, H., K. Sandberg, and K.J. Catt. Novel angiotensin-II antagonists distinguish amphibian from mammalian angiotensin-ll receptors expressed in xenopus laevis oocytes. Mol. Pharmacol. 39: 120-123. 1990.

17. Khairallah, P.A., A.L. Robertson, and D. Davita. Effects of angiotensin-II on DNA, RNA, and protein synthesis. In: Hypertension, edited by ). Genest aild E. Kolw. Berlin: Springer Verlag, p 212-220, 1972.

18. Le Noble, J.L.M.L., G.J. Tangelder, D.W. Slaaf, H. van Essen, R.S. Reneman, and H.A.J. Struyker-Boudier. A functional morphometric study of the cremaster muscle microcirculation in young spontaneously hypertensive rats. J. Hypertens. 8: $741 \cdot 748$, 1990.

19. Le Noble, F.A.C., J.W.M. Hekking, H.W.M. Van Straaten, D.W. Slaaf, and H.A.J. Struyker-Boudier. Angiotensin-II stimulates angiogenesis in the chorio-allantoic membrane of the chick embryo. Eur. J. Pharmacol. 195: 305-306, 1991.

20. Mizuno, K., M. Nakamaru, K. Higashimori, and T. Inagami. Local generation and release of angiotensin-II in peripheral vascular tissue. Hypertension 11: 223-229, 1988.

21. Murphy, T.J, R.W. Alexander, K.K. Griendling, M.S. Runge, and K.E. Bernstein. Isolation of a cDNA encoding the vascular type1 angiotensin-II receptor. Nature 351: 233-236, 1991.

22. Ray, P.E., G. Aguilera, J.B. Kopp, S. Horikoshi, and P.E. Klotman. Angiotensin-II receptor-mediated proliferation of cultured human fetal mesangial cells. Kidney Int. 40: 764-771. 1991. 
23. Rogg. H., A. Schmid, and M, de Gasparo. Identification and characterization of angiotensin-II receptor subtypes in rabbit ventricular myocardium. Biochem. Biophys. Res. Commun. 173: 416-422, 1990.

24. Sasaki, K., Y. Yamano, S. Bardhan, N. Iwai, I.J. Murray, M. Hasegawa, Y. Matsuda, and T. Inagami. Cloning and expression of a complementary DNA encoding bovine adrenal angiotensin-II type-1 receptor. Nature 351: 230-232, 1991.

25. Schelling, P., H. Fischer, and D. Ganten. Angiotensin and cell growth: a link to cardiovascular hypertrophy? I. Hypertens. 9: 3-15, 1991.

26. Schiavone, M.T., R.A.S. Santos, K. Bridget, M.C. Khosla, and C.M. Ferrario. Release of vasopressin from the rat hypothalamoneurohypophysial system by angiotensin (1-7) heptapeptide. Proc. Natl. Acad. Sci. USA 85: 4095-4098, 1988.

27. Strick, M.D., R.L. Waycaster, J.P. Montani, W.J. Gay, and T.H. Adair. Morphometric measurements of chorioallantoic membrane vascularity: effects of hypoxia and hyperoxia. Am. J. Physiol. 260 (Heart Circ. Physiol. 29): H1385-H1389, 1991.

28. Tallant, E.A., D.I. Diz, M.C. Khosla, and C.M. Ferrario. Identification and regulation of angiotensin-ll receptor subtypes on NG108-15 cells. Hypertension 17: 1135-1143, 1991.

29. Tallant, E.A., N. Jaiswal, D.I. Diz, and C.M. Ferrario. Human astrocytes contain two distinct angiotensin receptor subtypes. Hypertension 18: 32-39, 1991.

30. Taubman, M.B., B.C. Berk, S. Izumo, T. Tsuda, R.W. Alexander, and R. Nadal-Ginard. Angiotensin-II induces c.fos mRNA in aortic smooth muscle. J. Biol. Chem. 264: 526-530, 1989.

31. Timmermans, P.B.M.W.M., P.C. Wong. A.T. Chiu, and W.F. Herblin. Nonpeptide angiotensin-II receptor antagonists. Trends Pharmacol. Sci. 12: $55^{\cdot 62}, 1991$.

32. Tsutsumi, K., M. Viswanathan, C. Strîmberg, and I.M. Saavedra. Type-1 and type-2 angiotensin-ll receptors in fetal rat brain. Eur. J. Pharmacol. 198: 89-92, 1991.

33. Van Krimpen, C., J.F.M. Smits, I.P.M. Cleutjens, J.J.M. Debets, R.G. Schoemaker, H.A.J. Struyker-Boudier, F.T. Bosman, and M..A.P. Daemen. DNA synthesis in the non-infarcted cardiac interstitium after left coronary artery ligation in the rat: effects of captopril. J. Mol. Cell. Cardiol. 23: 1245-1253. 1991.

34. Wang, D.H., and R.L. Prewitt. Captopril reduces aortic and microvascular growth in hypertensive and normotensive rats. Hyopertension 15: 68-77, 1990.

35. Wiest, S.A., A. Rampersaud, K. Zimmerman, and M.I. Steinberg. Characterixation of distinct angiotensin-II binding sites in rat adrenal gland and bovine cerebellum using selective nonpeptide antagonists. I. Cardiovasc. Pharmacol. 17: 177-184, 1991. 


\section{Chapter 3}

The role of angiotensin-II

and prostaglandins in arcade formation in a developing microvascular network 


\subsection{Introduction}

The vascular branching patterns in the terminal part of the arteriolar tree are characterized by two types of morphology. On the one hand, in a number of tissues the branching pattern is dichotomous ${ }^{1-3}$, whereas in other tissues many arteriolar-arteriolar connections, or arcades, are found ${ }^{*}$. The type of morphology of the terminal section of the arteriolar tree is of great influence on blood flow distribution and resistance control ${ }^{4,5}$.

The vascular branching pattern of the developing chick embryo chorio-allantoic membrane (CAM) normally is dichotomous and almost fractal'. In a recent study, we observed that administration of angiotensin-II (Ang-II) increased microvascular growth of the $\mathrm{CAM}^{b}$. In that study we did not investigate how Ang-II affected the branching pattern. However, in some preparations we noted marked formation of arcades. This seemed particularly the case in CAM's that were treated with the combination of Ang-II and losartan, an angiotensin type $1\left(\mathrm{AT}_{1}\right)$ receptor antagonist. Interestingly, in our previous study ${ }^{6}$ we showed the absence of $\mathrm{AT}_{1}$ receptors in the chick embryo CAM. There is now evidence that losartan in addition to its $\mathrm{AT}_{1}$ receptor antagonism influences prostaglandin synthesis and receptor action ${ }^{7.9}$. In view of the strong effects of certain prostaglandins on vascular growth ${ }^{10}$, it may be hypothesized that an interaction with prostaglandin action is responsible for the Ang-II and losartan induced arcade formation.

The purpose of this study is to evaluate the role of prostaglandins in Ang-II mediated changes in vascular branching patterns. For this purpose, we combined the administration of Ang-II with losartan and CGP 42112A, a drug previously shown to antagonize Ang-II induced angiogenesis through AT receptor antagonism ${ }^{6}$ as well as with the prostaglandin synthesis inhibitor acetyl-salicylic acid (ASA). We used parameters that allow the quantification of drug induced changes in vascular branching patterns. The standard parameter to quantify microvascular growth is the stereological parameter vascular density index $\left(\mathrm{VDI}^{3.12}\right)$. However, to obtain information about the spatial distribution of vascular patterns, we applied previously described ${ }^{13}$ parameters for characterizing arcading networks: number of arcade loops per $\mathrm{cm}^{2}$ area, mean surface area of arcade loops, branch-node ratio of an arcading network and number of segments per arcade loop.

\subsection{Materials and Methods}

\section{Protocol}

To assiay the vascular effects of the compounds, the standard angiogenesis assay of the chick embryo chorio-allantoic membrane (CAM) was used ${ }^{6}$. Fertile Lohman selected white leghorn eggs were incubated for 3 days a $37^{\circ} \mathrm{C}, 55 \%$ relative air humidity, and rotated once every hour. At day 3 , a rectangular window, $1 \times 1.5 \mathrm{~cm}$, was made in the eggshell using a small iron saw (dimensions $6 \times 1 \times 0.3 \mathrm{~cm}$ ). The window was covered with Scotch tape to prevent dehydration. The eggs were returned to the incubator, but the rotation was stopped. At day 7, a silastic ring (diameter: $1.0 \mathrm{~cm}$, weight: $17 \mathrm{mg}$ ) was placed on the CAM to allow local application of compounds. 
Drugs were applied within the ring once daily in aliquots of $65 \mu \mathrm{l}$ until day 14. All drugs were filtered through a $0.22 \mu \mathrm{m}$ Millipore filter to assure sterility. Application of the drugs was performed within a laminar flow hood. At day 14 the treated area was photographed using a Wild M8 stereo-microscope equipped with a photo-extension tube, Nikon F501 camera and 64 ASA Kodak ectachrome color slide film. The membrane was then fixed with $4 \%$ buffered formaldehyde, excised and mounted on a preparation glass. The slides together with the fixed membranes were used to redraw the vascular pattern; vessels with a diameter of 10-100 $\mu \mathrm{m}$ could be discriminated. Final optical magnification was 30x. Eggs were assigned at random to the different treatment groups. Analysis of the vascular patterns was performed without knowledge of the identity of the experimental groups.

\section{Vascular pattern analysis}

We attempted to describe the vascular pattern using (a) number of arcade loops in the treated area, (b) mean surface area of arcade loops, (c) branch-node ratio within a network, and(d) number of vessel segments in an arcade loop (see fig. 1). The arrows in figure 1 indicate that flow may enter this network from three feeding vessels.

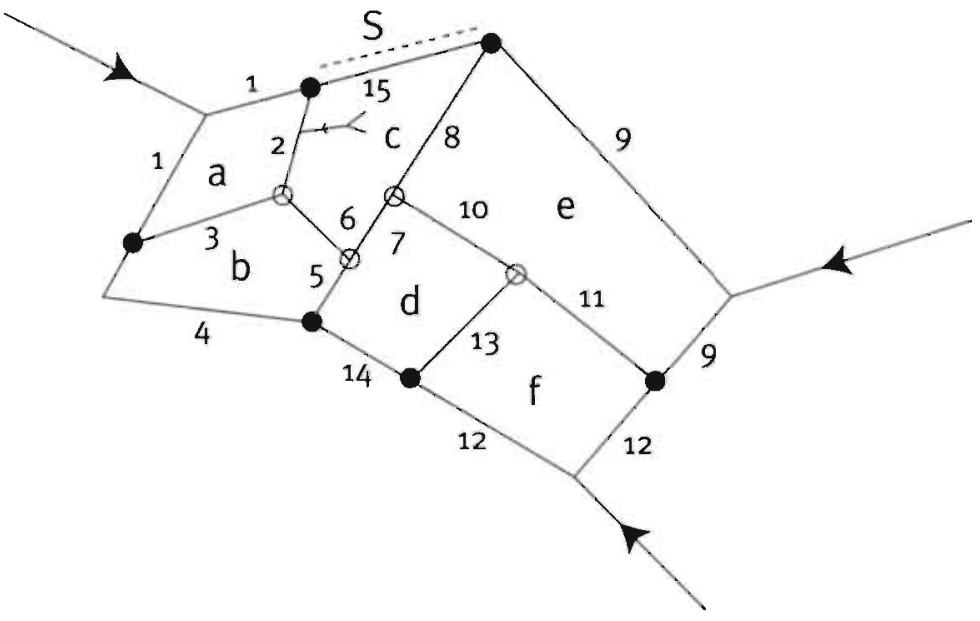

Figure 1. Schematic representation of an arcading network. S: arcade segment (1-15); a-f: arcade loops. Number of perimeter branch nodes: $6(\bullet)$,interior nodes: (O).

The number of arcades. The number of arcade loops was determined by counting the number of smallest arteriolar-arteriolar loops within the treated area. A loop is being defined as the smallest arteriolar interconnection yielding a closed fluid circuit. The data are presented as number of arcades per $\mathrm{cm}^{2}$ treated arca. 
In figure 1 the arcade loops constituting the total network have been indicated by the symbols a- $\mathrm{f}(6$ in total).

The mean surface area per arcade loop. The surface area of the total arcading network was measured and this value was then divided by the number of arcades within the network. Arcade loops not interconnecting with other arcade loops in a network were measured separately. For each egg the surface area of an arcade loop is presented as the mean surface area of all individual loops measured within the treated area. Surface area was measured using a digipad (Jandel Scientific Software, USA).

The branch-node ratio. The branch-node ratio was determined by counting the total number of branch nodes in the arcade network divided by the number of perimeter branch nodes in the network (cf. reference 12). In the example of figure 1 we count 6 perimeter branch nodes and a total of 10 branch nodes. The first bifurcation points of the input vessels are not counted, since the input vessels themselves are not part of an arcade loop. Thus, a branch node is always shared by at least two arcade loops. If a treated area consisted of arcade loops that did not form a closed network, the branchnode ratio was considered to be zero. The branch node ratio gives insight in the relation of arcade surface and circumference.

Vessel segments per arcade. An arcade vessel segment is defined as the connection between two branch nodes. In the example of figure 1 segments have been indicated with numbers (1-15). Since the first bifurcation points of input vessels are not regarded as branch nodes, their branches are regarded as only 1 segment. Since the treatment sometimes induced the formation of more than 200 interconnecting arcade loops, we did not count the segments manually. Instead, we counted the number of internal and perimeter branch nodes. On this basis, and by applying Euler's law, we could calculate the number of segments; Euler's law: $P$ (number of branch nodes) $+A$ (number of arcades) $=S$ (number of segments) $+1 ; S$ can be calculated since $P$ and $A$ are known. To calculate the number of segments per arcade loop, we had to discriminate between external and internal edges since the latter ones were counted twice because they are shared by two arcades. This parameter was only calculated for arcade loops in a network.

\section{Calculations \\ $\mathrm{P}+\mathrm{A}=\mathrm{S}+1$ \\ $\mathrm{ES}=\mathrm{EP}$ \\ IS $=S-E S$ \\ $\mathrm{S}=\mathrm{ES}+2 \times \mathrm{IS}$ \\ $\mathrm{S} \#=\mathrm{S} / \mathrm{A}$}

P, number of branch nodes; $A$, number of arcade loops; $S$, number of segments in network

ES, number of external segments; EP, number of external branch nodes

IS, number of internal segments

$S$, calculated number of segments per arcade network with respect to common ed yes

S\#, calculated number of segements per arcade loop 


\section{Data analysis}

In order to compare two experimental groups, the non-parametric Marn-Whitney Utest was used. To test for dose related effects, the non-parametric Kruskall Wallis test was used. To correlate data, the Spearman test was used. A p<0.05 in a two-talled test was accepted as statistically significant ${ }^{3}$. Data were analyzed using the statistical package SPSS version 6.0 for a PC.

Data are presented as box plots. A box plot shows the 10 th and 90 th percentiles, the 25 th and 75th percentiles (box outlines), the median (within the box), and the outlers (open dots). Sigma plot version 2.0 Windows was used to construct the box plots.

\section{Drugs}

The drugs and doses used as well as the number of eggs per treatment group are given in table 1 . The daily applied doses of Ang-II, losartan and CGP 42112A were based upon the doses used in a previous study. The doses of acetylsalicylic acid (ASA) were selected in the range causing adequate prostaglandin synthesis inhibition it. All drugs were solved and diluted in sterile $0.9 \% \mathrm{NaCl}$ (saline), except for ASA, which was suspended in water, with subsequent administration of $\mathrm{NaHCO}_{3}$ until ASA dissolved completely. The final $\mathrm{pH}$ of this solution was 7.4.

Ang-II was obtained from Peninsula Laboratories, ASA from Sigma, whereas losartan was a generous gift from DuPont Chemicals and CGP $42112 \mathrm{~A}$ (Tyr-(Na-benzyl-oxycarbonyl-Arg)Lys-His-Pro-Ile-OH) was a gift from Ciba-Geigy.

Table 1. Composition of the various experimental groups in this study

Experimental group (daily dose)

Ang-II $670 \mathrm{ng}$

Ang-II $670 \mathrm{ng}+$ ASA $1.95 \mu \mathrm{g}$

Ang-II $670 \mathrm{ng}+$ ASA $19.5 \mu \mathrm{g}$

ASA $1.95 \mu \mathrm{g}$

ASA $19.5 \mu \mathrm{g}$

Ang-II $670 \mathrm{ng}+$ losartan $29.25 \mathrm{ng}$

Ang-II $670 \mathrm{ng}+\mathrm{CGP} 42112 \mathrm{~A} 420 \mathrm{ng}$

saline $(0.9 \% \mathrm{NaCl}) 65 \mu \mathrm{l}$

\section{Number of eggs}

15

6

21

5

17

11

8

6

The doses were applied once daily in a $65 \mu$ volume into the ring on the CAM as described in the methods section. 


\subsection{Results}

\section{Effect of Ang-ll and AT receptor blockers}

Fig. 2 shows the typical arcade vascular structure after treatment with Ang-II + losartan. Treatment with Ang-II alone significantly increased the number of arcade loops versus saline treated controls (fig. 3A). Simultaneous addition of Ang-II + losartan resulted in a significant increase in number of arcade loops versus both Ang-II alone $(\mathrm{p}<0.001)$ and saline $(\mathrm{p}<0.001)$ (fig. 3A). Combined administration of Ang-II + CGP $42112 \mathrm{~A}$ did not result in an extra effect compared to Ang-II alone, neither was there a significant increase versus saline control. The branch-node ratio (fig. 3B) increased significantly after administration of Ang-II + losartan compared to both Ang-II alone $(p<0.001)$ and saline $(p<0.001)$. Compared to saline control, administration of Ang-II + CGP 42112A resulted in a significant increase in branch-node ratio $(\mathrm{p}<0.05)$.

The average surface area (fig. 3C) of an arcade loop decreased significantly after administration of Ang-II + losartan when compared to saline ( $p<0.001)$ and Ang-II $(\mathrm{p}<0.01)$. Although treatment with Ang-II + CGP 42112A resulted in a larger variation,

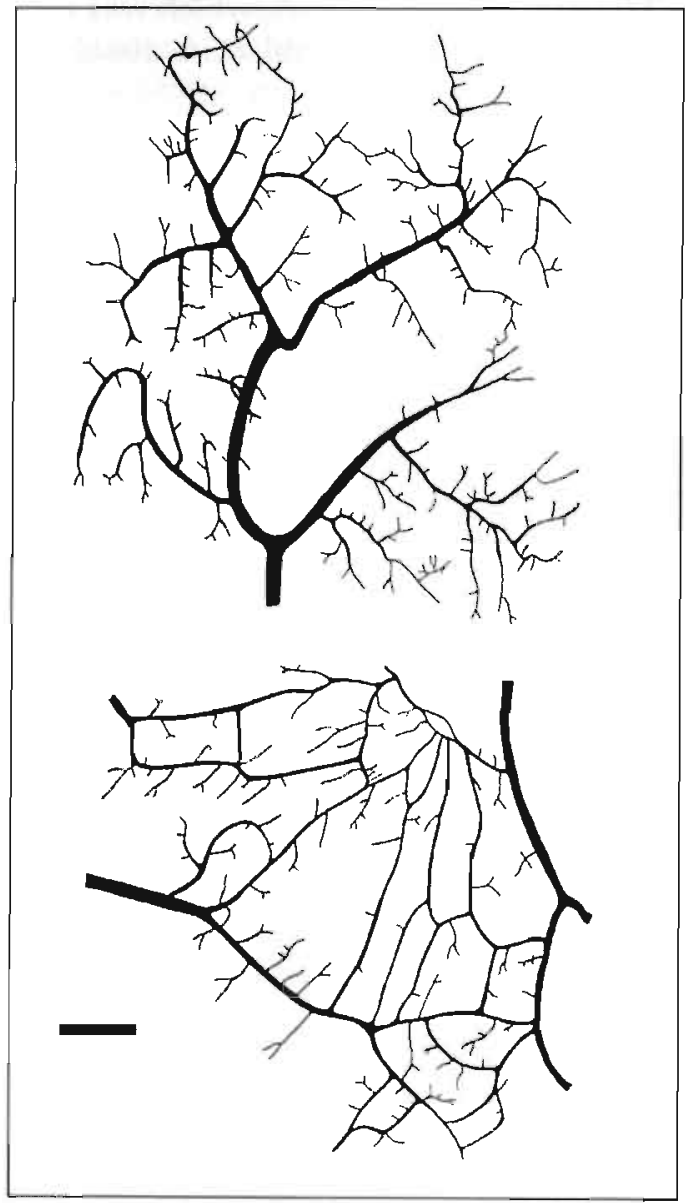
no significant differences were observed. A significant decrease in mean surface area was also observed after administration of Ang-II alone $(\mathrm{p}<0.01)$. Addition of either AT receptor antagonist alone did not result in significant changes versus saline control (data not shown in fig ure).

Fig 2. Normal branching pattern in the chick embryo chorioallantoic membrane after 7 days of $0.9 \% \mathrm{NaCl}$ treatment (top). Arcading pattern after 7 days of treatment with angiotensin-II +losartan (bot-

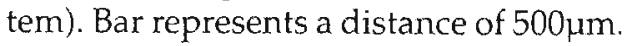




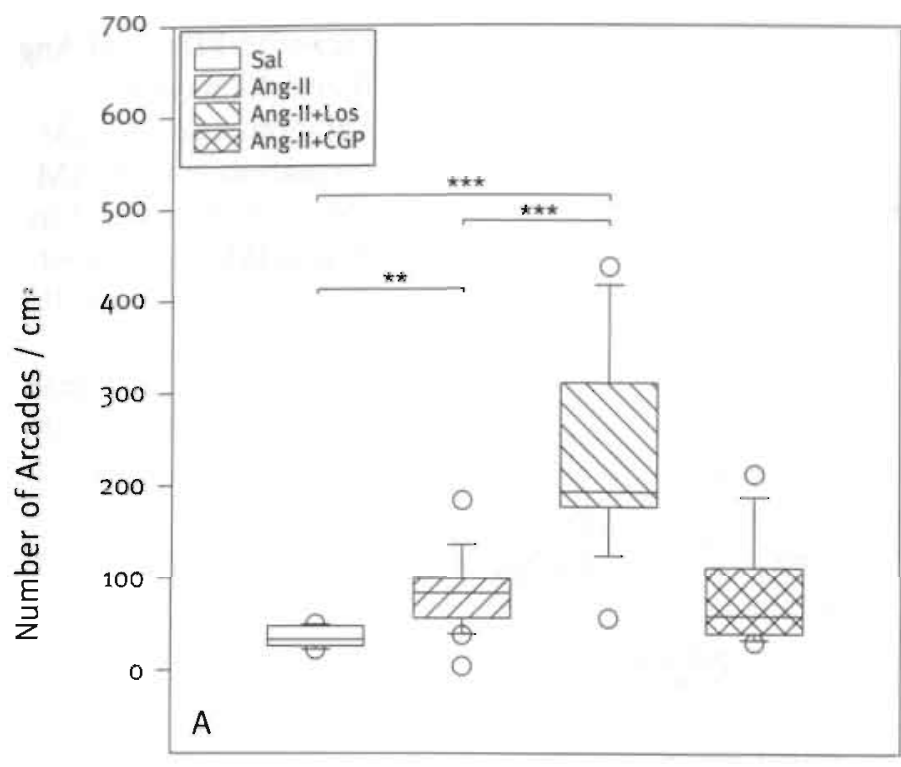

Treatment group

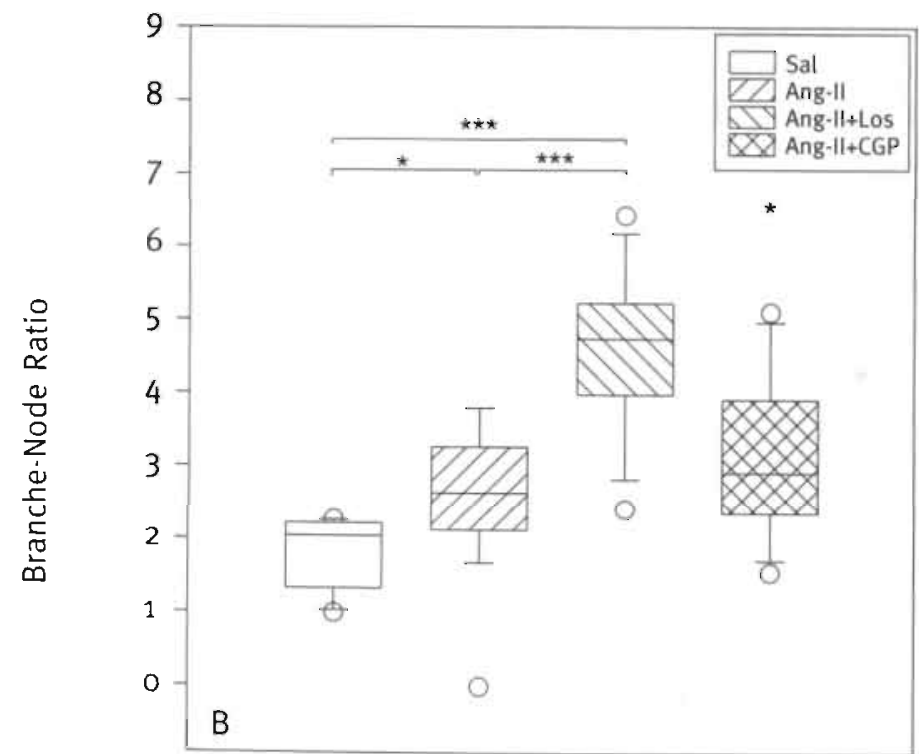

Treatment Group
Figure $3 a$. Effects of AngII and AT receptor antagonists on arcade formation in the CAM. ${ }^{* *} \mathrm{p}<0.01$; ${ }^{* * *} \mathrm{p}<0.001$ in Mann-Whitney U-test. Ang-II, angiotensin-II; Los, losartan; CGP, CGP42112A. Note that losartan but not CGP42112A potentiates the Ang-II induced response.

Figure $3 b$. Effects of AngII and AT receptor antagonists on arcade formation in the CAM * $p<0.05$; $* * * * 00.001$ in Mann-Whitney U-test. Ang-II, angiotensin-II; Los, losartan; CGP, CGP42112A. Note that losartan potentiates the response to Ang-II. 


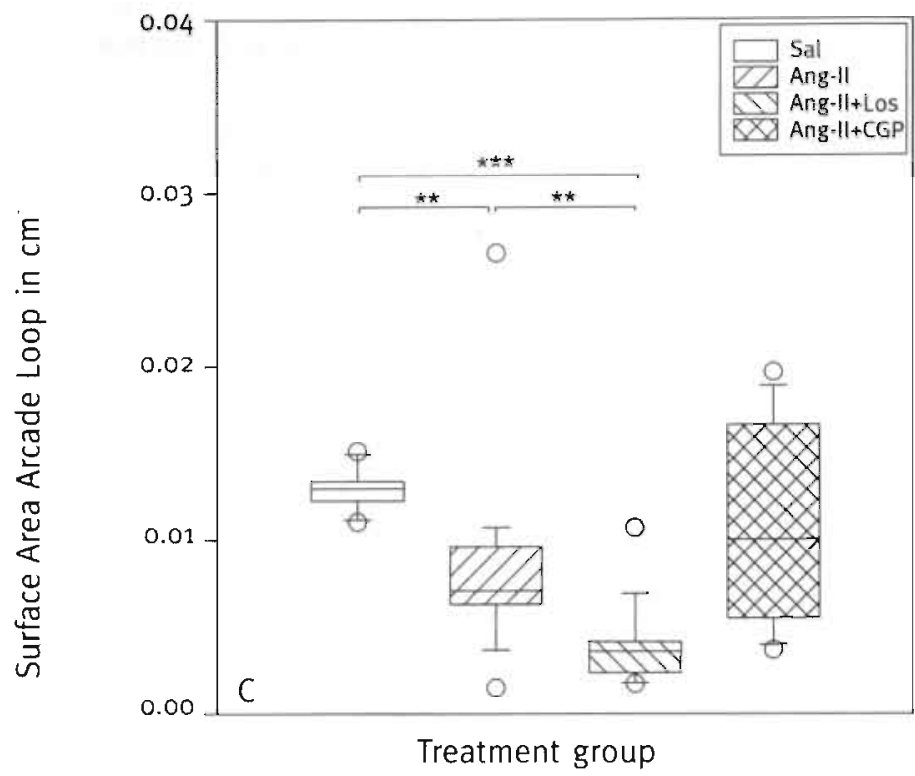

Figure 3c: Effects of AngII and AT receptor antagonists on arcade formation in the CAM. ${ }^{* *} \mathrm{p}<0.01 ;{ }^{* * *} \mathrm{p}<0.001$ in Mann-Whitney U-test. Ang-II, angiotensin-II; Los, losartan; CGP, CGP42112A. Note that losartan potentiates the response to Ang-II.

\section{Effects of Ang-// and ASA}

In this set of experiments, combined treatment of Ang-II with ASA resulted in a dosedependent enhancement in number of arcade loops versus Ang-II alone $(\mathrm{p}<0.05)$ (fig, 4A). Post-hoc testing showed that Ang-II and Ang-II + ASA $19.5 \mu \mathrm{g}$ differed significantly ( $\mathrm{p}<0.05)$. Compared to saline control, Ang-II + ASA $19.5 \mu \mathrm{g}$ differed significantly $(\mathrm{p}<0.001)$.Compared to saline control, the branch-node ratio increased significantly $(\mathrm{p}<0.05)$ after treatment with Ang-II (fig. 4B). Combined treatment with ASA resulted in a dose-dependent further increase in branch-node ratio $(\mathrm{p}<0.05)$.

The branch-node ratio of Ang-II + ASA $19.5 \mu \mathrm{g}$ differed significantly ( $\mathrm{p}<0.001)$ from Ang-II alone. The average surface area of an arcade loop (fig. 4C) decreased after treatment with Ang-II $(p<0.01)$. Combined treatment with ASA did not result in a significant dose-dependent effect on surface area. Treatment with Ang-II + ASA $19.5 \mu \mathrm{g}$ resulted in a significant decrease in surface area compared to saline control $(p<0.001)$. 


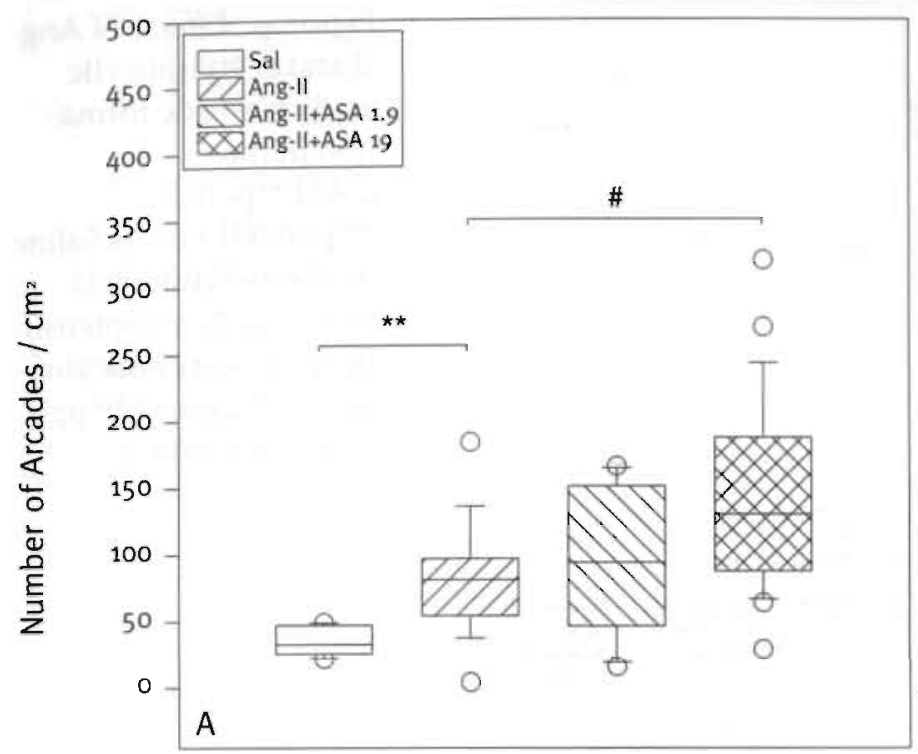

Treatment group

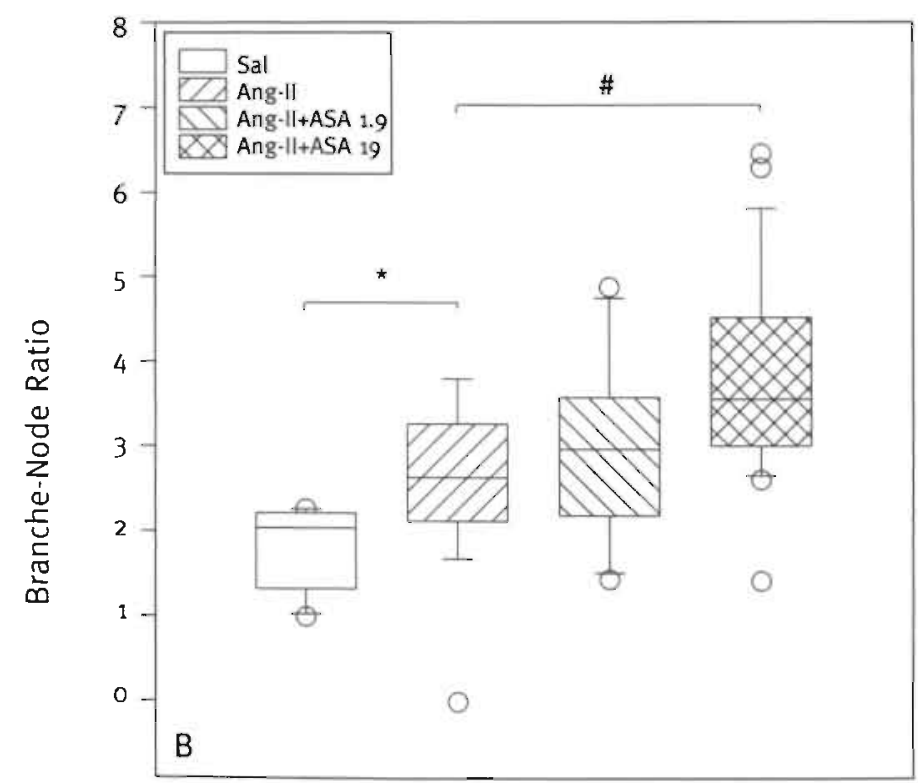

Treatment group
Figure 4a. Effects of AngII and acetylsalicylic acid on arcade formation in the CAM.

** $p<0.01$ in Mann-

Whitney U-test; \#p $<0.05$ in Kruskall-Wallis test. Ang-II, angiotensin-II; ASA, acetylsalicylic acid (1.9 $\mu$ g and $19 \mu \mathrm{g}$ resp.). Acetyl-salicylic acid causes a dose-dependent enhancement of Ang-II induced arcade formation.

Figure $4 b$. Effects of Ang-II and acetylsalicylic acid on arcade formation in the CAM. ${ }^{*} p<0.05$ in MannWhitney U-test; $\# p<0.05$ in KruskallWallis test. Ang-II, angiotensin-II; ASA, acetylsalicylic acid $(1.9 \mu \mathrm{g}$ and $19 \mu \mathrm{g}$ resp.). Acetylsalicylic acid causes a dose-dependent enhancement of Ang-II induced arcade formation. 


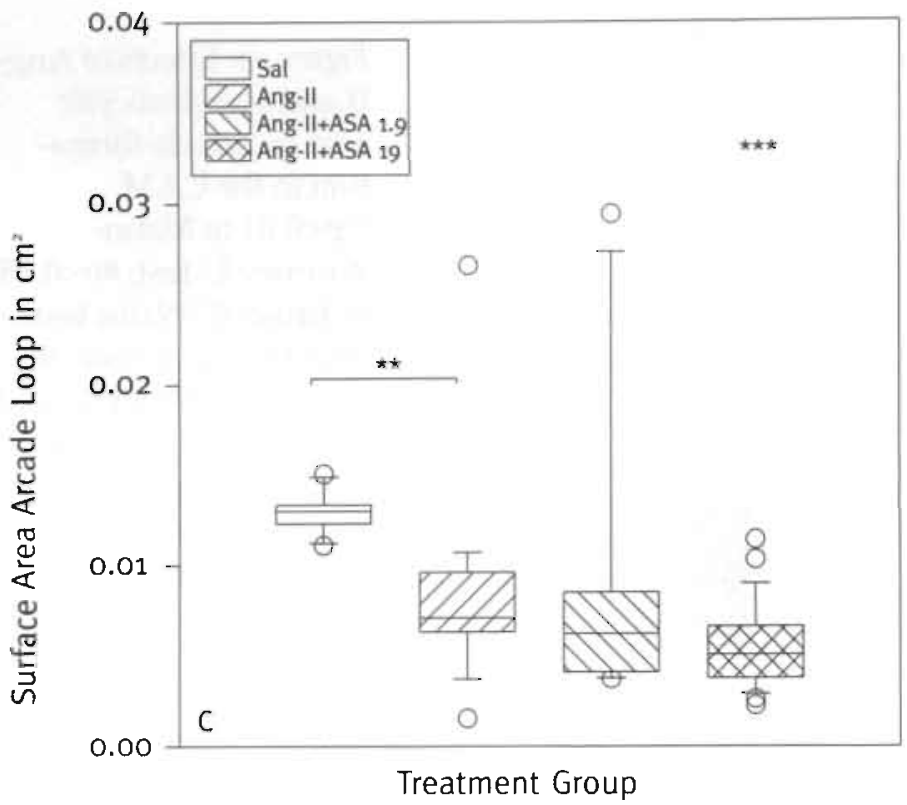

Figure 4c. Effects of AngII and acetylsalicylic acid on arcade formation in the CAM. ${ }^{* *} \mathrm{p}<0.01$; ${ }^{* *} \mathrm{p}<0.001$ versus Saline in Mann-Whitney Utest; Ang-II, angiotensinII; ASA, acetylsalicylic acid $(1.9 \mu \mathrm{g}$ and $19 \mu \mathrm{g}$ resp.); Sal, saline.

\section{Effect of ASA alone}

Compared to saline control neither ASA $1.95 \mu \mathrm{g}$ daily nor ASA $19.5 \mu \mathrm{g}$ daily influenced the number of arcade loops (fig. 5A). However, the branch-node ratio (fig. 5B) increased significantly $(\mathrm{p}<0.05)$ after treatment with ASA $1.95 \mu \mathrm{g}$ when compared to saline control. No significant differences in mean surface area of arcade loops were observed between the different treatments. 

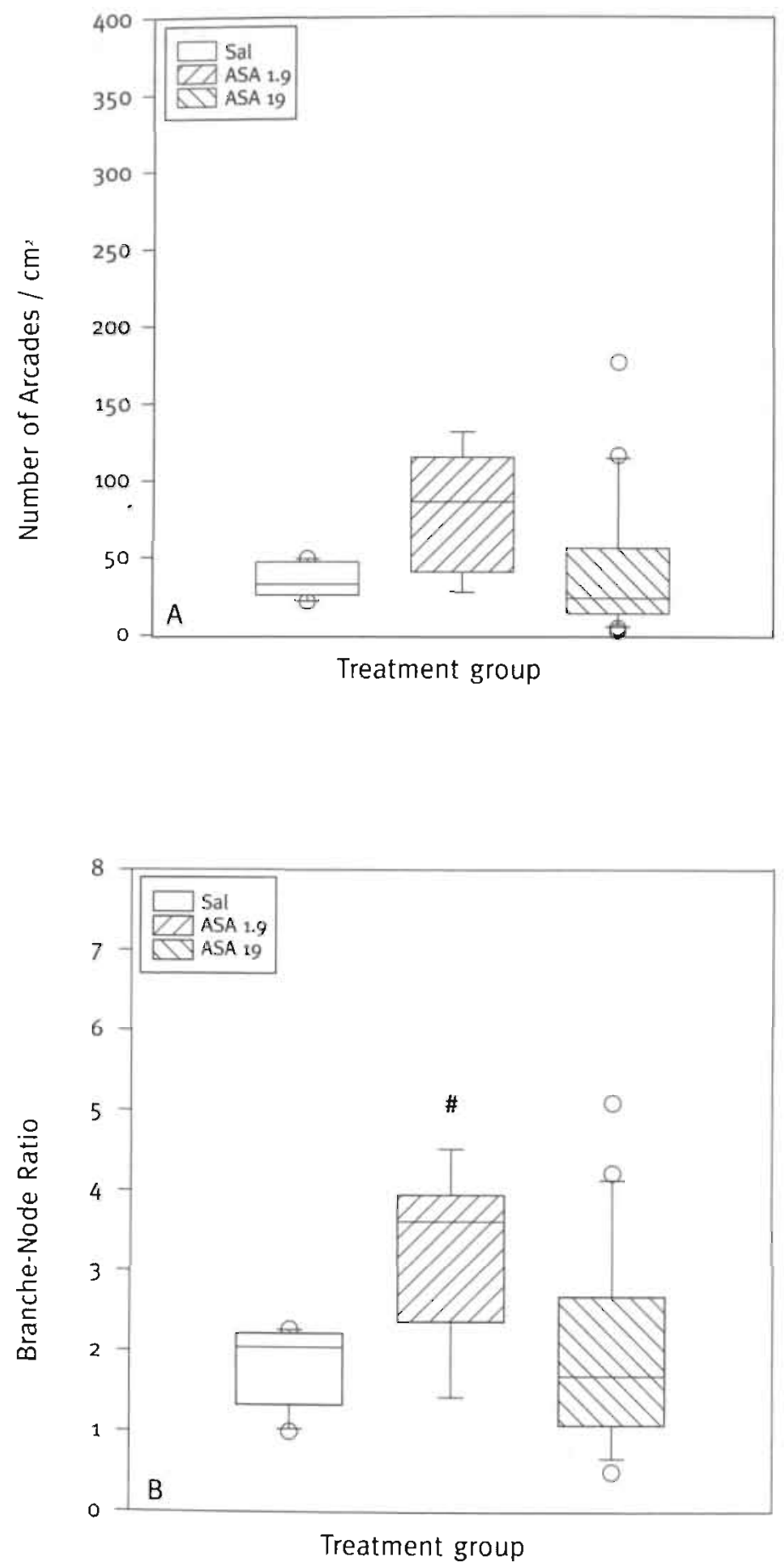

Figure 5a. Effects of acetyl-salicylic acid on arcade formation in the CAM. ASA, acetylsalicylic acid

(1.9 $\mu \mathrm{g}$ and $19 \mu \mathrm{g}$ resp.); Sal, saline. Note that acetyl-salicylic acid has little effect on arcade formation.
Figure $5 b$. Effects of acetyl-salicylic acid on arcade formation in the CAM. \#p<0.05 in MannWhitney U-test; ASA, acetylsalicylic acid (1.9 $\mu \mathrm{g}$ and $19 \mu \mathrm{g}$ resp.); Sal, saline. Note that acetylsalicylic acid in a dose of $1.9 \mu \mathrm{g}$ increased the branch-node ratio. 


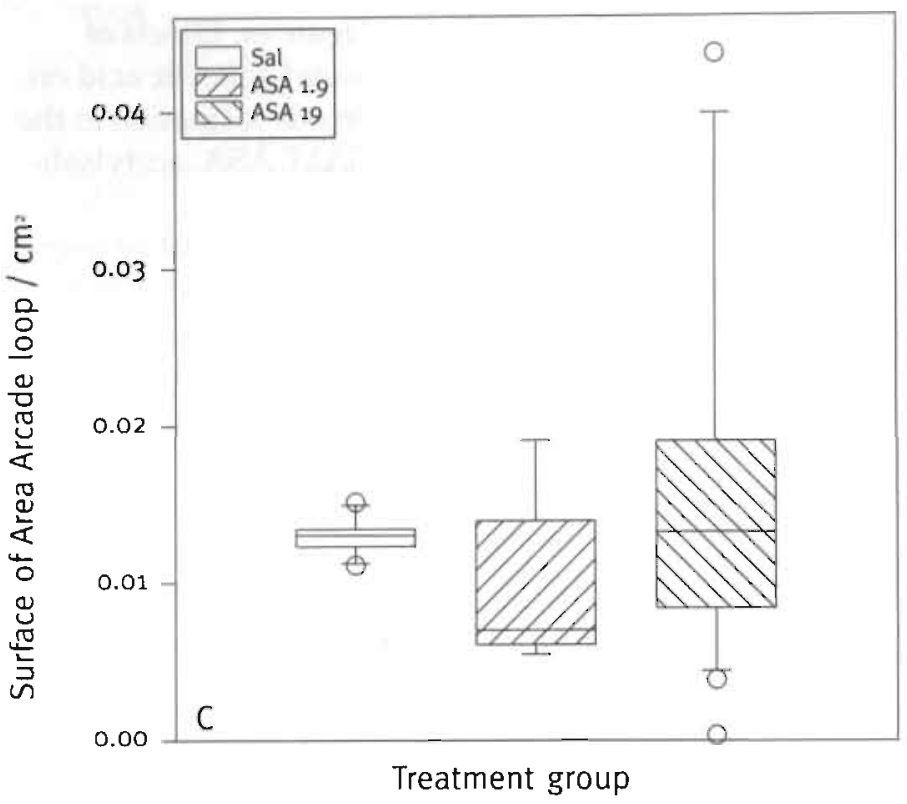

Figure 5c. Effects of acetyl-salicylic acid on arcade formation in the CAM. ASA, acetylsalicylic acid

( $1.9 \mu \mathrm{g}$ and $19 \mu \mathrm{g}$ resp.); Sal, saline. Note that acetylsalicylic acid has little effect on arcade formation.

\section{Number of segments per arcade}

The average number of segments for arcades in a network did not differ between the treatment groups. It averaged 5 in all groups, with a range from 3-9 and a distribution with a skewness to the right.

Relationship between arcade loop number,

surface area and branch-node ratio

In order to establish a relationship between the measured parameters for arcade formation, a Spearman rank correlation was calculated. The Spearman correlation coefficients were: for number of arcade loops and branch-node ratio 0.9039 ( $\mathrm{p}<0.05)$, for number of arcade loops and surface area $-0.7508(\mathrm{p}<0.05)$ and for branch-node ratio and surface area $-0.6690(\mathrm{p}<0.05)$.

\subsection{Discussion}

Morphological analyses of the vascular architecture in the terminal part of the arteriolar tree has revealed that there are basically two types of branching patterns. One is a dichotomous pattern of branching, whereas the other is characterized by arteriolararteriolar arcades ${ }^{14}$. This study shows that it is possible to induce arteriolar arcade formation within a normally dichotomous, developing microvascular network using pharmacological tools. The observed morphological changes in vascular pattern could be quantified using different parameters. 
Of these, the number of arcade loops per unit surface and the branch-node ratio are the most sensitive in discriminating between the treatment groups. The additional value of the time consuming measurement of surface area and number of segments per arcade is rather small. After induction of arcade formation, surface area and number of segments per arcade hardly show variation. The number of segments, 5 per arcade loop (with a range of 3-9), is comparable to that in a study in cat sartorius mus$\mathrm{cle}^{12}$. A recent study using a mathematical model to simulate arcade formation also led to an average of 5-6 segments per loop ${ }^{15}$. This indicates that the morphology of the arcades in different networks share the same characteristics, suggesting a common pathway for their formation.

\section{How are arcades formed?}

Arcades can be formed by the induction of sprouts from different arterioles and their subsequent fusion. It is not clear which trophic signal would cause the fusion of the sprouts. Moreover, experimental evidence thus far suggests that sprout formation mainly takes place at the capillary and small venular level ${ }^{16}$. We have never observed sprout formation at the arteriolar level in the CAM.

An alternative pathway for arcade formation is arterialization of capillaries. The capillary plexus in the developing CAM is in alignment with the outer epithelial layer'. The arteriolar network is comprised of vessels that lay underneath this layer with the terminal arterioles feeding the capillary plexus ${ }^{1}$. In vascular networks, terminal arterioles can be formed when capillaries become invested with cells that express smooth muscle contractile proteins ${ }^{17}$. Price and Skalak ${ }^{18}$ have postulated that arcade arterioles are formed when terminal arterioles from adjacent transverse arteriole trees cross along back-connecting capillaries and connect to each other. This process of arterialization can be the result of direct effects of growth factors acting on endothelial cells and vascular smooth muscle cells or can be caused by local hemodynamic changes within the terminal segments of the arteriolar tree ${ }^{18}$. Such hemodynamic mechanisms were recently discussed in detail in a series of mathematical modeling studies ${ }^{18-20}$. From these studies it was concluded that both circumferential wall stress and shear stress can influence capillary and arteriolar growth. More specifically, Price and Skalak proposed that above a certain threshold value for circumferential wall stress, capillaries are upgraded to arcade vessels. The pharmacological agents we used in our study may have influenced circumferential wall stress of the terminal vessels in the CAM arteriolar network. However, it is technically still not possible to verify whether this is indeed the case. This leaves the direct effects of Ang-II and prostaglandins on endothelial and vascular smooth muscle cells as the most important mechanism of explaining our observation of arcade formation. 


\section{Vascular growth effects of angiotensin II and prostaglandins}

Both Ang-II and prostaglandins can exert direct effects on the growth of endothelial cells and vascular smooth muscle cells. Ang-II can induce vascular smooth muscle cell hypertrophy and hyperplasia both in vitro and in vivo ${ }^{21}$. Research on processes involved in restenosis revealed an important role of Ang- $\Pi$ in neointima formation through smooth muscle cell replication and migration ${ }^{2122}$. Ang-II acts as an angiogenic factor in the rabbit cornea and CAM angiogenesis assay ${ }^{6.23}$. Blockade of Ang-II formation through ANG-I converting enzyme inhibition attenuates vascular development in different rat tissues ${ }^{28-31}$. In contrast to the generally observed growth promoting effect of Ang-II on vascular smooth muscle cells, its effects on endothelial cells are less clear. Several authors have even proposed an inhibitory effect of Ang-II on endothelial cell growth ${ }^{26,27}$.

The growth effects of prostaglandins depend on the specific prostaglandin studied and the assay used. Prostacyclin, prostaglandin E1 and E2, but not thromboxane A2, inhibit mitosis and DNA synthesis of cultured vascular smooth muscle cells ${ }^{2829}$. Mixed effects, both inhibitory and stimulatory, have been found with different prostaglandins on cultured endothelial cell grow $\mathrm{th}^{30,31}$. In in vivo assays for angiogenesis prostaglandins $E_{1}$ and $E_{2}$ have angiogenic properties, whereas prostaglandin $F_{2}$ and thromboxane $\mathrm{A}_{2}$ inhibit angiogenesis ${ }^{10,32,33}$. Furthermore, it has been postulated that the release of prostaglandins may act as a negative growth signal for vascular smooth muscle cell growth induced by polypeptide growth factors ${ }^{34,35}$.

Taking into account these differential effects of Ang-II and prostaglandins on vascular growth processes, we come to the following hypothesis. In the CAM, arterioles grow through upgrading of capillaries by deposition of vascular smooth muscle cells around the endothelial tubes. An arcade arteriole is formed by upgrading of capillaries interconnecting two terminal arterioles. Ang-II stimulates the process of arterialization by enhancing vascular smooth muscle cell migration and growth. At the same time Ang-Il causes the release of prostaglandins, which act as inhibitors of vascular smooth muscle cell growth. The prostaglandin releasing potential is an established aspect of the in-vivo actions of Ang- $\left[1^{36}\right.$. Bv inhibiting vascular smooth muscle cell growth, prostaglandins counteract part of the vascular growth effect of Ang-II. However, if prostaglandin synthesis or action is blocked, the response to Ang-II is greatly enhanced and this leads to pronounced arcade formation. This hypothesis could be tested using more selective tools to influence the release and activity of various prostaglandins.

\section{Losartan and arcade formation}

The hypothesis formulated above is based on our findings of the potentiation by ASA of Ang-II induced arcade formation. However, our study was triggered by incidental observations on the potentiating effect of losartan on arcade formation. Losartan is best known for its $\mathrm{AT}_{\text {i }}$ receptor antagonistic properties ${ }^{36}$. In a previous study we showed the absence of $\mathrm{AT}_{1}$ receptors in the chick embryo CAM by using both ligand binding and functional studies. 
The AT receptor in this preparation differs from the $\mathrm{AT}_{1}$ and $\mathrm{AT}_{2}$ receptors described in different species thus far, but shows marked similarities with the turkey adrenal gland AT receptor ${ }^{37}$ and the AT receptor recently described in human endometrium involved in angiogenesis ${ }^{38}$. All these receptors share a lack of affinity for losartan, whereas CGP $42112 \mathrm{~A}$ binds and acts pharmacologically as an antagonist at that AT-receptor. CGP $42112 \mathrm{~A}$ inhibits Ang-II induced angiogenesis in the CAM${ }^{6}$. It did not potentiate but rather inhibited arcade formation although the inhibitory effect did not reach statistical significance. It cannot be ruled out that CGP 42112A has a certain degree of intrinsic activity at the AT receptor in the CAM, which contributes to the lack of significance of the inhibitory effect ${ }^{26}$.

The marked effects of losartan are most likely not caused by AT receptor interaction because of the lack of losartan-sensitive AT receptor binding sites in the CAM" In view of the similarities with the effects of ASA on arcade formation and losartan's known competitive antagonism of the thromboxane $A_{2}$ / prostaglandin $F_{2 a}$ (TP) receptor ${ }^{79}$, we propose that the effects of losartan on arcade formation are prostaglandin dependent. Future research should define the exact nature of the molecular mechanisms involved.

\subsection{Conclusion}

In conclusion, we have shown that the normal dichotomous branching pattern of the arteriolar tree in the CAM can be transformed into a more arcade-like network using drugs interfering with the renin-angiotensin and/or prostaglandin systems. Furthermore, we have applied quantitative topological methods to quantify various aspects of arcade formation. Future studies on drug-induced changes of vascular growth should take into account these fundamentally different patterns of vascular branching.

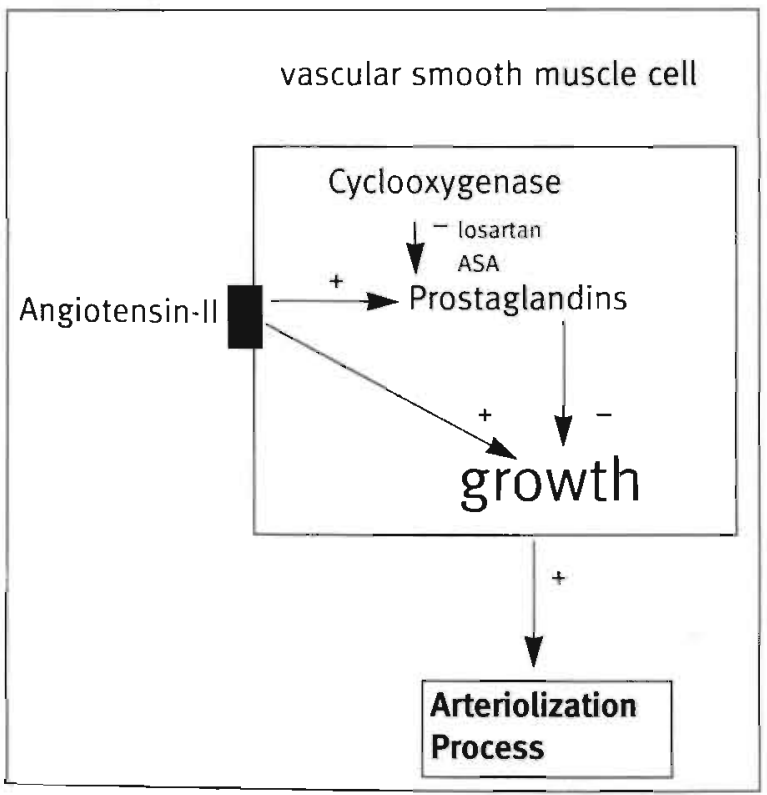

Figure 6. Schematic representation of the proposed role for angiotensin-II (Ang-II) and prostaglandins (PG) in arteriolar arcade formation. Ang-II stimulates vascular smooth muscle cell (VSMC) growth. PG's inhibit VSMC growth. Blocking PG synthesis with acetylsalicylic acid (ASA) will enhance the Ang-II induced growth response. This will enhance the arteriolization process, hence, increase arcade formation. Losartan may either block PG synthesis directly or act as a PG receptor antagonist. 


\section{References}

3. MacDonald IC, Schmidt EE, Morris VL, Chambers AF, Groom AC: Intravital microscopy of the chorioallantoic membrane microcirculation: a model system for studying metastasis. Microvasc Res 1992:44:185-199.

2. Kassab GS, Rider CA, Tang NJ, Fung, YB: Morphometry of pig coronary arterial trees. Am I Physiol 1993:265:H350-H365.

3. Van Bavel E, Spaan JAE: Branching patterns in the porcine coronary arterial tree. Estimation of flow heterogeneity. Circ Res 1992; 71:12:00-1212.

4. Engelson ET, Schmid-Schînbein GW, Zweifach BW: The microvasculature in skeletal muscle. II. Arteriolar network anatomy in normotensive and spontaneously hypertensive rats. Microvasc Res 1986;31:356-374.

5. Struijker Boudier HAJ, Le Noble JLML, Messing MWJ, Huijberts MSP, Le Noble FAC, Van Essen H: The microcirculation and hypertension. I Hypertens 1992;10 (suppl 7):147-157.

6. Le Noble FAC, Schreurs NHJS, Van Straaten HWM, Slaaf DW, Smits JFM, Rogg H, Struijker Boudier HAJ: Evidence for a novel angiotensin II receptor involved in angiogenesis in chick embryo chorioallantoic membrane. Am J Physiol 1993;264:R460R465.

7. Liu ECK, Hedberg A, Goldenberg H], Harris DN, Webb ML: DuP753, the selective angiotensin II receptor blocker, is a competitive antagonist to human platelet thromboxane A2/prostaglandin H2 (TP) receptors. Prostaglandins 1992;44:89-99.

8. Jaiswal N, Diz DI, Tallant EA, Khosla MC, Ferrario CM: The non-peptide angiotensin II antagonist DuP753 is a potent stimulus for prostacyclin synthesis. Am J Hypertens 1991;4:228-233.

9. Corriu C, Bernard S, Schott C, Stoclet IC: Effects of losartan on contractile responses of conductance and resistance arteries from rats. I Cardiovasc Pharmacol 1995;26:688-692.

10. Form DM, Auerbach R. PGE2 and angiogenesis. Proc Exp Biol Med 1983;172:214-218.

11. Dusseau IW, Hutchins PM, Malbasa DS: Stimulation of angiogenesis by adenosine on the chick chorioallantoic membrane. Circ Res 1986:59: $163-170$.

12. Torres IPF, Cyrino FZGA, Popol AS, Bouskela E, Johnson PC: Morphometric analysis of the anastomosing arteriolar network in cat sartorius muscle. Int I Microcirc: Clin Exp 1994;14:3-13.

13. Johnson R: Elementary statistics (ed 4). Boston, PWS Publishers, 1984.

14. Kăhler CM, Kieselbach GF, Reinisch N,Troger J, Göttinger W, Wiedermann C): Fibroblast growth promoting activity in prolifera. tive vitreoretinopathy: antagonism by acetylsalicylic acid. Eur / Pharmacol 1994:262:261-269.

15. Kiani MF, Hudetz AG: Computer simulation of growth of anastomosing microvascular networks. I Theor Biol 1991:150:547 560 .

16. Hudlicka O, Tyler KR: Angiogenesis: The growth of the vascular system. London, Academic Press, 1986.

17. Price RJ, Owens GK, Skalak TC: Immunohistochemical identification of arteriolar development using markers of smooth mus cle differentiation: evidence that capillary arterialization proceeds from terminal arterioles. Circ Res 1994:75:520-527.

18. Price RJ, Skalak TC: A circumferential stress-growth rule predicts arcade arteriole formation in a network model, Microcirculation 1995:2:41-51.

19. Hacking WIG, Van Bavel E, Spaan JAE: Shear stress is not enough to control growth of vascular networks: a model study. As! J Physiol 270, 1996, in press.

20. Price Rf, Skalak TC. Circumferential wall stress as a mechanism for arteriolar rarefaction and proliferation in a network model. Microvasc Res 1994:47:188-202.

21. Jackson CL, Schwartz SM: Pharmacology of smooth muscle cell replication. Hypertension 1992;20:713-736.

22. Daemen MIAP, Lombardi DM, Bosman FT, Schwartz SM: Angiotensin 11 induces smooth muscle cell proliferation in the nor. mal and injured rat arterial wall. Circ Res 1991;68:450-456.

23. Fernandez LA, Twickler J, Mead A: Neovascularization produced by angiotensin 11. J Lab Clin Med 1985:105:141-145.

24. Wang DH, Prewitt RL: Cantopril reduces aortic and microvascular growth in hypertensive and normotensive rats. Hypertension 1190; $15: 68 \cdot \%$.

25. Nelissen-Vrancken HIMG, Struijker Boudier HAJ, Daemen MJAP, Smits IFM: Anthypertensive therapy and adaptive mechänisms in peripheral ischemia. Hypertension 1993:2:2:780-788. 
26. Bell L, Madri JA: Influence of the angiotensin system on endothelial and smooth muscle cell migration. Am I Pathol $1990 ; 137: 7 \cdot 12$.

27. Stoil M, Steckelings M, Paul M, Bottari SP, Metzger R, Unger T: The angiotensin AT2 receptor mediates inhibition of celi proliferation in coronary endothelial cells. J Clin Invest 1995:95:651-657.

28. Morisaki N, Kanzaki T, Motoyama N, Saito Y, Yoshida S: Cell cycle dependent inhibition of DNA synthesis by prostaglandin I2 in cultured rabbit aortic smooth muscle cells. Atherosclerosis 1988;7t:165-171.

29. Nagata T, Uehara Y, Numabe A, Ishimitsu T, Hirawa N, Ikeda T, Matsuoka $H$, Sugimoto T: Regulatory effect of thromboxane $A 2$ oin proliferation of vascilar smooth muscle cells from rats. Am ! Physiol 1992:263: $\mathrm{H}_{1331}-\mathrm{H} 1338$.

30. Kanayasu T, Nakao-Hayashi J, Asuwa N, Morita I, Ishii T, Ito H, Murota S: Leukotriene $\mathrm{C}_{4}$ stimulates angiogenesis in bovine carotid artery endothelial cells in vitro. Biochem Biophys Res Commun 1989;159:572-578.

3.1. Foultier MT, Patrice T, Harb J, Robillard L, Houillon G, Galmiche JP, Le Bodic L: Endothelial or cancer cells growth regulation by PGE1 analog misoprostol; in Samuelsson B (Ed): Advances in prostaglandin, thromboxane and leukotriene research (vol 21). New York, Raven Press Ltd, 1990, p 855.

32. Ziche M, Jones J, Gullino PM: Role of prostaglandin $E_{1}$ and copper in angiogenesis. J Nat Canc Inst 1982;69:475-482.

33. Folkman J, Klagsbrun M: Angiogenic factors. Science 1987:235:442-447.

34. Ristimaki A: Transforming growth factor $\alpha$ stimulates prostacyclin production by cultured human vascular endothelial cells more potently than epidermal growth factor. Biochem Biophys Res Commun 1989;160:1100-1105.

35. Libby P. Warner SI, Friedman GB: Interleukin 1: A mitogen for human vascular smooth muscle cells that induces the release of growth inhibitory prostanoids. J Clin Invest 1988;81:487-498.

36. Timmermarns PBMWM, Wong PC, Chiu AT, Herblin WF, Bentield P. Carini DJ, Lee RI, Wexler RR, Saye JAM, Smith RD: Angiotensin-Il receptors and angiotensin-II receptor antagonists. Pharmacol Rev 1993;45:205-251.

37. Murphy TJ, Nakamura Y, Takeuchi K, Alexander RW: A cloned angiotensin receptor isoform from the turkey adrenal gland is pharmacologically distinct from mammalian angiotensin receptors. Mol Pharmacol 1993:44:1·7.

38. Ahmed A, Li XF, Shams M, Gregory J, Rollason T, Barnes NM, Newton JR: Localization of the angiotensin II and its receptor subtype expression in human endometrium and identification of a novel high affinity angiotensin II binding site. I Clin Invest 1995:96:848-857. 


\section{Chapter 4}

Localization and expression of the chick embryo angiotensin receptor in the developing vasculature of the chorio-allantoic membrane 


\subsection{Introduction}

It has recently become evident that the renin-angiotensin system (RAS) plays a pivotal role in cardiac hypertrophy and vascular growth ${ }^{17}$. Selective inhibition of these processes could contribute to a decrease in morbidity due to cardiovascular diseases. Since the active component of the RAS, angiotensin-II, exerts its effect through activation of specific Ang-II receptors, information about quantity and distribution of these receptors is vital.

Molecular cloning techniques revealed the existence of two distinct isoforms of angiotensin receptors in mammals, the $\mathrm{AT}_{1}$ and the $\mathrm{AT}_{2}$ receptor ${ }^{8.9}$. Ligand-binding studies in birds ${ }^{10.11}$ and amphibians ${ }^{12}$, suggest the existence of a third type of angiotensin receptor. This isoform has recently been cloned from the turkey adrenal gland Evidence is emerging that $\mathrm{AT}$ receptors other than $\mathrm{AT}_{1}$ and $\mathrm{AT}_{2}$ are present in mammals and might have al functional role in pathological conditions ${ }^{9.14}$.

Using the chick-embryo as a model, the existence was shown of a single class of AT receptors functionally coupled to vascular growth". The ligand-binding spectrum deviates from the mammalian $\mathrm{AT}_{1}$ and $\mathrm{AT}_{2}$ receptors and shows similarity with the turkey AT receptor. Recently it was proposed that this receptor is also present in human endometrium with a functional coupling to periodic vascular growth ${ }^{14}$. The celltype and second messenger system activated by Ang-II to produce vascular growth in vivo are unknown.

The aim of this study was to localize the chick-embryo AT-receptor and to quantify AT receptor expression during vascular development of the chorio-allantoic membrane.

\subsection{Materials and methods}

\subsubsection{Ligand-Binding assay}

Fertile Lohman selected white leghorn eggs were incubated for either 7,10 or 14 days at $37^{\circ} \mathrm{C}$ and $55 \%$ relative air humidity. At the day of the experiment, the chick-embryo chorio-allantoic membrane (CAM) was dissected free from the embryo and remnants of amnionic- and yolk-sac membrane were seperated and discarded. The CAM was then wrapped in aluminum foil and put on ice. Subsequently, the CAM was homogenized $2 \times 30 \mathrm{sec}$. in $4 \mathrm{ml}$ of Tris-buffer $(50 \mathrm{mM}$ Tris- $\mathrm{HCl}, 5 \mathrm{mM}$ EDTA, $120 \mathrm{mM} \mathrm{NaCl}$ ) using a polytron at level 1 . The homogenate was then centrifuged for 20 minutes at $1200 \mathrm{rpm}$. at $4^{\circ} \mathrm{C}$. The supernatant was collected and saved in a $10 \mathrm{ml}$ test-tube. The pellet was washed with $4 \mathrm{ml}$ of Tris-buffer and again homogenized during $30 \mathrm{sec}$ using a polytron at level 1 . The homogenate was centrifuged during 20 minutes at $1200 \mathrm{rpm}$. at $4^{\circ} \mathrm{C}$. The supernatant was collected and pooled. The collected pooled supernatant was then centrifuged (ultracentrifuge TY 65) at $25000 \mathrm{rpm}$. (300.000g) for 30 minutes. The obtained pellet was resuspended in $300 \mu l$ Tris-buffer and pottered. 
To determine the protein content of the membrane fraction, Bio-rad assay nr. 600-0005 according to Coomassie Brilliant Blue staining ${ }^{15}$, was used with bovine serum albumin as standard. To determine the protein content of the sample $10 \mu \mathrm{l}$ was added to $390 \mu \mathrm{l}$ of Tris-buffer and $4 \mathrm{ml}$ of dye reagents. After determining the protein content the sample was diluted with assay buffer (Tris buffer supplemented with $0.2 \%$ BSA) to get a final concentration of $5 \mu \mathrm{g}$ protein $/ 100 \mu \mathrm{l}$ sample. To establish total binding, aliquots of $100 \mu \mathrm{l}$ sample were incubated during 60 minutes at room temperature with increasing concentrations of ${ }^{12} \mathrm{I}$-angiotensin-II (Amersham U.K., specific activity $2000 \mathrm{Ci} / \mathrm{mmol}$ ) ranging from $0.1 \mathrm{nM}$ to $10 \mathrm{nM}$. The non-specific binding was determined in the presence of $250 \mathrm{nM}$ unlabelled Val ${ }^{5}$ Ang-II (total incubation volume 250 $\mathrm{\mu l}$ ). After 1 hour incubation, samples were filtered over Whatman GF/C filters followed by three additional washes with $4 \mathrm{ml}$ of Tris buffer. The radio-activity on the filter was measured using a gamma-counter (LKB) with $75 \%$ efficiency. The ligand-binding curves were analyzed with Ligand, a non-linear weighted least square curve fitting programm calculating $\mathrm{Kd}$, affinity constant, and Bmax, receptor density ${ }^{16}$. Data were obtained from six separate sets of experiments each performed in triplicate.

\subsubsection{Autoradiography}

The CAM was dissected from the embryo and frozen immediately into liquid $N_{2}$ cooled iso-pentane and subsequently into liquid nitrogen. Tissue sections of $16 \mu \mathrm{m}$ thick were cut at $-20^{\circ} \mathrm{C}$ using a microtome, collected on an object glass and kept frozen. A parallel section was used for haematoxillin-eosin (HE) staining to evaluate the morphology of the tissue. Tissue sections selected for autoradiography were first allowed to reach room temperature. To determine total binding, the sections were incubated in $50 \mu \mathrm{l}$ of ${ }^{12} \mathrm{I}$-Ang-II $0.2 \mathrm{nM}$ diluted in assay buffer. To determine non-specific binding, tissue sections were incubated with $50 \mu \mathrm{l}$ of ${ }^{125}$-Ang-II $0.2 \mathrm{nM}$ in the presence of an excess

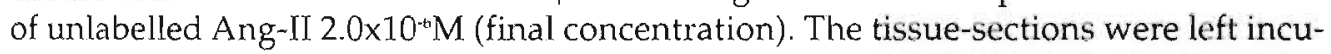
bating for 60 minutes at room-temperature. After 60 minutes the sections were washed $2 \times 1$ minute with cold Tris buffer $\mathrm{pH}=7.4$ and deionized water and left to dry for 60 minutes. The sections were then covered with a coverslip previously coated with photo-emulsion (Type NTB2, Kodak) and glued tightly at one side, to the objectglass. The exposure time was 3 to 7 days. The exposed cover-slips were developed by slightly lifting the cover-slip followed by submerging the whole preparation in D19 developer (Kodak) for 4 minutes. This was followed by washing with deionized water, fixing for $8 \mathrm{~min}$. (sodium thiosulfate $20 \%$, potassium metabisulfite $2 \%$ ), washing with deionized water and HE staining during $30 \mathrm{sec}$. The preparation was dehydrated with increasing concentrations of ethanol (70-100\%) and embedded in entellan.

\subsubsection{Histology of the vascular wall}

To evaluate the morphology of the chorio-allantoic membrane vasculature, immunohistochemistry for endothelial cells and vascular smooth muscle cells was employed. To detect collagen, an Azan staining was used ${ }^{17}$. For endothelial cells, staining for Von Willebrand factor was employed on deparafined $4 \mu \mathrm{m}$ thick sections of the CAM. 
In short, the tissue section was put in $100 \%$ alcohol. Subsequently, the tissue section was incubated with $0.3 \%$ peroxyde (diluted in methanol) for 20 minutes. The tissue section was rinsed with PBS buffer ( $3 \times 5$ minutes) after which pepsin was added $(1 \mathrm{mg} / \mathrm{ml}$ in $0.1 \mathrm{~N} \mathrm{HCl})$. The tissue section was washed with PBS buffer ( $3 \times 5$ minutes) and incubated with the primary antibody against Von Willebrand factor (rabbit antihuman (DAKO) 1:200 in PBS with 1\% bovine serum albumen) during 60 minutes at room temperature. Subsequently the tissue section was washed with PBS buffer $(3 \times 5$ minutes) and incubated with the secondary antibody (Swine-anti-rabbit SWARPO $1: 150$, PBS with $1 \% \mathrm{BSA}$ ) during 60 minutes at room temperature. Finally it was washed with PBS, and incubated with diamino-benzidin (DAB) for 7 minutes, rinsed with water and stained with haematoxilline during 2 minutes, rinsed again, dehydrated with alcohol and embedded in entallan.

Staining of smooth muscle cell $\alpha$-actin was similar to Von Willebrand staining expect for the used antibodies. Primary anti-body against $\alpha$-actin (1:300, mouse monoclonal anti- $\alpha$. smooth muscle actin, Sigma), secondary antibody (1:200 rabbit-anti-mouse RAMPO).

Azan staining for collagen was performed as follows: tissue sections were incubated with Azan I solution (0.5g Azocarmine G (Sigma), $1 \mathrm{ml}$ acetic acid, $100 \mathrm{ml}$ water) during 20 minutes at $37^{\circ} \mathrm{C}$. Subsequently the section was incubated in $5 \%$ phosphotungstic acid (Aldrich) during 45 minutes and rinsed with water. The tissue section was then incubated with A s.an solution II ( $0.5 \mathrm{~g}$ aniline blue (Clin-Tech), $2 \mathrm{~g}$ orange $\mathrm{G}$ (Sigma), $8 \mathrm{ml}$ acetic acid, $100 \mathrm{ml}$ water) diluted $1: 3$ in water, during 10 minutes. Finally, the tissue section was rinsed in $96 \%$ alcohol, dehydrated and embedded in entellan.

\subsubsection{Statistics}

To analyze changes in receptor density and affinity an analyzes of variance (ANOVA) and subsequent post-hoc least square difference test were used. Data were analyzed with SPSS-PC version 6.0 for a PC. A p $<0.05$ was considered statistically significant. Data will be presented as mean and standard error.

\section{$4 \cdot 3$ Results}

\subsubsection{Regulation of receptor density and affinity in time}

The results of the receptor density measurements are presented in figure 1 . The receptor density $B \max$ (in $\mathrm{fmol} / \mathrm{mg}$ protein) had a mean value of $322.5( \pm 33.7)$ at day 7 , increased to $604.2( \pm 90.0)$ at day 10 and decreased to $415.8( \pm 44.9)$ at day 14 . Analyses of variance showed that these differences were statistically significant $(p<0.05)$. The post-hoc least square difference test showed that the Bmax at day 10 is significantly higher compared to day 7 or day $14(\mathrm{p}<0.05)$. The densities on day 7 and day 14 did not differ significantly. The $\mathrm{Kd}$ had a mean value of $0.58 \mathrm{nM}( \pm 0.05)$ at day 7 , increased to $0.85 \mathrm{nM}( \pm 0.04)$ at day 10 and decreased to $0.59 \mathrm{nM}( \pm 0.08)$ at day 14 . Analyses of variance of the receptor affinity $\mathrm{Kd}$ in time showed that it varied significantly $(p<0.05)$. 
The post-hoc least square difference test showed that the $\mathrm{Kd}$ on day 10 is significantly higher compared to day 7 and day $14(\mathrm{p}<0.05)$. The latter two did not show significant differences.

Expression of chick embryo ATx receptor

CAM day $7,10,14$

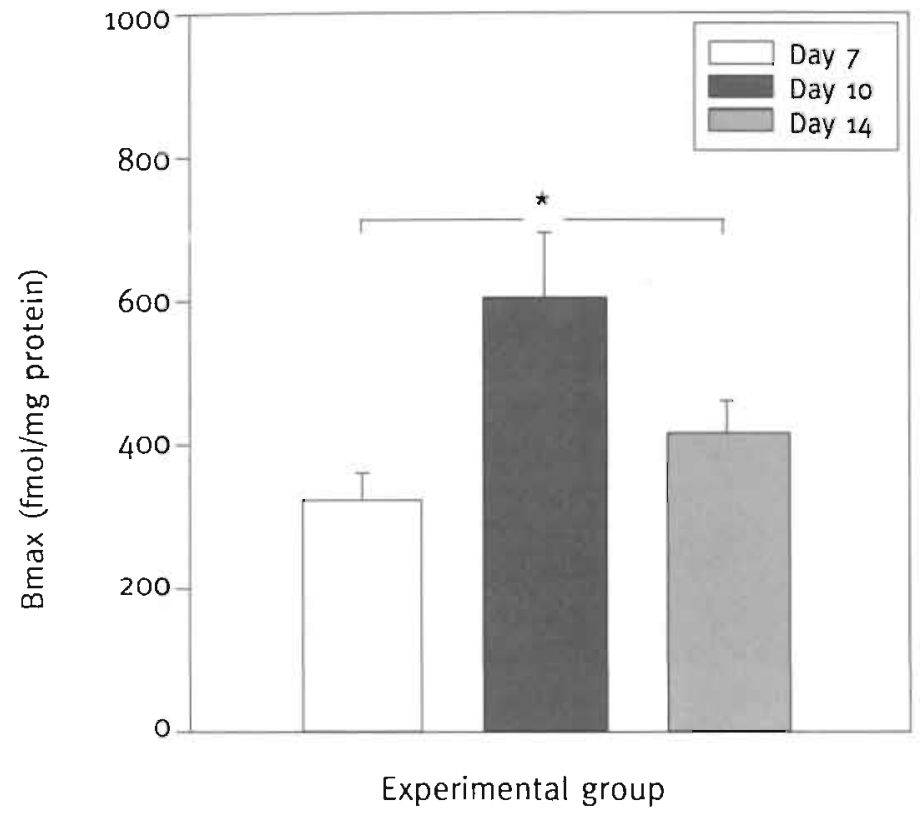

Figure 1. Expression of the chick embryo AT receptor in time. Data are expressed as mean and standard error $(n=6)$. Note that the Bmax at day 10 is significantly different from day 7 and day 14 as analyzed with a post-hoc least square difference test; ${ }^{*} \mathrm{p}<0.05$.

\subsubsection{Localization}

Photo la shows a transverse section of a CAM arteriole. Photo $1 \mathrm{~b}$ and $1 \mathrm{c}$ represent respectively total and aspecific binding for ${ }^{125} \mathrm{I}$-Ang-II. The specific binding sites for ${ }^{125} \mathrm{I}-$ angiotensin-II were predominantly detected inbetween the vascular wall, adventitia or extracellular matrix, and the CAM inner epithethelial layer. Adjacent to main areas of specific binding, labelling was also present within parts of the vascular wall but it did not seems to follow the circular contour of the vascular wall. Thus, labelling was present predominantly in the adventitial area and to a lesser extent in the media of the CAM vasculature. 


\subsubsection{Morphology of the Vascular Wall Immunohistochemistry}

A typical staining for Von Willebrand factor is shown in photo 2. Brown staining indicating the presence of endothelium, was located at the luminal side of the vessel. However, overall staining for VWF was weak.

A typical staining for smooth muscle $\alpha$-actin is shown in photo 3. A strong brown staining indicating the presence of $\alpha$-actin could be detected in the vascular wall. The $\alpha$-actin was present in a least three cell layers. In general, $\alpha$-actin labelling could be detected in both arterioles and venules. Additional Lawson stainig did not reveal the presence of a lamina elastica interna and externa.

\section{Azan staining}

A typical example of an azan staining of a CAM arteriole is shown in photo 4 .

The positive staining for collagen (blue) was not located exclusively in the media but distributed diffusely in the media, inbetween vascular smooth muscle cells, and adventitia. The collagen was present in a circular fashion around the vessel lumen. A weak staining for collagen was also present in the mesodermal interstitial area of the CAM and around the ectodermal epithelial layers. 

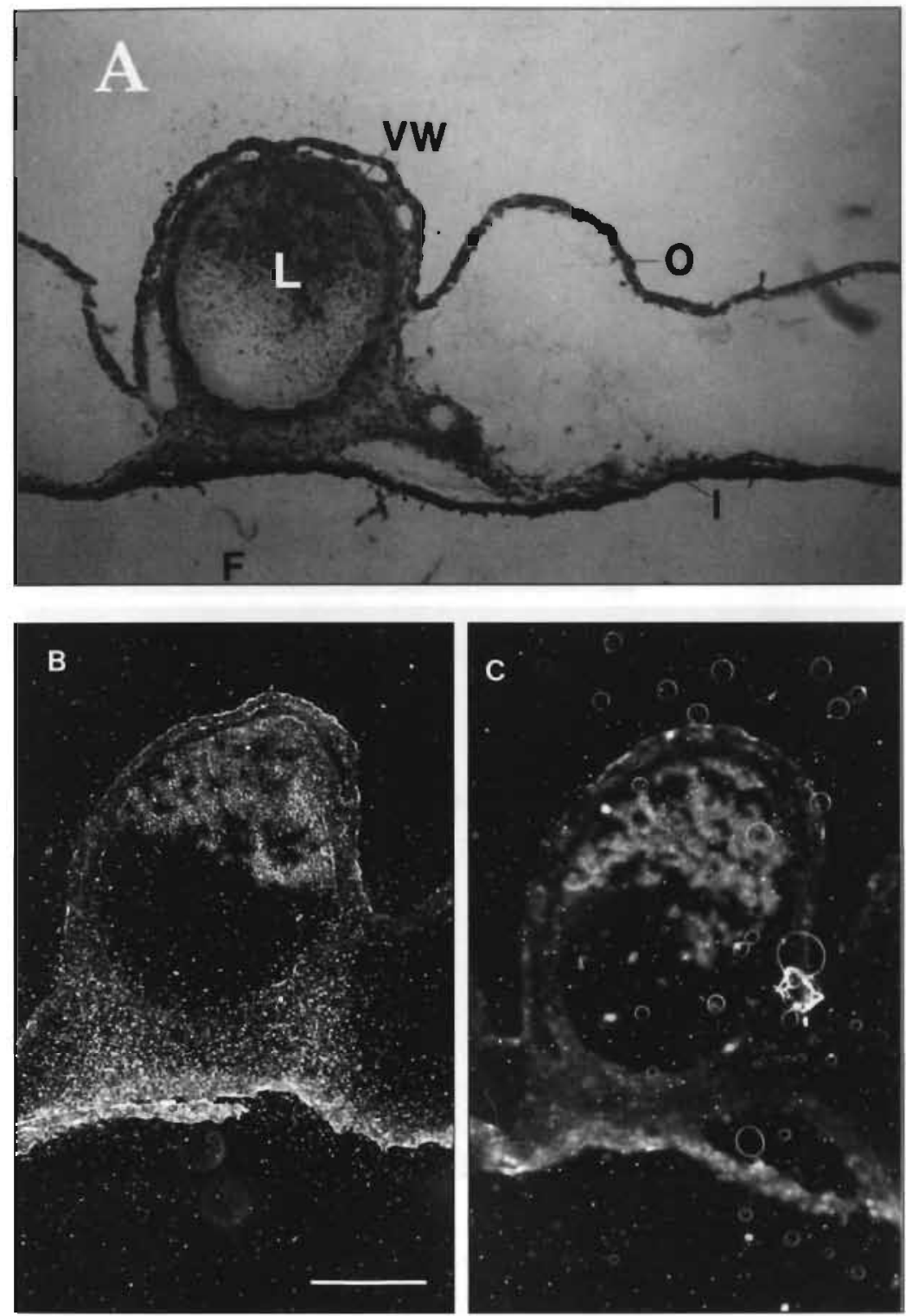

Photo $1 a$ (top). Transverse section of a CAM arteriole at day 10. VW, vascular wall; L, lumen; $O$, outer epithelial layer; I, inner epithelial layer (embryonic side). Bar represents $100 \mu \mathrm{m}$.

Photo $1 b$ (bottom lett). Specific labelling for ${ }^{125} \mathrm{I}$-Angiotensin-II. CAM at day 10.

Photo xc (bottom right). Aspecific labelling for ${ }^{125} \mathrm{I}$-Angiotensin-II. CAM at day 10. 

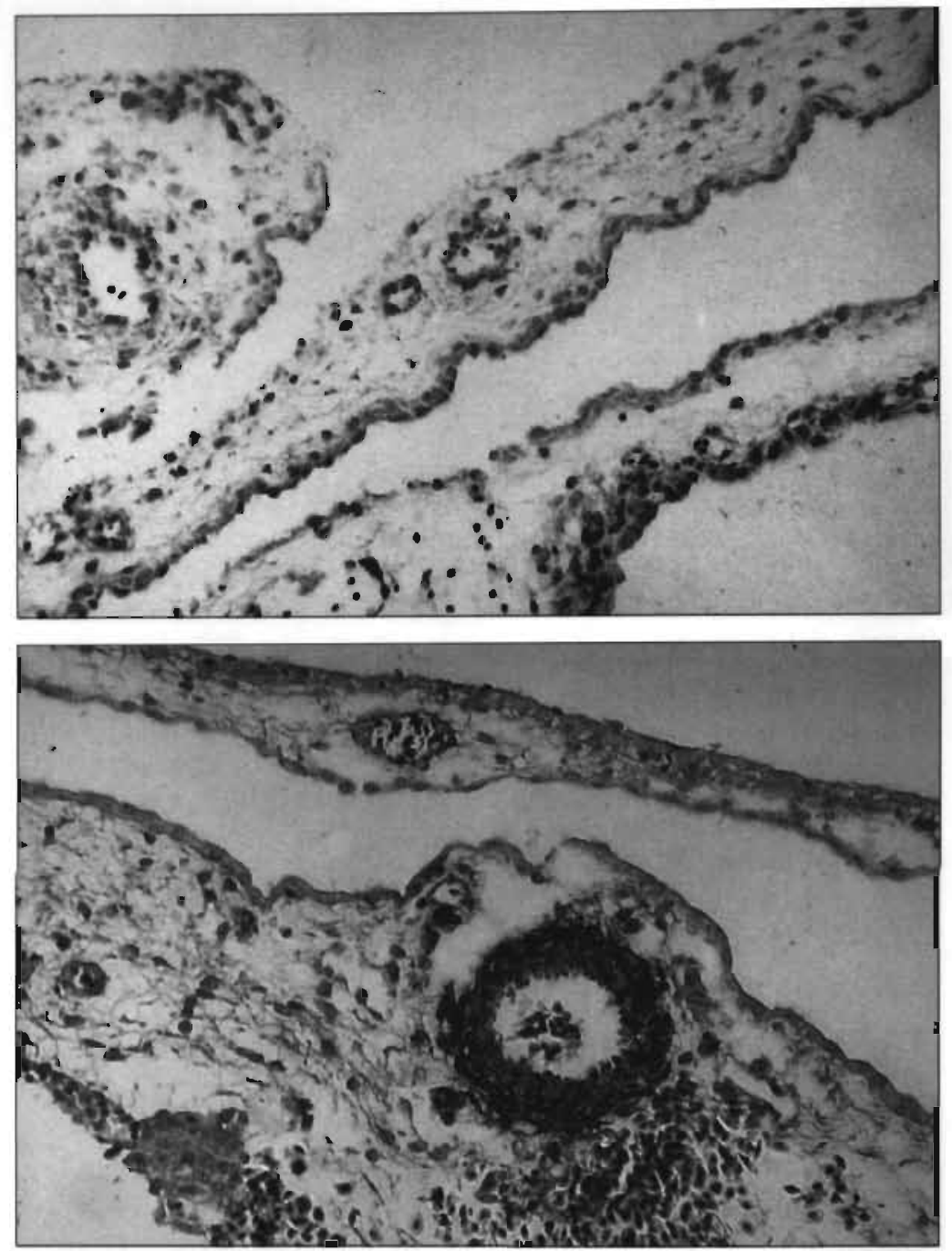

Photo 2 (top). Staining of endothelium in a CAM arteriole (diam. of $50 \mu \mathrm{m}$ ) with antibody against Von Willebrand factor. Brown staining indicates the presence of endothelium.

Photo 3 (bottom). Staining for vascular smooth muscle cells in a CAM arteriole (diam. of $50 \mu \mathrm{m}$ ) with antibodies against smooth muscle $\alpha$-actin. Dark brown indicates the presence of vascular smooth muscle. 


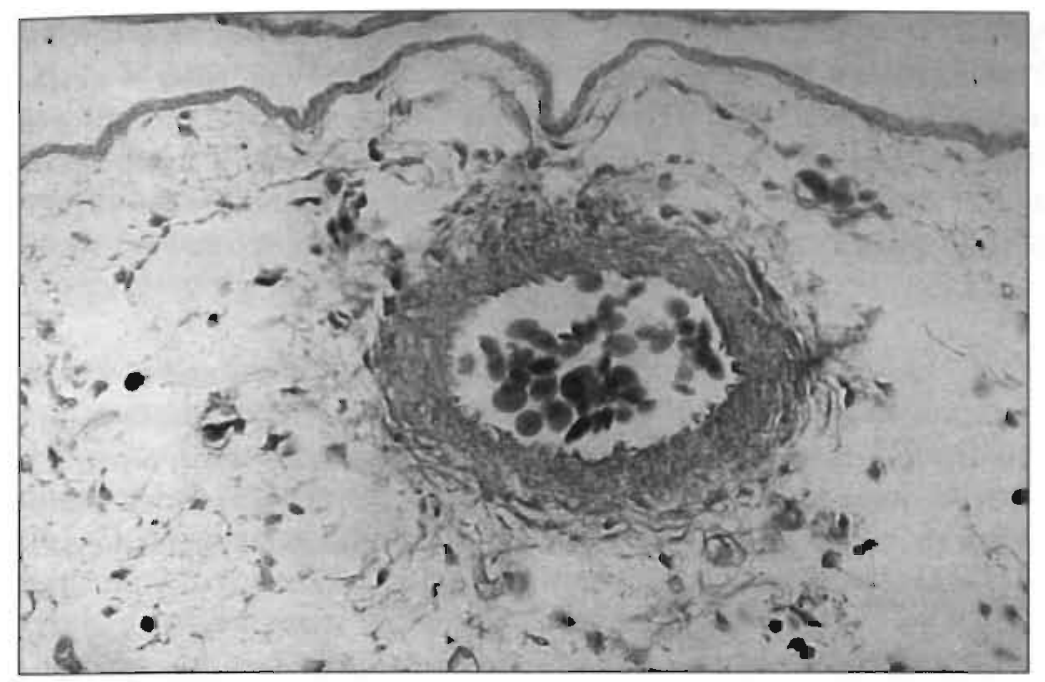

Photo 4. Azan staining for collagen in a CAM arteriole (diam. of $50 \mu \mathrm{m}$ ).

Collagen is stained blue; chromatine is stained red.

\subsection{Dissussion}

An autoradiography study was employed to identify the cell types involved in the Ang-II induced angiogenic response. On a transverse section highest density of labelling was found inbetween the vascular wall and the inner epithial layer of the CAM. Ang-II binding sites were identified in the media, adventitia and extracellular matrix of the chorio allantoic vasculature. Labelling did not seem to follow the contours of the vascular wall. In general, labelling of CAM arterioles and venules was not universal, some showed labelling others not, without preference for either one. Receptor density was developmentally regulated between day 7 and 14 of embryo gestation. The affinity constant $\mathrm{Kd}$, of Ang-II for the CAM AT receptor is comparable to affinities found for mammalian AT receptors.

The interpretation of cellular localization based on auto-radiography is compromised by several limitations. Since direct dipping of the preparation in photo-emulsion is technically not possible, coated coverslips have to be used. This introduces a relative large distance between binding site and film. The use of the gamma emitter ${ }^{12} \mathrm{I}$-Ang-II can therefore introduce labelling above cells that do not contain AT receptors. This disables a clear quantitative cellular localization and might explain the non-uniform labelling of the media adjacent to structures with high AT density. The use of tritiated Ang-II analogs would be an alternative but this technique is compromised by very long exposure times. Auto-radiography employing electron microscopy (EM) could overcome these problems under the premise that AT receptors retain their binding ability after EM fixation. 
In rats the renin-angiotensin system is very active during development of the cardiovascular system ${ }^{36}$. The expression of AT receptor subtypes depends on time of gesta. tion and is developmentally regulated. The density of the chick-embryo AT receptor is also developmentally regulated between day 7 and day 14 of gestation. If the receptor was to be expressed on cells of the vascular wall, the quantity would increase with age since the volume of the vascular system or the vascular density increases four-fold between day 7 and day $14^{37}$.

However the density of CAM AT-receptors decreased after day 10. If, instead of vascular density, vascular growth velocity expressed as ${ }^{3} \mathrm{H}$-thymidine incorporation into CAM endothelial cells ${ }^{38}$ or vascular density change per unit of time is used, a correlation can be found with AT receptor density. This suggests that AT receptors are predominantly expressed in the CAM during the period in which the most extensive vascular growth takes place.

Cell-types in the vascular wall that are recognized to play a role in vascular development are endothelial cells, vascular smooth muscle cells, fibroblasts and pericytes" Angiogenesis, also referred to as capillary sprouting, is characterized by endothelial cell migration and proliferation, and secondly lineage of new endothelial tubes with a basement membrane. This type of vessel growth is initiated at the capillary level. If Ang-II would exert its effect through direct stimulation of capillary sprouting, labelling of endothelial cells would be expected. The capillary plexus of the CAM is located at the outer CAM epithelial cell layer, but autoradiography did not reveal specific binding in this area. Since endothelial cells also aligne arterioles and venules, labelling might be expected at the luminal side of the vessel wall. However, autoradiography failed to show specific binding at the luminal side of the vascular wall.

Pericytes are also implicated to play a role in angiogenesis ${ }^{20}$. Since specific antibodies against pericytes are lacking, pericytes have to be identified based on morpholog!: Normally, pericytes are found at the capillary and precapillary level, and on a transverse section located inbetween endothelial cells and the basal membrane. Since specific Ang-II labelling could not be identified around endothelial cells, it seems unlikely that pericytes contain AT receptors. Modulation of vascular smooth muscle cell growth might influence growth of arterioles. It has been proposed that arterioles might grow through upgrading of existing capillaries by investing capillary tubes with vascular smooth muscle cells ${ }^{21}$. This would involve vascular smooth muscle cell migration and proliferation. As shown in photo $1 \mathrm{~b}$, specific labelling is present in an area of the vascular wall where VSMC are present. However, the vascular wall consists of one or more circular layers of VSMC, but specific labelling was preferentially located at only one segment of the vascular wall, not along the VSMC layers. 
Based on the autoradiography of the chick embryo CAM, the presence of AT receptors on endothelial cells can not be confirmed whereas the vascular smooth muscle cells might contain AT receptors. Specific AT binding sites have been identified in adult fowl vascular smooth muscle cells and endothelial cells ${ }^{22-2 x}$. However, this difference between embryo and adult in cellular expression pattern of AT receptors might be age dependent as has been shown for the mammalian $\mathrm{AT}_{2}$ receptor which is predominantly expressed during embryonic development'.

Specific Ang-II binding was predominantly found in the adventitial area and possibly in a part of the media. Azan staining revealed that a constituent of the extracellular matrix, collagen, was also abundantly present in the adventitial area and media, inbetween the vascular smooth muscle cells. Normally, fibroblasts are found in the adventitia. However, there is no clear lamina elastica externa and fibroblast could therefore be present in the media as well. The fibroblast is the major cell type responsible for the synthesis of collagen. The presence of fibroblasts both in media and adventitia would coincide with the distribution of collagen. It might therefore be concluded that fibroblasts are present both in media and adventitia, and contain AT receptors.

The extracellular matrix might indeed play an important role in vascular growth ${ }^{20.2831}$. The extracellular matrix can control effectiveness of vascular growth factors by influencing cell shape, by offering attachment or expressing adhesion molecules for growing sprouts, and by storage of growth factors. It has also been shown that Ang-II can activate fibroblasts to produce collagen and influence extracellular matrix composition $^{32-34}$. Furthermore, Ang-II might decrease matrix metalloproteinase activity ${ }^{32}$, and thereby influence the process of vascular grow $\mathrm{th}^{35}$.

\subsection{Conclusion}

The chick-embryo AT receptor could be identified in the media and adventitia of chorio-allantoic membrane blood vessels. The cell type predominantly expressing the AT receptor might be identified as fibroblast. The expression of the AT receptor is developmentally regulated and seems to run parallel to the vascular growth velocity. 


\section{References}

1. Dzau V]. Molecular and physiological aspects of tissue renin-angiotensin system: emphasis on cardiovasscular control. I Hyper. 6(Suppl. 3), S7-S12, 1988.

2. Sadoshima J. Izumo S. Molecular characterization of angiotensin-II induced hypertrophy of cardiac myocytes and hyperplasia of cardiac fibroblasts: critical role of the AT1 receptor subtype. Circ Res. 73, 413-423, 1993.

3. Smits JF, Van Krimpen C, Schoemaker RG, Cleutjens JP, Daemen MJ. Angiotensin-II receptor blockade after myocardial infarction in rats: effects on hemodỵnamics, myocardial DNA synthesis, and interstitial collagen content. I Cardiovasc Pharmacol, 20, $772-778,1992$.

4. Passier RCIJ, Smits JFM, Verluyten MIA, Studer R, Drexler H, Daemen MJAP. Activation of angiotensin-converting enzyme expression in infarct zone following myocardial infarction. Am J Physiol. 269, H1268.H1276, 1995.

5. Daemen MJAP, Lombardi DM, Bosman FT. Schwartz SM. Angiotensin-1I induces smooth muscle cell proliferation in the normal and injured rat arterial wall. Circ Res. 68, 450-456, 1991.

6. Vani Kleef EM, Smits IFM, De Mey IGR, Cleutjens IPM, Lombardi DM, Schwartz SM, Daemen MJAP. Alpha 1-adrenoreceptor blockade reduces the angiotensin-ll induced vascular smooth muscle DNA synthesis in the rat thoracic aorta and carotid artery. Circ Res. 70, 1122-1127, 1992.

7. Wang DH, Prewitt RL. Longitudinal effect of captopril on aortic and arteriolar development in normotensive rats. Am J Physial. 260, H1959·H1965. 1991.

8. Inagami T, Guo DF, Kitami Y. Molecular biology of angiotensin-ll receptors: an overview. J Hypertens، 12(5uppl. 10), 583-S94. 1994.

9. Timmermans PBMWM, Wong PC, Chiu AT, Herblin WF, Benfield P, Carini DJ, Lee R], Wexler RR, Saye JAM, Smith RD. Angiotensin-11 receptors and angiotensin-II receptor antagonists. Pharmacological Reviews. 45, 205-251, 1993.

10. Nishimura H, Walker OE, Patton CM, Madison AB, Chiu AT, Keiser I. Novel angiotensin receptor subtypes in fowl. Am J Physiol. 267, R1174-R1181, 1994.

11. Le Noble FAC, Schreurs NHJS, Van Straaten HWM, Slajf DW, Smits JFM, Rogg H, Struijker-Boudier HAl. Evidence for a novel angiotensin-ll receptor involved in angiogenesis in chick embryo chorioallantoic membrane. Am J Physiol. 264, R460-R465. 1993.

2. Bergsma D], Ellis C, Nuthulaganti PR, Nambi P, Scaife C, Kumar C, Aiyar N. Isolation and expression of a novel angiotensin-t! receptor form Xenopus leavis heart. Mol Pharmacol. 44, 277-284, 1993.

13. Murphy TI. Nakamura Y, Takeuchi K, Alexander RW. A cloned angiotensin receptor isoform from the turkey adrenal gland is pharmacologically distinct from the mammalian angiotensin receptor. Mol Pharmacol. 44, 1-7, 1993.

14. Ahmed A. Li XF, Shams M, Gregory I, Rollason T, Barnes NM, Newton IR. Localization of the angiotensin-II and its receptor subtype expression in human endometrium and identification of a novel high-affinity angiotensin-ll binding site. I Clin Invest. $96,848-857,1995$.

25. Bradford MM. A Rapid and Sensitive Method for the Quantitation of Microgram Quantities of Protein Utilizing the Principle of Protein-Dye Binding. Ana Biochem. 72, 248-254. 1976.

16. Munson PI, Rodbard D. Ligand: a versatile computerized approach for characterization of ligand-binding systems. Ana Biochem. 107, 220-239, 1980.

17. Burck HC: Histologische technik(ed 5). Stuttgart, Thieme Verlag, 1982.

18. Hudlicka O, Tyler KR: Angiogenesis: the growth of the vascular system(ed 1). London, Academic Press, 1986

19. Zetter Bruce.R. Angiogenesis. CHEST. 93/3 (Suppl. y), 159S-1665, 1988.

20. Montesano.R. Regulation of angiogenesis in vitro. Eur I Clin Invest. 222, 504-515. 1992.

21. Price RJ, Owens GK, Skalak TC. Immunohistochemica! identification of arterialar development using markers of smooth muscle differentiation: evidence that capillary arterialization proceeds from terminal arterioles. Circ Res. 75, 520-527, 1994.

22. Stallone IN, Nishimura H, Nasjletti A. Angiotensin-II binding sites in aortic endothelium of the domestic fowt. Am I Physiol. 258, R777-R782, 1990.

23. Nakamura Y, Nishimura H. Khosla MC. Vasodepressor action of angiotensin in conscious chicken. Am I Physiol. 243, H456$\mathrm{H}_{4} 62.1982$. 
24. Nishimura H, Nakamura Y, Sumner RP, Khosla MC. Vasopressor and depressor actions of angiotensin in conscious chickens. Am I Physiol. 242, $\mathrm{H}_{314} \cdot \mathrm{H}_{32} 4,1982$.

25. Nishimura $H$, Nakamura $Y$, Tayler AA, Madey MA. Renin-angiotensin and adrenergic mechanisms in control of blood pressure in fowl. Hypertension. 3(Suppl. 1), 141-149, 1981.

26. Stallone IN, Nishimura H, Khosla MC. Angiotensin-fl vascular receptors in fowl aorta: binding specifity and modulation by divalent cations and guanine nucleotides. I Pharmacol Exp. Ther. 251, 1076-1082, 1989.

27. Takei Y, Stallone JN, Nishimura H, Campanile CP. Angiotensin receptors in the fowl aorta. General and Comparative Endocrinology. 69, 205-216, 1988.

28. Noden Drew.M. Embryonic Origins and Assembly of Blood Vessels. Am Rev Respir Dis. 140, 1097·1103, 1989.

29. Iruela-Arispe ML, Diglio A, Sage EH. Modulation of Extracellular Matrix Proteins by Endothelial Cells Undergoing Angiogenesis in Vitro. Arteriosclerosis and Thrombosis. 11 (Suppl. 4), 805-815, 1991.

30. Vernon RB, Sage HE. Between molecules and morphology: extracellular matrix and creatibn of vascular form. American Journal of Pathology. 147, 873-883, 1995.

31. Pepper MS, Vassalli JD, Orci L, Montesano R: Proteolytic balance and capillary morphogenesis in vitro, in Steiner R, Weisz: PB, Langer R (eds): Angiogenesis: key principles - Sciene - Techology - Medicine. Basel, Birkhäuser Verlag. 1992, p 494

32. Brilla CG, Zhou G, Matsubara L. Weber KT. Collagen metabolism in cultured aduit rat cardiac fibroblasts: response to angiotensin-Il and aldosterone. Mol Cell Cardiol. 26, 809-820, 1994.

33. Brilla CG, Reams GP, Maisch B, Weber KT. Renin-angiotensin system and myocardial fibrosis in hypertension: regulation of myocardial collagen synthesis. Eur heart ). 14 (Suppl. 1). 57-61, 1993.

34. Weber KT, Sun Y, Katwa LC, Cleutjens IPM. Connective tissue: a metabolic entity. Mol Cell Cardiol. 2.7, 107-120, 1995.

35. Moses MA, Langer R: Metalloproteinase inhibition as a mechanism for the inhibition of angiogenesis, in $S$ teiner $R$, Weisz PB, Langer R (eds): Angiogenesis: Key principles - Science - Technology - Medicine. Basel, Birkhâuuser Verlag, 1992, $p 494$

36. Hunt RA, Ciuffo GM, Saavedra IM. Tucker DC. Quantification and localisation of angiotensin II receptors and angiptensin converting enzyme in the developing heart. Cardiovasc Res. 29, 834-840, 1995.

37. Strick.D.M, Waycaster.R.L, Montani.J, Gay.W.J, Adair.T.H. Morphometric measurements of chorioallantoic membrane vascularity: effects of hypoxia and hyperoxia. Am J Physiol. 260, H1385-H1389, 1991.

38. Ausprunk DH, Knighton DR, Folkman J. Differentiation of vascular endothelium in the chick chorioallantois: a structural and autoradiographic study. Dev Biol. 38, 237-248, 1974. 
Chapter 5

Effects of Angiotensin-II on isolated endothelial cells in culture 


\subsection{Introduction}

Growth of new capillary blood vessels by sprouting of an established vascular bed is defined as angiogenesis ${ }^{1}$. The process of angiogenesis can be characterized by several distinct events: (1) degradation of the basal membrane surrounding the vasculat endothelial cells, (2) movement of endothelial cells towards the angiogenic stimulus, (3) formation of a vascular sprout by both elongation and proliferation of the endothelial cells, (4) tube formation by the growing sprout and (5) finally formation of a new basal membrane $e^{1,2}$. These processes can be influenced by a number of endogenous mediators and drugs. Furthermore, mast cells, lymfocytes, pericytes, and the extracellular matrix composition may modulate the angiogenic response ${ }^{1,3,4}$. Evidence is accumulating that angiotensin-II can stimulate angiogenesis in vivo, in different animal species and in different experimental models ${ }^{\mathrm{5}}{ }^{8}$. However, it is not known through activation of which cell type angiotensin-II is actually causing angiogenesis.

The effect of angiotensin-II on a cell depends on the specific AT receptor activated. In mammals the existence has been shown of two distinct classes of angiotensin receptors, the $\mathrm{AT}_{1}$ and the $\mathrm{AT}_{2}$ receptor. Both the $\mathrm{AT}_{1}$ and the $\mathrm{AT}_{2}$ receptor belong to the family of seven transmembrane receptors ${ }^{10-13}$. Most physiological responses to Ang- 11 , vasoconstriction $^{14}$, catecholamine release and drinking behaviour are associated with activation of the $\mathrm{AT}_{1}$ receptor. The physiological funtion of the $\mathrm{AT}_{2}$ receptor is largely unknown. Binding of Ang-II to the AT, receptor might activate phospholipase D which has been associated with cell growth ${ }^{15-17}$. Since the $\mathrm{AT}_{2}$ receptor is mainly expressed during embryonic development ${ }^{\mathrm{s} .19}$, it is suggested that the $\mathrm{AT}_{2}$ receptor plays a role in proliferation and differentiation of cells. However, Stoll et $\mathrm{al}^{\mathrm{l}^{47}}$ showed that angiotensin-II could inhibit endothelial cell proliferation through activation of the $\mathrm{AT}_{2}$ receptor. It has been shown in the rat heart that Ang-II can induce the expression of the proto-oncogenes c-fos, c-myc and c-jun ${ }^{20}$. Furthermore, Ang-II can induce the expression of the growth factors PDGF and TGF in vascular smooth muscle cells ${ }^{212}$. The process of wound healing involves angiogenesis and has been associated with changes in expression of both $\mathrm{AT}_{1}$ and $\mathrm{AT}_{2}$ receptors $^{23,24}$. It has been postulated that wound healing after myocardial infarction is associated with enhanced expression of angiotensin-converting enzyme within endothelial cells $s^{25}$. Myocardial infarction also increases the DNA synthesis in rat cardiac interstitium endothelial cells ${ }^{26}$. Specific $\mathrm{AT}_{\text {: }}$ receptor blockade partially inhibited this response-: Thus, in mammals, Ang-II may influence vascular growth, by activating either the $\mathrm{AT}_{1}$ or $\mathrm{AT}_{2}$ receptor.

The chick-embryo chorio-allantoic membrane expresses a single class of angiotensin receptors that has a binding-spectrum different from the classical mammalian AT receptors ${ }^{6}$. This AT receptor is held responsible for angiotensin-II induced angiogene sis in the CAM. Recently an AT receptor with a similar binding-spectrum was cloned from the turkey adrenal gland ${ }^{28}$. A recent clinical study suggests that this receptor could also play a role in vascular growth in the human endometrium ${ }^{-4}$. 


\section{Aim of this study}

Almost all substances known to stimulate angiogenesis, influence endothelial cell growth. To answer the question whether Ang-II is a real growth factor for endothelial cells and how expression of AT receptors determines the response to Ang-II, an in vitro approach with endothelial cells in culture was used. Endothelial cells were shown to contain elements of the renin-angiotensin (RAS) system and it is therefore not unlikely that Ang-II, through an autocrine pathway, regulates endothelial growth $^{30.33}$. We wanted to isolate endothelial cells from the chick-embryo and compare their growth response to angiotensin-II and specific receptor antagonists with rat cardiac endothelial cells.

\subsection{Materials and Methods}

\subsubsection{Rat Coronary Endothelial Cells (RCEC)}

The mammalian cells used in this study were rat coronary endothelial cells isolated from normotensive adult Wistar rats using the Langendorff perfusion model. The cells were a generous gift from dr. M. Linssen (dept. of Physiology, University of Limburg, Maastricht The Netherlands) $)^{34-36}$. The cells were obtained from the continuous cell line RCEC-116 with positive staining for the endothelial cell markers, Von Willebrand factor $^{37}$ (factor VIII), Dil-acetylated-LDL ${ }^{3835}$, and RECA-1 ${ }^{40}$. Furthermore, confluent layers of these cells showed a cobblestone appearance, also characteristic of endothelial cells in culture ${ }^{1,1,22}$. These specific endothelial characteristics were kept present for more than 100 passages. The RCEC used in this study underwent 35 passages betore the start of the experiment. During the experiment the endothelial cells were regularly histologically tested for the presence of endothelial cell markers and compared to the histological characteristics of a negative control group consisting of vascular smooth muscle cells (VSMC) isolated from the aorta of an adult Wistar Kyoto rat.

\subsubsection{Isolation and characterization of chick-embryo endothelial cells}

To achieve isolation of endothelial cells from the chick embryo two different approaches were tried: a) enzy matic digestion from isolated vessels and, b) by culturing of vessel segments. For the digestion technique, aorta and a large arteriole $(200 \mu \mathrm{m})$ from the chorio-allantoic membrane were isolated from a day 18 chick-embryo and mounted tightly on a small injection needle (24G, Terumo) using a small suture. The vessels were flushed with PBS buffer several times to remove blood remnants. The other end was then closed lonsely using a suture and the vessel carefully filled with either a collagenase type III $(0.2-0.5 \%$, Worthington), collagenase type I $(0.2 \%$, Sigma) or trypsin/EDTA $(0.025, \cdots / 0.05 \%)$ solution. 
The enzymatic solutions were then allowed to digest the vascular cells for 5-30 min. utes after which the digested cells were collected and transferred into a fibronectir coated petri-dish with 10\% dialyzed fetal calf serum (dFCS, Gibco) diluted in DMEN (Dulbecco's modified eagle's medium, Gibco). For explanting, isolated vascular seg. ments were cut into small rings, or turned inside out with the endothelial cells facing the abluminal side. Then the segments were put onto a matrix of vitrogen gel (95-98\% collagen type I, $2-5 \%$ collagen type III; Collagen cooperation) supplemented with 100 $\mu \mathrm{g} / \mathrm{ml}$ endothelial cell growth supplement diluted in endothelial cell medium (10\%dFCS in DMEM). The cells that showed sprouting from the explant were harvested using $0.25 \%$ collagenase type CLS III, centrifuged, and cultured in a fibronectin coated petri-dish. Using anti-bodies and electron microscopy the nature of the outgrowing cells was established. Our technique enabled the isolation of embryonic endothelial cells and vascular smooth muscle cells. However, the quantity of isolated cells was too small to be used for further culturing. Therefore, the results presented in this chapter represent only data obtained from experiments with rat coronary endothelial cells.

\subsubsection{Growing Endothelial and Vascular Smooth Muscle Cells}

Both endothelial cells (EC) and vascular smooth muscle cells (VSMC) were cultured in Dulbecco's modified Eagle's medium (DMEM, Gibco) supplemented with dialyzed fetal calf serum (dFCS, Gibco), glutamine $10 \mu \mathrm{l} / 10 \mathrm{ml}$ (Gibco), penicillin $100 \mathrm{IU} / \mathrm{ml}$ and streptomycin $100 \mu \mathrm{g} / \mathrm{ml}$. The fetal calf serum had to be dialyzed to remove small vaso. active substances with potential growth effects like angiotensin-II and serotonin.

The culture disks for EC (Petri-dish or 24 wells plate) were coated with fibronectin (Sigma) whereas VSMC were allowed to grow on plastic. The cells were cultured in a Salvis Biocenter 2001 incubator at $37^{\circ} \mathrm{C}, 90 \%$ relative air humidity and $5 \% \mathrm{CO}_{2}$. The number of cells in a suspension was quantified using a hemocytometer. Before the start of the experiment (day -2) the endothelial cells were growth arrested and synchronized in the Go phase of the cell cycle using insulin-transferrin (IT) medium (d. Libby \& O'Brein ${ }^{43}$ ). The serum free IT medium contains $5 \mu \mathrm{g} / \mathrm{ml}$ insulin (bovine pancreas, Sigma), $5 \mu \mathrm{g} / \mathrm{ml}$ transferrin (human, Sigma) diluted in DMEM. Handling of endothelial cells and changing medium was performed in a sterile laminar flow hood.

\subsubsection{Passaging endothelial cells}

The first batch of endothelial cells was grown on petri-dishes coated with fibronectin In order to achieve a sufficiently large number of endothelial cells for the experiment they had to reach confluency in the dish after which they could be passed into nen dishes, a process repeated until the appropriate number of cells was obtained. In short: the growth medium was removed and the cells were washed with Hank: buffered salt solution depleted of both $\mathrm{Ca}^{2+}$ and $\mathrm{Mg}^{2+}$ (HBSS -/-). After washing the cells, they were digested during 5-10 minutes with 0.025\% trypsin (in $0.05 \%$ EDTA ant HBSS - / ) to allow disconnecting of the cells from the monolayer and fibronectin. The proper release of the cells was checked under the microscope. 
The process of digestion was stopped after adding DMEM or HBSS with $\mathrm{Ca}^{2}+$ and $\mathrm{Mg}^{2+}(\mathrm{HBSS}+/+)$. The cell suspension was then transferred into a centrifuge tube and centrifuged at $1240 \mathrm{rpm}$ at $4^{\circ} \mathrm{C}$. The obtained cell pellet was diluted in $1 \mathrm{ml}$ growth medium and transferred into 3-4 new petri-dishes.

\subsubsection{Histology protocol Cell Markers}

To identify cell types specific cell markers were used. Von Willebrand-factor marker for endothelial cells, RECA-1 marker specific for rat endothelial cells ${ }^{40}$, DiI-Ac-LDL specific for living endothelial cells. To stain vascular smooth muscle cells, anti-bodies ayainst alpha-actine (SM1) and smooth muscle-myo heavy chain (SM-MHC) were used.

Tabel 1. Primary and secondary antibodies against endothelium and vascular smooth muscle cells. RECA = rat anti-endothelial cell antibody, SWARPO $=$ swine anti-rabbit immunoglobulin peroxidase, $\mathrm{RAMPO}=$ rabbit anti-mouse immunoglobulin peroxidase, $\mathrm{SM}-\mathrm{MHC}=$ smooth muscle-myosin heavy chain.

$\begin{array}{lll}\begin{array}{l}\text { Antibody } \\ \text { VonWillebrand factor } \\ \text { (endothelium) }\end{array} & \text { Primary } & \text { Secondary } \\ \text { RECA (endothelium) } & \operatorname{VWF}(1 / 200) & \operatorname{SWARPO}(1 / 200) \\ \alpha \text {-actine (VSMC) } & \begin{array}{l}\text { primary-RECA }(1 / 500) \\ \text { alpha-smooth muscle } \\ \text { actin }(1 / 200)\end{array} & \operatorname{RAMPO}(1 / 200) \\ \text { SM-MHC (VSMC) } & \begin{array}{l}\text { SM-myosin-heavy-chain } \\ (1 / 50)\end{array} & \operatorname{RAMPO}(1 / 200) \\ & \end{array}$

Antibodies were diluted in PBS buffer supplemented with $1 \%$ bovine serum albumen (BSA). Control sections were incubated with PBS/BSA alone.

The staining of rat coronary endothelial cells and vascular smooth muscie cells was performed as follows: The cells were seeded in 24 wells plates with appropriate growth medium. The bottom part of the well consisted of a removable circular plastic cover slip. After reaching confluency the growth medium was removed and the cells fixed with cold methanol during 10 seconds. The plastic coverslips were removed and washed with $200 \mu \mathrm{l}$ PBS buffer three times five minutes. The cells were then incubated with the primary antibody during 60 minutes at room temperature. Next, the cells were washed $3 \times 5$ minutes with PBS. 
This was followed by incubation with the secondary antibody during 60 minutes a room temperature. Cells were then incubated with $\mathrm{DAB}$ during 7 minutes, washe with water and stained with haematoxiline during 2 minutes at room temperature dehydrated in ethanol and covered with a glass coverslip.

Staining with Dil-Ac-LDL had to be performed on living endothelial cells since the method is based on the active uptake of LDL through the scavenger pathway. Th endothelial cells were seeded into a 96 wells plate and allowed to attach for 24 hours After 24 hours DiI-Ac-LDL was added with an end concentration in the medium o $10 \mu \mathrm{g} / \mathrm{ml}$. After 6 hours incubation at $37^{\circ} \mathrm{C}$, the medium was removed and the cell were washed thoroughly to remove all non-bound Ac-LDL. The labelled cells wen visualized using fluorescent microscopy with an excitation wavelength of $496 \mathrm{~nm}$ (rho damine). The results were compared with the negative control group, aortic smootl muscle cells.

\subsubsection{Measurement of protein content}

The protein content of the cell cultures was measured with Bio-Rad assay nr. 500-00: based on the Bradford method ${ }^{+4}$. Cells in culture were trypsinized $(0.025 \%)$ during 5 . 10 minutes. HBSS $+/+$ is added to stop digestion and the cell suspension was cent trifuged 10 minutes at $1240 \mathrm{rpm}$ at $4^{\circ} \mathrm{C}$. The cell pellet was incubated with $0.5 \mathrm{~N}$ $\mathrm{NaOH}$ during 15-30 minutes under continuous stirring (vortex) to allow complett lyses of the cells. From this suspension $200 \mu \mathrm{l}$ was diluted with water to get a concentration of $0.1 \mathrm{M} \mathrm{NaOH}$. Subsequently $200 \mu \mathrm{l}$ of assay reagens was added. After $10 \mathrm{~min}$ utes the extinction at $595 \mathrm{~nm}$ was measured and the protein content determined using the gamma-globulin standard curve

Validation Protein Content Measurement number of Endothelial Cells versus Protein content

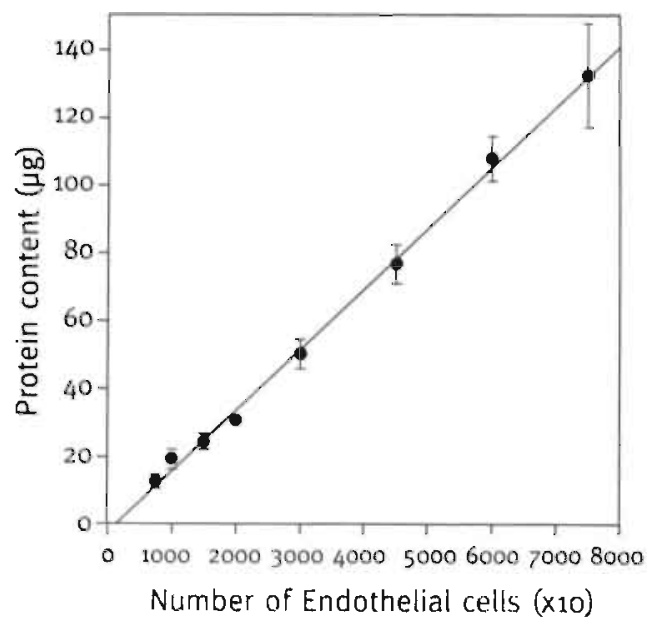

Protein measurements were performed in duplo. To validate the relationship between cell number/volume and protein content, protein measurements were made of different numbers of CEC ranging from 7,500 to 75,000 cells (fig. 1 )

Fix. 1. Relationship between num. ber of endothelial cells and protein content measurements.

Data are expressed as mean \pm SEM. Correlation coefficient $r=0,99, b(0)=-2.17, b=(1) 1.79 \times 10^{-3}$ 


\subsubsection{Ligand-Binding Study for AT receptors}

To establish the presence of AT receptors a ligand-binding study was performed according to previously described methods. In short: the endothelial cells were trypsinized from the culture dishes and lysed with $20 \mathrm{mM} \mathrm{NaHCO}$. The cell suspension was centrifuged at $300.000 \mathrm{~g}$ during 30 minutes to isolate the cell membranes. The pellet consisting of membranes was incubated overnight with $50 \mathrm{mM}$ Tris-buffer $(\mathrm{pH}=7.4)$ at $-20^{\circ} \mathrm{C}$. The protein content of the membranes was determined using the Bio-Rad assay nr. 500-001 with BSA as standard. After determining the protein content the sample was diluted with assay buffer (Tris buffer supplemented with $0.2 \%$ $\mathrm{BSA}$ ) to get a final concentration of $5 \mu \mathrm{g}$ protein $/ 100 \mu \mathrm{l}$ sample. To establish total binding, aliquots of $10 \mathrm{\mu l}$ sample were incubated during 60 minutes at room temperature with increasing concentrations of ${ }^{12} \mathrm{I}$-angiotensin-II (Amersham U.K., specific activity $2200 \mathrm{Ci} / \mathrm{mmol}$ ) ranging from $0.1 \mathrm{nM}$ to $10 \mathrm{nM}$. The non-specific binding was determined in the presence of $250 \mathrm{nM}$ unlabelled Ang-II (total incubation volume 250 $\mathrm{\mu l}$ ). After 1 hour incubation, samples were filtered over Whatman GF/C filters followed by three additional washes with $4 \mathrm{ml}$ of Tris buffer. The radio-activity on the filter was measured using a gamma-counter (LKB) with $75 \%$ efficiency. The ligand-binding curves were analyzed with Ligand, a non-linear weighted least square curve fitting programm calculating $\mathrm{Kd}$, affinity constant, and Bmax, receptor density.

\subsubsection{Drugs}

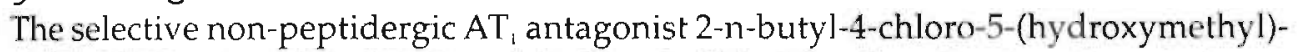
1-\{[2'-C1-H-tetrazol-5-yl)biphenyl-4-yl]methyl\}-imidazole potassium (losartan) was a generous gift from DuPont (Wilmington, USA), the non-peptidergic $\mathrm{AT}_{2}$ antagonist (S)-1-\{[4-(dimethylamino)-3-methylphenyl]methyl]-5-(diphenylacetyl)-4,5,6,7-

tetrahydro-1H-imidazol[4,5-c]pyridine-6-carboxylic acid (PD123319) was a generous gift from Park-Davis (USA). Ang-II was purchased from Peninsula Labs (USA), ${ }^{12} \mathrm{I}-$ Ang-II was purchased from Amersham (UK, specific activity $2200 \mathrm{Ci} / \mathrm{mmol}$ ).

\subsubsection{Statistics}

To compare different treatment groups, Student's t-test was used ${ }^{45}$. Statisics were calculated using SPSS $(X)-P C$ version 6.0. A $p<0.05$ was considered to be statistically significant. 


\subsubsection{Experimental Design}

\section{Time course}

Day

day -2: $\quad 9.00 \mathrm{~h}$, seeding of 15,000 cells per well in a 24 wells plate, volume per well $0.5 \mathrm{ml}$. At $17.00 \mathrm{~h}$ inspection of cell attachment to fibronectin coated well, induction of growth arrest with IT medium.

day -1: changing IT medium.

day 0: $\quad$ start of experiment, trypsinization of control group to determine basal protein content. Incubation of experimental groups with dFCS diluted in DMEM with or without Ang-II (experiment I) and the receptor antagonist DuP753 or PD123319 (experiment II). Each group is incubated three times. The growth medium is changed daily.

day 2: trypsinization of one third of each treatment group and determination of protein content.

day 4: trypsinization of one third of each treatment group and determination of protein content.

day 6: trypsinization of one third of each treatment group and determination of protein content. End of experiment.

Experiment $I$. Number of cells seeded: 15,000 on 24 wells plate. Protein content determined on day $0,2,4$, and 6 . The experiment was repeated 4 times.

Experimental Groups

$\begin{array}{llll}1 \% & \text { dFCS } & 1 \% & \text { dFCS + Ang-II } 10^{\circ} \mathrm{M} \\ 5 \% & \text { dFCS } & 5 \% & \text { dFCS + Ang-II } 10^{\circ} \mathrm{M} \\ 7.5 \% & \text { dFCS } & 7.5 \% & \text { dFCS + Ang-II } 10^{\circ} \mathrm{M} \\ 10 \% & \text { dFCS } & 10 \% & \text { dFCS + Ang-II } 10^{\circ} \mathrm{M} \\ 15 \% & \text { dFCS } & 15 \% & \text { dFCS + Ang-II } 10^{\circ} \mathrm{M} \\ 20 \% & \text { dFCS } & 20 \% & \text { dFCS + Ang-II } 10^{\circ} \mathrm{M}\end{array}$


Experiment 2. Number of cells seeded: 30,000 on a 24 wells plate. Protein content was determined at day 6. The experiment was repeated 2 times. Los=Losartan, $\mathrm{PD}=\mathrm{PD} 123319, \mathrm{dFCS}=$ dialyzed fetal calf serum,

Ang-II=angiotensin-II.

\section{Experimental Groups}

$5 \%$ dFCS +Ang-II $10^{-6} \mathrm{M}+\operatorname{Los} 10^{-6} \mathrm{M}$

$5 \%$ dFCS +Ang-II $10^{-6} \mathrm{M}+$ Los $10^{-7} \mathrm{M}$

$5 \%$ dFCS+Ang-II $10^{-6} \mathrm{M}+\operatorname{Los} 10^{-8} \mathrm{M}$

$5 \%$ dFCS+Ang-II $10^{-6} \mathrm{M}+\operatorname{Los} 10^{-9} \mathrm{M}$

$5 \%$ dFCS+Ang-II $10^{-5} \mathrm{M}+\operatorname{Los} 10^{-10} \mathrm{M}$

$$
\begin{aligned}
& 5 \% \mathrm{dFCS}+\text { Ang-II } 10^{-6} \mathrm{M}+\mathrm{PD} 10 \mathrm{M} \\
& 5 \% \text { dFCS+Ang-U } 10^{-6} \mathrm{M}+\text { PD } 10^{\circ} \mathrm{M} \\
& 5 \% \text { dFCS+Ang-II 10-6 M + PD 10 }{ }^{-8} \mathrm{M} \\
& 5 \% \text { dFCS + Ang-II 10-6 } \mathrm{M}+\text { PD 10.4 } \mathrm{M} \\
& 5 \% \text { dFCS+Ang-II } 10^{-6} \mathrm{M}+\mathrm{PD} 10^{-1 ;} \mathrm{M}
\end{aligned}
$$

\subsection{Results}

\subsubsection{Experiment I: effect of dFCS and Ang-II on CEC protein content of rat coronary endothelial cells}

Endothelial cells were incubated at different levels of dFCS with and without Ang-II (figure 2). The protein content at the start of the experiment, day 0, was $14.60 \mu \mathrm{g}$ (SE = 0.75). In 1\% dFCS, Ang-II differed significantly from control at day $2(\mathrm{p}<0.05)$, however this was due to a reduction of growth in the control group. No effects were found on day 4 and 6 . In 5\% dFCS, Ang-II caused a statistically significant increase in protein content at day $6(\mathrm{p}<0.05)$. At day 2 no statistical difference was observed but at day 4 , incubation with Ang-II had the tendency to increase protein content but just failed to reach statistical significance ( $p=0.052)$. The Ang-II curve however on each day exceeded the control level and showed a positive growth rate in the whole treatment period. In $7.5 \%$ dFCS the Ang-II curve also raised above the control level and was statistically significant different at day 2 and $4(p<0.05)$. Between day 4 and 6 a negative growth rate was observed. The absolute protein content at day 4 of $7.5 \%$ dFCS+Ang-II $(56.80 \mu \mathrm{g})$ was the largest observed in all treatment groups, and could only be approximated by the protein content in 10\% dFCS+Ang-II $(56.5 \mu \mathrm{g})$ at day 6 or $20 \%$ dFCS $(56.5 \mu g)$ at day 6 . The curves of $10 \%$ dFCS with or without Ang-II did not differ at any day within the treatment period. Both curves displayed the characteristics of an ideal cell-growth curve. In 15\% dFCS and in $20 \%$ dFCS no difference could be observed between treatment and control. 


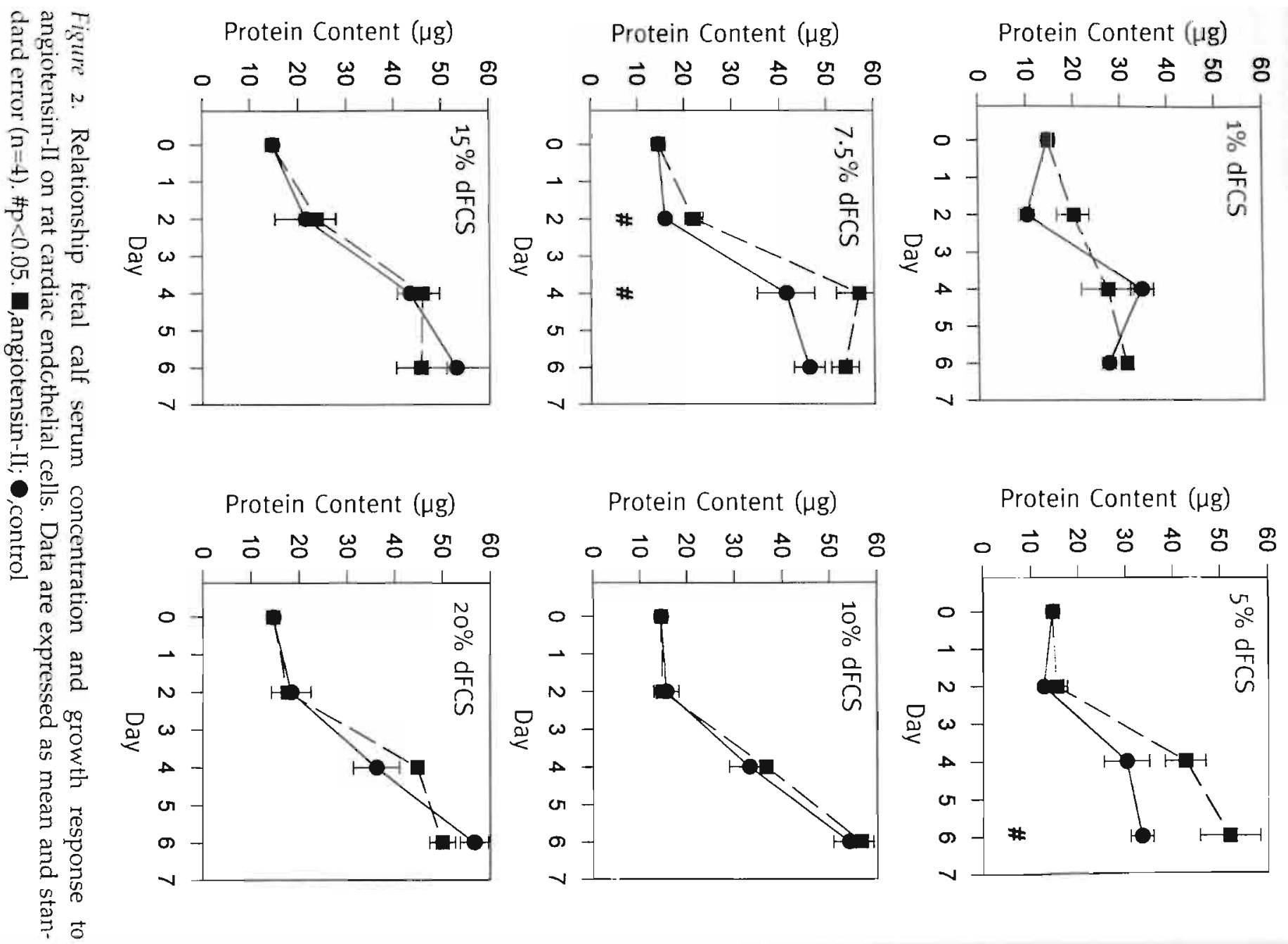




\subsubsection{Experiment II: effect of AT receptor antagonists}

on growth of rat coronary endothelial cells

The effects of the different AT receptor antagonist on Ang-II induced growth at day 6 are displayed in figure $3 a, b$. Because of the limited number of experiments $(n=2)$ no statistical analysis were performed. Angiotensin-II induced a $17.2 \%$ increase in protein content versus $5 \% \mathrm{dFCS}$. Addition of losartan $10^{\circ} \mathrm{M}$ or PD123319 $10^{\circ} \mathrm{M}$ caused a slight increase in protein content of respectively $9.6 \%$ and $7.3 \%$ versus $5 \%$ dFCS.

Incubating Ang-II together with the $\mathrm{AT}_{1}$ antagonist losartan $10^{-6} \mathrm{M}$ (fig. $3 \mathrm{~b}$ ) showed a growth reduction of $10.6 \%$. Incubating Ang-II with the $\mathrm{AT}_{2}$ antagonist PD123319 (fig. $3 \mathrm{~b}$ ) at the concentration of $10^{-6} \mathrm{M}$ resulted in a $1 \%$ reduction of growth.

\subsubsection{Ligand-Binding AT receptor}

Analysis of the ligand-binding spectrum revealed the existence of AT receptors with a density Bmax of $60 \mathrm{fmol} / \mathrm{mg}$ protein and an affinity constant $\mathrm{Kd}$ for angiotensin-II of $0.8 \mathrm{nM}$.

Effect of AT-Il and AT receptor antagonists percentage increase versus $5 \% \mathrm{dFCS}$

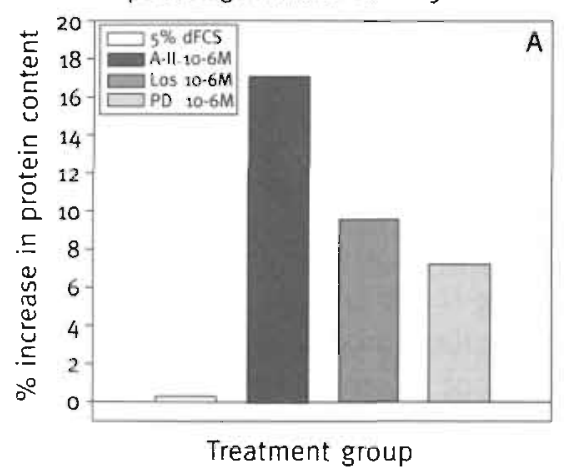

Effect of AT receptor antagonists percentage increase versus $5 \%$ dFCS

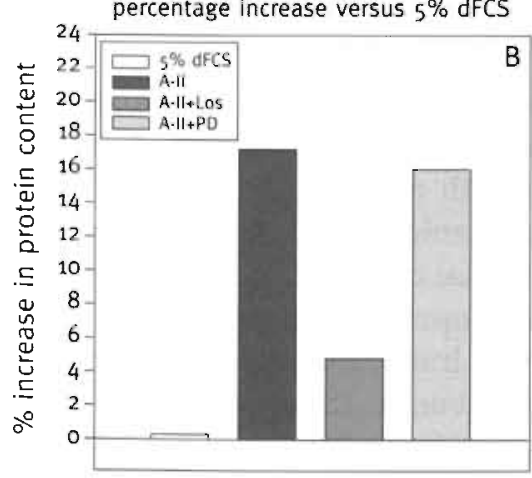

Treatment group
Figure 3a. Effect of angiotensin-II (Ang-II) $10^{-4} \mathrm{M}$, losartan (Los) $10^{-6} \mathrm{M}$, and PD123319 (PD) $10^{-6} \mathrm{M}$ alone on protein synthesis of rat cardiac endothelial cells. Percentage protein increase versus $5 \%$ dFCS at day 6 .

Figure 36 . Effect of losartan (Los) $10^{\circ} \mathrm{M}$ and PD123319 (PD) $10^{\circ} \mathrm{M}$ on angiotensin-II (Ang-II) $10^{\circ} \mathrm{M}$ stimulated protein synthesis of rat cardiac endothelial cells. Percentage protein increase versus $5 \%$ dFCS at day 6 . 


\subsection{Discussion}

\section{Effects of Ang-II on protein synthesis in Rat Coronary Endothelial Cells}

Our results show that Ang-I is capable of stimulating endothelial cell protein synthesis in vitro. The effectiveness of Ang-II inducing protein synthesis depends on the concentration dFCS. The concentrations of dFCS at which Ang-II was able to increase protein synthesis were $5 \%$ and $7.5 \%$.

However, at $10 \%$ dFCS, the standard incubation medium for endothelial cells ${ }^{42}$, Ang-II did not exert an effect on growth. This effect is comparable to the physiological growth factor adenosine which was shown to increase human umbilical endothelial cell proliferation at $4 \%$ but not at $10 \% \mathrm{FCS}^{46}$. However, the magnitude of response at $4 \%$ was far greater compared to angiotensin-II. Therefore, Ang-II can not considered to be a very potent stimulator for endothelial cell growth. Selective AT receptor inhibition can reduce the Ang-II induced growth in 5\% dFCS. Since the $\mathrm{AT}_{1}$ antagonist losartan showed the largest reduction, it might be speculated that Ang-II exerts its effect through the $\mathrm{AT}_{1}$ receptor.

The observed $\mathrm{Kd}$ for Ang-II of $0.8 \mathrm{nM}$ is in agreement with affinities observed in other studies, whereas the $\mathrm{Bmax}$ of $60 \mathrm{fmol} / \mathrm{mg}$ protein is comparable to the density observed in the membrane fraction of cultured rat cardiac endothelial cells in other studies $^{47}$.

\section{Is Angiotensin-Il a growth factor?}

Extensive literature is available showing that Ang-II can induce hypertrophy, hyperplasia, DNA and protein synthesis in arterial vascular smooth muscle cells ${ }^{22.48-55}$. It has been shown that Ang-II can induce the expression of the early oncogenes c-fos, c-myc and c-jun ${ }^{20,50,56}$. Ang-II can also act on growth by activation of the MAP-kinase and tyrosine-kinase signal transduction pathways ${ }^{57.58}$. Others however claim that Ang-II is not a real growth factor for VSMC but only a modulator of the balance between the growth factors bFGF, PDGF and TGF ${ }^{45.56,59,50}$. It has also been shown that Ang-II can stimulate VSMC migration in vitro ${ }^{61}$, an effect which might be important in the arteriolization process.

Interpreting the effects of angiotensin-II on endothelial cell growth is more difficult. Angiotensin-II can induce neovascularization in the rabbit cornea'. Normally the cornea is avascular, and the Ang-II induced growth response implies both capillary sprouting and arterialization towards the angiogenic stimulus. Therefore, in vivo, Ang-II seems to be capable of stimulating endothelial cell migration, proliferation and tube formation. A role for Ang-II in vascular development is supported by the observation that blocking of Ang-II production by ACE inhibition attenuated the vascular development of the rat cremaster muscle ${ }^{7.8}$. However, in these studies, the capillary bed was not examined. 
Therefore, it is difficult to discern whether Ang-II exerts an effect only on the arterialization process, which is shown to proceede from upgrading of capillaries by deposition of vascular smooth muscle cells around capillary tubes ${ }^{62}$, or also influences capillary sprouting or tube formation.

An in vitro study with rat coronary endothelial cells expressing both $\mathrm{AT}_{1}$ and $\mathrm{AT}_{2}$ receptors, showed that Ang-II could induce endothelial proliferation through the $\mathrm{AT}_{2}$ receptor under simultaneous blockade of the $\mathrm{AT}_{\text {. }}$ receptor if incubated in $1 \% \mathrm{FCS}^{4}$. It was hypothesized that the antiproliferative actions of the $\mathrm{AT}_{2}$ receptor, offset the growth promoting effects mediated by the $\mathrm{AT}$, receptor. Our results support the observation that Ang-II can induce endothelial growth however, only in 5 or $7.5 \%$ dFCS. However, our cells underwent more passages and could therefore have lost AT receptor subtypes which might have influenced Ang-II effectiveness. In vitro research showed that blocking Ang-II production with the ACE inhibitor lisinopril or antagonizing AT receptors with saralazine stimulated endothelial cell migration ${ }^{61}$. Angiotensin-II alone had no effect on either migration or proliferation ${ }^{\circ .}$. An explanation for the observed discrepancy in efficacy of Ang-II between the in vivo and in vitro data might be due to the loss of interaction between the endothelium, vascular smooth muscle cells and extracellular matrix components ${ }^{4,6365}$.

It can be concluded that there is evidence that Ang-II may induce endothelial cell growth. The magnitude of this response seems to be dependent on the concentration of supplemented growth serum and the specific AT receptor subtype present. Most likely $\mathrm{AT}_{1}$, receptors mediate the stimulatory response.

\section{Concerning angiogenesis the following might be concluded}

Ang-II is a weak promotor of endothelial cell growth and might influence capillary formation. 


\section{References}

1. Hudlicka O, Tyler KR: Angiogenesis: the growth of the vascular system(ed 1). London, Academic Press, 1986

2. D'Amore PA, Thompson RW. Mechanisms of angiogenesis. AnnRevPhysiol. 49. 453-45.4. 1987.

3. Shepro D, Morel N, Pericyte physiology. FASEB 1. 7, 1031-1038, 1993.

4. Vernon RB, Sage HE. Between molecules and morphology: extracellular matrix and creation of vascular form. American Journal of Pathology, 147, 873-883, 1995.

5. Fernandez LA, Twickler I, Mead A. Neovascularization produced by angiotensin-ll. The journal of Laboratory and Clinica! Medicine. $105,141-145,1985$.

6. Le Noble FAC, Schreurs NHJS, Van Straaten HWM, Slaaf DW, Smits JFM, Rogg, H, Struijker-Boudier HA]. Evidence for a novel angiotensin-ll receptor involved in angiogenesis in chick embryo chorioallantoic membrane. Am J Physiol. 264 . R460-R465. 1993 .

7. Wang DH, Prewitt RL. Captopril reduces aortic and microvascular growth in hypertensive and normotensive rats. Hypertension. 15.68-77, 1990.

8. Wang DH. Prewitt RL. Longitudinal effect of captopril on aortic and arteriolar development in nomotensive rats. Am J Physiol. 260, H1959-H1965, 1991.

9. Timmermans PBMWM, Wong PC, Chiu AT, Herblin WF, Benfield P, Carini DJ, Lee RJ, Wexler RR, Saye JAM, Smith RD. Angiotensin-II receptors and angiotensin-ll receptor antagonists. Pharmacological Reviews. 45, 205-251, 1993.

10. Murphy T), Alexander RW. Griendling KK, Ringer MS, Bernstein KE. Isolation of cDNA encoding the vascular type-1 angiotensin-ll receptor. Nature. $351,233-236,1991$.

1t. Sasaki K, Yamaño Y, Bardhan S, Iwai N, Murray II, Hasegawa M, Matsuda Y, Inagami T. Cloning and expression of a complementary DNA encading a bovine adrenal angiotensin-1I type-1 receptor. Nature. 351, 230-232, 1991.

12. Kambayashi Y, Bardhan S. Takahashi K, Tsuzuki S, Inui H, Hamakubo T, Inagami T. Molecular cloning of a novel angiotensinII receptor iscform involved in phosphotyrosine phosphatase inhibition. I Biolog Chem. 268, 24543-245,46. 1993.

13. Mukoyama M, Nakajima M, Horiuchi M, Sasamura H, Pratt RE, Dzau VI. Expression cloning of type 2 angiotensin-II receptor reveals a unique class of seven-transmembrane receptors. J Biolog Chem. 268, 24539-24542, 1993.

14. Chiu AT, Roscoe WA, McCall DE, Timmermans PB. Angiotensin II-1 receptors mediate both vasoconstrictor and hypertrophic responses in rat aortic smooth muscle cells. Receptor. 1, 133-140, 1991.

15. Lassegue B, Alexander RW, Clark M, Akers M, Griendling KK. Phosphatidylcholine is a major source of phosphatidic acid and diacylglycerol in angiotensin-il stimulated vascular smooth muscle cells. B M J. 292, 509-517. 1993 .

16. Ohanian J, Ollerenshaw J, Collins P, Heagerty A. Agonist induced production of 1,2 diacylglycerol and.phosphatidic acid in intact resistance arteries. Evidence that: accumulation of diacylg!ycerol is not a prerequisite for contraction. J Biolog Cnem. 265. $8921-8928,3990$,

17. Ollerenshaw JD. Lassegue B. Alexander RW: Intracellutar signaling in arteries and vascular smooth muscte cells in culture, in Mulvany M! (ed): Resistance arteries: structure and function. Amsterdam, Elsevier, 1991, P 73

18. Miltan MA, facobowitz DM, Aguitera G, Catt K! Differential distribution of AT1 and AT2 angiotensin-II receptor subtypes in the rat brain fluring development. Proceedings of the National Acadamy of Sciences USA. 88, 11440-11444. 1991.

19. Tsutsumi K, Stromberg C, Viswanathan M, Saavedra JM. Angiotensin-ll receptor subtypes in fetal tissue of the rat: autoradiography. guanine nucleotide sensitivity, and association with phosphoinositide hydrolysis. Endocrinology. 129, 1075.1082, 1991.

20. Lyall F, Daman ES, McQueen J. Boswell F, Kelly M. Angiotensin-II increases proto-oncogene expression and phosphoinositide turnover in vascular smooth muscle cells via the angietensin-11 type I receptor. I Hyper. 10. 1463-1469, 1992.

21. Gibbons GH, Pratt RE, Dzua VJ. Vascular smooth muscle hypertrophy vs. hyperplasia. Autocrine Transforming Growth Factorbeta1 expression determines, growth response to angiotensiri-II. J Clin Invest. 90, 456-461, 1992.

22. Schwartz SM, DeBlois D, O'Brein ERM. The Intima: soil for atherosclerosis and restenosis. Circ Res. $77,445 * 465,1995$.

23. Kimura B, Sumners C. Philips M!. Changes in skin angiotensin-ll receptors in rats during wound healing. Biochem Biophys Res Commun. 187, 1083-1090, 1992.

24. Viswanathan M, Saavedra IM. Expression of angiotensin AT-2 receptors in the rat skin during experimental wound healing. Peptides. 13. 783·786, 1992. 
25. Passier RCIJ, Smits JFM, Verluyten MJA, Studer R, Drexler H, Daemen MJAP. Activation of angiotensin-convertin enzyme expression in infarct zone following myocardial infarction. Am J Physiol. 269, H1268-H1276, 1995.

26. Kuizinga MC, Cleutjens JPM, Smits JFM, Daemen MJAP. Griffonia simplificolia I (GSI): a suitable rat cardiac miciovascular marker on paraffin embedded tissue (Abstract). Mol Cell Cardiol. 24 (Suppl. V). S57, 1992.

27. Smits JFM, Passier RCJJ, Nelissen-Vrancken MG. Cleutjens JPM, Kuizinga MC, Daemen MJAP. Do ACE-inhibitors limit the struCtural changes in the heart followin myocardial infarction? Eur heart J. in press, 1996.

28. Murphy T). Nakamura Y, Takeuchi K, Alexander RW. A cloned angiotensin feceptor isoform from the turkey adrenal gland is pharmacologically distinct from the mammalian angiotensin receptor. Mol Pharmacol. 44, $17,1993$.

29. Ahmed A, Li XF, Shams M, Gregony, Rollason T, Barnes NM, Newton JR. Localization of the angiotensin-Il and its receptor subtype expression in human endometrium and identification of a novel high-affinity angiotensin-1! birding site. I Clin Invest. $96,848 \cdot 857,1995$.

30. Kifor I, Dzau V. Endothelial renin-angiotensin pathway: evidence for intracellular synthesic ind secretion of angioteinins. Circ Res. $60,422 \cdot 428,1987$.

31. Tang SS, Stevenson L, Dzau VJ. Endothelial renin-angiotensin pathway. Circ Res. 66, 103-108, 5900.

32. Dzau J. Multiple pathways of angiotensin production in the blood vessel wall: evidence, possibilities and hypotheses. I Hyper. 7, 933-936, 1989.

33. Lincoln J, Loesch A, Burnstock G. Localization of vasopressin, serotonin and angiotensin-ll in endothelial cells of the renal and mesenteric arteries of the rat. Cell Tissue Res. 259, 341.344, 1990.

34. Linssen MCJG, Vork MM, De Jong YF, Glatz JFC, Van der Vusse G]. Fatty acid oxidation capacity and fatty acid-binding protein content of different cell types isolated from rat heart. Molecular and Cellular Biochemistry. 98, 19-25, 1990.

35. Linssen MCJG, Engels W. Lemmens PJMR, Heijnen WV, Van Bilsen M, Reneman RS, Van der Vusse Gl. Production of arachidonic acid metabolites in adult rat cardiac myocytes, endothelial cells and fibroblast-like cells. Am f Physiol. 264, H973-H982, 1993.

36. Linssen MCJG, Van Nieuwenhoven FA, Duijvestijn AM. Glatz JFC, Van der Vusse GJ. Continuous endothelial cell lines from adult heart. In vitro cellular and developmental biology. 29A, 611-613, 1993.

37. Lyons SE, Ginsburg D. Molecular and cellular biology of Von Willebrand factor. TCM. 4. 34-39, 1994 .

38. Stein 0, Stein Y. Bovine aortic endothelial cells display macrophage-like properties towards acetylated 125-1-labelled low density lipoprotein. Biochimica Biophysica Acta. 620, 631-635. 1980.

39. Voyta IC, Via DP, Butterfield CE, Zetter BR. Identification and isolation of endothelial cells basect on their increased uptake of acetylated los density lipoprotein. I Cell Biol. 99, 2034-2040, 1984.

40. Duijvestijn AM, Bussel van E, Breda Vriesman van PJC. Antibodies defining rat endotheliai cells: RECA-1 and pan-endothelial cell specific monoclonal antibody. Lab Inv. 66, 459-466, 1992.

41. Nishida M, Carley WW, Gerritsen ME, Ellingsen O, Kelly RA, Smith TW. Isolation and characterzation of humar and rat cardiac microvascular endothelial cells. Am J Physiol. 264. H639-H652, 1993.

42. Piper HM, Spahr R, Mertens S, Krützfeldt A, Watanabe H: Microvascular endothelial tetls from the heaft, in Piner HM (ed): Cell culture techniques in heart and vessel research. Berlin, Springer Verlag, 1990, p 158.

43. Libby $P, O^{\prime} B r e i n ~ K V$. Culture of quiescent arterial smooth muscie cells in a defined serum free medium. I Cell Physiol. 115. $217-223,1983$

44. Bradford MM. A Rapid and Sensitive Method for the Quantitation of Microgram Quantities of Protein Utilizing the Principle of Protein-Dye Binding. Ana Biochem. 72, 248-254, 1976.

45. Johnsoin R: Elementary Statistics(ed 4). Boston, PWS publishers, 1984.

46. Ethier MF, Chander V, Dobson JG. Adenosine stimulates proliferation of human endothelial cells in culture. An J Physiol. 265. $\mathrm{H}_{131}-\mathrm{H}_{138}, 1993$.

47. Stoll M, Steckelings M, Paul M, Bottari SP. Metzger R, Unger T. The angiotensiñ AT2-receptor mediates inhibition of cell proliferation in coronary endothelial cells. J Clin Invest. 95, 651-657. 1995.

48. Weber $\mathrm{H}$. Taylor DS, Molloy Cl. Angiotensin II induces delayed mitogenesis and cellular proliferation in rat acrtic smooth muscle cells: correlation with the expression of specific endogenous growth factors and reversa! by suramin. I Clin Invest. 93 . $788-798,1994$. 
49. Katz. Angiotensin-ll: hemodynamic regulator or growth factor? Mol Cell Cardiol. 22, 739-747, 1990.

50. Schelling P. Fischer H, Ganten D. Angiotensin and cell growth: a link to cardiovascular hypertrophy? I Hyper. 9, 3-15, 1991. 51. Berk BC, Vekhstein V, Gordon. HM, Tsuda T. Angiotensin-II stimulated protein synthesis in cultured wascular sinooth muscle cells. Hyperterision, 13, 305-314, 1989.

52. Berk BC, Rao. GN. Angiotensin-II induced vascular smooth muscle cell hypertrophy: PDGF-A chain mediates the increase in. cell size. J Cell Physiol. 154, 746-754, 1993.

53. Holycross B], Peach MI. Owens GK. Angiotensin-II stimulates increased protein synthesis, not increased DNA synthesis, in intact rat aortic segments in vitro. JVascRes. 30, 80-86, 1993.

54. Owens GK. Control of hypertrophic versus hyperplastic growth of vascular smooth muscle cells. Am I Physiol. 257. H1755$\mathrm{H}_{17} 65,2989$.

55. Dzau VI, Giḅ̨̧onș GH. Vasçular remodeling: mechanisms and implications. / Cardiovasc Pharmacol. 21 (Suppl. 1), S1-S5, 1993.

5.6. Itoh H, Mukoyama M, Pratt RE, Gibbons GH, Dzau V]. Multiple autocrine growth factors modulate vascular smooth muscle growth response to angiotensin-[l. ! Clin Invest. 91. 2268-2274, 19913.

57. Rogers TB, Lokuta AJ. Angiotensin II signal transduction pathways in the cardiovascular system. TCM. 4, 110-116, 1994 .

58. Seyer r, Richoux J, Aumelas A. Probing Angiotensin Receptors. Minireview. Int J Biochem. 24 (Suppl. 3), 369-377, 1992.

59. Koibuchi Y, Lee WS, Gibbons GH, Pratt RE. Role of the transforming growth factor-betas in the cellular repons to angiotensin-II. Hypertension. 21, 1046-1050, 2993.

60. Dzau V]. Ceili biology and genetics of angiotensin in cardiovascular disease. I Hyper. 12 (Suppl. 4), 53-510, 1994.

61. Bell L, Madri JA. Influence of the angiotensin system on endothelial and smoroth muscle cell migration. American loumal of Pathology. 137: $7-12,1990$.

62. Price RI, Owens GK, Skalak TC. Immunohistochemical identification of arteriolar development using markers of smooth muscle differentiation: evidence that capillary arterialization proceeds from terminal arterioles. Circ Res. 75. 520.527. 1994.

63. Ingber DE, Madri IA, Folkman J. Endothelial growth factors and extracellular matrix regulate DNA synthesis through modulation of cell and nuclear expansion. In vitro cellular and developmental biology. 23. 387-394. 1987.

64. Fillinger MF, O'Connor SE, Wagner RJ, Cronenwett IL. The effect of endothelial cell coculture on smooth muscie cell proliferation. IVastSurg. 17, 1058-1068, r993.

65. De Mey JGR, Schiffers PM. Effects of the endothelium on growth responses in arteries. I Cardiovasc Pharmacol. 22 (Suppl. 1), S22.S25, 1993. 
Chapter 6

Angiogenic properties

of WKY and SHR rat serum 


\subsection{Introduction}

A common feature observed in the microcirculation of essential hypertensives is arteriolar and capillary rarefaction, i.e,, a decreased number of vessels available to carry flow'. Computer simulation studies have shown a significant contribution of these architectural changes to the increased peripheral resistance ${ }^{2}$. Furthermore, in a genetic model of hypertension, the spontaneously hypertensive rat (SHR), microvascular rarefaction was found already in early developmental stages ${ }^{3.4}$.

In the spontaneously hypertensive rat blood pressure starts to rise above that of Wistar Kyoto (WKY) controls around week 5-6 after birth. During the established phase of hypertension, the increased arterial pressure is attended by a relative rise in peripheral resistance; during the period of 6-12 weeks of age the peripheral resistance decreases in WKY and slightly increases in SHR. It was proposed that the peripheral resistance decrease in WKY is due to proper outgrowth of the vascular system, making more parallel coupled vessels available to carry flow. This outgrowth would be hampered in SHR'.

Previous research suggests a close relationship between somatic growth and blood pressure ${ }^{6.7}$. Plasma growth hormone levels and pituitary growth hormone content are decreased in young ( 4 weeks old) but not old ( 9 weeks old) SHR compared to WKY ${ }^{8}$. This abnormality in growth homone production precedes the development of hypertension in SHR. Since the SHR fetus has been shown to be significantly underweight compared to WKY control, is has also been postulated that intra-uterine growth control contributes to the genesis of hypertension at a later stage?

Epidemiological studies in humans have shown that a low birth weight and, increased placenta size are well correlated with the development of hypertension at later age $e^{10.1}$. It was therefore postulated that attenuated growth during fetal development, especially of the vasculature, might underly the development of hypertension ${ }^{12}$.

The cause of the attenuated vascular growth in hypertension is poorly understood. Factors contributing to the formation of the vasculature include local mechanical factors such as shear stress and circumferential wall stress, and paracrine and autocrine growth and anti-growth factors ${ }^{12-15}$. Since rarefaction seems to be a general response in several vascular beds, circulating blood-borne factors may also contribute to the hampered outgrowth of the vasculature in SHR. There is indeed evidence for the existence of humoral factors in essential hypertensive humans and SHR rats that induce hypertension when transferred to normotensive controls ${ }^{10-19}$. 
The aim of this study was to evaluate whether blood-borne factors can contribute to vascular growth in the microcirculation. Because the drastic changes in vascular resistance and blood pressure in SHR take place in the period around week 6 to week $12^{20}$, we investigated angiogenic properties of SHR and WKY serum of 6 and 12 weeks old rats. To test for angiogenic properties the chick-embryo chorio-allantoic membrane was used. This is a standard bio-assay to quantify vascular growth capacity in vivo ${ }^{21}$.

\subsection{Materials and Methods}

\subsubsection{Angiogenesis Assay}

The model of the chick-embryo chorio-allantoic membrane (CAM) was used to test for angiogenic properties of the plasma. Fertile Lohman selected white leghorn eggs were incubated for three days at $37^{\circ} \mathrm{C}$ and a relative air humidity of $55 \%$. The eggs were rotated once every hour to prevent sticking of the embryo to the eggshell. At day 3 , a rectangular window $(1 \times 1.5 \mathrm{~cm})$ was made in the eggshell using a little iron saw. Two $\mathrm{ml}$ of albumen were withdrawn and the window was sealed with Scotch tape to prevent dehydration. The embryos were then put into an incubator at $37^{\circ} \mathrm{C}$ and $55 \%$ humidity without rotation. At day 7 a silastic ring (dimensions: diameter $1.0 \mathrm{~cm}$, weight of $17 \mathrm{mg}$ ) was placed on the chorio-allantoic membrane. Serum was administered once every day in aliquots of $65 \mu \mathrm{l}$ within the ring until day 14 . Since the serum contains albumen it is very prone to bacterial growth. Therefore the plasma was stored at $4^{\circ} \mathrm{C}$ overnight and filtered through a $0.22 \mu \mathrm{m}$ Millipore filter, every day. At day 14 , color slides of the treated area were taken through a microscope. Subsequently, the membrane was fixed with $4 \%$ buffered formaldehyde and mounted on an object glass. All eggs were assigned at random to one of the treatment groups: serum derived from normotensive Wistar Kyoto (WKY) rats ( 6 and 12 weeks), spontaneously hypertensive rats (SHR, 6 and 12 weeks) or pasteurized human plasma (GPO). To prevent infections, administrations took place in a laminar flow hood.

\subsubsection{Vascular Density Measurements}

The treated area was photographed through a Wild M8 stereomicroscope equipped with a Nikon F501 camera, on Kodak 64 ASA color-slide film.

The slides were projected onto a white screen obtaining a $30 \mathrm{x}$ final magnification. To determine vascular density, stereological principles were applied according, to previously described methods ${ }^{22}$. A rectangular grid with a grid constant of $\mathrm{d}=19 \mathrm{um}$ with respect to the microcirculation was placed over the projected image and the number of intersections with the grid was counted. The number of counts per unit length is rela-ted to the vascular density according to:

Density $=(\pi \times N) / 2 \times L$ in which $N=$ number of intersections with the grid and $L$ the total length of the grid with respect to the microcirculation. Counted were both arterioles and venules with a resolving power of $15 \mu \mathrm{m}$. Preparations were analyzed without knowledge of the experimental group. 


\subsubsection{Serum isolation}

Wistar Kyoto rats (WKY) and spontaneously hypertensive rats (SHR) were obtained from the local laboratory animal facilities at the University of Maastricht. Experiments were performed according to the standard guidelines regarding the use of laboratory animals and approved by the University ethical committee. Six male SHR and WKY rats of 6 weeks of age and 2 male SHR and WKY rats of 12 weeks of age were used to isolate serum. For this purpose the rats were put under ether anaesthesia. The abdominal aorta was dissected free while the rat heart was kept beating. Then a $21 \mathrm{G}$ needle for the 6 week old or 20G needle for the 12 week old rats was inserted quickly into the aorta. The blood was drawn into a syringe and left coagulating overnight at $4^{\circ} \mathrm{C}$. After 24 hours the serum was carefully withdrawn. To inactivate the immune complementary system, the serum was heat-inactivated at $56^{\circ} \mathrm{C}$ during 30 minutes in a water bath. Normal sterile pasteurized human plasma (GPO, Central Laboratory for Blood products, Amsterdam) was used as control. In a separate set of experiments with animals derived from the same colony during the same period, blood pressures were measured.

\subsubsection{Arterial blood pressure measurements}

To assess arterial blood pressure, animals were equipped with a catheter constructed from PE-10 tubing, heat sealed to a piece of PE-50 tubing. The terminal end of the PE50 tubing was heat-sealed to $1 \mathrm{~cm}$ of PE-100 tubing. A rinyl tubing was slid over the PE-100 tubing and fixed with a 2-0 suture.

The abdominal aorta was always cannulated at the side of the left femoral artery. The rat was put under ether anesthesia and a small incision was made in the groin. The connective tissue was dissected free. Connective tissue around the artery was carefully removed. Next, the artery was clamped with a 4-0 silk suture and a small incision was made in the artery. The PE-10 tip of the catheter was inserted into the femoral artery and advanced about $1 \mathrm{~cm}$ above the iliac artery bifurcation but below the bifurcation of the renal artery. The position of the catheter was secured to the artery (2 sutures 4-0 silk) and to the underlying hindlimb muscle (1 suture 3-0 silk) and guided subcutaneously to the neck where it was exteriorized and anchored to the neck muscle with a $2-0$ silk suture. The catheter was filled with saline $(0.9 \% \mathrm{NaCl})$ and closed with a metal plug.

Animals were allowed to recover for one day before pressure were recorded. To measure arterial pressure the catheter was connected to a low-volume displacement pressure transducer (CP-01, Century Technology Compagny, Inglewood, CA, USA). The transducer was calibrated at 0 and $200 \mathrm{mmHg}$ using a mercury manometer. The signal was recorded on a Grass 7D polygraph (Grass instruments, Quincy, Mass, USA). Low-pass filtering $(0.5 \mathrm{~Hz})$ of the signal resulted in mean arterial pressure. 


\subsubsection{Experimental Groups}

The treatment groups were as follows:

Serum of 6 weeks old WKY (number of treated eggs $n=17$ ), serum of 6 weeks old SHR $(n=17)$, serum of 12 weeks old WKY $(n=7)$, serum of 12 weeks old SHR $(n=9)$, GPO control $(n=6)$. Blood pressure measurements were performed on 6 WKY and 6 SHR rats at 6 and 12 weeks of age, respectively.

\subsubsection{Statistical Analysis}

To compare vascular densities after SHR, WKY and GPO treatment, the non-parametric Mann-Whitney U-test was used. For comparison of blood pressure data, Student's t-test was used. Statistical calculations were performed using SPSS-X version 6.0 for a PC. A $p<0.05$ was accepted as statistically significant. Data represent mean and standard error.

\subsection{Results}

6.3.1 Pressure measurements

Mean arterial blood pressure data are presented in table 1.

Note the difference between SHR and WKY at 12 weeks of age.

Table 1. Mean arterial blood pressure (in $\mathrm{mmHg}$ ) at 6 and 12 weeks.

Data represent mean and standard error.

$\begin{array}{lll}\text { Age: } & \text { 6 weeks } & \text { 12 weeks } \\ \text { WKY }(n=6) & 115.3 \pm 3.2 & 118.7 \pm 4.1 \\ \text { SHR }(n=6) & 116.5 \pm 3.5 & 145.2 \pm 3.8 \text { * } \\ \text { *, } p<0.05 \text { (versus WKY control). }\end{array}$




\subsubsection{Angiogenesis assay}

The effects of application of SHR and WKY rat serum on vascular growth in the CAM are presented in figure 1. Both SHR and WKY derived serum from 6 weeks old rats caused a significant increase in vascular density ( $p<0.05$ and $p<0.001$ resp.) versus GPO control. However, the vascular density in the SHR group was significantly lower compared to the WKY group $(\mathrm{p}<0.05)$. The vascular densities after treatment with serum from 12 weeks old SHR or WKY rats were comparable and did not differ significantly from GPO control. Significant differences could be observed between the 6 and 12 weeks treatment groups. Both the vascular density of 6 weeks SHR $(p<0.05)$ and 6 weeks WKY (p<0.001) were significantly higher than their respective 12 weeks controls.

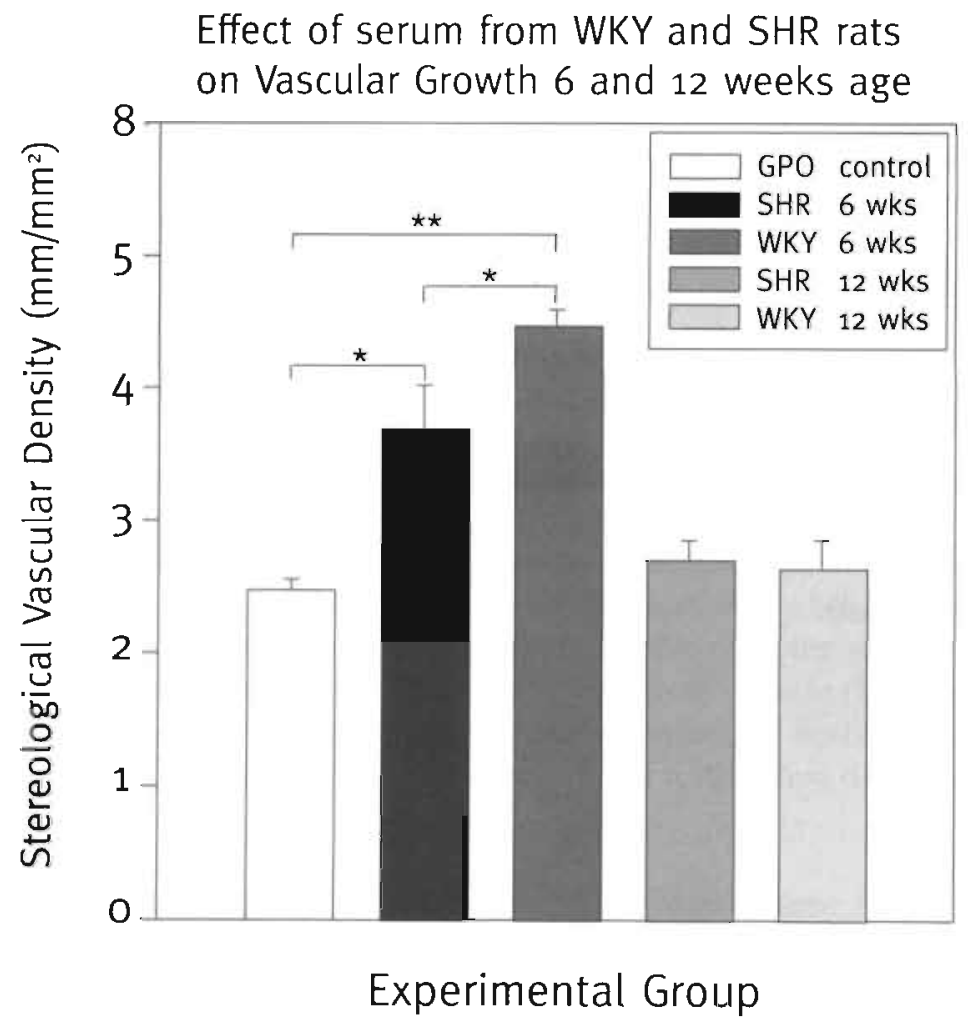

Figure 1. Angiogenic properties of WKY and SHR rat serum on the chick-embryo chorio-allantoic membrane. Data are expressed as mean and standard error. ${ }^{*} \mathrm{p}<0.05,{ }^{* *} \mathrm{p}<0.001$. 


\subsection{Discussion}

The CAM proved to be a good angiogenic assay for serum of WKY and SHR rats. This is in agreement with earlier studies demonstrating that the CAM has a good predictive value for angiogenic effects of various growth factors in mammals ${ }^{23}$.

The vascular growth stimulating potential of serum of 6 weeks old rats is larger compared to serum from 12 weeks old rats for both WKY and SHR. At 6 weeks of age, however, the growth stimulating potential of WKY rats is larger compared to of SHR rats, a difference that disappears at 12 weeks. This suggests that in SHR there is a transient period in which the vascular growth stimulating capacity is smaller than in WKY. At 6 weeks of age, rats are still in their somatic growth period. Therefore, although blood pressures are not yet different between WKY and SHR, the presence of a growth factor in serum of 6 weeks old rats is not surprising. After 12 weeks, rats can be considered adult, and indeed there is no difference between the growth stimulating potential of serum from WKY and SHR. It might therefore be postulated that during the somatic growth period, the serum of both WKY and SHR contains a factor that can stimulate vascular growth. However, the growth stimulating capacity of the SHR serum is smaller during this period compared to WKY. Since this period parallels the blood-pressure and peripheral resistance dissipation of SHR and WKY it might be possible that there is a functional relation between angiogenic capacity of the serum and resistance. This raises the question whether vascular growth and resistance are coupled.

For the CAM, a vascular bed with a minimum of neuro-endocrine control, it has been show that resistance decreases concomittant with outgrowth of the vascular system (chapter 7, this thesis). Furthermore, a computer simulation study simulating hampered outgrowth of a microvascular network showed an increase in resistance ${ }^{24}$. To achieve a decrease in resistance only based on outgrowth of the vasculature, without affecting arteriolar lumen diameters, however, new vessel segments have to be coupled parallel to the existing vasculature, hence segmental growth (chapter 7). Therefore, vascular growth may contribute to a decrease in peripheral resistance. Although the information about the contribution of factors other than architectural organization such as neuro-endocrine control, in peripheral resistance control during ageing is lacking, these results indicate that the decrease in peripheral resistance as observed in WKY rats may be caused by proper outgrowth of the vascular systern due to a circulating angiogenic factor.

It can be argued that in SHR production of vascular growth factors takes place at a later stage. It could therefore be useful to screen the growth capacity of serum of $8-10$ weeks old rats. However, it is a well known principle in developmental biology that certain growth stimuli have to be generated within a small time-frame ${ }^{25.20}$. Outside this period, cells are not sensitive to the stimulus and will not show a growth response. 
The observation that serum of 12 weeks old rats lacks angiogenic potential supports the idea that there is no need for a continuous presence of growth factors. Since the blood pressure changes between SHR and WKY become most clear after week 6 postnatally, this is considered to be the critical time-frame for vascular growth. Therefore, the results obtained in the CAM angiogenesis assay are likely to reflect the vascular growth potential in vivo in the rat.

\section{Nature of angiogenic substance}

The serum contains a cocktail of possible growth factors like interleukins, angiotensinII, serotonin and lack of any of these factors may influence the angiogenic proper$\operatorname{ties}^{27.25}$. On the other hand, the final growth stimulating potential of the serum is determined by the balance of growth and anti-growth factors. Immunological differences exist between SHR and WKY and they could be the source of different anti-angiogenic stimuli ${ }^{2930}$. Circulating levels of antibodies and leukocytes are increased in SHR and macrophages and leukocytes show an increased tendency to infiltrate the vascular wall. It also possible that the naturally occuring cell-death in the vascular wall, apoptosis, is elevated by serum derived factors ${ }^{31}$. Thus, both factors influencing growth rate or turn-over of components of the vascular wall can be considered candidate.

The nature of the angiogenic substance will be subject for further investigations. What is known, is that the substance is heat-stable at $56^{\circ}$ celsius. In this respect it is interesting to notice that the plasma of the SHR rats contains a transferrable hypertension inducing factor that is heat-stable. This factor has recently been identified as a member of the family of di-adenosine-polyphosphates ${ }^{32}$. The role of these substances in angiogenesis is still unknown.

\subsection{Conclusion}

This study supports the hypothesis that hampered outgrowth of the vascular system due to a reduction in the capacity to induce vascular growth, underlies the relative increase in peripheral resistance in the spontaneously hypertensive rat and therefore contributes to the genesis of this form of hypertension. 


\section{References}

1. Struijker Boudier HAJ. Le Noble JLML, Messing MW], Hijberts MSP, Le Noble FAC, Van Essen H. The microcirculation and hypertension. ) Hyper. 10 (Suppl. 7). S147-5157, 1992.

2. Greene AS, Tonellato PI, Lui J, Lombard JH, Cowley AWJ. Microvascular rarefaction and tissue vascular resistance in hypertension. Am / Physiol. 256.(Heart Circ. Physiol. 25), H126.H131, 1989.

3. Le Noble JLMI, Tangelder GJ, Slaaf DW, Van Essen H, Reneman RS, Struyker-Boudier. A functional morphometric study of the cremaster muscle microcirculation in young spontaneously hypertensive rats. I Hyper. 8, 741-748, 1990.

4. Hutchins PM, Damell AE. Observation of a decreased number of small arterioles in spontaneously hypertensive rats. Circ Res. 34/35 (Suppl. 1), 161-165, 1974.

5. Evenwel RT, Kasbergen CM, Struyker Boudier HAJ. Central and regional hemodynamics and plasma volume distribution during the development of spontaneous hypertension in rats. Clin and Exper Hypertension. A5, 1511-1536, 1983..

6. Schork NJ, Jokelainen P, Grant EJ, Schork MA, Weder AB. Relationship of growth and blood pressure in inbred rats. Am J Physiol. 266, R702-R708, 1994.

7. Lever AF, Harrap SB. Essential hypertension: a disorder of growth with origins in childhood? I Hyper. 10, 101-120, 1992.

8. Aguilar E, Rodriguez L. Bellido C, de la Fuente M. Pinilta, L. Changes in growth hormone secretion in spontaneously hypertensive rats. Neuroendocrin. 52, 337-341, 1990.

9. Erkadius IDI, Lucente F, Bramich C, Morgan T, Nicolantonio RD. Role of uterine factors in the development of hypertenion in SHR. Clin Exp Pharmacol Physiol. 21, 239-242, 1994.

10. Barker DIP, Bull AR, Osmond C, Simmonds SJ. Fetal and placental size and risk of hypertension in adult life. BM]. 301, 259262, 1990.

11. Law CM, Barker DJP, Bull AR, Osmond C. Maternal and fetal influences on blood pressure. Arch Dis Childhood. 66, 1291-1295, 1991.

12. Struijker Boudier HAJ: Vascular growth and hypertension, in 5 wales 10 (ed): Textbook of Hypertension(ed 1). London, Blackwell Scientific Publications, 1994, p 200.

13. Adair TH, Gay WI. Montani I. Growth regulation of the vasculai system: evidence for a metabolic hypothesis. Am I Physiol. 259.(Regulatory Integrative Comp. Physiol. 28), 393-404. 1990.

14. Prewitt RL, Wang DH, Nakamura T, Smith EG: Growth and modification in number of resistance vessels, in Bevan $1 A$ (ed): The resistance vasculature., Humana Press, 1991, p 127

15. Hudlicka O, Tyler KR: Angiogenesis: the growth of the vascular system (ed 1). London, Academic Press, 1986

16. Bachman J, SchlÄter H, Storkebaum W, Witzel H. Wessels F, Zidek W. Effect of plasma from patients with essential hypertension on vascular resistance in the isolated perfused rat kidney. Clin Sci. 80, 17-23, 1991.

17. Zidek W. Heckmann U, Vetter $\mathrm{H}$. A circulating hypertensive factor in spontaneously hypertensive tats and its effects on intracellular free calcium. Regulatory Peptides, 152-155, 1985.

18. Bachmann I. SchlẢter H, Storkebaum W. Witzel H, Zidek W. Effect of plasma from essential hypenensives on vascutar tone of aortic strips, isolated perfused mesentery and isolated perfused kidney. Life Sci. 47, 1365-1374, 19 \% .

19. Zidek W. Heckmann $U$, Losse $H_{2}$ Vetter $H$. Effects on blood pressure of cross circulation between spontaneously hypentensive and normotensive rats. Clin Exper. Theory and Practice. A8(3), 347-35.4, 1986.

20. Janssen BJA, Debet5 IIM, Struyker Boudier HAJ. Smits JFM. Role of sensory renal nerves in the development of spontaneous hypertension in rats. Clin Exper. Theory and Practice. Ag (Suppl. 1), 227-239, 1987.

21. Nguyen M, Shing $Y$, Folkman !. Quantitation of angiogenesis and anti-angiogenesis is the chick chorio-allantoic membrane. Microvasc Res. $47,31-40,1994$.

22. Schmid-Schoenbein GW, Zweifach BW, Kovalcheck S. The application of stereological principles to morphometry of the microcirculation in different tissues. Microvasc Res. 14, 303-317, 1977.

23. Folkman 1, Klagsbrun M. Angiogenic factors. Science. $235,442-447,1987$.

24. Hudetz AG. Percolation phenomenon: The effect of capillary network rarefaction. Microvase Res. 45, 1-10, 1993.

25. Van Straaten HWM, Hekking IWM. Wiertz-Hoessels EjLM, Thors F, Drukker J. Effect of the notochord on the differentiation of a floor plate area in the neural lube of the chick embryo. Development. 177, 317-324, 1988. 
26. Van Straaten HWM, Hekking IWM. Development of floor plate, neurons and axonal outgrowth pattern in the early spinal cord of the notochord-deficient chick embryo. Anat Embryol. 184, 55-63, 1991.

27. Fernandez LA, Twickler I. Mead A. Neovascularization produced by angiotensin-1I. The journal of Laboratory and Clinical Medicine. 105, 141-145, 1985 .

28. Hudlicka O, Brown M, Egginton S. Angiogenesis in skeletal and cardiac muscle. Physiological reviews. 72, 369-417, 1992.

29. Khraibi AA. Immunoregulatory failure in the pathophysiology of hypertension. NIPS. 9. 27-30, 1994.

30. Shen K, Delano FA, Zweifach BW, Schmid-Schoenbein GW. Circulating leukocyte counts, activation, and degranulation in Dahl hypertensive rats. Circ Res. 76, 276-283, 1995.

31. Cho AC, Courtman DW, Langille BL. Apoptosis (programmed cell death) in arteries of the neonatal lamb. Circ Res. 76 , 168175, 1995 .

32. Schluter H, Offers E, Brüggemann G, Van der Giet $M$, Tepel M, Nordhoff E, Karas M, Spieker C, Witzel H, Zidek W. Diadenosine phosphates and the physiological control of blood pressure. Nature. $367,186-188,1994$. 


\section{Chapter 7}

Vascular growth in the chick embryo chorioallantoic membrane: towards an integrative approach for analyzing vascular architecture 


\subsection{Introduction}

The peripheral circulation performs several functions such as meeting the metabolic dernand of tissues and maintaining central hydrostatic pressure through modulation of vascular diameter, hence, peripheral resistance ${ }^{26}$. The largest pressure drop takes place along the arterioles of the microcirculation ${ }^{7,12,6}$. Arterioles are therefore considered to play a pivotal role in hemodynamic homeostasis. For cells in tissues, the arterioles of the microcirculation are important since they control flow distribution, and thereby, oxygen and nutrient distribution ${ }^{2.32}$.

Closed loop regulation is necessary to keep flow to the tissues within safe boundaries, and to avoid over or under perfusion of the tissue, and high rises in pressure in the proximal part of the arterial tree, that would result in vascular damage. Flow through a tissue is determined by driving pressure and vascular geometry. If flow is to be regulated with constant pressure, vascular diameter has to be adapted and, hence, vascular resistance. Vascular resistance is a variable that cannot be measured, but can be estimated using Poiseuille's law and including the influence of network architecture ${ }^{10,55}$. Resistance of a vascular segment is linearly related to its length and inversely related to its lumen diameter to the fourth power. Resistance is also related to the instantaneous viscosity of the flowing blood. Within the microcirculation, arteriolar vessel segments are arranged in a network. The total resistance of the arteriolar network is dependent on how the vessel segments are interconnected, the network architecture.

Short-term mechanisms which are recognized to play a role in arteriolar flow regulation through alterations in lumen diameter include the myogenic response, flow dependent vasodilation, propagation of vasodilator responses, and vasomotion $^{10,20,22.29 .45 .52}$. In addition, external factors, such as nerves and certain hormones may affect arteriolar diameter acutely ${ }^{1.11,17: 18}$. Long-term adaptations include changes in vascular wall mass, due to hyperplasia, hypertrophy, or apoptosis of vascular smooth muscle cells, rearrangements of vascular smooth muscle in the vascular wall without changes in wall mass, and radial growth of the arterial wall ${ }^{4,13,1,8,40,50}$. Since resistance is also determined by network architecture, alterations in the number of vessels available to carry flow may be an important long-term mechanism in the regulation of flow ${ }^{40.55}$.

Alterations in number of vessels may be achieved by either regression of vessels, i.e., structural rarefaction, or formation of new vessels ${ }^{40,55}$. The latter process might be comprised of two physiologically distinct mechanisms: 1. angiogenesis, i.e., formation of new capillaries through sprouting of the existing capillary bed ${ }^{32}$, and 2 . the arteriolization process, i.e., upgrading of capillaries into arterioles ${ }^{41,13}$. 
It is now recognized that mechanisms controlling vascular development under physiological conditions include (1) metabolic demand ${ }^{231}$, (2) wall shear stress ${ }^{2 \times 40}$ and (3) circumferential wall stress ${ }^{0,42,3}$ adaptation. The final vascular architecture might be the result of these processes all striving for an optimal value. Vascular adaptations as to meet metabolic demand, depend on tissue oxygen tension and cellular oxygen consumption. Thus, an other origin of the growth stimulus resides within the tissue. Adaptation to wall shear stress and circumferential wall stress are the result of the perfusion status of the vessels. Therefore, perfusion controls growth from within the existing vascular tree, although the initial changes may be induced by tissue factors.

Substantial experimental evidence is available showing that changes in metabolic demand may influence vascular growth, by both angiogenesis and the arteriolization process ${ }^{2}$. Growing of chick embryos under hypoxic conditions leads to increased vascularization, both arterioles and venules, of the chorio-allantoic membrane ${ }^{14.15}$. Hypoxia also affects the vascular growth in the chick embryo proper'. Using whole body and hindlimb perfusion techniques it was shown that the resistance to flow of the maximally dilated vascular bed, the structural vascular resistance, was reduced more than $50 \%$ during hypoxia ${ }^{36}$. The flow transporting capacity at a given perfusion gradient was enhanced in both the whole body and the hindlimb. The observed changes in resistance and flow transporting capacity may be due to an increase in the available cross-sectional area for flow, either through radial growth of arterioles or the formation of new arterioles. These observations indicate that vascular growth and resistance are linked. A substance implicated to play a role in hypoxia associated vascular growth is adenosine. Adenosine is also a known vasodilator and it may alter the flow characteristics in the vasculature and change the ability of the vessel to act upon the shear stress induced signals to regulate flow ${ }^{14.16,32}$. This has been suggested as the mechanism responsible for arteriolar growth in rabbit skeletal muscle during chronic excercise"

On the other hand, if resistance decreases, due to growth, pressure dissipation in the arterial tree may shift towards the smaller vessels. This means that the microcirculation faces an increased pressure which may alter growth through circumferential wall stress adaptation ${ }^{42}$. This demonstrates that the final architecture results from a complex interplay between growth controlled by the perfusion status of the vasculature and growth signals generated by the tissue itself.

To evaluate the contribution of various growth governing forces, computer models were constructed. Computer simulation studies have demonstrated that changing input pressure, in an existing arteriolar network, may modulate the number of arteriolar vessels through regression or formation, mediated by circumferential wall stress (CWS) adaptation ${ }^{42,43}$. Additional simulation studies showed that the same mechanism could hold for upgrading of capillaries into arterioles ${ }^{43}$. Both studies assume a local CWS setpoint. Vessels with a CWS value below this setpoint regress whereas a CWS value above this setpoint would be a stimulus for growth. However, adaptation to CWS alone does not lead to formation of a stable vascular network. 
Other simulation studies have shown that adaptation to shear stress is a stimulus for radial outgrowth of arterioles preferential of carrying flow ${ }_{r}$ and causes regression of vessels perpendicular to the preferential flow direction ${ }^{28}$. However, also adaptation to shear stress alone cannot explain the formation of a stable vascular network ${ }^{25}$.

Computer modeling studies have also shown that it is possible to construct arteriolar trees based on local oxygen demand, that result in an architecture resembling those in vivo $^{2224}$. It is assumed that a cell that is relatively hypoxic generates an angiogenic stimulus, inducing formation of a vessel sprout by the nearest vascular segment. Although the architecture of vascular trees generated by this model look realistic, the model does not yet take into account vessel diameter or local autoregulation.

Computer models used to explain vascular growth based on perfusion status, i.e., the wall shear stress and circumferential wall stress models, start with an already existing vascular network but fail to explain the genesis of that particular network. Changes in vessel dimensions and vascular architecture due to changes in the perfusion status, may therefore be regarded as a remodeling process of the already existing tree. Modeling trees based on local oxygen availability proposes an interesting explanation for the creation of a vascular tree during embryogenesis. The model itself is purely based on the process of tissue expansion (as observed during maturation) and oxygen diffusion distance. Interestingly enough, based on simple rules with regard to oxygen diffusion distance and tissue growth, it is possible to create organ characteristic arterial architectures suggesting that the various vascular patterns found in different tissues may be determined by local metabolic demand. However, this model fails to explain vascular changes in a quiescent system.

It is likely that tissue factors control the genesis of the earliest vascular network. As soon as the network starts to carry flow, the perfusion status of the vasculature may start to induce remodeling of the exising tree through wall shear stress and circumferential wall stress control mechanims residing in the vascular tree. The time of onset of the remodeling mechanism during development is not known.

Changes in the arteriolar network, i.e., a reduction in the available cross-sectional area for flow due to regression of arterioles, have been linked with the genesis or maintenance of essential hypertension ${ }^{34,4055}$. However, it is not clear whether the network changes are due to a defect in its primary formation, or due to aberrant remodeling of the existing tree. It is therefore of great interest to know at which instant which processes contribute to formation and maintenance of the arteriolar vascular bed. However, the observation of microcirculatory changes in laboratory animals is usually limited to thin skeletal muscle preparations that can not be monitored continuously ${ }^{36,3}$. Skin preparations allow for study of only a very limited part of the vascular tree. A microcirculatory model is required in which alterations in structure of a large part of the vascular bed can be followed from just before the onset of hypertension until the established phase. 
If the vasculature results from an equilibrium of growth control mechanisms, each with its specific contribution, it may be possible to analyze, given a certain arteriolar network structure, when and in which quantity each mechanism governed control. This stresses the need for parameters which give a retrospective insight of the growth process and may help to deconvolute the contributing forces. Morphological parameters used to quantify a microvascular network like vascular density or volume, lack information about spatial distribution and are not unique in the sense that distinctively different vascular patterns may have similar parameter values.

The aim of this study was therefore to assess the morphological development of an arteriolar network with time and, by combining computer growth models and in vivo observations, to assess which parameters are useful to gain insight in the physiological control of vascular architecture.

A microvascular network that can be monitored continuously during development is the chick embryo chorio-allantoic membrane (CAM). We recorded developing arteriolar trees of the CAM with time and measured diameter and length of individual vascular segments. This allowed calculation of resistance to flow. The arteriolar branching pattern was analyzed topologically according to centripetal and centrifugal ordering rules $^{21,35,38,4457}$. Subsequently, a computer model was used to generate topological arteriolar trees according to various branching rules. It was then investigated under which parameter settings the computer model could generate arteriolar trees with branching patterns similar to those of an in vivo developing arteriolar tree, and evaluated which topological parameters are useful in describing the architecture of an arteriolar tree. Furthermore, an algorithm was developed which assigns in vivo measured diameters and lengths to vascular segments in the modeled topological trees depending on their site in the vascular tree ${ }^{57}$. It was then investigated how the arteriolar branching pattern contributes to resistance and flow distribution.

This study supports the idea that it is possible to obtain a retrospective insight in the morphogenesis of the arteriolar tree by applying topological rules to in vivo data.

\subsection{Materials and Methods}

\subsubsection{Protocol}

Fertile Lohman selected white leghorn eggs were incubated for three days at $37^{\circ} \mathrm{C}$, $55 \%$ relative air humidity and rotated once every hour. At day 3, a rectangular window $(1 \times 1.5 \mathrm{~cm})$ was made in the eggshell using a little saw. The window was covered with Scotch tape to prevent dehydration. The window allowed undisturbed observation of the developing vasculature of the chorio-allantoic membrane (CAM). At day 7, observation of one arteriolar tree in the vasculature of the CAM started. This arteriolar tree was selected based on optical clarity and observed until day 14. 
To record vessel images, an intravital microscope set-up was used. In short, a chick embryo was placed under the microscope and kept at $37^{\circ} \mathrm{C}$ using a small incubator. The vasculature was visualized with a $4 x$ objective (N.A. $=0.12$, optical resolving power about $3 \mu \mathrm{m}$ ) using polarized epi-illumination from a $100 \mathrm{~W} \mathrm{Hg}$ lamp. A crossed polarisation filter was positioned in the imaging pathway to eliminate direct reflections $^{50,51}$. The final image was projected onto a Bosch camera with a light intensifying unit (SIT). The camera was set on automatic gain. The camera was connected to a Panasonic Super VHS videorecorder model NV-FS100HQ and images were stored on JVC S-XG tapes. Vessel diameter and length were analyzed off-line from still frame images on a Sony monitor model PVM-122CE using a digital ruler. Resolution at the monitor screen was $5.7 \mu \mathrm{m}$. All vessels with a diameter ranging from $10-200 \mu \mathrm{m}$ were traced. The vascular tree was reconstructed and each vessel segment was numbered and consecutive daughter branches were identified. Typically, one segment would give rise to two daughter branches. Trifurcations and arteriolar-arteriolar connections, arcades, were very rare, i.e., less than $0.5 \%$ from total number of segments analyzed. For modeling purposes, trifurcations were considered to be two bifurcations with an insert segment, length approximating zero $(0.1 \mu \mathrm{m})$. Arcades were cut in two and assigned to either daughter tree depending on the flow direction. Thus, from each (mother) segment, vessel diameter and length were deteremined, as well as daughter 1 and daughter 2 were vessels were identified. Diameter in a vascular segment was measured in triplicate, at the same position, immediately after the branch node. Data of the vascular tree were stored on a computer disk. A complete arteriolar vascular tree was stored from data obtained at day 7,10 , and 14 .

\subsubsection{Structure of the arteriolar network}

The terms and topological ordering rules used in this study were applied to arteriolar trees. The arteriolar tree could be either experimentally obtained (the chorio-allantoic membrane vasculature) or generated by a computer model.

\subsubsection{Definition of terms used in arteriolar pattern analysis}

A segment is a part of the tree between two successive bifurcations. A terminal segment is one at the distal end of the tree. In vivo, precapillary arterioles are regarded as terminal segments. A node is a bifurcation point. The segment which divides will be referred to as the mother segment, the two segments connecting at the other side, downstream of the node will be referred to as the daughter segments.

\subsubsection{Topology, centrifugal and centripetal ordering}

Topology measures describe how vessel segments are interconnected. In order to apply topological measures, tree segments have to be ordered. Ordering of the segments was performed centripetally or centrifugally (Fig. 1). Centripetal ordering was applied using Strahler's ordering ${ }^{30,35.535}$ (Fig. 1b). This ordering starts at the distal part of the vascular tree and proceeds in proximal direction. 


\section{Fig. 1a Generation order}

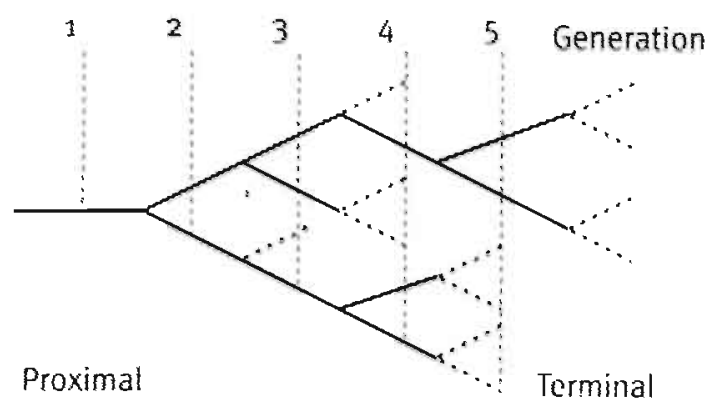

Fig. 1b Strahler order

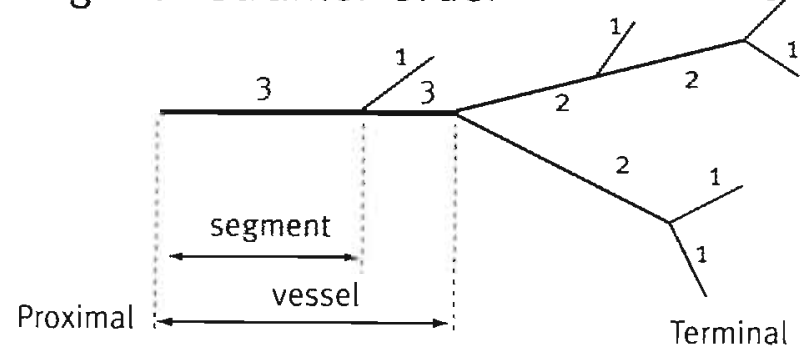

Figure 1. Ordering of a vascular tree

All terminal vessels are assigned order 1 . For each node, the order of the proximal segment is the maximum of the Strahler orders of the 2 daughter vessels, except when these are equal; in that case, the mother segment is assigned one order higher. Centrifugal ordering ${ }^{21,38}$, originally introduced by Weibel ${ }^{58}$, proceeds by assigning; order 1 to the root segment. At every bifurcation, the order is increased by one (Fig. 1a). Note that these topology measures do not take into account vessel dimensions. 


\section{Segmental growth:}

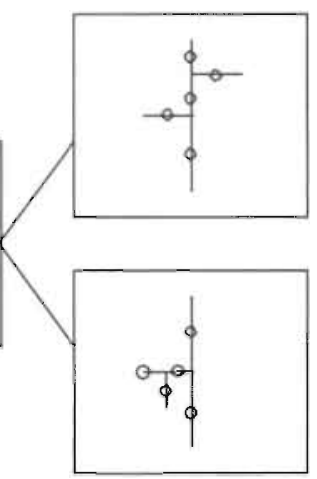

o: site for addition new segment

\section{Terminal growth:}

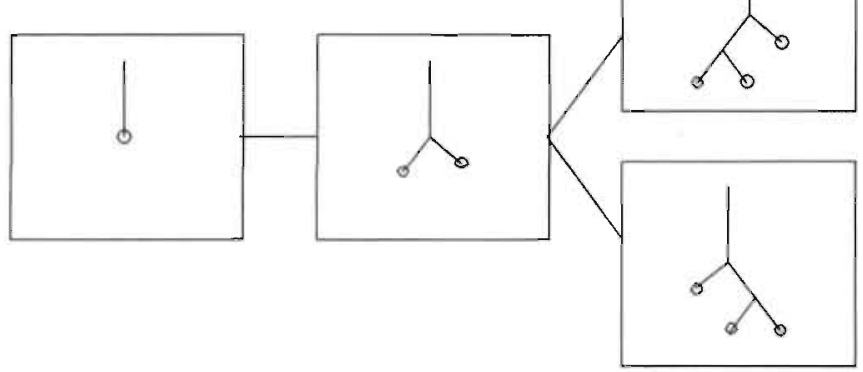

Figure 2a. Segmental and terminal growth

\subsubsection{Growth of the vasculature, terminal and segmental growth}

To model growth of a vascular tree, a computer algorithm was constructed ${ }^{27}$. Initially the vasculature consists of one mother segment. New segments can be added to the existing vascular tree according to either terminal growth (TG) or to segmental growth (SG) (Fig. 2a). Addition of new segments to terminal segments is referred to as terminal growth. From the set of existing terminal segments one is chosen with equal probability for all segments. Two parallel coupled terminal segments are added to this segment. The tree now consists of three segments. Modeling according to segmental growth allows addition of new segments along all segments. The added segment divides the initial segment in two new segments. 

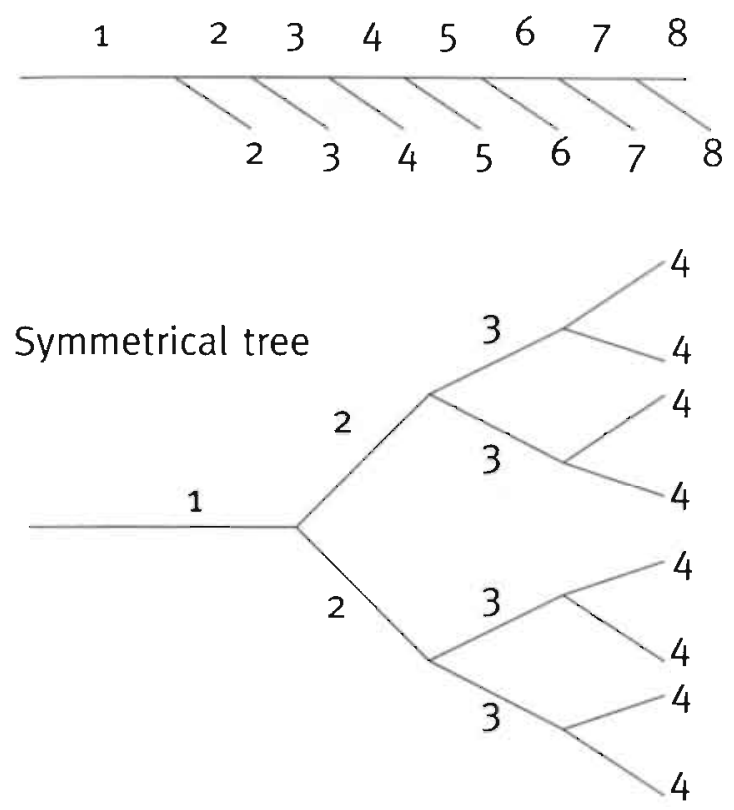

Figure 2b. Vascular (a)symmetry

In a dichotomous branching tree, pure TG or SG represent the extremes of growth processes. Theoretically, growing according to terminal growth and seginental growth can create all possible vascular patterns provided the right strategy is applied ${ }^{9,40}$. Based on topology of in vivo analyzed vascular trees, it has been postulated that the branching pattern may be described by a stratified combination of both processes. The two most simple vascular patterns are the complete symmetrical and the complete asymmetrical vascular trec (Fig. 2 b). On average, random SG will result in more asymmetrical trees than random TG, for equal tree size ${ }^{38}$. Therefore, the mean centrifugal generation of a tree constructed according to pure random SG is larger than a tree constructed according to random TG, for an equal number of terminal vessels ${ }^{38}$. Growth according to either process will result in an almost symmetric distribution about the mean (mean centrifugal order), with a larger standard deviation for random SG (Fig. 5). On arerage the mean centrifugal order for random TG is smaller compared to random SG, for the same number of segments. Combination of TC and SG growth will result in a generation distribution proportional to the contribution of either process. To explain experimentally obtained topological order distributions, they will be fitted with the distributions of $\mathrm{SG}$ and $\mathrm{TG}^{38}$. 


\subsubsection{Strahler Analysis}

According to Strahler's ordering, a vessel may be defined as the vascular structure of all subsequent segments with equal Strahler order. The length of such a vessel can be expressed as the number of segments of which it consists. To characterize a vascular tree, one may use the distribution of the occurrence of vessels with a certain segmental length given their Strahler order. Based on Strahler order s, a plot can be made of the distribution of vessel lengths expressed in number of segments. It has been shown that this distribution resembles the geometric distribution of the following relation; the number of vessels $N(L)$ of a certain length $L$ is related to vessel length by:

$N_{s}(L)=N_{\operatorname{tot} s} q(1-q)^{L-1}$, with $N_{w s, s}$ is the total number of vessels with order $s$, and $q$ a positive constant ${ }^{57}$. The value $\mathrm{q}$, reflects the probability of termination for a given Strahler order, and can be calculated by fitting the experimentally obtained distributions with this relationship. The probability of continuation of a vessel with Strahler order s, is constant and equals 1-q. It was investigated whether differences in branching pattern could be detected using the probability of termination.

\subsubsection{Computer modeling, the S-Model}

Assuming that vascular trees result from the topological processes terminal and segmental growth, growth of a vascular tree was simulated using the S-model ${ }^{27}$. Using a single parameter, $\mathrm{S}$, the differential contribution of TG and SG can be regulated. According to this model, each of the individual segments was assigned a probability $P(s)$ that reflects the chance that a next new branch develops at that segment with Strahler order $\mathrm{s}$. The model assumes these probabilities to decrease exponentially with the Strahler order. The relation between probability and Strahler order is assumed to be:

$$
P(s)=\frac{e^{-\pi / s}}{\sum s=1 \ldots s_{\text {not }} N(s) e^{-/ s}}
$$

where $s_{\text {rot }}$ is maximum Strahler order in the tree assigned to the root segment; $N(s)$ is the number of segments having Strahler order S; $\mathrm{S}$ is the model parameter regulating the contribution of TG and SG.

The modeling procedure starts by selecting a value for the model parameter $\mathrm{S}$ (chosen by the user). Subsequently, the probabilities for each Strahler order s are calculated. Based on the calculated probability distribution, a segment is chosen. A new segment is added to this chosen segment. Adding a new segment changes the topology. Hence, after adding a segment, a new probability distribution is to be calculated. This procedure is repeated until the requested tree size is reached. Although the probability distribution varies during tree growth, the contribution of $\mathrm{TG}$ and SG remains fixed. 
For $S=0$, only the terminal segments have a finite probability. Hence, $S=0$ reflects terminal branching. For $\mathrm{S}=\infty$, the probability for each segment becomes equal, hence, $\mathrm{S}=\infty$ approaches segmental branching. Intermediate values of $\mathrm{S}$ represent an interpolation between SG and TG. To simulate transitions from one process dominating growth to the other, the $S$ has be changed at a certain instant in the tree generating process. Using the S-model, vascular trees were generated according to either TG, SG, or mixed forms. The generated trees were ordered according to centrifugal and centripetal ordering rules and the distributions of these orders compared to the distributions of the in vivo arteriolar tree. It was than investigated which value of the parameter $S$ in the S-model could simulate trees with similar order distributions as the in vivo trees.

\subsubsection{In vivo measurements of diameter and length}

For each arteriolar tree at day 7,10 , and 14, segmental length and diameters were measured. Centrifugal and Strahler order distributions were determined. Relationships between length and diameter, mother $\left(\mathrm{d}_{0}\right)$ and daughter diameters $\left(\mathrm{d}_{1}, \mathrm{~d}_{2}\right)$, and area growth $\left(\mathrm{d}_{1}{ }^{2}+\mathrm{d}_{2}{ }^{2} / \mathrm{d}_{0}{ }^{2}\right)$, were calculated and plotted (Appendix figs. 1-5).

Since we were able to follow one complete arteriolar tree in time, we also calculated resistance, volume, and flow for this tree during development. To increase the number of experimental data sets, the large trees were subdivided in smaller trees. Specifically those trees were selected that could be identified at a later instant. Subtrees of the large tree were selected both at the proximal and at the terminal end of the network. This allowed the establishment of relationships between changes in diameter, length, volume, resistance and flow. Thus, we experimentally observed the in vivo developing CAM arteriolar vasculature. Computer modeling employing the S-model, was used to generate trees according to a stratified topology. Combining the observation of the experimental trees and the computer generated trees, we attempted to gain insight in the process of vascular growth. Based on the conclusions drawn from these (combined) observations, we attempted to estimate what consequences this might have for resistance and flow.

\subsubsection{Estimation of local flow and resistance}

CAM rasculature data and the modeled networks were used to estimate resistances to flow. To calculate resistance, a number of assumptions was made. Diameter of each segment was assumed to be constant. Resistance was determined using Poiseuille's law, assuming a constant riscosity equal to that of Ringer's solution. A possible effect of branching-angle on resistance or hindrance at nodes was neglected. Precapillary pressure was assumed to be homogeneously distributed and set to be zero". Other experimental studies provided data on perfusion pressures in the chick embryo chorio-allantoic artery ${ }^{33}$. These pressure were $6 \mathrm{mmHg}, 9 \mathrm{mmHg}$, and $16 \mathrm{mmHg}$ at day 7,10 , and 14 respectively. Flow through the experimentally observed CAM vasculature was calculated, as the ratio of perfusion pressure and calculated network resistance. 
Based on the experimentally obtained distributions of segmental length, diameter, and area growth of the CAM vasculature (Appendix), length and diameter could be assigned to the modeled trees. Terminal segments of modeled trees, were assigned a diameter and length. For this choice, we used the fit through the experimental data of segmental diameter and length, as well as the variability. After assigning diameter and length to the terminal segments, diameters could be assigned to the next proximal segment based on area growth. Again, we used the fit through area growth versus mother diameter as well as the variability. This was repeated until the most proximal segment, the entrance segment, was reached. Subsequently, resistance of the modeled network was calculated.

\subsection{Results}

Table 1 summarizes the general characteristics of the experimentally observed CAM arterioles, during development. The significance of these parameters with regard to vascular growth, will be analyzed in the subsequent sections.

Tabli . Characteristics of the C.AM arteriolar tree at day 7, 10, and 14, respectively.

Parameter

Segments

Resistance

Conductance

A. Volume

$\mathrm{MCO}$
Day 7

543

466

$2.15 \times 10^{-3}$

0.15

14.95
Day 10

1630

458

$4.08 \times 10^{-3}$

0.32

20.22
Day 14

Units

2757

406

Pamm-3s

$32.0 \times 10^{-3}$

0.51

21.06

Abbreviation: A, arteriolar; $\mathrm{MCO}$, mean centrifugal order.

\subsubsection{Topology, CAM Generation Analysis}

At day 7 (Fig. 4a, top), centrifugal analysis revealed 30 orders. The frequency distribution exhibits a bimodal distribution with peaks about generation 10 and 20 , respectivily. The frequency distribution of the day 10 arteriolar tree (Fig. $4 \mathrm{~b}$, middle) also exhibits a bimodal distribution. The first peak is about generation 14, the second peak about generation 25-30. A total of 48 generations was observed. The frequency distribution of the day 14 arteriolar tree (Fig. 4c, bottom) exhibits a bimodal distribution with a peak about generation 17 and a peak about generation 25. A total of 48 generations was observed, which is the same as at day 10. 


\subsubsection{Topology, Generation Analysis, Terminal and Segmental Growth}

To investigate the process of vascular tree formation, we compared the in vivo data with those of trees modeled according to either random segmental or random terminal growth. Figure 5 shows the centrifugal distribution for either random terminal branching or random segmental branching for a vascular tree with 2700 segments. The $\mathrm{MCO}$ for random terminal growth was 11 , with a relative occurrence of 0.13 . For random segmental growth, mean generation number was 28 , with a relative occurrence of 0.035 .Note that both curves display a single peak, with small variance for terminal growth and large variance for segmental growth.
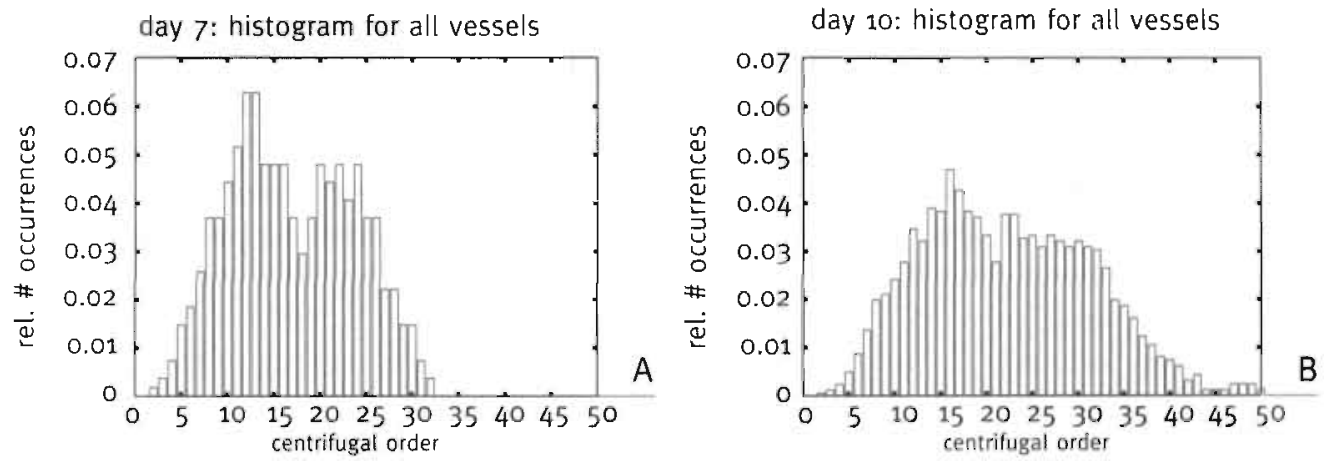

day 14: histogram for all vessels

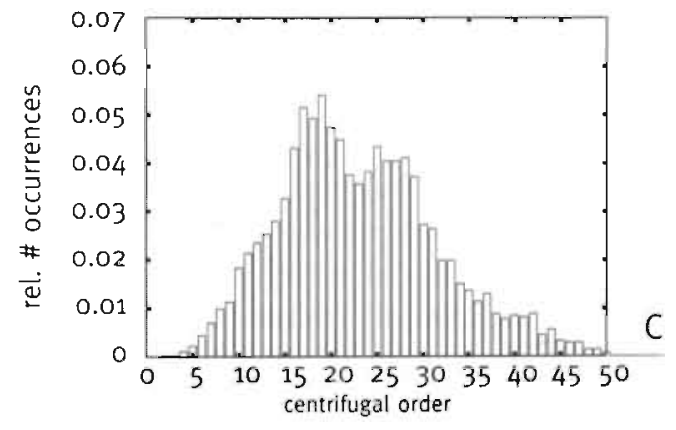

Fig. 4. Relative cumulative centrifugal order distribution for the in vivo C.AM arteriolar tree at day 7(a, top L), day 10 (b, top R) and day 14 (c, middle) respectively. Note that the distributions show two peaks. 
Theoretically, terminal growth, segmental growth, and a combination of both, can generate any dichotomous tree. This can be accomplished by applying the right strategy when forming the tree. If one assumes that the in vivo tree is formed by a random mixture of the two processes, the experimentally obtained centrifugal order distributions may be fitted with the sum of the theoretical distributions for random generated trees. Figure 5a displays the distribution of the theoretical distribution curves (solid lines) for random TG and random SG, and, the summated curve for equal chance of terminal and segmental growth (dotted line) for a tree with 2700 segments. This curve has one peak about generation 10 and is skewed to the right. We furthermore calculated distributions with other mixed forms of SG and TG (95\%SG and 5\%TG; Fig. 5b; dotted line). Distributions of this mixed form also displays one peak. Thus, summation of the distributions for random TG or random SG could not explain centrifugal order distributions with two peaks, i.e., the process is not likely to be a random mixture of the two forms. Some strategy has to be present.

We therefore tried to explain the nature of the experimentally observed centrifugal distributions using the S-model, in which a certain change in distribution between the two forms is assumed. We were able to simulate centrifugal order distributions resembling the experimentally obtained distributions assuming that the growth process started with a dominant contribution of segmental growth and that during the process of modeling the contribution of terminal growth increased (Fig. 6). The parameter settings for the S-model were: at the start of the modelling procedure $S=30$ (towards segmental growth). After 2700 segments $S=5$ and after 5400 segments $S=0.2$ (towards terminal growth). We assumed a linear decrease in $S$ between $S=30$ and 5 , and between $S=5$ and 0.2 . Note broadening of the peak and emergence of two peaks.

Fig. 5 A

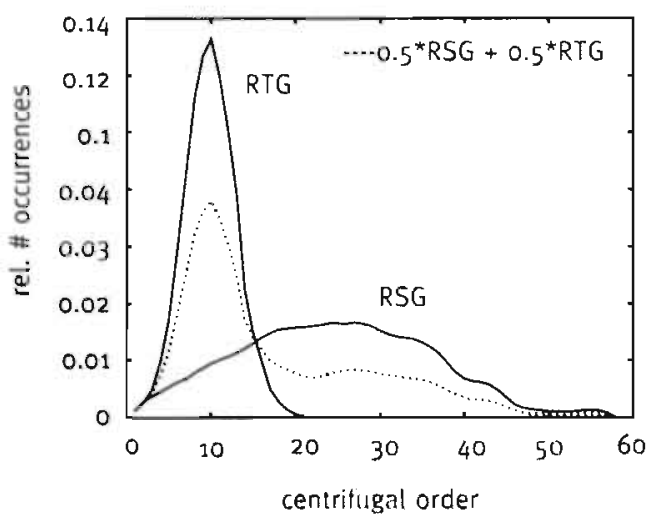

Fig. $5 B$

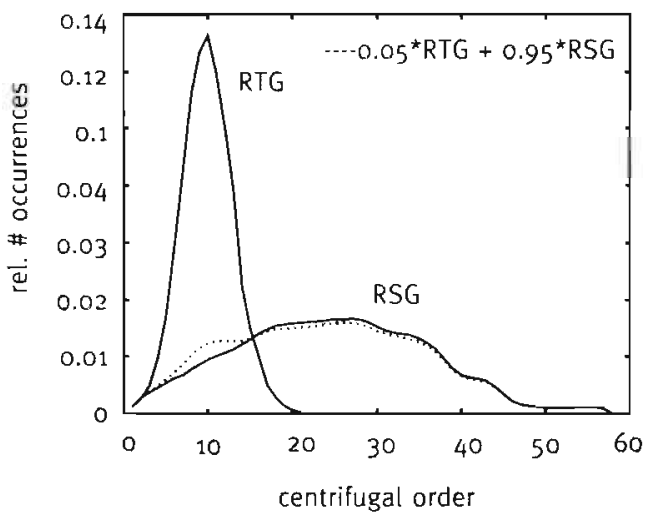

Fig. 5. Relative cumulative centrifugal order distribution for random terminal (RTG) and segmental (RSG) growth, and the summated curves for mixed forms of RTG and RSG 


\section{S-model simulation}

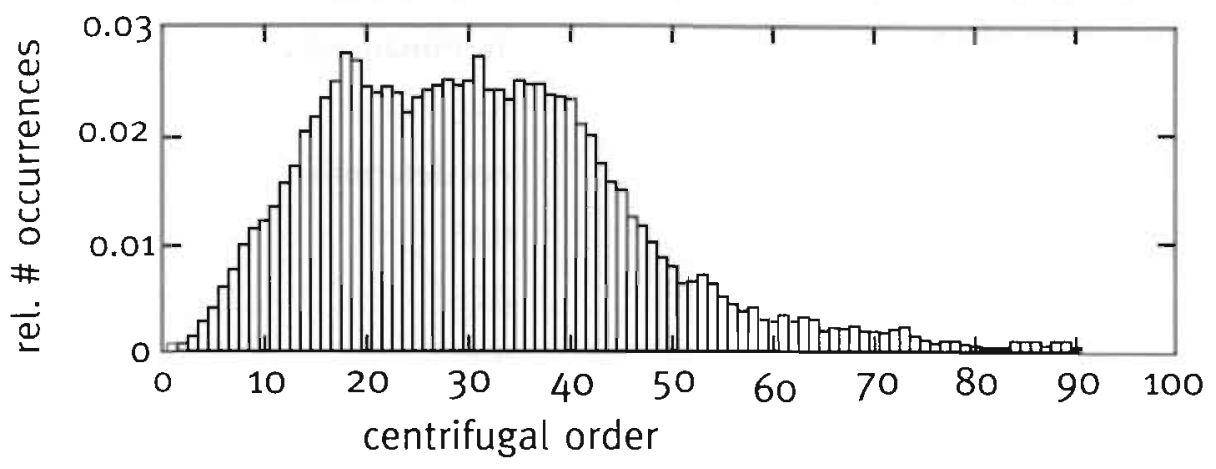

Fig. 6. Relative cumulative centrifugal order distribution obtained with S-model simulation for a tree with 5400 segments, and a linear decrease in $S$ from $S=30$ to $S=0.2$ during simulation.

\subsubsection{Topology, Generation analysis, Mean Centrifugal Order (MCO)}

The mean centrifugal order of the CAM arteriolar trec increased with time from 14.9 at day 7, to 20.2 and 21.0 at day 10 and 14, respectively (Table 1.). The relatively small increase in MCO in the period day 10-14 with an almost twofold increase in network size, suggests that during this period new ressels were mostly coupled according to terminal growth. Using the S-model, with one single S value, best fits were obtained using $S$ values of $4,3.5$, and 2.5 at day 7,10 and 14 , respectively. This suggests an increasing contribution of terminal growth with time.

\subsubsection{Topology, Strahler analysis}

The results of the Strahler analysis of the in vivo measured arteriolar tree at day 7,10 and 14 are displayed in fig. $7 \mathrm{a}, \mathrm{b}, \mathrm{c}$, respectively. For each Strahler order, the number of vessels is plotted as a function of vessel length, expressed in number of segments on a semi-logarithmic scale. Note that the highest Strahler order is 4 on day 7 and 7 on day 14. On average, a symmetrical tree will result in higher Strahler ordurs than an asymmetrical tree of equal size. Therefore, the small occurrence of large Strahler values at days 7 and 10 may be attributed to an asymmetrical branching pattern of the arteriolar tree at day 7 and 10 , respectively. To calculate the termination probability $(\mathrm{q})$, experimental data were fitted with the geometric distribution of $N(L)$. Since the number of experimentally obtained observations for Strahler urders 4 and 5 was limited, q was only calculated for orders 2 and 3. 
Table 2. Termination probability for Strahler orders 2 and 3 of the CAM vasculature observed at day 7,10 , and 14 , respectively.

$\begin{array}{lll}\text { Day } & \text { Strahler order } & \text { Termination Probability }(\mathrm{q}) \\ 7 & 2 & 0.40 \\ & 3 & \text { not determined } \\ 10 & 2 & 0.45 \\ & 3 & 0.28 \\ 14 & 2 & 0.47 \\ & 3 & 0.35\end{array}$
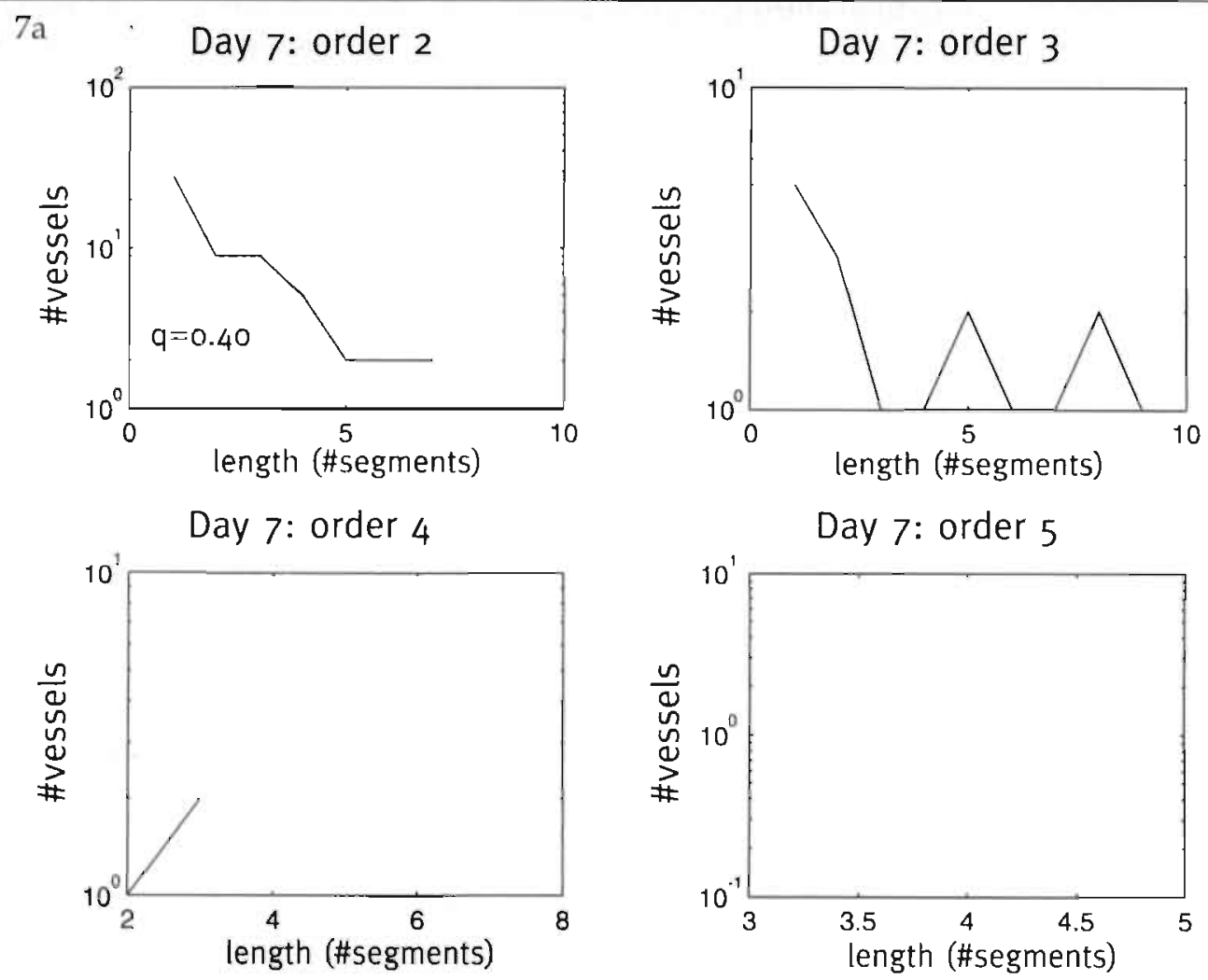

Fig. 7a. Strahler analysis of the in vivo CAM arteriolar tree at day 7 (a). Plotted are the length of a vessels with a certain Strahler order expressed in number of segments versus the occurrence (\# vessels is plotted on a log scale). 
$7 \mathrm{~b}$

Day 10: order 2
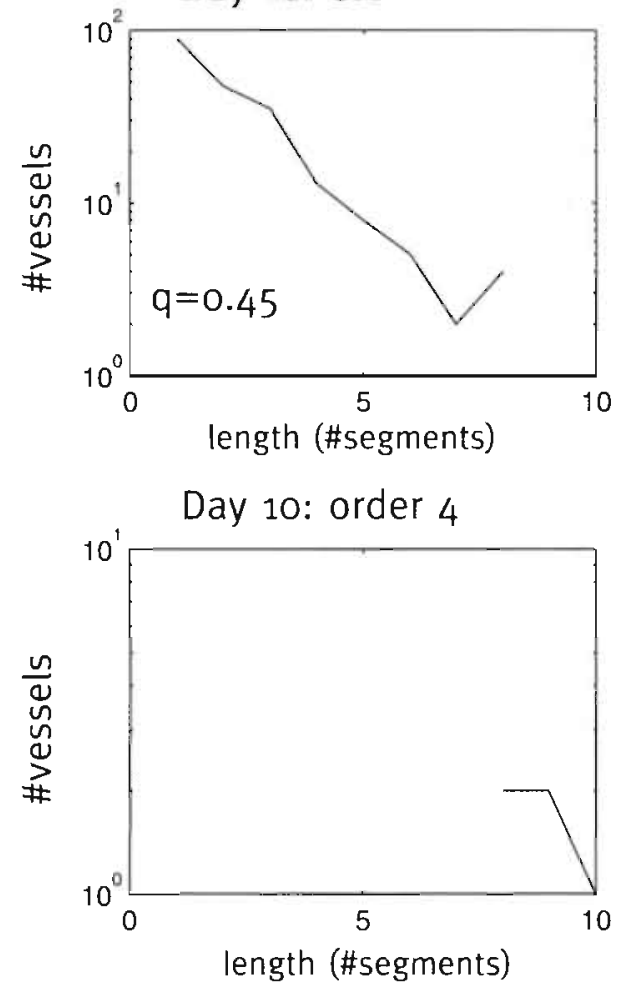
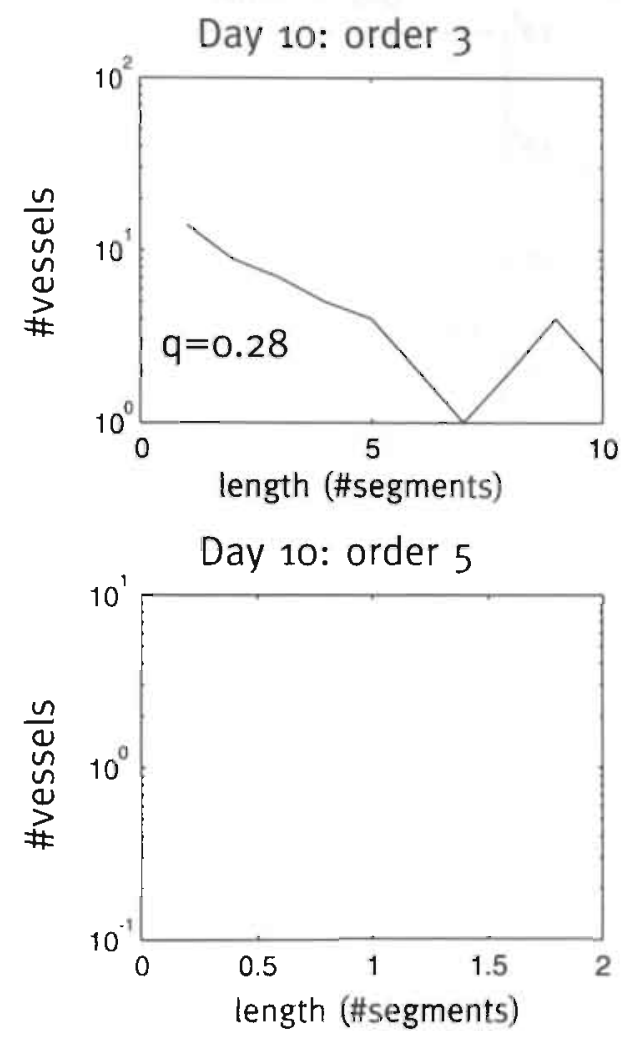

Fig. 7b. Strahler analysis of the in vivo CAM arteriolar tree day 10 (b). Plotted are the length of a vessels with a certain Strahler order expressed in number of segments versus the occurrence (\# vessels is plotted on a log scale). 

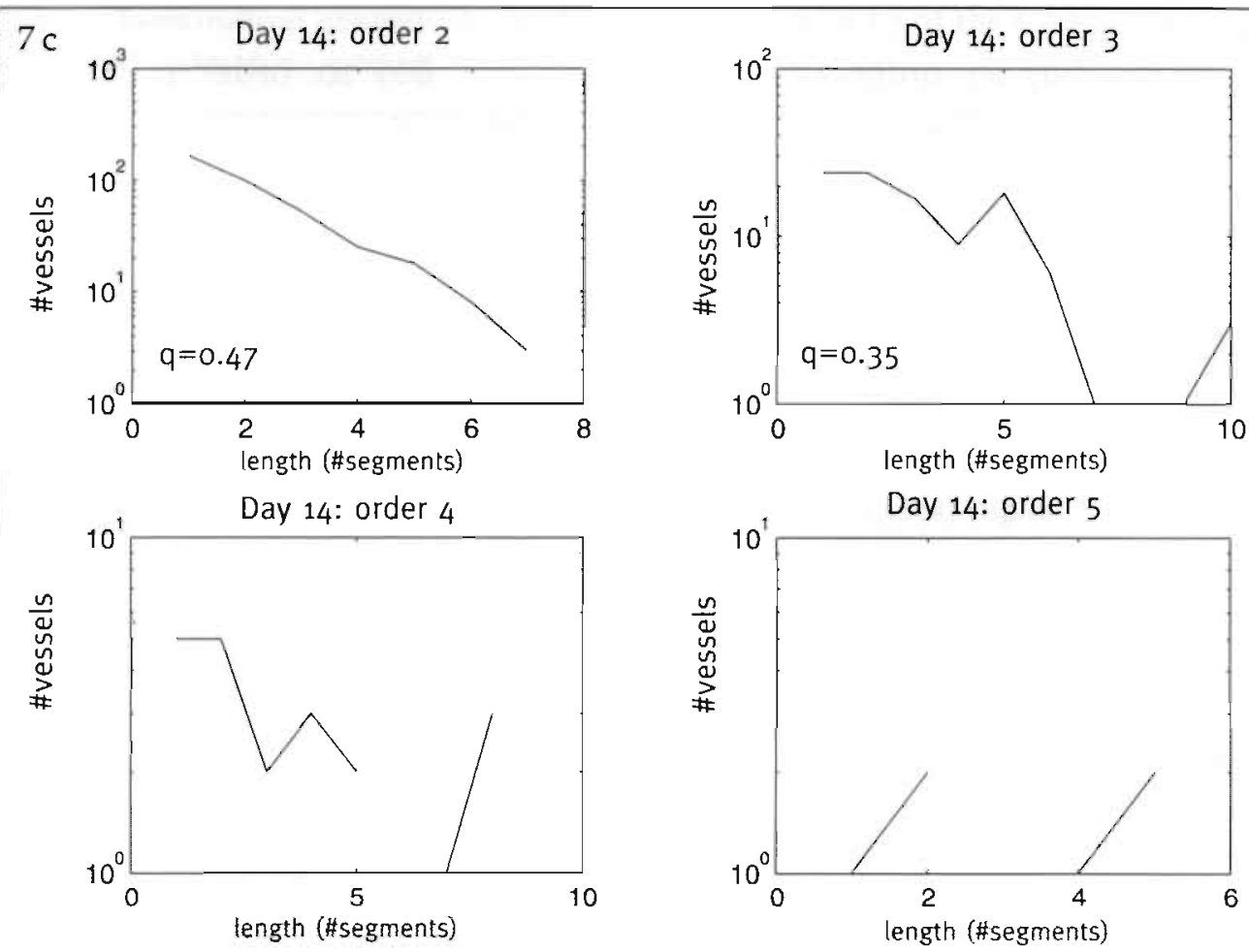

Fig. 7c. Strahler analysis of the in vivo CAM arteriolar tree day 14 (c). Plotted are the length of a vessels with a certain Strahler order expressed in number of segments versus the occurrence (\# vessels is plotted on a log scale).

\subsubsection{Strahler analysis, the S-model}

In order to compare the effect of differences in branching pattern on the termination probability $(\mathrm{q})$, vascular trees were modeled using various parameter values for the Smodel. Figure 8 shows the relationship between the model parameter $\mathrm{S}$ and the termination coefficient $q$ for Strahler orders 2 ( $q 2$ ) and 3 (q3) vessels. Plotted are the mean $q$ and standard deviation for 20 trees with 8000 segments each as a function of $S$.

For Strahler order 2, mean q decreased from $q=0.56$ at $S=0$ (terminal growth), to $q=0.50$ at $S=5$ (towards segmental growth). For $S \geq 5$ q2 only showed a very slight decrease. Compared to the absolute decrease in mean $q 2$, the standard deviation for $q 2$ was large. For Strahler order 3, mean q decreased from 0.35 at $S=0$ (terminal growth) to $\mathrm{q} 3=0.22$ at $S=5$ (towards segmental growth). For $S z 5, \mathrm{q} 3$ varied around 0.22 with the standard deviations diverging outwards. Again, the standard deviations were large compared to the absolute decrease in q3. In general, for Strahler order 2 and 3 vessels, the mean value of the termination coefficient $(q)$ decreased with increasing values for $S$. 
Termination probability q for Strahler order 2
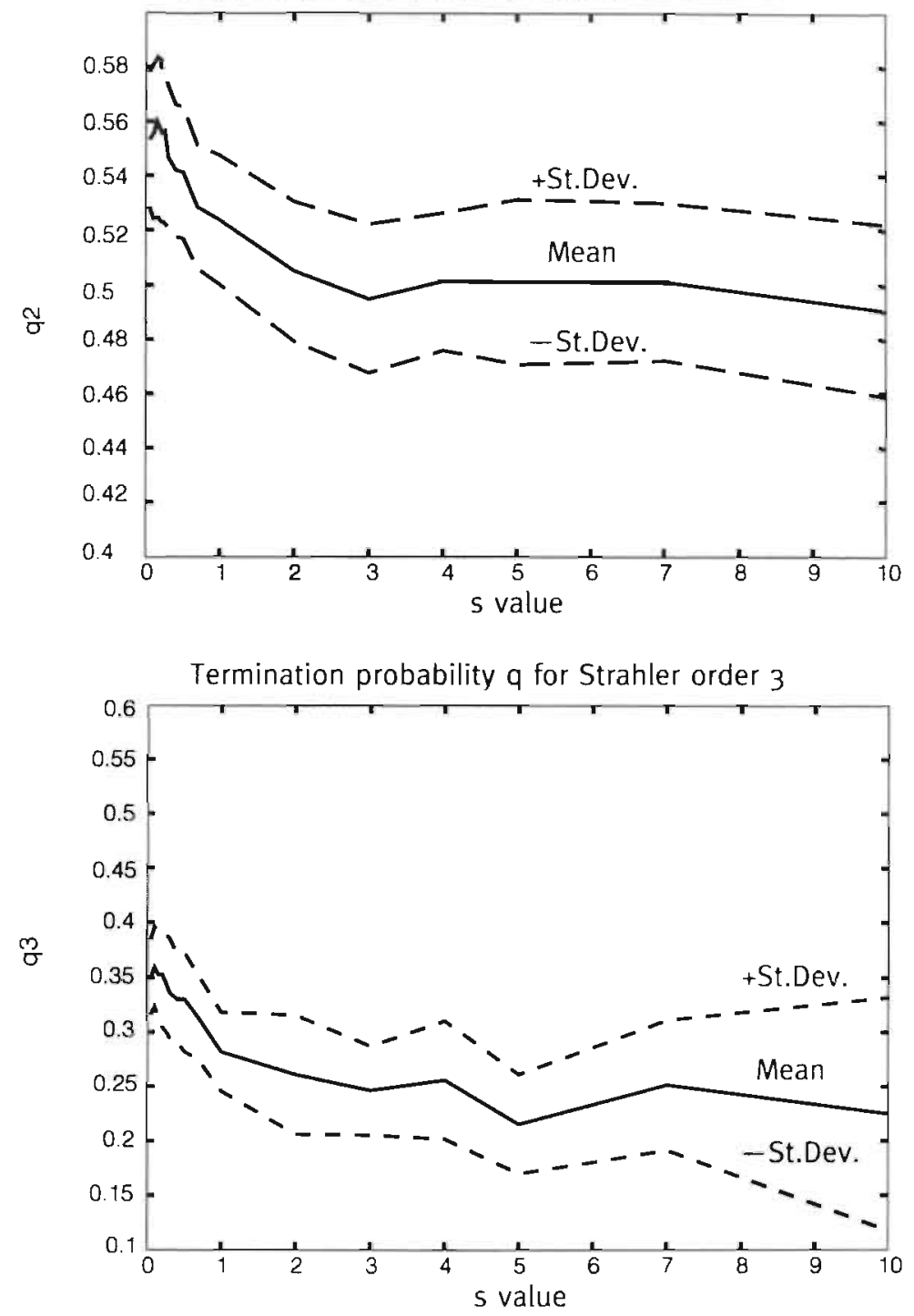

Fig. 8. Termination probability q for Strahler order 2 (top) and order 3 (bottom) as a function of the parameter $S$ in the S-model simulation. Presented are mean $q$ and standard devation (St.Dev.) for 20 trees with 8000 segments. 
Thus, the probability of continuation, 1-q, increased with increasing values for $\mathrm{S}$. Hence, with an increasing contribution of segmental growth in the growth process, Strahler order 2 and 3 vessels will be longer, when expressed in number of segments per vessel. Given the large variation about the mean $\mathrm{q} 2$ and $\mathrm{q} 3$ (Fig. 8) and the relatively small change in mean $\mathrm{q} 2$ and $\mathrm{q} 3$ for large changes in the topological growth process, it may be difficult to draw conclusions from the $q$ values obtained from the experimentally observed CAM vasculature. The observed increase in the termination coefficient $\mathrm{q}$ (see table two) in the period day 7-10 of Strahler order 2 vessels of the CAM arteriolar tree, suggests an increasing contribution of random terminal growth with time. The minor variation between day 10 and 14 indicates that the relative contribution of the topological growth processes TG and SG did not change in this period. The termination coefficient (q) for order 3 vessels showed a slight decrease between day 10 and day 14, suggesting a shift towards segmental growth. However, it is questionable whether these experimentally observed changes in termination coefficient $\mathrm{q}$ are significant.

\subsubsection{Resistance and Conductance of the developing arteriolar tree}

Based on the in vivo measurements of vessel diameter and length, resistance to flow could be calculated (Table 1). The resistance of the developing arteriolar tree decreased with time. Resistance decreased from $466 \mathrm{~Pa} \cdot \mathrm{mm}^{3}$.s at day 7 , to 458 and 406 at day 10 and 14, respectively. The conductance increased from $2.15 \times 10^{-3} \mathrm{~Pa}^{-4} \cdot \mathrm{mm}^{3} \cdot \mathrm{s}^{-1}$ to $2.18 \times 10^{-3}$ and $2.46 \times 10^{-3}$ at day 7,10 , and 14 , respectively. The relative decrease in resistance was $2 \%$ during the period day $7-10$, and $13 \%$ during the period day $10-14$.

\subsubsection{Volume of the developing arteriolar tree}

The volume of the arteriolar tree increased from $0.15 \mathrm{~mm}^{3}$ at day 7 to 0.32 at day 10 and 0.51 at day 14 (Table 1 ). The relative increase in arteriolar volume was $114 \%$ for day 7 10 and $57 \%$ for day $10-14$. The volume is dependent on both length and diameter of vessels. An increase in volume may be achieved through increase in length, which will increase resistance, or an increase in diameter, which will lower resistance. It would be interesting to quantify which part of the volume and resistance change can be explained from changes in diameter and which part by changes in length. However, resistance is also dependent on network architecture. It therefore seems not possible to uncouple the contribution of diameter and length using the combined observations on volume and resistance change.

\subsubsection{Resistance and arteriolar architecture Growth and Resistance}

Addition, read growth, of new vessel segments to an existing arteriolar tree influences the total vascular resistance. The change in resistance depends on the site were the segments are added to the existing arteriolar tree. Let's consider example 1 . The vasculature consists of one segment with a resistance $\mathrm{Ri}$, and two new segments are added according to terminal growth. 
In the new situation, the vasculature consists of three segments. The added segments. are coupled parallel, and have a substitute resistance (Rs) that is larger than zero. Assuming that Ri does not change after addition of the new segments, the total resistance (Rtot) of the vascular tree now equals $R t o t=R i+R s$. Hence, addition of two parallel coupled segments to the terminal part of the vasculature increases resistance.

Let's now consider example 2. New segments can be added according to segmental growth. In this case a segment is added along an existing segment. The resistance of this initial segment is Ri. After addition of a new segment, the vascular tree consists of three segments. Note that the topological structure is now identical to that of example 1. The resistance of the initial segment is now divided into two parts with resistance $\mathrm{Ri}-\mathrm{Rn}$ and $\mathrm{Rn}$, respectively. The added segment with resistance Ra is coupled parallel to $\mathrm{Rn}$. The substitute resistance Rs of the parallel coupled segments is always smaller than $R n ; R s=R n-\Delta R$. Therefore, total resistance of the vascular tree Rtot equals Ri- $\Delta R$, and is smaller than $\mathrm{Ri}$. Thus adding a new segment along an existing vessel lowers total resistance, because the length of the segment in which the new segments is inserted does not change. From these two examples it may be concluded that the effect of addition of new vessel segments on total vascular resistance, depends on the site were new vessels are added.

In the developing CAM vasculature, existing vessels may change in length or change their diameter. Furthermore, new vessels are added to the existing tree. The resistance of the experimentally observed arteriolar tree changes during development. The question now arises to what extent this is due to changes in diameter and length, and to vascular growth. To investigate the contribution of (1) addition of new vessels, (2) length, and (3) diameter scaling on arteriolar network resistance, a computer model was constructed. The user can vary the site where new vessels are added to the existing tree, and define the magnitude of length and diameter scaling. New vessel segments may be added either at the terminal part of the rascular tree (terminal growth), or along an existing vascular segment (segmental growth).

The added segments were assigned a diameter of $8 \mu \mathrm{m}$ and a length of $20 \mu \mathrm{m}$. A segment added according to segmental growth, divides the parent vessel in two segments with equal lengths. Length scaling was performed by multiplying the length of all vessel segments in the vascular tree with the same value. Diameter scaling was done by multiplying the diameter of all vessel segments within the vascular tree with the same value. The aim of this process was to explain the nature of the observed changes in calculated resistance to flow of the CAM arteriolar tree in the period day 7-14. Thus, what changes (growth, length, diameter) have to occur in the arteriolar tree of day 7 during the period day 7-10, to obtain the calculated resistance to flow and arteriolar volume of the day 10 arteriolar tree, and what changes hare to occur in the day 10 arteriolar tree, to obtain the calculated resistance to flow and arteriolar volume of the day 14 arteriolar tree. 
For the modeling procedure we used the arteriolar trees of day 7 and day 10, and examined possible effects of vascular growth, and length and diameter changes on resistance. The vascular tree of day 7 was enlarged with 250 new segments (50\% increase in tree-size) by adding them according to either terminal growth (TG) or segmental growth (SG). An increase of about $50 \%$ in number of segments means the addition of about one generation of vessels. We choose to add no more than this number of segments to avoid unrealistic development of the vascular tree. After addition of the vessel segments, total resistance of the new arteriolar tree, Radd, was calculated. Subsequently, length scaling was set at 1.4 and again resistance was calculated, Rlength. The value for length scaling was obtained from interpolation of the observed volume changes of the total CAM during the period day $7-10^{45}$. Subsequently, the diameter scaling was estimated that would result in the new resistance being the same as the initial resistance.

The vascular tree of day 10 was enlarged with 750 segments (50\% increase in tree-size) by adding them according to either terminal growth or segmental growth. Next, resistance, Radd, was calculated. Based on the volume changes of the CAM during the period day 10-14, length scaling was set at 1.0.5. Hence, this did not affect resistance. Finally, the diameter scaling was estimated that would result in the new resistance being the same as the initial resistance. The modeling procedure was repeated 14 times for either random terminal or segmental growth and for each vascular tree (day 7 and day 10 ). The results of the modeling procedure are presented in tables $3 \mathrm{a}, 3 \mathrm{~b}$.

Table 3a. Terminal Growth and Resistance. Presented are Rin, the initial resistance of the arteriolar tree at day $7, V$ tot, the volume of the arteriolar tree, $R$ add, the resistance after adding segments, $R$ length, the resistance after length scaling, and the required diameter scaling to obtain Rin. Presented are the mean and standard error of the calculated resistances and the range (Rlow - Rhigh). Resistance in Pa.mm ${ }^{-3}$.s, volume in $\mathrm{mm}^{3}$.

\begin{tabular}{llll} 
Parameter: & & Day 7, TG & Day 10, TG \\
\hline Rin at start: & & 466 & 458 \\
\hline Vtot at start: & & 0.15 & 0.32 \\
\hline Radd: & R mean: & 711 & 565 \\
\hline & SE: & 103 & 48 \\
\hline & R low: & 474 & 464 \\
\hline & R high: & 1480 & 945 \\
\hline & Vtot: & 0.15 & 0.32 \\
\hline R+Length: & R mean: & 995 & \\
\hline & SE: & 144 & \\
\hline & Rlow: & 664 & \\
\hline Diameter scaling: & Rhigh: & 2072 & $1.007(<1 \%)$ \\
\hline & mean & $1.09(9 \%)$ & $1.053(5 \%)$ \\
\hline & high & $1.21(21 \%)$ & $1.198(20 \%)$ \\
\hline
\end{tabular}


Compared to the initial resistance ( $\mathrm{Rin}$ at start) adding vessels according to terminal growth increased resistance (Radd). For the arteriolar tree of day 7, resistance increased on average by $53 \%$ after terminal addition of 250 segments. For the arteriolar tree of day 10, resistance increased on average by $23 \%$ after addition of 750 terminal segments.

The range in resistance in the 14 modeling procedures after adding (Radd) to the day 7 tree (Rlow-Rhigh) was remarkably high, Rhigh was 3.1 times larger than Rlow. For comparison, for the experimentally monitored network resistance decreased only $2 \%$ in the period day 7-10. The smallest modeled resistance increase (Rlow) was $2 \%$ whereas the largest increase (Rhigh) was $200 \%$. The range in resistance after adding to the day 10 tree, was smaller compared to the day 7 tree, Rhigh was 2 times larger than Rlow. The smallest increase in resistance (Rlow) was 1.3\%, the largest (Rhigh) $106 \%$. Length scaling (factor 1.4) of the day 7 network increased resistance by $40 \%$. To annihilate the increase in resistance as caused by addition of segments and length scaling, on the average, an increase in diameter of $2.135^{1 / 4}=1.209$, about $21 \%$, is required. For the day 10 tree this is only $5 \%$. The range for the day 7 network was $9 \%-45 \%$ (low-high), for the day 10 netwurk $0.7^{\prime \prime}, 20^{\prime \prime}$, (low-high). From these results it may be concluded that addition of new vessels according to terminal growth, increased resistance.

The magnitude of resistance increase was dependent on the site of addition based on the large variation and the tree-size of the existing tree. On average, addition of new vessels combined with length scaling increase the resistance of the day 7 arteriolar tree 2.14 times, and only 1.23 times for the day 10 arteriolar tree. To obtain the actual reduction in resistance as observed in the in vivo CAM networks, diameter scaling by a factor of $2.179^{1 / 4}=1.215$, about $22 \%$, would be required for the day 7 tree. For the day 10 , after increasing the tree-size by about $50 \%$, diameter scaling by a factor of $(565 / 406)^{1 / 4}=1.086$, about $9 \%$, would be required to obtain the resistance reduction as observed in vivo in the period day 10-14. However, it has to be noted that we added only a small part of the actual amount added in vivo. Therefore, the required diameter scaling may even be larger in the case of addition of 1000 segments using terminal growth. 
Table $3 b$. Segmental Growth and Resistance. Presented are Rin, the initial resistance of the arteriolar tree at day 10, Vtot, the volume of the arteriolar tree, $\mathrm{R}$ add, the resistance after adding segments, $R$ length, the resistance after length scaling, and the required diameter scaling to obtain Rin. Presented are the mean and standard error of the calculated resistances and the range (Rlow - Rhigh). Resistance in Pa.mm $\mathrm{mm}^{-3}$.s volume in $\mathrm{mm}^{3}$.

\begin{tabular}{llll} 
Parameter: & & Day 7, SG & Day 10, SG \\
\hline Rin at start: & & 466 & 458 \\
\hline Vin at start: & & 0.15 & 0.32 \\
\hline Radd: & R mean: & 435 & 432 \\
\hline & SE: & 0.6 & 1.4 \\
\hline & R low: & 431 & 424 \\
\hline & R high: & 439 & 441 \\
\hline & Vtot: & 0.15 & 0.32 \\
\hline R+Length: & R mean: & 609 & \\
\hline & SE: & 0.84 & \\
\hline & R low: & 603 & \\
\hline Diameter scaling: & R high: & 615 & nowe \\
\hline & mean: & $1.067(7 \%)$ & none \\
\hline & high: & $1.069(7 \%)$ & none \\
\hline
\end{tabular}

Compared to the initial resistance (Rin at start) adding vessels according to segmental growth decreased resistance (Radd). For the arteriolar tree of day 7 , the resistance decreased on the average by $7 \%$ after addition of 250 segments. For the arteriolar tree of day 10, resistance decreased on the average by $6 \%$ after addition of 750 segments. For individual trees, resistance decrease varied between $6 \%$ and $8 \%$ for the day 7 arteriolar tree, and $4 \%$ to $7 \%$ for the day 10 arteriolar tree.

Although new segments were added at random according to segmental growth, variation in resistance of the individual trees is small compared to terminal growth. Length scaling of the day 7 arteriolar increased resistance by $40 \%$. To annihilate the increase in resistance as caused by a combination of addition of segments and length scaling, an increase in diameter of only $7 \%$ is required at day 7 and none at day 10 . From these results it may be concluded that addition of new vessels according to segmental growth decreased network resistance. Although new vessels were added at random according to segmental growth, the small variation for individual resistances suggests that the effect on resistance is rather independent of the site were segmental growth occurs. However, compared to the effect of diameter scaling on network resistance, addition of vessels according to segmental growth has only a minor influence on total network resistance. 
From day 7 to day 10 , the number of segments increased from 543 to 1630 whereas resistance of the vascular network decreased $2 \%$. In our model calculations TG of 250 segments combined with a length growth of 1.5 resulted in a more than two-fold increase in resistance of the modeled trees. If this process were to be repeated with addition of more segments, a further increase in resistance is to be expected. To obtain a reduction of $2 \%$ in resistance with random $\mathrm{TG}$, a diameter scaling would be required of at least the product of the scaling to annihilate the increase in resistance caused by growth (1.526) and length scaling (1.4), and that required to reduce the resistance by $2 \%$ of its original value. Hence, a diameter scaling of $(1.526 \times 1.4 \times 1.02)^{1 / 4}=1.215$ would be required (for the day 7 network). In case of segmental addition, on average, additional diameter scaling by a factor of $1.074(7 \%)$ would be required. This may be less for adding more than 1000 segments according to segmental growth. During the period of day 10 to 14 , the number of segments increased from 1630 to 2757 and, resistance of the $\mathrm{C}+\mathrm{M}$ network is reduced by $12 \%$. In case of $\mathrm{TG}$, scaling to explain the change becomes a factor of $1.086(9 \%)$. In cases of a growth process dominated by random segmental growth, diameter scaling of 1.016 is required, indicating a generalized increase in diameter of about $2 \%$.

Figure 9 shows the relationship between diameter and the absolute frequency of occurrence of a certain diameter during development on a double logarithmic scale. For diameters ranging from $10 \mu$ to $80 \mu \mathrm{m}$, diameter scaling ranges from 1.6 to 1.1 . Vessels with diameters between 80 and $110 \mu \mathrm{m}$ did not seem to alter diameter whereas the vessels with diameters ranging from $100 \mu$ to $200 \mu \mathrm{m}$ increased diameter during development. Interestingly enough, large vessel scaling was more prominent during the period day 10-14 compared to the period day 7-10. The change in smaller vessel diameter (below $80 \mu \mathrm{m}$ ) is on the average about $50 \%$.

This leaves the option open that at least a considerable part of the tree development between day 7 and 10 has occurred through a terminal growth process. Combining the observed in vivo diameter scaling with segmental growth in the period day $7-10$, may result in a larger resistance reduction than observed in vivo. This suggests that during the period day 7-10, segmental growth may have occurred simulateneous with terminal growth. In the period of day 10-14, diameter increase in the intermediate vessels, $30-80 \mu \mathrm{m}$, is strongly reduced, but the large vessels increased their diameter by about $40 \%$. However, the observed in vivo diameter scaling is sufficient to explain the $12 \%$ resistance decrease during the period day 10-14 with either segmental or terminal growth. Our topological analysis revealed that during the period day 7-10, adding according to segmental growth may have been the dominating grow th process. Since a diameter scaling of $10-60 \%$ was observed during the period day $7-10$ (fig. 9), a combination with adding new vessels according to segmental growth and terminal growth may explain the observed in vivo decrease in resistance. 


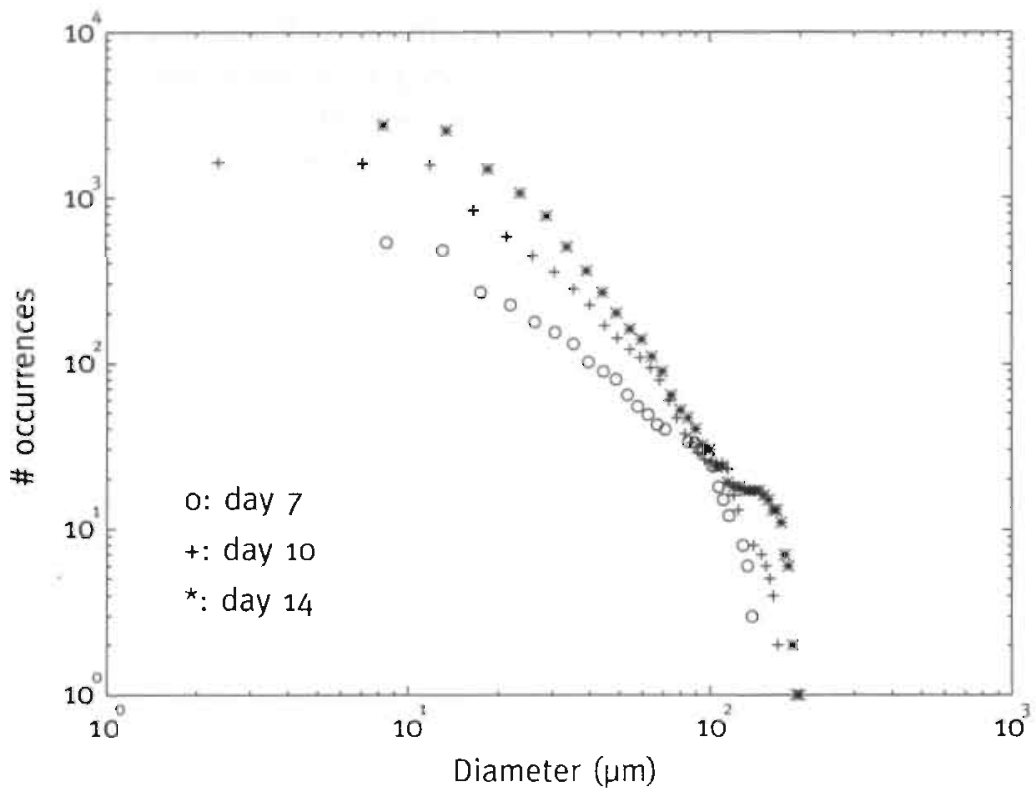

Fig 9. Relationship between diameter and the absolute frequency of occurrence of a certain diameter during development on a double logarithmic scale.

Topological analysis of the CAM network during the period day 10-14, revealed that adding new vessels according to terminal growth may have been the dominant grow th process. Given the magnitude of resistance increase after adding vessels to the terminal part of the network, an increase in vessel diameter of at least $9 \%$ would be required to obtain the actual $12 \%$ resistance decrease as observed in vivo. The experimental data on changes in diameter (fig. 9) exhibit such an increase in diameter. Thus a combination of terminal growth and a general diameter scaling of about $9^{n}{ }_{1}$ may explain the nature of the resistance decrease during the latter period. Although segmental growth may also explain the in vivo resistance decrease, the very small increase in MCO concomitant with addition of about 1000 segments during this period, suggests that segmental growth may only have occured to a minor extent, hence, only slightly contributed to the resistance decrease.

The differences in observed diameter scaling during in vivo development may be explained from two processes. First, during the period day 7-10, the CAM rapidly expands, whereas after day 10 the CAM almost ceases to grow. Expansion of the CAM may result in an increase of tensile forces exerted by the extracellular matrix on the vessels in the CAM. This may cause them to grow in length but also in diameter. During the period day 10-14 these tensile forces may be less pronounced, which may explain that length and diameter of the smaller vessels did not change. 
However, diameter regulation may also depend on the ability to sense shear stress. This may involve the local release of vasodilatory substances like nitric oxide but also the presence of a signal transduction pathway. It is postulated that later during development, the ability to synthesize vasodilatory substance and sense vasodilatory substance is enhanced. Assuming that this process predominantly takes place in the larger vessels, this may explain the diameter scaling for the larger vessels $(>100 \mu \mathrm{m})$ during development.

In conclusion: adding new vessels according to segmental growth decreases network resistance whereas adding according to terminal growth increases network resistance. The magnitude of resistance change depends on the tree size and the site where new vessels are coupled to the existing tree. Combining topological analysis and the in vivo observed diameter changes, a combination of segmental and terminal growth may explain the in vivo resistance decrease during the period day 7-10, whereas terminal growth may explain the in vivo resistance decrease during the period day 10-14.

\subsubsection{Estimation of vascular resistance using the S-model}

From the previous section it was concluded that differences in diameter scaling along the arteriolar tree might be an important determinant of total vascular resistance during development. That model however, did not include differences in diameter scaling based on the position of in the vascular tree. An alternative modeling procedure, as has been proposed by VanBavel ${ }^{7}$, might overcome this shortcoming since this model includes the site in the vascular tree in the assignment of segment diameter. However, the results strongly depended on the topological branching pattern. Realistic results were only obtained with rather symmetrical branching patterns. Since the CAM arteriolar network is rather asymmetric (asymmetry ranging from $0.67-0.60$ ), the VanBavel model was not suitable for explaining the observed changes in resistance of the developing CAM vasculature. The theoretical considerations with regard to the use and limitations of this model are beyond the scope of this chapter but can be found in the appendix.

\subsubsection{Analysis of arteriolar subtrees, in vivo data}

7.3.10.1 Number of terminal vessels during development

Figure 10 shows the relationship between the number of terminal segments in the analyzed subtrees as a function of the input diameter of the subtrees, plotted on a semi-logarithmic scale, at day 7,10 , and 14 , respectively. The correlation coefficient (r) reflects first order linear regression. At day 7 and 10, the number of terminal segments increased almost linearly with an increase in input diameter. At day 14 it was noted that for input diameters larger than $100 \mu \mathrm{m}$, change in diameter was accompanied by a smaller increase in number of terminal segments compared to day 7 and 10 . For a given input diameter, the number of terminal vessels is smaller at day 7 compared to day 10 and 14. For identical subtrees, concomitant increase in input diameter and number of terminal vessels was observed during development (data not shown in figure). 

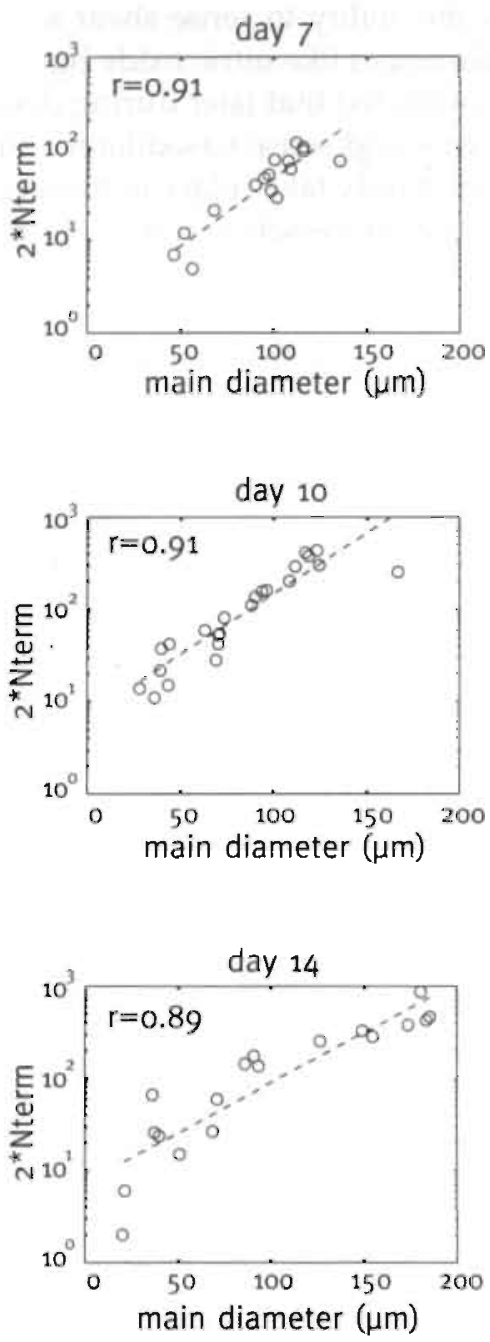

Fig. 19. Number of terminal vessels in a subtree as function of the input diameter of the subtree at subsequent days during development.
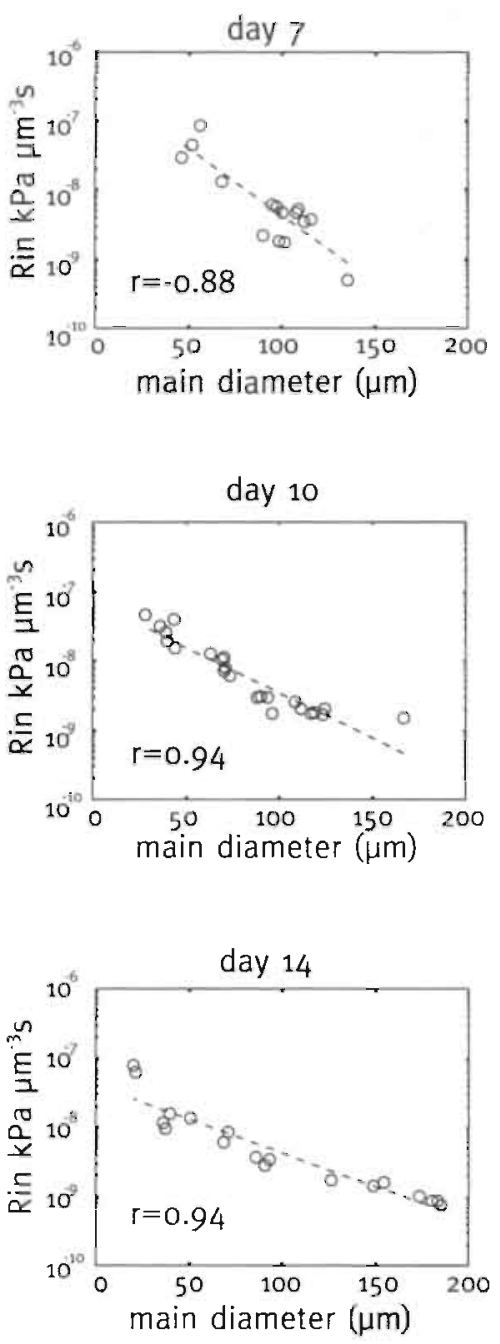

Fig. 11. Calculated resistance to flow in a subtree as function of the input diameter of the subtree at the subsequent days during development. 

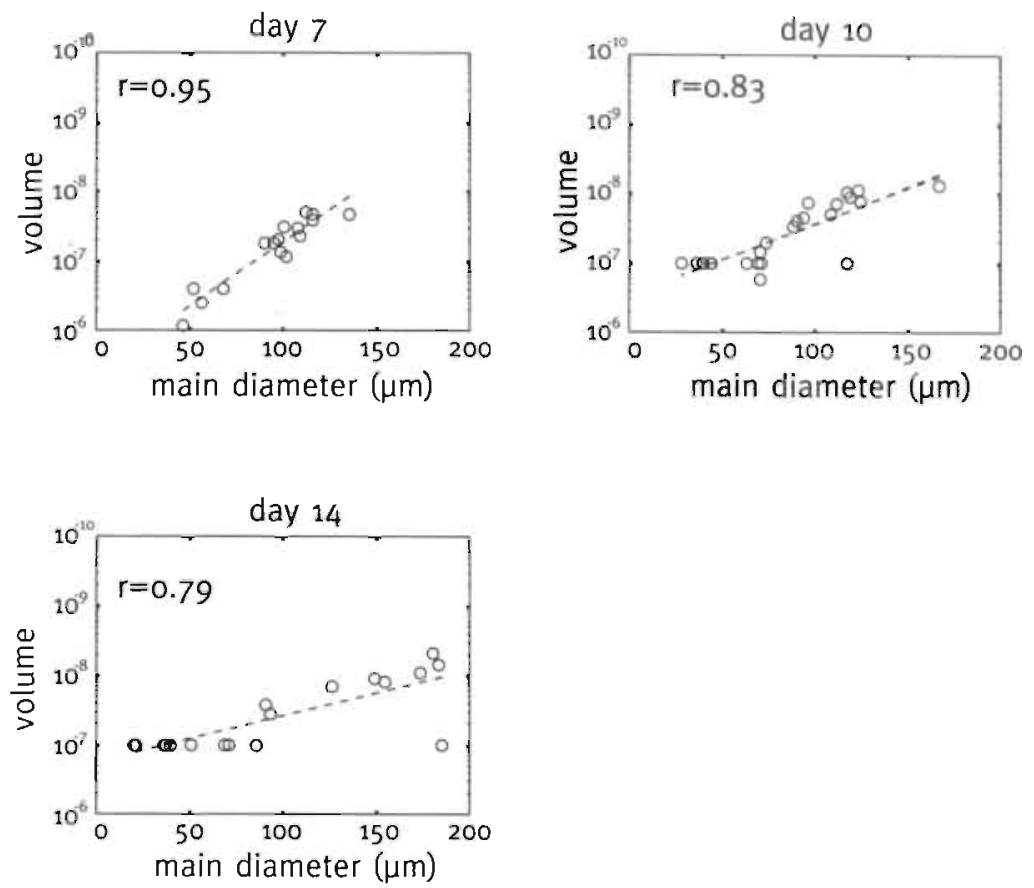

Fig 12. Volume of a subtree as function of the input diameter of the subtree at the subsequent days during development. Volume in $\mu \mathrm{m}^{3}$.

\section{3-10.2 Resistance of sub-trees during development}

Figure 11 shows the input resistance of subtrees as a function of input diameter on a semi-logarithmic scale. At all instants, resistance decreased with an increase in input diameters. For a given input diameter in the range of $20-100 \mu \mathrm{m}$, resistance tended to decrease with time. For larger input diameters, this effect was less clear. For individual subtrees, resistance changed inversely to alterations in input diameter (data not shown in figure).

\subsubsection{Volume of sub-trees during development}

Figure 12 shows the input diameter of subtrees as a function of volume of the tree for individual sub-tret's plotted on a semi-logarithmic scale. The volume of the sub-trees increased with increasing input diameters, both at one instant as well as during development. Analvsis revealed that during development, for a given input diameter, volume increased. 

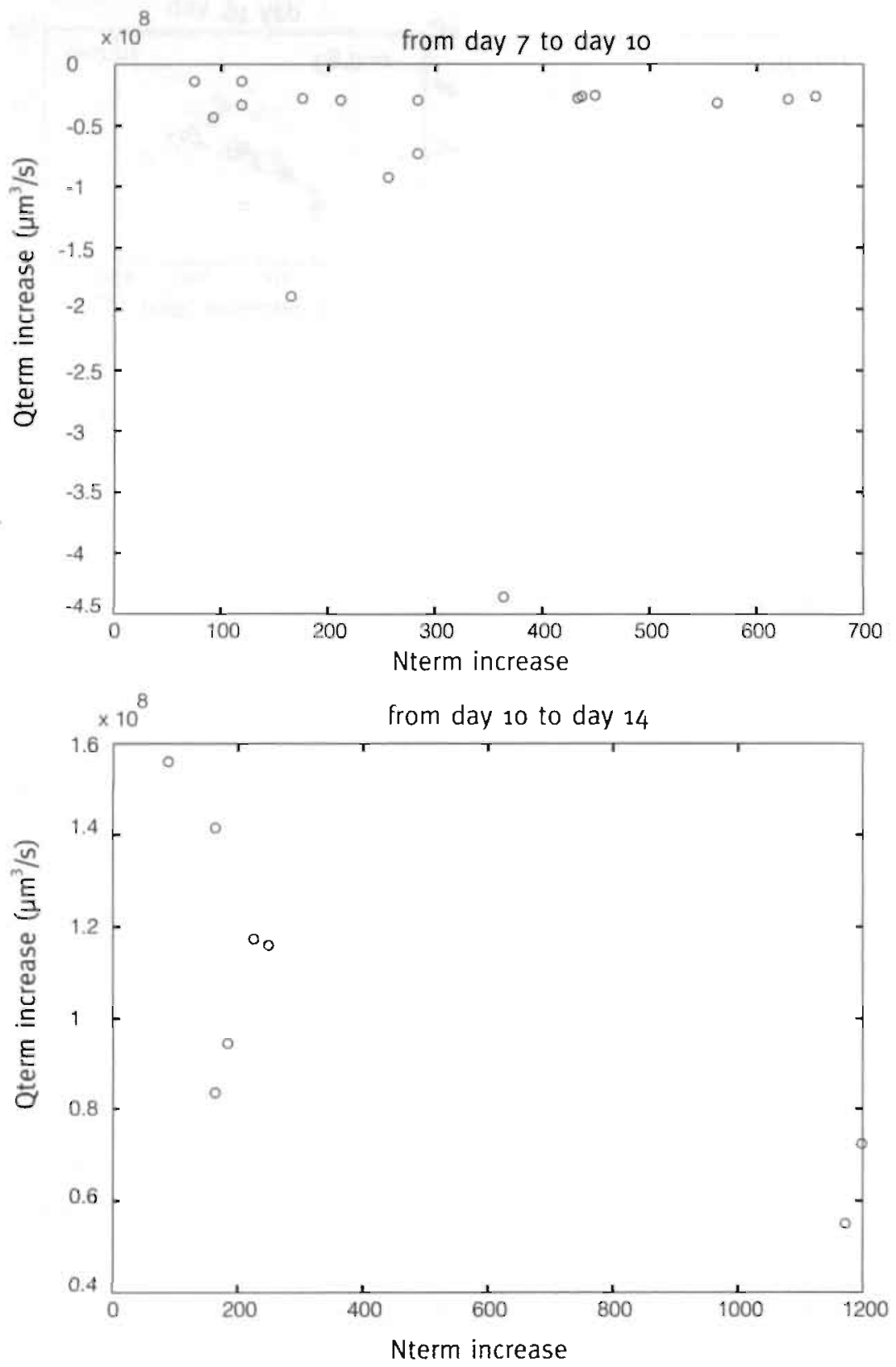

Fig. 13. Changes in calculated flow through the terminal segments of subtrees during the period day 7-10 (top) and day 10-14 (bottom) as a function of the change in number of terminal segments of the subtree. 


\subsubsection{Calculated flow through terminal segments}

Based on measured diameters and lengths of vessel segments in the sub-trees and assuming Poiseuille's law, resistances $(R)$ of subtrees could be calculated. Flow through the sub-trees depends on driving pressure ( $\left.{ }^{\mathbf{A}} \mathrm{P}\right)$ and resistance $(\mathrm{R})$. Assuming; arteriolar pressures $(\mathrm{P})$ as have been measured by other investigators, and a homoge-neously distributed pressure at the capillary level, flow $(Q)$ through the subtrees could be calculated according to $Q=\triangle P / R$ at day 7,10 , and 14 , respectively. Since the number of terminal segments (Nterm) in a subtree was known, the average flow through the terminal segments could be calculated according to $Q / N$ term. Figure 13 shows the: relationship between changes in mean flow through the terminal segments of the subtrees in the period day 7-10 and 10-14 as a function of the change in number of terminal segments in the subtree.

In the period day $7-10$ (fig. 13, top), the mean flow through the terminal segments was independent of the number of added segments. Hence, the increase in number of terminal segments was larger than the increase in input flow. Thus, on average, flow through the terminal segments decreased in the period day 7-10. In the period day 1014 (fig. 13, bottom), the increase in number of terminal segments was attended by an increase in mean flow through the terminal segments. Hence, increase in input flow exceeded the increase in number of terminal vessels. Thus, on average, flow through the terminal segments increased in the period day 10-14.

The experimentally observed pressures in the CAM artery may differ from the actual pressure in the sub-trees. Since a difference in pressure may account for the observed differences in flow, we also calculated flow assuming the driving pressure to be 1 $\mathrm{mmHg}, 2 \mathrm{mmHg}$, and $3 \mathrm{mmHg}$, at day 7, 10 and 14, respectively. Based on these pressures we found that the direction in change in average flow through the terminal segments, a decrease in the period 7-10 and an increase in the period day 10-14, did not. change. Hence, the changes in flow may not be attributed to the changes in pressure but more likely due to changes in resistance. 


\subsection{General Discussion}

\section{Comparing in vivo arteriolar development and topological growth models}

The experimentally obtained centrifugal order distributions of the developing CA.M arteriolar network exhibited peaks at about generation 10 and 20. Using a computer model, the S-model, the existence of these peaks could only be explained by starting the topological growth process with a dominance of segmental growth and a transition during the growth process towards terminal growth. Hence, a time-dependent variation in the contribution of segmental and terminal growth is required. This indicates that during early development of the $(1 \mathrm{M}$, new vessels were added along existing vascular segments, whereas during later development, vessels were added predominantly at the terminal part of the arteriolar network.

A time-dependent relative contribution of terminal and segmental growth is novel for analyzing the topology of a vascular bed. In previous studies on vascular architecture of the rat mesentery under normal conditions in spontaneous hy pertension and after stimulation with growth factors, the experimentally obtained centrifugal order distributions were fitted with distributions obtained from summation of the curves for pure terminal and pure segmental growth ${ }^{38,39}$. The summated curve displayed only one peak and was skewed to the right. Using this approach, no differences were observed between the experimental groups and the controls. Careful inspection of the experimentally obtained centrifugal order distributions (obtained by Linke ${ }^{34}$ ) revealed two or more distinct peaks in all cases. Analysis of these distributions with the S-model may elucidate the mechanism causing the observed distributions.

On average, topological growth dominated by segmental growth generates trees that are less symmetric than trees modeled using terminal growth. Hence, the mean centrifugal order (MCO) of trees modeled using segmental growth is, on average, larger than that of terminal growth ${ }^{39}$. The increase in MCO from 15 to 20 of the in vivo tree in the period day 7-10 might therefore be explained by a growth process that is dominated by segmental growth. The relatively small increase in MCO from 20 to 21 in the period day 10-14 of the experimental data, concomitant with an almost twofold increase in tree size, can only be explained assuming that during this period extensive terminal growth had taken place. These implications are confirmed by the S-model.

We postulate that the topological growth process does not occur at random but follows a strategy, which may be determined by the tissue through the (local) release of growth factors, or by the perfusion status of the vasculature, i.e., pressure and flow. Since the site where new vessels are added to the existing arteriolar network may vary with time, changes in the contribution of or in the ability to respond to tissue factors or perfusion status may vary during development. In the CAM, early vascular growth is characterized by scaling of existing vessels and adding new vessels. The subsequent phase lacks tissue growth and scaling and the remaining tissue is filled with vessels by terminal growth. This postulate is not in agreement with the hypothesis of Pries ${ }^{2639}$. 
He suggested that in the rat mesentery addition of new vessels using terminal growth dominates the early phase of development, whereas segmental growth may dominate later development. Although direct evidence was not presented, he suggested that during early development, terminal vessel growth occurs more or less at random just to fill in the available space in the tissue. When tissue expansion ceases at a later stage and the tissue becomes filled with vessels, less space is available for new vessels, and some kind of coordination is needed to avoid interference between vessels. The network characterisics determined that filling of the remaining tissue was achieved by segmental growth, probably because the spaces to fill were smaller.

A second approach used to analyze changes in arteriolar network structure during development employed Strahler's ordering, using the termination probability coefficient $\mathrm{q}^{57}$. However, $\mathrm{q}$ varies only little with time. Simulations using the S-model showed that, for a given value of $S$, thus with a constant topological growth process, variation about the mean $q$ value for Strahler order 2 and 3 vessels was large. The change in $q$ value, when varying the topological growth process between terminal growth $(S=0)$ and segmental growth $(S=10)$ was only about $10 \%$ for Stahler order 2 and $15 \%$ for Strahler order 3 vessels. This change is small compared to the variation about the mean given a constant topological growth governing force. Thus, changes in $q$ might not seem sensitive enough to detect differences in the topological growth process. Hence, interpreting changes in termination coefficient $q$ might not seem adequate in analyzing growth of the vasculature. Therefore, to explain changes in morphology of the experimentally monitored arteriole, Strahler analysis was not used.

\section{Influence of branching pattern on network resistance}

The calculated resistance to flow of the experimental arteriolar network, changed little in the period day 7-14. During the period day $7-10$ the decrease was $2 \%$, and during the period day $10-14$ almost $12 \%$. This change in resistance may result from changes in vessel diameter and vessel length. It may, however, also be influenced by vascular growth, i.e., the addition of new vessels to the arteriolar tree. The effect of vascular growth on network resistance depends on the site were vessels are added to the existing tree, the number of vessels added, and the size of the existing tree. Adding segments parallel with an existing segment, hence, segmental growth, decreases network resistance. Adding two segments at terminal segments, hence, terminal growth, increases network resistance.

During development of the CAM arteriolar network, vessel diameters generally increased. The mere increase in diameter will lower network resistance. Since the CAM tissue also expands during development $t^{45}$, the length of individual vessels may increase simultaneously. This will increase resistance.

To investigate the effects of the mentioned parameters on network resistance, a computer model was used. Expanding the day 7 in vivo arteriolar tree by about $50 \%$ through addition of 250 segments using terminal growth, resulted in an increase in network resistance of on average $53 \%$. The required length scaling during the same period resulted in an additional $40 \%$ increase in resistance. 
Hence, after addition of vessels and subsequent length scaling, network resistance was, on average, increased by $110 \%$. Increasing the day 10 in vivo arteriolar tree by about $50 \%$ through addition of 750 segments according to terminal growth, resulted in an increase in network resistance of on average $23 \%$. In this stage no scaling occurs. From these results, it may be concluded that adding new vessels using terminal growth results in increased network resistance, but the magnitude of resistance increase may depend on tree-size and architecture.

Increasing the day 7 in vivo arteriolar tree by about $50 \%$ through addition of $250 \mathrm{seg}$ ments using segmental growth, resulted in a decrease in network resistance of on average $7 \%$. Length scaling resulted in a $40 \%$ increase of network resistance. Hence, after addition of vessels and subsequent length scaling, resistance was increased by $33 \%$. Increasing the day 10 in vivo arteriolar tree by about $50 \%$ through addition of 750 segments according to terminal growth, resulted in a decrease in network resistance of on average $6 \%$. From these results, it may be concluded that adding new vessels using segmental growth decreases network resistance, but again the magnitude of resistance change may depend on tree-size and architecture. The results furthermore show that although adding new vessels using segmental growth decreases network resistance, the contribution is rather small.

Given the observations on in vivo diameter scaling during the period day 7-10, both segmental and terminal growth combined with length scaling may explain the in vivo observed CAM network resistance decrease. Based on the topological analysis during the same period, however, segmental growth may have been the dominating growth process. Terminal growth may have occured simultaneously, but to a lesser extent. Assuming only segmental growth and the in vivo observed diameter scaling, estimates of resistance reduction bccame even larger than actually occured in vivo. Therefore, a combination of segmental growth, which lowers resistance, and terminal growth, which increases resistance, combined with the in vivo observed diameter scaling may explain the resistance decrease of $2 \%$ for the in vivo network.

For the period day 10-14, both segmental and terminal growth combined with the in vivo observed diameter scaling may explain the in vivo observed CAM network resistance decrease. Based on the changes in MCO, however, extensive terminal growth must have taken place during the period day 10-14. Combining both results, it may be postulated that during the period day 10-14, the growth process was dominated by torminal growth combined with a general increase in vessel diameter of about $9 \%$.

The effects of growth on network resistance were investigated using a computer simulation model. However, it may be that the modeling procedure is not completely realistic. Vessel segments were added to vessel segments of the existing tree using terminal or segmental growth. These segments were selected at random. However, in vivo there may be a strategy in the addition of vessels. Theoretically, based on at random selection, a subtree of the exisiting tree may develop that, using either scgmental growth or terminal growth or a combination, is completely asymmetric. 
If this subtree has a resistance that is several orders of magnitude smaller compared to the tree it is parallel coupled with, and develops at the promixal part of the network, it obviously contributes more to network resistance than when it is coupled to the terminal part of the network. Hence, the resistance decrease predicted by the model would be too large. To avoid this problem, we only increased the tree-size by about 1 . generation ( $50 \%$ of the total amount of vessels). To investigate which strategy is used in vivo, more observations of the developing vasculature, are needed within smaller timeframes.

In order to allow calculations of resistance to flow in the in vivo tree, we assumed that capillary pressures were homogeneously distributed ${ }^{57}$. Although this simplified approach is frequently used in network analysis, it might prove to be wrong for the CAM. Measurement of local capillary pressure and flow might improve the understanding of the relation between network architecture and resistance. However, such an approach is seriously limited by experimental difficulties to quantify capillary pressures in the fragile tubes of the CAM capillary plexus.

\section{Flow through the CAM arteriolar network}

Flow through an arteriolar network may be estimated according to $Q=\Delta P / R$. Resistances of the in viro observed CAM arteriolar tree were calculated according to Poiseuille's law. Assuming that perfusion pressure did not alter, flow through the network would have to increase by $2 \%$ in the period of day $7-10$, and by $13 \%$ from day $10-$ 14 due to the resistance reduction. Simultaneously, the number of segments increased. Therefore, under such conditions average flow through the terminal segments would be reduced by $65 \%$ during day $7-10$ and another $40 \%$ during day $10-14$. Assuming that perfusion pressure increases ${ }^{33}$ from $6 \mathrm{mmHg}$ on day 7 , to $10 \mathrm{mmHg}$ on day 10 , and 16 $\mathrm{mmHg}$ on day 14 , average flow through the terminal segments is reduced by $40 \%$ during the period day $7-10$, and another $9 \%$ during day $10-14$. Subsequently, we analyzed several subtrees of the in vivo arteriolar network. Average flow through terminal segments slightly decreased in the period day $7-10$, and increased during day 10-14. The former results from a larger relative increase in number of terminal segments than in perfusion pressure. The latter by the fact that the relative increase in number of terminal vessels was reduced during this period. Although the data of the complete tree and the subtrees are quantitatively not the same, in both cases average flow through the terminal vessels is increased in the later stage as compared to the early stage.

The origin of the larger calculated resistance reduction during the period day 10-14 compared to the period day 7-10 remains unclear. An attractive hypothesis is that during the period day 10-14, vessels are more capable sensing shear stress. A more pronounced flow induced vasodilation may decrease resistance and, hence, reinforce flow delivery to the network. It may however also be speculated that the lower resistance is the result of an increased flow delivery to the CAM vasculature during development. The delivery of flow to the arteriolar network depends on the cardiac output of the chick embryo. 
Cardiac output increases during development ${ }^{15}$ and, subsequently, the delivery of flow to the CAM arteriole may also increase. This may facilitate a reduction in network resistance through shear stress adaptation. The question whether the observed decrease in resistance is the result of an increased delivery of flow to the network, or whether a decrease in resistance precedes an enhanced delivery to the network, may be solved by simultaneous recordings of cardiac output and local flow in the CAM during development. Whether the differences in resistance are caused by differences in the position of new arteriolar vessel formation, differences in diameter scaling, or induced by changes in local hemodynamics, remains to be solved by performing additional studies and observing the developing vasculature at shorter intervals and examining heterogeneity in diameter scaling along the vascular tree and measuring local flow employing the non-invasive capi-flow system.

\section{Growth of the Vasculature, facts and speculations}

Growth of a vascular tree may be governed by tissue factors or the perfusion status of the vasculature, i.e., pressure and flow. A computer modeling study has shown that adaptation to circumferential wall stress may explain changes, both growth and regression, of the vasculature.2. It was assumed that changes in network input pressure are followed by an autoregulatory myogenic response. Assuming autoregulation, an increase in input pressure resulted in reductions of lumen diameter which eventually might explain regression of arterioles. A major influence of circumferential wall stress adaptation during development would counteract the development of extensive networks. This view is not supported by our calculations. If we assume that an increase in central pressure, as occurs during development of the chick embryo, is transmitted into the CAM arterioles, circumferential wall stress adaptation would, according to the simulation study, predict regression of terminal arterioles. However, the number of terminal vessels in the CAM arteriolar network increased during development.

This discrepancy between model predictions on adaptations and in vivo development may be due to lack of a myogenic response. It is generally believed that the CAM rasculature does not exhibit autoregulation and, the vasculature itself is maximally dilat$\mathrm{ed}^{14.45}$. Furthermore, isolated CAM arterioles mounted in a Mulvany myograph did not respond to addition of vaso-active substances (vasopressin, angiotensin-II, adenosine). Only direct depolarisation with a high $\mathrm{K}^{*}$ solution stimulated arteriolar contraction (F. leNoble, unpublished observations). If we assume that autoregulation does not occur in the CAM, intraluminal pressures in the CAM arterioles and capillaries might increase during development. Additional computer simulation studies suggest that an increased intraluminal pressure stimulates the upgrading of capillaries into arterioles ${ }^{43}$. Investing capillaries with circular layers of vascular smooth muscle cells was regarded as a response to compensate for an increased intra-luminal pressure and subsequently optimize circumferential wall stress. Without autoregulation, circumferential wall stress adaptation might account for the formation of new arterioles through upgrading of capillaries. 
Adaptation to shear stress has also been shown to influence arteriolar development ${ }^{2 s}$. In general, vessels preferential for flow increase their diameter, either acutely through vasodilation or with time through radial growth. Vessels perpendicular to the preferential flow channels were predicted to regress. Based on the anticipated pressure increase in the CAM during development and the calculated resistance, total flow through the CAM arteriole was predicted to increase during development. Assuming that the CAM vascular bed is maximally dilated, increments in flow may increase local shear stress and, therefore, stimulate radial outgrowth of arterioles. On the other hand, the CAM expands during development. The vasculature in the CAM migth theretore sense tensile forces of the developing tissue. This might, independent of the flow input, cause changes in vessel dimensions, both elongation of vessels and increases in diameter. Since changes in vessel caliber affect resistance, expansion of the CAM might affect flow input to the CAM vasculature. The observed increase in flow during development could result of radial growth of the arterioles in the CAM. However, if the changes in vessel caliber match the increased flow, local shear stress might not change and could not provide a stimulus for radial outgrowth of arterioles.

Calculations showed that flow through the in vivo arteriolar subtrees increased with time, but at the same time the number of terminal vessels increased more rapidly. Consequently, assuming absence of autoregulation, average shear stress values will decrease in the terminal vessels independent of their diameter. If the growth process is dominated by shear stress adaptation, this would result in diameter reduction and counteract the diameter scaling as observed in vivo. Hence, based on the applied assumptions, shear stress adaptation seems no to be involved in the early stage of development. During the period of day 10-14, however, average flows through the terminal arterioles of the subtrees were increased. This may imply that the resulting shear stress increase acts as a growth stimulus during that period. One should realize, however, that many assumptions underly this reasoning and it is therefore rather speculative.

Finally, metabolic homeostasis might play a role in the development of the CAM vasculature'. Cells within the CAM need to be provided with oxygen and nutrients. On the other hand, the CAM as funtional lung tissue, has to provide the developing chick embryo with sufficient amounts of oxygen. Relative hypoxia of the developing chick embryo or the CAM tissue itself may also trigger the release of angiogenic substances. These angiogenic substances, for example adenosine, may influence growth of the CAM vasculature. It may be postulated that, during the period day 7-14, adaptation to metabolic demand, of either the local tissue or the embryo proper, accounts for vascular development. 
Although adaptation to circumferential wall stress, shear stress and metabolic demand each give a plausible explanation for vascular growth, it does not seem to provide a clear answer to the question why segmental growth dominated the period day 7-10 and terminal growth, the period day 10-14. Understanding this difference might be of critical importance with regard to the interpretation of changes in vascular architecture during pathological conditions like essential hypertension. Future studies employing local flow and pressure measurements should therefore aim at elucidating the mechanisms responsible for local outgrowth of the vasculature.

\section{Implications of this study}

Based on the observation that primary forms of hypertension are accompanied by a reduction in the number of vessels available to carry flow, rarefaction, it has been suggested that due to attenuated growth of vessels, peripheral resistance becomes elevated. This led to the suggestion that inducing growth of vessels may result in a reduction of peripheral resistance. However, we have shown that the effect of growth on network resistance depends on the site where new vessels are added and the size of tree they are added to. Pharmacological interventions aiming at stimulating growth of the vasculature in order to get a decrease in network resistance, should specifically result information of parallel vessels, hence, segmental growth.

A second implication may be found in the way to analyze changes in microvascular architecture in order to allow statements about changes in resistance. Experimental data show a 1.7 fold increase in CAM vascular density during the period day 7-10 and a 1.5 fold increase during the period day $10-14^{54}$. For the experimental network, we found a $2 \%$ decrease in the calculated resistance to flow during the first period and a $12 \%$ decrease during the later period. Together with the results of growth modeling, this shows that changes in vascular density and resistance to flow are independent. This might have important implications for interpretation of microvascular alterations in pathological conditions ${ }^{55}$. A frequently used parameter to quantify changes in microvascular architecture during pathological conditions like hypertension, is microvascular density ${ }^{4755}$. The observed correlation between decreased microvascular density in hypertension, and increased peripheral resistance has led to the idea that density and resistance are linked ${ }^{53}$. However, the present study provides evidence that this does not necessarily have to be the case.

The parameter microvascular density only estimates total vessel length and does not take into account total number of vessels or how vessels are interconnected, nor vessel diameter. Theoretically, it would even be possible to observe a pronounced reduction in the number of vessel segments in a tree generated according to segmental growth and still calculate a resistance lower than a corresponding tree modeled according to terminal growth. 
The fact that computer modeling studies have shown that rarefaction may contribute to an increase in network resistance, may not be interpreted as an argument that an increase in number of vessels, hence, outgrowth decreases resistance ${ }^{25}$. Because arterioles are coupled parallel with other arterioles, regression of a single vessel changing parallel coupling into serial coupling, hence, an increase in resistance. However, the modeling procedure employed to examine the consequences of rarefaction was based on eliminating only one segment in a parallel coupled circuit ${ }^{25}$. If, however, a strategy was choosen in which regression of a complete parallel coupled circuit would be possible, it may also predict a reduction in network resistance. Thus, although computer models are useful with regard to network analysis, care should be taken that the outcome is not dependent on the strategy put into the model. Furthermore, rarefaction should be more carefully defined, and include statements about site of regression, number of vessels involved, and the resulting interconnections with other vessels in the network.

In order to allow more adequate statements about changes in resistance with regard to alterations in microvascular density, an other parameter that gives insight in network branching pattern should be included. The parameter $S$ in the S-model, describing the strategy of development might prove to be a more suitable candidate. Presentation of diameter data in a retrograde cumulative way on log.log scale provides a simple means to estimate diameter growth. 


\subsection{Summary and Conclusions}

1. The resistance of the developing chick embryo chorio-allantoic membrane arteriolar network is rather stable in time. Calculations of resistance to flow of the experimentally monitored chorio-allantoic membrane arteriole revealed a $2 \%$ decrease during the period day 7-10 and a $12 \%$ decrease during the period day $10-14$.

2. Centrifugal order distributions of the experimental network could only be explained by assuming that the topological growth process starts with segmental growth and with time shifts towards terminal growth. Hence, during development of the arteriole, contribution of the topological growth procesess was time dependent.

3. Adding new vessels using segmental growth decreases network resistance, adding new vessels using terminal growth increases network resistance. The magnitude of resistance change depends on tree size and architecture.

4. The $2 \%$ resistance decrease during the period day 7-10 could be explained assuming that 1) the growth process was dominated by segmental growth and 2) a general increase in vessel diameter as observed in vivo during the same period. The $12 \%$ resistance decrease during the period day 10-14 could be explained assuming that 1 ) the growth process was dominated by terminal growth and 2) a general increase in vessel diameter as observed in vivo during the same period.

5. It is not accurate to state that rarefaction results in an increase in resistance without specification of the site in the vascular tree, the number of vessels involved, and the effect on vascular arrangement. Growth of vessels may reduce resistance only if new vessels are coupled along existing segments, hence, segmental growth.

6. Analysis aiming at elucidating the contribution of arteriolar network architecture in network resistance and flow distribution should include parameters that can give insight in the arrangement or the interconnection of vessel segments. A combination of the topological generation analysis and the parameter $\mathrm{S}$ of the S-model may prove to be suitable candidates.

7. During development, adaptation to circumferential wall stress may have contributed to outgrowth of the experimental network by upgrading of capillaries into terminal arterioles, under the assumption that an autoregulatory myogenic response was absent. Shear stress adaptation more likely influenced outgrowth of arterioles during the period day 10-14 than during the period day 7-10. Finally, adaptation to the metabolic demand may have influenced vascular development during the period day 7-14, either locally, by cells in the CAM tissue generating angiogenic stimuli, or generally, through release of angiogenic substances by the developing chick-embryo. 


\section{Appendix}

1) Relation diameter and length (Figure 1)

Figure 1 (Appendix, top left) shows the relation between the length of a vessel segment as a function of its diameter on a double logarithmic scale. The variability observed is large; length of vessel can vary almost 100-fold for a given diameter. Data analysis revealed a weak correlation between lenght and diameter. Analysis furthermore indicated that in the diameter range $10-200 \mu \mathrm{m}$, for equal diameters, segments will become progressively smaller towards day 14 . The in vivo data are presented seperately for day 7 (fig. 1a), day 10 (fig. 1b) and day 14 (fig. 1c) respectively.

\section{2) Relation mother diameter and larger daughter diameter (Figure 2)}

Figure 2 (Appendix, top right) shows the relation between mother diameter and larger daughter diameter on a logarithmic scale at day 7,10, and 14. Analysis showed a high correlation, with the regression line almost equaling $\log$ (Dlarg) $=1^{*} \log$ (Dmoth) at all instants. This means that after branching, the diameter of the larger daughter is almost comparable to the diameter of the mother segment. The in vivo data are presented seperately for day 7 (fig. 2a), day 10 (fig. 2 b) and day 14 (fig. 2c) respectively.

\section{3) Relation mother diameter, smaller daughter diameter (Figure 3)}

Figure 3 (Appendix, middle left) shows the relationship between mother diameter and smaller daughter diameter plotted on a logarithmic scale. It is obvious that for a given Dmother the variation of Dsmaller is much larger compared to Dlarger. This is manifested in the smaller correlation coefficients. For a given Dmother, Dsmaller can vary almost 2-6 fold. The in vivo data are presented seperately for day 7 (fig. 3a), day 10 (fig. 3b) and day 14 (fig. 3c) respectively.

4) Relation between the diameters of the daughter segments (Figure 4)

Figure 4 (Appendix, middle right) shows the relationship between the diameters of the daughter segments normalized for the diameter of the mother segments of that particular branch-node. The line $\mathrm{y}=\mathrm{x}$ is the line of identity and reflects the upper limit for the data points. The in vivo data are presented seperately for day 7 (fig. 4a), day 10 (fig. 4b) and day 14 (fig. $4 \mathrm{c}$ ) respectively.

\section{5) Relation between mother diameter and area growth (Figure 5)}

Figure 5 (Appendix, bottom left) shows the area growth as a function of the mother diameter plotted on a semi-log scale. Area growth is being defined as $\left(\mathrm{Ds}^{2}+\mathrm{Dl}^{2}\right) / \mathrm{Do}^{2}$ and is a parameter quantifying luminal cross-sectional area expansion. For branchnodes in which the area growth was smaller than 1, available cross-sectional area decreased, for area grow th larger than 1, cross-sectional area increased. At all instants, analysis revealed an inverse relation between diameter and growth, with low correlations, indicating that only a limited part of the variation in area growth can be accounted for on dependency of the mother diameter. The in vivo data are presented seperately for day 7 (fig. 5a), day 10 (fig. 5b) and day 14 (fig. 5c) respectively. 
Appendix: Assigning diameters and lengths to trees modeled with the S-model based on the in vivo observed statistics of diameter, area growth, and length (The VanBavel model $^{\text {7) }}$. Simulations and limitations of the model.

Using the S-model, arteriolar trees were constructed according to terminal (TG, $S=0.1$ ) and segmental ( $S G, S=30$ ) branching rules. Subsequently, experimentally obtained diameters and lengths from the data sets of day 7 , day 10 or day 14, were assigned to the modeled trees (Section 2.9), and their resistance to flow calculated. The assignment of diameters is based on the relation between daughter diameters and mother diameter. This relation is based on the diameter statistics of the subsequent days. Since the relation varies depending on the site in the vascular tree, it takes into account differential diameter scaling. Modeled were 100 trees. The effect of the topology on resistance based on the data sets of the subsequent days is listed in table 4. For each day the results are presented for: a) starting with the in vivo topology and assigning diameters and length (first section), b) modeling topology according to random segmental growth with S-model, and assigning diameters and length, c) modeling topology according to random terminal growth with S-model, and assigning diameters and length. For each senario, resistance to flow (R) and input diameter (Diam.) are calculated. For comparison, the results of a complete (purely) asymmetrical and symmetric tree are presented in table 5.

Table 4. Topology and Resistance using the S-model. Modeled were 100 trees. To simulate RSG, S was 30, for RTG, S was 0.1. Presented are mean and standard deviation (StD) of the input diameter and network resistance. Resistance in $\mathrm{kPa \mu m}^{-3} \mathrm{~s}$, diameter in $\mu \mathrm{m}$.

Day 7: length and diameter added by add-diameter:

diam: mean $=1.84 \times 10^{.2} \mathrm{StD}=6.17$

R: $\quad$ mean $=12.9 \times 10^{-10} \mathrm{StD}=2.08 \times 10^{-10}$

tree-size $=543$, actual resistance day 7 tree: $4.66 \times 10-10$

Day 7: RSG, length and diameter added by add-diameter:

diam: mean $=1.89 \times 10^{-2} \mathrm{StD}=2.36$

$\mathrm{R}: \quad$ mean $=2.16 \times 10^{\circ} \mathrm{StD}=4.80 \times 10^{-10}$

tree-size $=543$

Day 7: RTG, length and diameter added by add-diameter:

diam: mean $=1.85 \times 10^{-2} \mathrm{StD}=6.00$

R: $\quad$ mean $=2.49 \times 10^{\circ} \mathrm{StD}=3.97 \times 10^{-10}$

tree-size $=543$ 
Day 10: length and diameter added by add-diameter:

diam: mean $=1.88 \times 10^{-2} \mathrm{StD}=1.27$

R: $\quad$ mean $=4.97 \times 10^{10} \mathrm{StD}=3.70 \times 10^{-11}$

tree-size $=1630$, actual resistance day 10 tree: $4.58 \times 10^{-10}$

Day 10: RSG, length and diameter added by add-diameter:

diam: $\quad$ mean $=1.92 \times 10^{+2} \mathrm{StD}=1.08 \times 10^{+3}$

R: $\quad$ mean $=1.05 \times 10^{-9} \mathrm{StD}=1.77 \times 10^{-10}$

tree-size $=1502$

Day 10: RSG, length and diameter added by add-diameter:

diam: $\quad$ mean $=1.94 \times 10^{-2} \mathrm{StD}=9.07$

$\mathrm{R}$ : $\quad$ mean $=8.38 \times 10^{-10} \mathrm{StD}=3.02 \times 10^{-10}$

tree-size $=2702$

Day 10: RTG, length and diameter added by add-diameter:

diam: $\quad$ mean $=2.01 \times 10^{+2} \mathrm{StD}=1.15 \times 10^{+1}$

$\mathrm{R}$ : $\quad$ mean $=8.81 \times 10^{\prime \prime} \mathrm{StD}=8.28 \times 10^{11}$

tree-size $=1502$

Day 14: length and diameter added by add-diameter:

diam: $\quad$ mean $=2.08 \times 10^{-2} \mathrm{StD}=6.67$

$\mathrm{R}: \quad$ mean $=3.96 \times 10^{-10} \mathrm{StD}=3.13 \times 10^{-1} 1$

tree-size $=2757$, actual resistance day 14 tree: $4.06 \times 10^{-10}$

Day 14: RSG, length and diameter added by add-diameter:

diam: $\quad$ mean $=8.87 \times 10^{+1} \mathrm{StD}=2.17 \times 10^{+1}$

R: $\quad$ mean $=2.61 \times 10^{-9} \mathrm{StD}=1.69 \times 10^{-9}$

tree-size $=2702$

Day 14: RTG, length and diameter added by add-diameter:

diam: mean $=2.01 \times 10^{-2} \mathrm{StD}=1.09 \times 10^{\text {:1 }}$

R: $\quad$ mean $=4.33 \times 10^{-10} \mathrm{StD}=3.21 \times 10^{-11}$

tree-size $=2702$ 
Table 5. The influence of a symmetric and asymmetric branching-pattern of network resistance. Presented are mean and standard deviation (StD) of input diameter and network resistance. Resistance in $\mathrm{kPa}^{-3} \mathrm{~m}^{-3}$, diameter in $\mu \mathrm{m}$.

Symmetric tree: length and diameter added by add-diameter:

diam: $\quad$ mean $=2.05 \times 10^{-2} \mathrm{StD}=1.01 \times 10^{+1}$

$\mathrm{R}: \quad$ mean $=2.60 \times 10^{-10} \mathrm{StD}=1.16 \times 10^{-11}$

tree-size $=4094$

Asymmetrical tree: length and diameter added by add-diameter:

diam: $\quad$ mean $=4.72 \times 10^{-1} \mathrm{StD}=1.20 \times 10^{-1}$

$\mathrm{R}: \quad$ mean $=1.42 \times 10^{-8} \mathrm{StD}=5.63 \times 10^{-9}$

tree-size $=5402$

Trees modeled based on the statistics of the day 14 arteriolar tree.

The results of the modeling procedure according to the VanBave ${ }^{57}$ concept show that they are dependent on the topology, used diameter statistics, and tree size.

Assigning diameters and lengths to the trees with the in vivo observed topology resulted in calculated resistances to flow that were 2.8 times (day 7), 1.1 times (day 10) the real resistance of the in vivo observed tree. For the day 14 tree, estimated resistance was 1.02 times the in vivo observed resistance.

Comparing the results of trees of which the topology was modeled with the S-model according to $\mathrm{SG}$ or TG, it becomes apparent that the results vary, depending on diameter statistics used. For the statistics of day 7, both SG and TG resulted in comparable estimates of resistance with SG being slightly lower than TG. Compared to the in vivo resistance, they differed by a factor of 5 . This means that the procedure that assigns diameter and length either underestimates diameter or overestimates length. This might be due to the fact that the assignment procedure is based on the regression line fitted through the experimental data and the estimation of variation about the regression line. This means that values outside the $95 \%$ percentiles of the diameter and length distribution are not likely to be selected. However, in the in vivo observed tree they might contribute significantly to the total network resistance. This becomes very clear in the cases in which the topology was generated by the S-model and diameter and length were assigned according to the statistics of day 10 or 14 . The resistances estimated with SG were several orders of magnitude larger compared to TG. This might be due to the fact that SG and TG are accompanied by different area growth ratio's. A vessel added to the existing tree according to segmental growth usually differs an order of magnitude in diameter with the parent vessel (for example 10 $\mu$ branching of $30 \mu \mathrm{m}$ ). The modeling procedure would now have to select an area growth ratio in the upper limit of the distribution. 
However, comparing entrance diameters, the smaller diameters with SG compared to TG suggest that in trees modeled according to $S G$, area growth was systematically underestimated, hence, assigned diameters were comparatively small, thus resistance larger. This difference was even more pronounced in the extreme cases of the complete symmetric and asymmetric tree.

For more symmetrical trees there might not be large differences but a more gradual change in area growth. Hence, statistical selection of regression line based average values, during the diameter assigning procedure may result in a more adequate estimation of total network resistance compared to the real resistance. This may explain why this modeling procedure was adequate in estimating resistances of the coronary arteriolar tree since the coronary tree is more symmetric compared to the CAM arteriolar tree.

Thus, estimating resistance starting with a fixed topology and subsequently assigning diameter and length to the tree based on in vivo observed relations between mother diameter and daughter diameter, did not result in realistic values. This effect was more pronounced in trees with an asymmetrical branching pattern (SG) compared to trees with a symmetrical branching pattern (TG). This might be due to the statistical exclusion of extreme values of diameters (underestimation of larger diameters) and length (overestimation of larger length). Hence, this type of modeling procedure might not be adequate for explaining changes in resistance during development. 

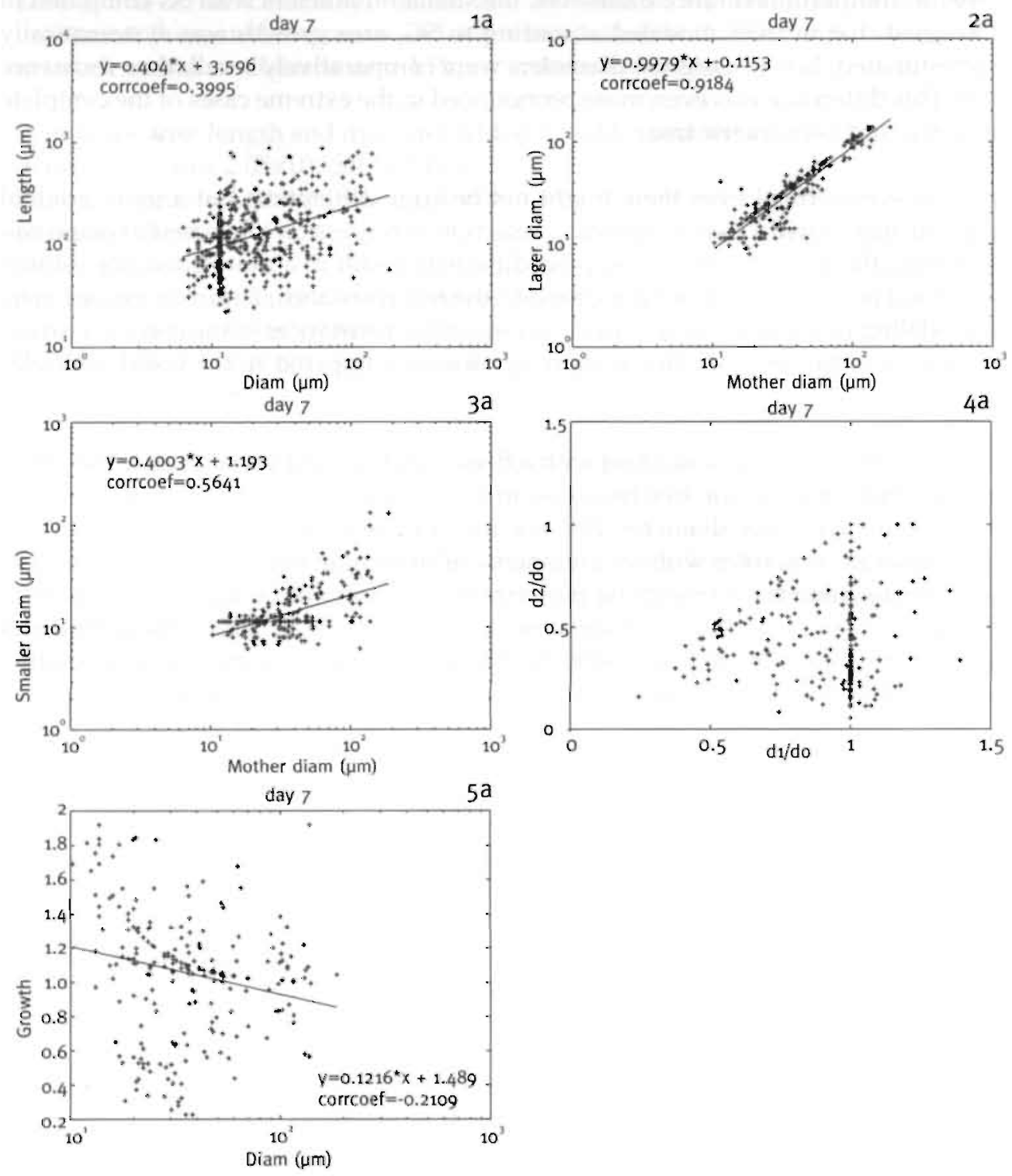

Appendix: morphometric data of the day 7 in vivo CAM arteriolar tree (figure 1a-5a). 

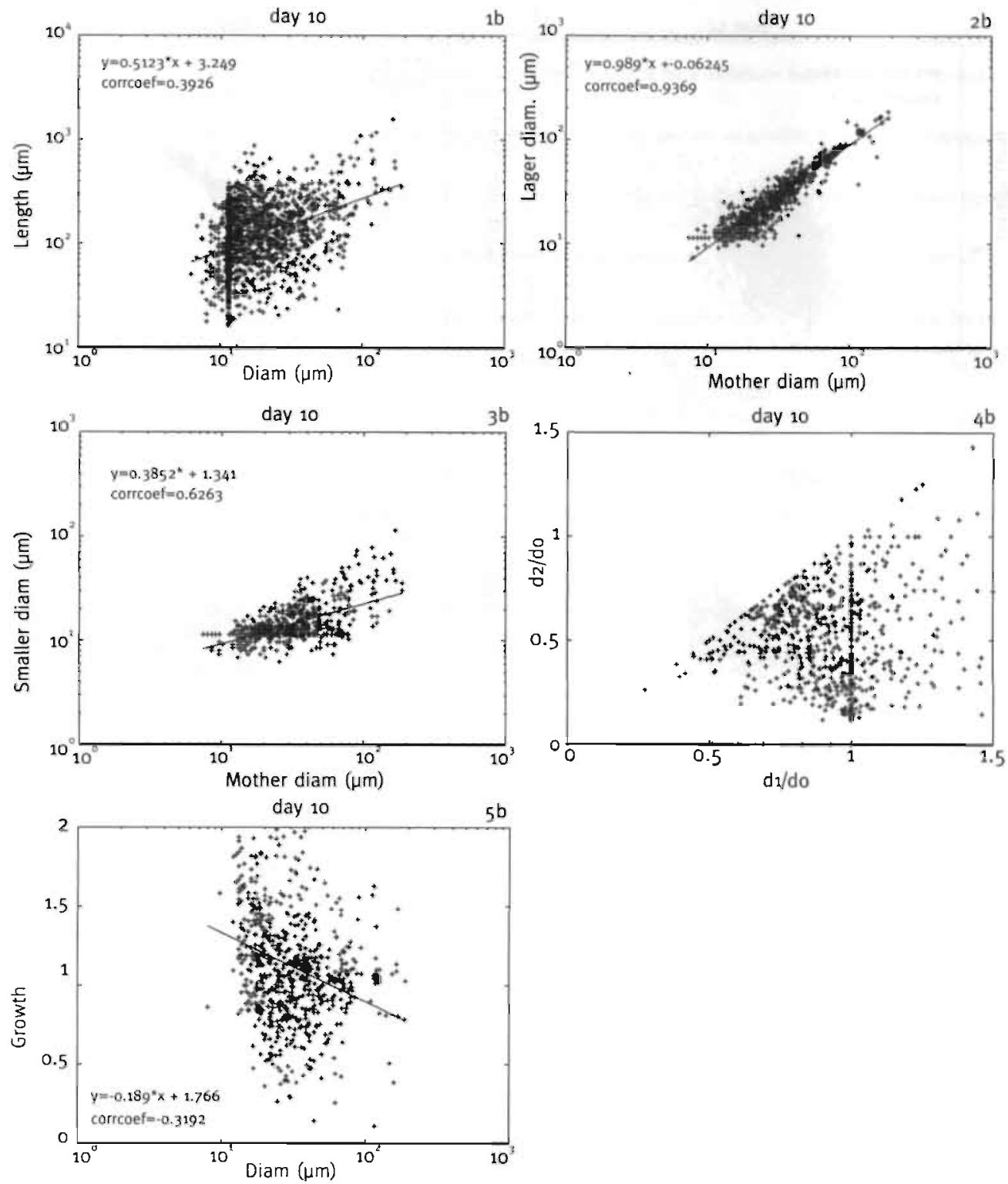

Appendix: morphometric data of the day 10 in vivo CAM arteriolar tree (figure $1 b-5 b$ ). 

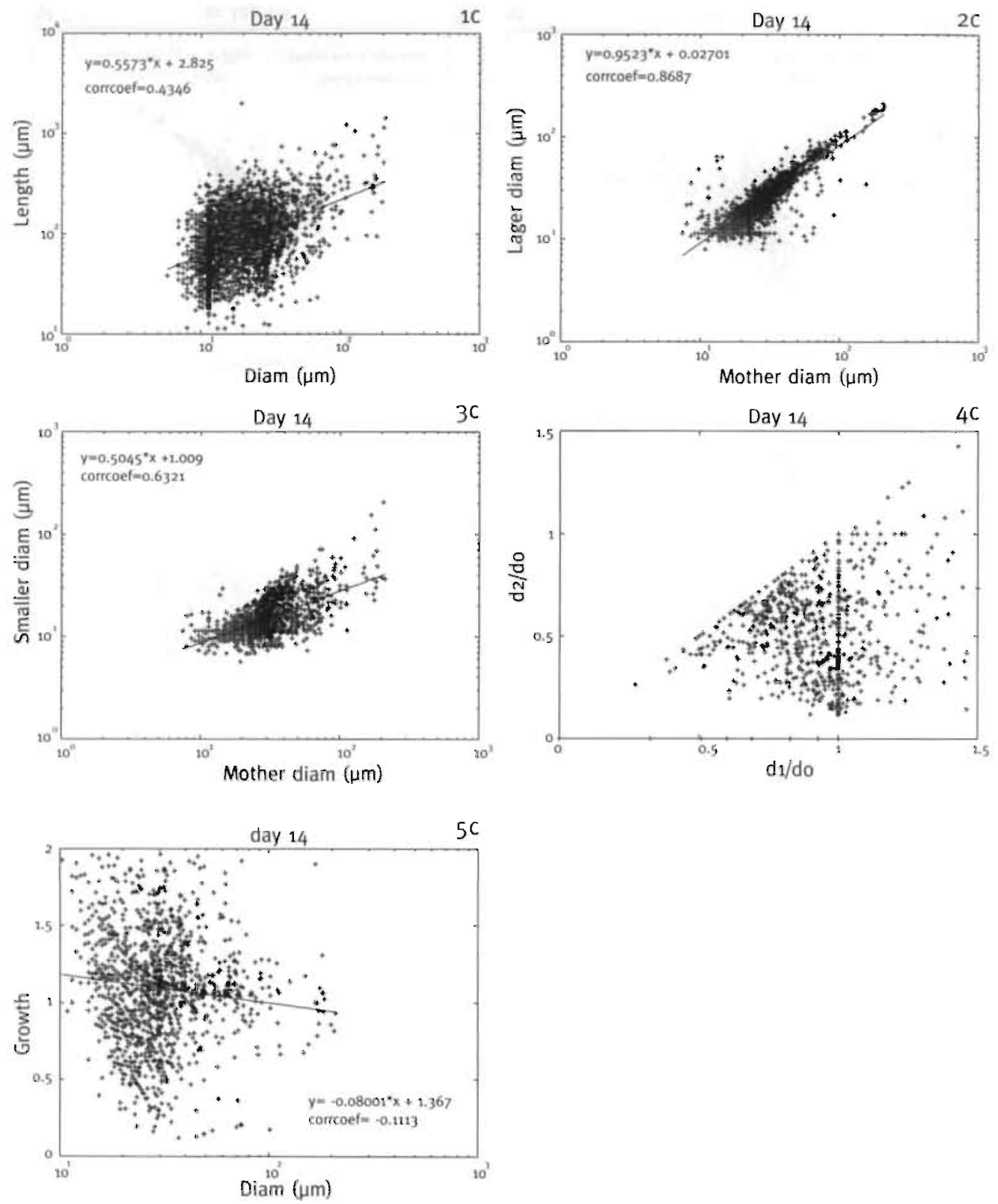

Appendix: morphometric data of the day 14 in vivo CAM arteriolar tree (figure 1c-5c). 


\section{References}

1. Abboud FM. The sympathetic system in hypertension. Hypertension. 4(suppl. II), 11208-11225, 1982.

2. Adair TH, Gay WJ, Montani ). Growth regulation of the vascular system: evidence for a metabolic hypothesis. Am ! Physiol. 259. (Regulatory integrative Comp. Physiol. 28), 393-404n 1990.

3. Adair TH, Guyton AC, Montani IP, Lindsay HL, Stanek KA. Whole body structural vascular adaptation to prolonged hypoxia in chick embryos. Am I Physiol. 252, H1228-H1234, 1987.

4. Adair TH, Hang I, Wells ML, Magee FD, Montani IP. Long-term electrical stimulation of rabbit skeletal muscle increases growth of paired arteries and veins. Am I Physiol. 269, $\mathrm{H} 717-\mathrm{H} 724,1995$.

5. Adair TH, Montani IP, Strick DM, Guyton AC. Vascular development in chick embryos: a possible ole for adenosine. Am I Physiol. 256, $\mathrm{H} 240-\mathrm{H} 246,1989$.

6. Adair TH, Montanie JP, Guyton AC. Effects of intermittent hypoxia on structural, vascular adaptation in chick. embryos. Am J Physiol. 254, H1194-H1199, 1988.

7. Bohlen HG. The microcirculation in hypertension. I Hyper. 7 (Suppl. 4), S117-S124, 1989.

8. Cho AC, Courtman DW, Langille BL. Apoptosis (programmed cell death) in arteries of the neonatal lamb. Circ Res. 76, 168175,1995 .

9. Dacey MF, Krumbein WC. Tree growth models for stream channel networks. I Geol. 84, 153-163, 1976.

10. Davis M): Myogenic response gradient in an arteriolar network, in Mulvany MJ, Aalkjear C, Heagerty AM, Nyborg NCB. Strandgaard S (eds): Resistance arteries: structure and function. Amsterdam, Elsevier, 1991, p 51

11. DeChamplain J. Pre- and postsynaptic adrenergic dysfunctions in hypertension. / Hyper. 8 (Suppl.), S77-S85, 1990.

12. DeLano FA, Schmid-Schonbein GW, Skalak TC, Zweifach BW. Penetration of the Systemic Blood Pressure into the Microvasculature of Rat Skeleta! Muscle. Microvasc Res. 41, 92-110, 1991.

13. DeMey JGR: Smooth muscle cell proliferation in hypertension: possible contribution to arterial remodeling in Schwartz SM, Mecham RP (eds): The vascular snooth muscle cell: molecular and biological responses to the extracellular matrix. San Diego. Academic Press, 1995, p 361.

14. Dusseau IW, Hutchins PM. Hypoxia-induced angiogenesis in chick chorio-allantoic membranes: a role for adenosine. Respiratory Physiology. 71, 33-44, 1988.

15. Dusseau JW, Hutchins PM. Microvascular responses. to chronic hypoxia by the chick chorioallantoic membrane: a morphometric analysis. Microvasc Res. 37, 138-147, 1989.

16. Dusseau JW, Hutchins PM, Malbassa DS. Stimulation of angiogenesis by adenosine on the chick chorio-aflantoic membrane. Circ Res. 59, 163-170, 1986.

17. Esler $M$, Lambert $G$, Jennings $G$. Increased regional sympathetic nervous activity in human hypertension: causes and conse. quences. I Hyper. 8 (Suppl.), $553-557,1990$.

18. Folkow 8, Karlström G. Altered relationships between design, transmural pressure, distensibility and contractility in hypertensive vessels. Prog appl Microcitc. 8, 82-95, 1985.

19. Fung YC: Biodynamics. New York, Springer-Verlag, 1984.

20. Funk W. Endrich B, Messmer K, Intaglietta M. Spontaneous arteriolar vasomotion as a determinant of peripheral vascular resistance. Int J Microcirc: Clin Exp. 2, 11-25, 1983.

21. Gaehtgens F, Ley K, Pries AR: Topological approach to the analysis of microvessel structure and hematocrit distribution, in Popel, Johnson (eds): Microvascular networks: experimental and theoretical studies. Basel, Karger, 1985 , 1152

22. Gerova M, Gero I. Barta E, Dolezel S, Smiesko V, Levicky V. Neurogenic and myogenic control of conduit coronary arteries: a possible interference. Basic Res Cardiol. 76, 503-507, 1981.

23. Gottlieb ME: Vascular Networks: fractal anatomies from non-linear physiologies. Abstract, 13 th annual conference of the IEEE, Engineering Medicine and Biology Society. november 1991.

24. Gottlieb ME: The VT model: a deterministic model of angiogenesis, and biofractals based on physiological rules. Abstract, IEEE 17 th annual northeast bioengineering conference; Hartford, CT; april 1991.

25. Greene AS, Tonellato PJ, Lui ], Lombard JH, Cowley AWI. Microvascular rarefaction and tissue vascular resistance in hyperten. sion. Am / Physiol. 256.(Heart Circ. Physiol. 25), H126-H131, 1989. 
26. Guyton AC, Hall JE: Textbook of medical physiology(ed 9). Philadelphia, W.B. Saunders Company, 1996.

27. Hacking W: The interaction between vascular structure and blood flow distribution [Dissertation]. University of Amsterdam, Department of Biophysics, 1995

28. Hacking WJG, VanBavel E, Spaan JAE. Shear stress is not sufficient to control growth of vascular networks: a model study. Am J Physiol. 270, $\mathrm{H}_{364} \cdot \mathrm{H}_{375}, 1996$.

29. Hintze TH, Vatner SF. Reactive dilation of large coronary arteries in conscious dogs. Circ Res. 54, 50-57, 1984.

30. Horton RE. Erosional development of streams and their dranage basins: hydrophysical approach to quantitative morphology: Geol Soc Am Bull. 56, 275-370, 1945.

31. Hudlicka O, Brown M. Egginton S. Angiogenesis in skeletal and cardiac muscle. Physiological reviews. 72, 369-417, 1992.

32. Hudlicka O, Tyler KR: Angiogenesis: the growth of the vascular system(ed 1). London, Academic Press, 1986.

33. Hughes AFW. The blood pressure of the chick embryo during development. I Exptl Biol. 19, 232-237. 1942.

34. Hutchins PM, Darnell AE. Observation of a decreased number of small arterioles in spontaneously hypertensive rats. Circ Res. $34 / 35$ (Suppl. 1), 161-165. 1974 .

35. Kassab GS, Rider CA, Tang NI. Fung YB. Morphometry of pig coronary arterial trees. Am I Physiol. 265, H350-H365, 1993.

36. Le Noble JLML, Smith TL, Hutchins PM, Struyker-Boudier HAJ. Microvascular alterations in adult conscious spontaneously hypertensive rats. Hypertension. 15. 415-419, 1990.

37. Le Noble JLML., Tangelder G], Slaaf DW, Van Essen H, Reneman RS, Struyker-Boudier. A functional morphometric study of the cremaster muscle microcirculation in young spontaneously hypertensive rats. J Hyper. 8, 741·748, 1990.

38. Ley K, Pries AR, Gaehtgens P. Topological structure of rat mesenteric microvessel networks. Microvasc Res. 32, 315-332. 1986.

39. Linke C: Die topologische struktur mesenterialer mikrogefässnetzwerke (german) [Dissertation]. Freien Universităt Berlin, 1991.

40. Prewitt RL, Wang DH, Nakamura T. Smith EG: Growth and modification in number of resistance vessels, in Bevan IA (ed): The resistance vasculature., Humana Press, 1991, p 127.

41. Price RJ, Owens GK, Skalak TC. Immunohistochemical identification of arteriolar development using markers of smooth muscie differentiation: evidence that capillary arterialization proceeds from terminal arteriole.s. Circ Res. 75, 520-527, 1994.

42. Price R], Skalak TC. Circumferential wall stress as a mechanism for arteriolar rarefaction and proliferation in a network model. Microvasc Res. 47, 188-202, 1994.

43. Price R]. Skalak TC. A circumferential stress-growth rule predicts arcade arteriole formation in a network model. Microcirculation. 2, 41-51, 1995.

44. Pries AR, Secomb TW, Gaehtgens P, Gross JF. Blood flow in microvascular networks: experiments and simulation. Circ Re5. $67,826-834,1990$.

45. Romarieff AL: The avian embryo: structural and functional development. New York, The MacMillan Company, 1960.

46. Roy RW, Mayrovitz HN. Microvascular blood flow in the normotensive and spontaneously hypertensive rat. Hypertension. 4, $264 \cdot 271,1982$.

47. Schmid-Schoenbein GW. Zweifach BW. Kovalcheck S. The application of stereological principles to morphometry of the microcirculation in different tissues. Microvasc Res. 14, 303-317, 1977.

48. Segal 5S, Duling B. Propagation of Vasodilation in Resistance Vessels of the Hamster: Development and Review of a Woiking Hypothesis. Circ Res. 61 (Suppt. 11), 11-20-11-25, 1987.

49. Shreve RL. Statistical law of stream numbers. / Geol. 74, 17-37, 1966.

50. Staaf́ DW. Jongsma FHM, Tangelder G, Reneman RS. Charaçteristics of Optical Systems for Intravital Microscopy. Microcirc Techn., 211-228, 1986 .

51. Slaaf DW, Tangelder G]. Reneman RS, Jéger K, Bollinger A. A versatile incident illuminator for intravital microscopy. Int ! Microcirc: Clin Exp. 6. 391-397, 1987.

52. Staaf DW. Tangelder G), Teirlinck HC, Reneman RS. Arteriolar vasomotion and arterial pressure reduction in rabbit tenuissimus muscle. Microvasc Res. 33. 71-80, 1987. 
53. Strahler AN. Hypsometric analysis of erosional topography, Bull Geol Soc Am. 63, 1117-1142, 1952.

54. Strick DM, Waycaster RL, Montani JP, Gay WJ, Adair TH. Morphometric measurements of chorioallantoic membrane vascularity: effects of hypoxia and hyperoxia. Am J Physiol. 260, Hi385-H1389, 1991.

55. Struyker-Boudier HAJ: Vascular growth and hypertension, in Swales JD (ed): Textbook of Hypertension. London, Blackwell Scientific Publications, 1994, p 200.

56. Struyker Boudier HAI, Van Bortel LMAB, De Mey IGR. Remodeling of the vascular tree in hypertension: drug effects. TiPS. 11, 240-245, 1990.

57. VanBavel E, Spaan JAE. Branching patterns in the porcine coronary arterial tree, estimation of flow heterogeneity. Circ Res. 71, 1200-1212, 1992.

58. Weibel E: Morphometry of the lung. New York, Academic Press, 196?. 
Chapter 8

General Discussion 


\section{General Discussion}

In this thesis experimental data have been presented about the putative role of the renin-angiotensin system in vascular development. It was furthermore investigated what implications vascular growth may have for vascular resistance and how changes in the regulation of vascular development may contribute to the genesis of primary forms of hypertension.

Development of high blood pressure in primary forms of hypertension has been explained on the basis of a change in peripheral vascular resistance. Peripheral vascular resistance is influenced by blood viscosity, vessel diameters, and vessel lengths. The vascular network structure, i.e., the interconnection of single vessels (parallel coupling), also contributes to total vascular resistance. It has been postulated that in primary forms of hypertension peripheral resistance becomes elevated due to changes in the arteriolar network structure, specifically a decrease in the available cross-sectional area for flow ${ }^{37}$. The origin of the change in arteriolar network structure is not yet known but it has been suggested that it depends on a diminished capacity to form new blood vessels ${ }^{49}$. This implies that primary forms of hypertension are related to a growth disorder of the vasculature ${ }^{6,27}$.

The process of post-embryonic vascular growth may be divided in at least two parts: growth of arterioles, the arteriolization process, and growth of capillaries, angiogenesis $1^{124}$. Arterioles may grow by upgrading of capillaries into arterioles by investing capillary tubes with circular layers of smooth muscle cells and by sprouting 40 . Growth of capillaries, angiogenesis, has been shown to involve five distinct events. First, degradation of the basal membrane by proteolytic enzymes, migration and proliferation of endothelial cells, and, finally, lumen formation and fusion with nascent sprouts $^{1724}$.

Since growth of arterioles may involve interaction with capillaries, attenuated growth of arterioles may result from both a defect in the arteriolization process itself or a diminished availability of capillaries utilized for the arteriolization process. This suggestion is supported by experimental evidence which shows that capillary densities tend to be decreased by $20-40 \%$ in primary forms of hypertension ${ }^{+8}$.

Growth of new blood vessels may be influenced by the local release of growth factors in the tissue, or by the perfusion status of the vasculature, transmural pressure and flow. Angiotensin-II has been implicated to act as a growth factor and actively stimulate vascular development. To assess the possible effects of angiotensin-II on the arteriolization process we used the standard angiogenesis assay of the chick embryo chorioallantoic membrane (CAM). To investigate whether angiotensin-II could also play a role in the capillarization process, we used an in vitro approach employing endothelial cells in culture. 


\section{Angiotensin-II and the arteriolization process}

Based on evidence from our functional studies in which we showed that angiotensinII could increase arteriolar growth (chapter 2) and stimulate arteriolar arcade formation in the CAM (chapter 3), we postulate that angiotensin-II can stimulate the growth of arterioles. This is in agreement with observations by Wang\&Prewitt who showed that blocking the formation of angiotensin-II results in attenuated growth of arterioles in the rat cremaster muscle ${ }^{50.51}$. It is furthermore in agreement with the observations by Hernandez et $\mathrm{al}^{23}$ who showed that the decrease in microvessel density occuring in normotensive rats during chronic elevations in dietary salt intake could be prevented by the infusion of subpressor doses of angiotensin-II.

Growth of arterioles may result from sprouting of existing arterioles or, from upgrading of capillaries into arterioles by investing capillary tubes with vascular smouth muscle cells ${ }^{38,40}$. Experimental evidence that arterioles indeed form sprouts, is lacking. Our intravital observations of the CAM vasculature, support the idea that arterioles grow by upgrading of capillaries (chapter 7). If we assume that angiotensin-II stimulates arteriolar growth by enhancing the upgrading of capillaries, we have to explain the origin of the smooth muscle cells utilized for investing capillary tubes.

The vascular smooth muscle cells may arise from the media of the terminal arterioles. Upgrading of capillaries might then involve two distinct processes: 1) prolif(ration of vascular smooth muscle cells and 2) migration of vascular smooth muscle colls through the extracellular matrix towards the capillary tubes.

\section{Proliferation of vascular smooth muscle cells}

\section{Direct effect of angiotensin-II}

Based on the experimental study with regard to the role of angiotensin-II in arcade formation (chapter 3) we hypothesized that angiotensin-II can stimulate arteriolar growth by enhancing the growth of vascular smooth muscle cells. We speculate that angiotensin-II acts as a growth factor. This is in agreement with other experimental studies which show that angiotensin-II can ind uce vascular smooth muscle cell hyperplasia and hypertrophy ${ }^{11,12: 8}$. On the other hand, activation of AT receptors on vascular smooth muscle cells may trigger the intracellular release of growth inhibitory substances like prostaglandins. Inhibition of the release of prostaglandins, by administration of acetyl-salicylic acid or losartan, indeed potentiated the growth reponse to angiotensin-II. Hence, the response to angiotensin-II may strongly depend on the intracellular balance of grow th stimulatory and inhibitory signals. The suggestion that a possible growth factor may also trigger the release of a growth inhibitory factor may have important implications. 
Attenuated arteriolar grow th may therefore not only result from a shortage of vascular growth factors, but also from an excessive release of growth inhibitory substances with normal amounts of growth stimulatory factors.

\section{Indirect effect of angiotensin-ll}

Based on results of the autoradiography study (chapter 4), we concluded that AT receptors may be present on fibroblasts and vascular smooth muscle cells. Fibroblasts and vascular smooth muscle cells with a synthetic phenotype are the major cell-types responsible for the synthesis of the extracellular matrix ${ }^{930}$. The extracellular matrix exerts tensile forces on the vascular smooth muscle cell, acts as a storage for growth factors, facilitates cell-cell interactions, and may therefore indirectly modulate growth of vascular smooth muscle cells ${ }^{42,19}$.

Furthermore, the extracellular matrix influences the state of differentiation of both endothelial cells and vascular smooth muscle cells ${ }^{33.34}$. In vitro experiments have shown that absence of basement membrane proteins may allow vascular smooth muscle cells to dedifferentiate ${ }^{34}$. The dedifferentiated vascular smooth muscle cells produce collagen and other matrix proteins, but also proteases, and exhibit a migratory and invasive phenotype, capable of destroying normal tissue architecture ${ }^{3 t}$. As pointed out, vascular smooth muscle cell migration may be prerequisite for the arteriolization process. In the presence of basement membrane proteins, the vascular smooth muscle cells cease proliferation and start to align and form tight junctions": The composition of the extracellular matrix is determined by the equilibrium of synthesis and breakdown. Angiotensin-II has been shown to actively alter this balance through stimulation of matrix synthesis or inhibition of degradation by metalloproteinases ${ }^{5.25}$ : Hence, it may be postulated that angiotensin-II indirectly influences smooth muscle cell growth through modulation of the extracellular matrix composition.

On the other hand, angiotensin-II may increase arteriolar tone in the microcirculation of the CAM and, hence, cause a reduction in arteriolar lumen diameter. A reduction in lumen diameter may alter local shear stress and circumferential wall stress. In view of the possible effects of shear stress and circumferential wall stress on vascular development, it cannot be ruled out that angiotensin-II influences arteriolar growth through modulation of the perfusion status of the vasculature. To clarify this process, additional studies measuring local flows and pressures should be performed.

\section{Migration of vascular smooth muscle cells}

Experimental evidence shows that angiotensin-II can stimulate migration of vascular smooth muscle cells? This response involves the release of proteolytic enzymes, i.e., the plasminogen activator uPa and subsequently the serine protease plasmin, by the endothelium. Plasmin may in its turn activate matrix metalloproteinases ${ }^{1326}$. Assuming that these enzymes degrade the extracellular matrix ${ }^{1326}$, they may facilitate the creation of a pathway in the matrix through which vascular smooth muscle cells can migrate, or, influence the state of differentiation of the vascular smooth muscle cell. 
Hence, specific release of the plasminogen activator by the endothelium may lead to degradation of the extracellular matrix which then directs the growing vascular smooth muscle cells towards the capillary endothelium, or, may cause dedifferentiation of the vascular smooth muscle cells, which in turn may start to proliferate and migrate.

An alternative mechanism to explain the spatial coordination of vascular smooth muscle cell migration may be found at the genetic level. Recently, a set of genes has been identified, so called polarity genes, which are involved in facilitating intra- and intercellular signal transduction and thereby play a role in tissue morphogenesis and differentiation ${ }^{8}$. These genes have been implicated to play a role in the spatial control of growth in the process of left ventricular hypertrophys. The recognition that growth is not merely the result of an interaction between cells, and growth and antigrowth factors but also comprises regulation of spatial control may be of critical importance. Literature reviewing the process of vascular development usually deals with the function of growth factors, morphological descriptions, and functional aspects of the vasculature. However, thus far, no attention has been paid to the mechanism of morphometric or architectural control of the vascular network structure. In view of the importance of structural changes in vascular networks in pathology, more emphasis should be put on elucidating the process of spatial control of the developing vasculature.

Finally, it cannot be ruled out that angiotensin-II mediated arteriolar growth depends on activation of lymphocytes and pericytes. Activation of lymphocytes may trigger the release of growth factors and chemo-attractants which may facilitate arteriolar growth. Furthermore, a transition of pericytes into vascular smooth muscle cells may be an alternative explanation for the origin of vascular smooth muscle cells used for upgrading of capillaries into arterioles.

\section{Nature of the AT receptor involved in the arteriolization process}

Angiotensin-II can actively stimulate vascular growth in the CAM. Evidence from the functional and the ligand-binding studies (chapter 2) suggests that this response is mediated through activation of a single class of angiotensin receptors with no affinity for the $\mathrm{AT}_{1}$ antagonist losartan, the $\mathrm{AT}_{2}$ antagonist PD123319, and only a moderate affinity for the $\mathrm{AT}_{2}$ antagonist CGP42112a. This receptor therefore differs from the classic mammalian $\mathrm{AT}_{1}$ and $\mathrm{AT}_{2}$ receptor. The ligand-binding data show similarity with the turkey angiotensin-II receptor". This receptor has been cloned and shows $60 \%$ homology with the mammalian AT receptors ${ }^{10.31}$. Thus, avian angiotensin-Il receptors may belong to an atypical, non-mammalian, class of AT receptors. However, experimental evidence has shown that an AT receptor with a similar ligand-binding spectrum is present in the human endometrium, and may be involved in vascular growth during the menstrual cycle 3 . 
The AT receptor density is developmentally regulated and its expression seems to run parallel with growth rate rather than with vascular density. This suggests that the AT receptor is predominantly expressed during the growth period of the vasculature and to a lesser extent in the quiescent phase of the vasculature. This is in agreement with the suggestion that angiotensin-II plays an important role in the control of vascular smooth muscle cell growth ${ }^{11.1218}$.

Although this atypical AT receptor might not be present in mammals, its mechanism of action may provide a valuable tool to get insight in the basic understanding of vascular development.

\section{Angiotensin-ll and the capillarization process}

Based on the results of the in vitro rat coronary endothelial cell culture study (chapter 5) it may be postulated that angiotensin-II can stimulate the growth of endothelial cells. The growth response to angiotensin-II, however, depends on the serum concentration used. The growth response may also depend on the endothelial expression of AT receptor subtypes ${ }^{45 . t 6}$. The use of specific AT receptor blockers indicates that the grow th response was mediated through the $\mathrm{AT}_{1}$ receptor. Furthermore, the expression of $\mathrm{AT}_{2}$ receptors tends to decrease after each passage. Since the endothelial cells used underwent more than 30 passages, the $\mathrm{AT}_{2}$ receptor might be absent. This favors the idea that the response is mediated through the $\mathrm{AT}_{1}$ receptor. Other experimental studies support the idea that activation of the $\mathrm{AT}_{1}$ receptor in mammalian endothelial cells can stimulate endothelial cell growth ${ }^{\text {th }}$. However, Stoll et al ${ }^{\text {th }}$ furthermore demonstrated that angiotensin-II could only exert a mitogenic effect when the $\mathrm{AT}_{2}$ receptor was inactivated. In a second set of experiments it was shown that the endothelial cell proliferation obtained with the growth factor bFGF could be abolished by angiotensin-II. This response was mediated through the $\mathrm{AT}_{2}$ receptor $r^{+0}$. This suggests that activation of the $\mathrm{AT}_{2}$ receptor can exert an antimitogenic effect on proliferating endothelial cells. Taken together it may be concluded that angiotensin-II can stimulate endothelial cell growth.

However, stimulation of endothelial cell growth is not a prerequisite to induce capillary growth ${ }^{44}$. Capillary growth, or angiogenesis, involves five distinct events. Thus far only evidence has been presented showing that angiotensin-II can stimulate endothelial cell growth. Evidence with regard to basement membrane degradation, endothelial cell migration, and lumen formation and fusion with nascent sprouts, is scanty. The in vivo experiments by Fernandez et $\mathrm{al}^{16}$ who showed that angiotensin-II could induce growth of new capillaries in the rabbit comea indicate that angiotensinII may influence these processes as well. Similar to the arteriolization process, this may involve modulation of the composition of the extracellular matrix, release of proteolytic enzymes, and interaction with pericytes or lymfocytes. To elucidate how angiotensin-II may induce capillary growth in vivo, future research should aim at understanding intra- and inter-endothelial cell communication, interaction with the extra-cellular matrix, and interaction with other cells in the tissue. 


\section{Growth of arterioles, network architecture and resistance}

Based on the observation that an elevated peripheral resistance in primary forms of hypertension is accompanied by regression of small arterioles, rarefaction, it was hypothesized that attenuated arteriolar growth results in an increased arteriolar network resistance ${ }^{48}$. Inversely, growth of arterioles may result in a reduction of network resistance. Calculations of the resistance to flow of the in vivo developing CAM arteriolar network (chapter 7) indeed shows that outgrowth of the arteriolar network is accompanied by a resistance decrease. However, we also observed a general increase in arteriolar lumen diameter during development. Increases in lumen diameter, however, account for a resistance decrease. To discern between the effects of arteriolar growth and diameter changes on network resistance, a computer model was constructed. The results of the modeling study show that the effect of arteriolar growth on network resistance strongly depends on the site were new arterioles grow, and the size of the existing tree they are coupled to. Adding new arterioles along existing arterioles, segmental growth, decreases network resistance. Adding new arterioles at the terminal part of the circulation, terminal growth, increases network resistance. The magnitude of resistance change decreases with increasing tree-size.

Based on topological analysis of the in vivo developing CAM arteriolar network, it was concluded that the growth process starts with adding new arterioles using segmental growth. During development the growth process shifts towards terminal growth. The observed decrease in the calculated resistance to flow of the developing CAM network during the period dominated by segmental growth, could be explained based on segmental addition of new arterioles to the existing tree. Hence, no additional increase in arteriolar lumen diameter was required to explain the in vivo resistance change. To explain the observed decrease in arteriolar network resistance during the period dominated by terminal growth, an additional diameter increase was required. Thus, the observed decrease in the CAM arteriolar network resistance during the latter period is not caused by outgrowth of the network but by a general increase in arteriolar lumen diameter. It is therefore concluded that growth of arterioles may reduce network resistance but only if they develop parallel to existing arterioles, hence, segmental growth.

This finding may also have important implications with regard to the interpretation of rarefaction. Literature dealing with microvascular alterations in hypertension defines rarefaction as regression of arterioles ${ }^{37,48}$. Based on the correlation between rarefaction and elevated resistance, rarefaction has been implied to contribute to an elevated peripheral resistance. Regression of arterioles is usually quantified by stereological assessment of microvascular density. Microvascular density is comprised of both vessel length and number ${ }^{33}$. However, it does not give insight in how these vessel interconnect with each other. Hence, it lacks information about the network structure. As pointed out, network structure, the arrangement of the individual vessels in parallel and serial coupled circuits, is a major determinant of network resistance. In the case of regression of two parallel coupled arterioles at the terminal part of the network, network resistance will decrease. 
In the case of regression of arterioles coupled along existing arterioles, network resistance will increase. Thus, although the microvascular density will decrease in both cases, the effects on resistance are contradictory. Hence, without specification of the site in the vascular tree, the number of vessels involved, and the effect on network arrangement (parallel and serial coupled circuits), the term rarefaction remains meaningless with regard to network resistance. Future studies addressing the role of changes in network structure in relation to resistance, should include parameters that give insight in network arrangement or structure. Topological analysis of the arteriolar network may provide a valuable tool.

\section{Spontaneous hypertension and vascular development}

In chapter 6 we showed that during early development (6-12 weeks) the angiogenic capacity of serum from normotensive Wistar Kyoto rats is transiently increased compared to spontancously hypertensive rats. Hence, a diminished availability of circulating grow th factors in SHR may account for attenuated vascular development or rarefaction. Since growth of arterioles may contribute to a network resistance decrease, under the premiss that new arterioles are coupled along existing arterioles, a reduction in the quantity of growth stimulating factors may explain the origin of the relatively higher peripheral resistance in SHR as compared to WKY during early development.

As pointed out, vascular growth may among others be governed by local growth factors or the perfusion status of the vasculature. Our results indicate that in spontaneous hypertension there may be a reduction in the capacity to generate growth factors. However, this defect at the level of the growth factors may not be prerequisite of rarefaction.

For example, the rat one-kidney one-clip $(1 \mathrm{~K} 1 \mathrm{C})$ renal model of secondary hypertension is also characterized by rarefaction of arterioles ${ }^{22.30}$. Circulating levels of angiotensin-II are elevated. Furthermore, due to the rarefaction, the peripheral tissues may become re-latively hypoxic ${ }^{19}$. Both angiotensin-II and hypoxia may provide a stimulus for arteriolar growth ${ }^{1}$. Since this does not actually occur, it may be postulated that vascular adaptations, remodelling, of the vascular bed to maintain a constant perfusion status of the vasculature prevails at the expense of growth control by local growth factors. A computer modeling study by Price \& Skalak ${ }^{39}$ supports this idea by showing that an elevated arterial blood pressure by itself may account for regression of arterioles only based on circumferential wall stress adapation. The critical assumption in this study is that an increase in pressure induces, through a myogenic response, an arteriolar lumen reduction and, thereby, a reduction in circumferential wall stress. Hence, effectively the reduced lumen diameter reinforces rarefaction. Thus, preventing the myogenic response, hence, lumen reduction may prevent rarefaction to occur. A similar line of reasoning may be used to explain rarefaction in spontaneous hypertension. 
The early developmental stage of spontaneous hypertension is characterized by a period of elevated cardiac output and an uneven fractional distribution of flow to the major organs, the so-called hyperkinetic phase ${ }^{15}$. It has been postulated that this results in an overperfusion of the peripheral tissues. The increased flow delivery may increase oxygen supply to the tissues which would prevent normal outgrowth of the vasculature and lead to rarefaction'. Furthermore, to compensate for the increased perfusion, the peripheral tissues display an acute autoregulatory response resulting in reduced lumen diameters ${ }^{20}$. Similar to the one-kidney one-clip renal hypertension model, the initial short-term arteriolar constriction may cause a reduction in circumferential wall stress. In response to a reduced circumferential wall stress, vessels may begin to rarefy ${ }^{30}$. Hence, rarefaction may result from changes in the perfusion status of the vasculature. Subsequently, rarefaction may contribute to a structural increase in network resistance, necessary to keep tissue flow constant at an elevated driving pressure, and allowing the diameters of the remaining vessels to return to their control values. This may explain the absence of prominent arteriolar constriction during later stages of spontaneous hypertension.

Taken together, our results indicate that rarefaction in spontaneous hypertension may be explained by a reduction in circulating vascular growth factors. In this case the primary defect would be a reduction in vascular growth factors. However, it cannot be ruled out that rarefaction also occurs as a response to changes in the perfusion status of the vasculature during early development. In this case, the microvascular changes are secondary, with the primary defect being the uneven fractional distribution of the cardiac output.

To elucidate the contribution of changes in flow and pressure to changes in the microvascular architecture during spontaneous hypertension, more emphasis should be put on understanding the origin and the effects of the autoregulatory response in the peripheral circulation during the hyperkinetic phase. Specifically, it is not known why lumen diameters are reduced in response to an elevated flow, since shear stress adaptation per se would predict an endothelium dependent vasodilation. It has been suggested that an increased oxygen availability may play a pivotal role in the vasoconstrictor response $e^{5}$. It has been demonstrated that arterioles of hypertensive animals will increase vascular resistance more than those of WKY, when oxygen availability is increased $^{25}$. Furthermore, exposure to high altitude with low ambient oxygen tension decreases the prevalence of hypertension in humans and experimental animals and reduces blood pressure to normal levels ${ }^{42935.41}$. Hypoxia induces changes that are associated with a reduced vascular resistance including a reduction of arteriolar constriction, and prevention of rarefaction ${ }^{35}$. These changes have been associated with the release of the vasodilator adenosine which has also been shown to have angiogenic activity, and an altered catecholamine metabolism ${ }^{1.25}$. Microcirculation studies have shown that hypoxia is a stimulus for blood vessel growth, whereas hyperoxia may cause regression of vessels ${ }^{47}$. 


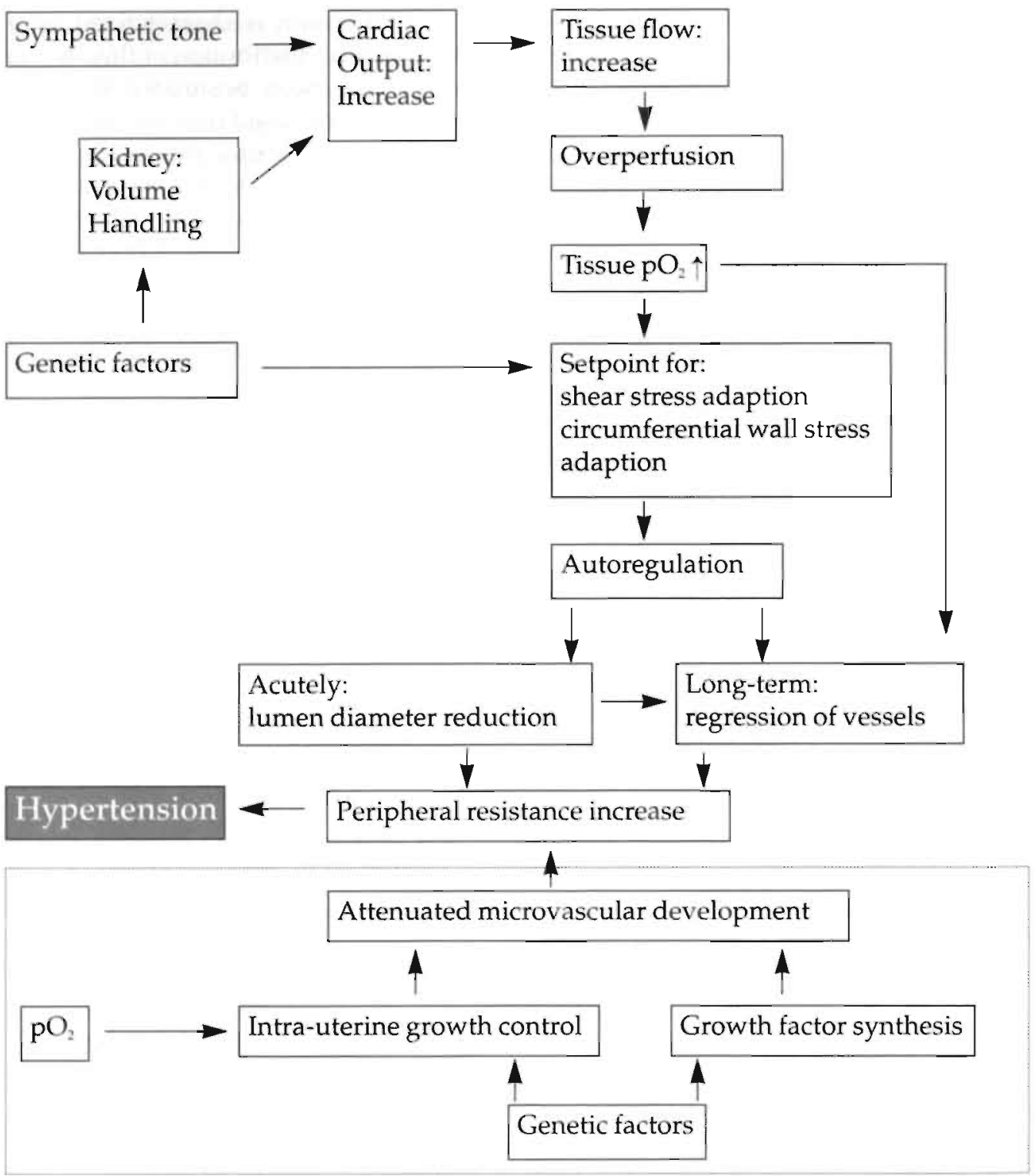

Figure 1. Schematic representation how changes in vascular structure arise. Changes in structure may either arise from primary defect in the outgrowth of the vascular system (surrounded by...... line), or , as secondary adaption to hemodynamic changes. 
Since oxygen may regulate the release of local vascular growth factors like vascular endothelial growth factor (VEGF) ${ }^{21}$, adenosine ${ }^{214}$, and angiotensin- $\Pi^{2}{ }^{2}$, its importance is obvious. Consequently, the observed decrease in angiogenic factors in the serum of young SHR may reflect an adaptation to the increased oxygen availability. Given the possible role of oxygen in arteriolar diameter control and growth regulation, more emphasis should be put on understanding the role of metabolic adaptations in the etiology of spontaneous hypertension.

\section{Outlook and Perspectives}

The results presented in this thesis demonstrate that besides arteriolar lumen diameter, vascular architecture is an important determinant of vascular resistance. Stimulation of arteriolar growth may result in a reduction of vascular resistance if these new arteriolar vessels grow along existing arterioles, segmental growth. Primary forms of hypertension have been explained on the basis of changes in microvascular architecture ultimately leading to a reduction in the cross-sectional area available for flow. Restoring a normal architecture by means of stimulation of segmental arteriolar growth, and, hence, increase the cross-sectional area available for flow, may lead to a reduction of peripheral vascular resistance and, consequently, to a lower blood pressure. A future approach to treat hypertension may therefore be to develop drugs that can selectively target the structure of the vascular tree, increasing the cross-sectional area available for flow, and thus lowering resistance on a structural basis.

Since angiotensin-II was shown to influence both arteriolar and capillary growth, it is suggested that future rescarch in this area should concentrate on the role of the reninangiotensin system.

Finally, the renin-angiotensin system may play a pivotal role in tumor angiogenesis. Volpert et al (J. Clin. Invest. 98 (3): 671-679) has recently shown that treatment with the angiotensin-converting enzyme inhibitor captopril blocked neovascularization in the rat cornea and reduced tumor growth. The recognition that the renin-angiotensin system may play an important role in somatic growth control, both physiologic and pathologic, opens a new field of interest for the use of drugs that interfere with the renin-angiotensin system. 


\section{References}

1. Adair TH, Gay W], Montani \}. Growth regulation of the vascular system: evidence for a metabolic hypothesis. Am I Physiol. 259.(Regulatory Integrative Comp. Physiol. 28), 393-404, 1990.

2. Adair TH, Montani JP, Strick DM, Guyton AC. Vascular development in chick: embryos: a possibie role for adenosine. Am I Physiol. 256, H240-H246, 1989.

3. Ahmed A, Li XF, Shams M, Gregory J, Rollason T, Barnes NM, Newton JR. Localization of the angiotensin-II and its receptor subtype expression in human endometrium and identification of a novel high-affinity angiotensin-II binding site. I Clin Invest. $96,848-857,1995$.

4. Banchero N. Capillary density of skeletal muscle of in dogs exposed to simulated high altidue. Proc Exp Biol Med. 148.435 439. 1975 .

5. Banchero N. Cardiovascular responses to chronic hypoxia. AnnRevPhysiol. 49, 465-476, 1987.

6. Barker DJP, Bull AR, Osmond C, Simmonds SJ. Fetal and placental size and risk of hypertension in adult life. BM]. 302, 259$262,1990$.

7. Bell L, Madri JA. Influence of the angiotensin system on endothelial and smooth muscle cell migration. American Journal of Pathology, 137, $7 \cdot 12,1990$.

8. Blankesteijn WM, Essers-janssen YPG, Ulrich MMW, Smits. JFM. Increased expression of a homologue of drosophila tissue. polarity gene "frizzled" in left ventricular hypertrophy in the rat, as identified by subtractive hybridization. Mol Cell Cardiol. 28, $1187^{-1191,1996 .}$

9. Campbell GR, Campbell JH: Development of the vessel wall: overview, in Schwartz SM, Mecham R.P (eds): The vascular smooth muscle cell: molecular and biological responses to the extracellular matrix. San Diego, Academic Press, 1995, p 1

10. Carsia CV, Mcllroy PJ, Kowalski KI, Tilly IL. Isolation of turkey adrenocontical cell angiotensin-1I (All) receptor partial cDNA: evidence for a singel-copy gene expressed predominantly in the adrenal gland. Biochem Biophys Res Commun. 191, 1073-1080, 1993.

11. Daemen MJAP, De Mey JGR. Regional heterogeneity of arterial structural changes. Hypertension. 25 (part 1), 464-473, 1995.

12. Daemen MJAP, Lombardi DM, Bosman FT, Schwartz SM. Angiotensin-4l induces smooth muscle cell proliferation in the norma! and injured rat arterial wall. Circ Res. $68,450-456,1991$.

13. Dạnọ D, Anḍ̛reașe PA, Grîndahl-Hansen J, Kriștensen P, Nielsen LS, Skriver L. Plasminogen activators, tissue degradation, and cancer. Adv Canc, Res. 44, 139-266, 1985.

14. Dusseau JW, Hutchins PM. Hypoxia-induced angiogenesis in chick chorio-allantoic membranes: a role for adenosine. Respiratory Physiology. 71, 33-44, 1988.

15. Evenwel RT. Kasbergen CM, Struyker Boudier HAJ. Central and regional hemodynamics and plasma volume distribution dur. ing the development of spontaneous hypertension in rats. Clin and Exper Hypertension. A5, 1511-1536, 1983.

16. Fernandez $L A$, Twickler I, Mead A. Neovascularization produced by angiotensin-II. The journal of Laboratory and Clinical Medicine. 105, 141-145, 1985.

17. Folkman 1. Klagsbrun M. Angiogenic factors. Science. 235, 442-447, 1987.

18. Gibbons GH, Pratt RE, Dzua VJ. Vascular smooth muscle hypertrophy vs. hyperplasia. Autocrine Transforming Growth Factor. beta1 expression determines growth response to angiotensin-1l. I Clin Invest. 90, 456-451, 1992.

19. Greene AS, Tonellato PJ, Zhang Z, Lombard JH, Cowley AW. Effects of microvascular rarefaction on tissue oxygen delivery in hypertension. Am J Physiol. 262. H2486-H1493, 1992.

20. Guyton AC, Granger JH, Coleman TG. Autoregulation of the total systemic circulation and its relation to control of cardiac output and arterial pressure. Circ Res. 28 (Suppl. 1), 93-97, $197 \%$.

21. Hang J. Kong L, Gu (W. Adair TH. VEGF gene expression is upregulated in electrically stimulated rat skeletal muscle. Am J Physiol. 269, $\mathrm{H} 1827-\mathrm{H} 1831,1995$.

22. Hashimoto H, Prewitt RL, Efaw CW. Alterations in the microvasculature of one-kidney, one-clip hypertensive rats. Am I Physiol. 253, H933-H940, 1987.

23. Hernandez I. Cowley AW, Lombard IH, Greene AS. Salt intake and angiotensin-II alter microvessei density in the cremaster muscle of normal rats. Am I Physiol. 263. H664-H667, 1992.

24. Hudlicka O, Brown M, Egginton S. Angiogenesis in skeletal and cardiac muscle. Physsiological reviews. 72, 369-417, 1992. 
25. Hudlicka 0, Tyler KR: Angiogenesis: the growth of the vascular system(ed 1). London, Atademic Press, 1986.

26. Koolwijk P, VanErck MGM, DeVree WJA, Vermeer MA, Weich HA, Hanemaaijer R, VanHinsbergh WM. Cooperative effect of TNF $¥$, bFGF and VEGF on the formation of tubular structures of human microvascular endothelial, cells in a fibrin matrix, role of urokinase activity. I Cell Biol. 132, 1177-1188, 1996.

27. Law CM, Barker DJP, Bull AR, Osmond C. Maternal and fetal influences on blood pressure. Arch Dis Childhood. 66, 1291. 1295, 1991.

28. Lombard JH, Hess ME, Stekiel W. Neural and local control of arterioles in SHR. Hypertension. 6, 530-535, 1984.

29. Marticornes E, Ruiz L, Severino J, Galvez J, Penaloza D. Systemic blood pressure in white men born at sea tevel: changes after long residence at high altitudes. American lournal of Cardiology. 23, 364-368, 1969.

30. Mecham RP, Stenmark KR, Parks WC. Connective tissue production by vascular smooth muscle in development and disease. CHEST. 99 (3) (Supplement), 43S-47S, 1991.

31. Murphy TJ, Nakamura Y, Takeuchi K, Alexander RW. A cloned angiotensin receptor isoform from the turkey adrenal gland is pharmacologically distinct from the mammalian angiotensin receptor. Mol Pharmacol. 44, 1-7, 1993.

32. Nelissen-Vrancken MHJ, Struyker-Boudier HAJ, Daemen MJAP, Smits JFM. Antihypertensive therapy and adaptive mechanisms in peripheral ischemia. Hypertension. 22, 780-788, 1993.

33. Owens GK. Regulation of differentiation of vascular smooth muscle cells. Physiological reviews. 75, 487-517, 1995.

34. Pauly RR, Passaniti A, Crow M, Kinsella JL, Papadopoulos N, Monticone R, Lakatta EG, Martin GR. Experimental models that mimic the differentiation and dedifferentiation of vascular cells. Circ. 86 (Suppl. III), III68-11173, 1992.

35. Prewitt RL, Cardoso SS, Wood WB. Prevention of arteriolar rarefaction in the spontaneously hypertensive rat by exposure to simulated high altitude. J Hyper. 4, 735-740, 1986.

36. Prewitt RL, Chen IIH, Dowell RF. Microvascular alterations in the one-kidney, one clip hypertensive rat. Am / Physiol. 246. $\mathrm{H}_{724}-\mathrm{H}_{732}, 1984$.

37. Prewitt RL, Wang DH, Nakamiura Y, Smith EG: Growth and modification in number of resistance vessels, in Bevan JA (ed): The resistance vasculature., Humana Press, 1991, p 127

38. Price RJ, Owens GK, Skalak TC. Immunohistochemical identification of arteriolar development using markers of smooth muscle differentiation: evidence that capillary arterialization proceeds from terminal arterioles. Circ Res. 75. 520-527, 1994 .

39. Price RJ, Skalak TC. Circumferential wall stress as a mechanism for arteriolar rarefaction and proliferation in a network model. Microvasc Res. 47, 188-202, 1994.

40. Price RJ, Skalak TC. A circumferential stress-growth rule predicts arcade arteriole formation in a network model. Microcirculation. 2, 41-51, 1995.

41. Ruiz L, Penaloza D. Altitude and hypertension. Mayo Clin Proc. 52, 442-445, 1977.

42. Sage EH, Vernon RB. Regulation of angiogenesis by extracellular matrix: the growth and the glue. I Hypei. 12 (Suppi. 10). $S_{145}-S_{152}, 1994$.

43. Schmid-Schoenbein GW, Zweifach BW, Kovalcheck S. The appitation of stereological principles to morphometry of the microcirculation in different tissues. Microvasc Res. 14, 303-317. 1977.

44. Sholley MM, Ferguson GP, Seibel HR, Montour JL. Wiison JK. Mechanisms of neovascularization: vascular sprouting can occur without proliferation of endothelial cells. Lab Inv. 51, 624-632, 1984 .

45. Stoll M, Meffert S, Stroth U, Unger T. Growth or antigrowth: angiotensin and the endothelium. J Hyper. 13, 1529-1534, 1995.

46. Stoll M, Steckelings M, Paul M, Bottari SP, Metzger R, Unger T. The angiotensin AT2-receptor mediates inhibition of cell proliferation in coronary endothelial cells. I Clin Invest. 95. 65,-657, 1995.

47. Strick DM, Waycaster RL, Montani JP, Gay W], Adair TH. Morphometric measurements of chorioallantoic membrane vascularity: effects of hypoxia and hyperoxia. Am I Physiol. 260, $\mathrm{H}_{1385} \cdot \mathrm{H}_{13} 89,1991$.

48. Struyker-Boudier HAl: Vascular growth and hypertension, in Swales JD (ed): Textbook of Hypertension. London, Blackwell Scientific Publications, 1994, p 200.

49. Vernon RB. Sage HE. Between molecules and morphology: extracellular matrix and creation of vascular form. American Journal of Pathology. 147, 873-883. 1995. 
50. Wang DH, Prewitt RL. Captopril reduces aortic and microvascular growth in hypertensive and normotensive rats. Hypertension. 15, 68-77, 1990.

51. Wang DH, Prewitt RL. Longitudinal effect of captopril on aortic and arteriolar development in nomotensive rats. Am I Physiol. 260, H1959-H1965, 1991.

52.Weber KT, Sun Y, Katwa LC, Cleutjens IPM. Connective tissue: a metabolic entity. Mol Cell Cardiol. 27, 107-120, 1995.

53. Weber KT, Sun Y, Tyagi SC, Cleutjens JPM. Collagen network of the myocardium: function, structural remodeling and regulatory mechanisms. Journal of molecular and cellular biology. 26, 279-292, 1994. 


\section{Summary}

In the general introduction (chapter 1) the main hypotheses about the genesis of essential hypertension are reviewed. These hypotheses point towards a primary role for functional and structural changes of the vasculature, in the genesis and maintenance of the increased peripheral resistance, and therefore the high blood pressure in essential hypertension. A change in vascular architecture, specifically, a decrease in the number of available vessels (both arterioles and capillaries) to carry flow, rarefaction, has been implicated to be the initiating event causing the increase in peripheral resistance. The vascular bed arises during early embryogenesis from the processes vasculogenesis and angiogenesis. Thereafter, the architecture of a vascular bed can be dynamically regulated depending on the perfusion status (pressure and flow), metabolic demand and the release of local growth factors. The factors that may influence formation and modulation of vascular architecture are briefly discussed. Restoring vascular architecture in essential hypertension by means of administration of microvascular growth factors may provide a useful clinal approach in the early treatment of essential hypertension. Given the putative role of the renin-angiotensin system in vascular development, drugs influencing this system are possible candidates.

Chapter 2 provides experimental evidence showing that angiotensin-II can stimulate microvascular growth in the chick embryo chorio-allantoic (CAM) angiogenesis assay. This response could only be blocked by the peptidergic $\mathrm{AT}_{2}$ antagonist CGP42112A. The nonpeptidergic AT antagonist PD123319 and $\mathrm{AT}_{1}$ antagonist losartan (DuP753) were not effective. Additional biochemical analysis revealed the existence of a single class of AT receptors with a total number of binding sites of $1190 \mathrm{fmol} / \mathrm{mg}$ protein and an affinity constant for angiotensin-II of $2.7 \mathrm{nM}$. The inhibitory concentrations (IC $\mathrm{I}_{\mathrm{si}}$ ) for CGP42112A, PD12.3319 and losartan were $724,>100.000$, and $59.000 \mathrm{nM}$ respectively. These data suggest that the AT receptor mediating microvascular growth is different from the $\mathrm{AT}_{1}$ and $\mathrm{AT}_{2}$ receptor.

The arteriolar branching pattern in the chick embryo chorio-allantoic membrane is in general dichotomous. It was observed that angiotensin- II and angiotensin-II in combination with losartan changed this pattern and induced the formation of arteriolar-arteriolar connections, arcades. Arcades may be formed by acceleration of the arteriolization process, the upgrading of pre-existing capillary tubes into arterioles by investing the capillary wall with vascular smooth muscle cells. Chapter 3 describes a method to quantify arcade formation, and it is shown that interfering with prostaglandin synthesis can mimick the same changes in arteriolar pattern as observed with angiotensin-II and losartan. It is therefore hypothesized that angiotensin-II can stimulate the process of capillary upgrading into arterioles by stimulation of arteriolar smooth muscle cell growth. Prostaglandins normally counteract this effect. After blockade of prostaglandin action, the angiotensin-II induced arteriolization is enhanced, resulting in pronounced arcade formation. The actions of losartan may be related to its inhibitory effects on prostaglandin synthe'sis or action rather than AT receptor antagonism. 
By means of autoradiography (chapter 4), the chick embryo chorio-allantoic AT receptor was localized in the vascular wall of developing arterioles. Cell-types identified to express AT receptors were fibroblasts and vascular smooth muscle cells. The expression of the AT receptor was developmentally regulated and it ran parallel with the vascular growth velocity. These observations are in accordance with the hypothesis that angiotensin-II, either directly, through stimulation of vascular smooth muscle growth, or indirectly, through activation of fibroblasts and subsequently changes in extracellular matrix, can stimulate growth of arterioles.

Growth of capillaries, true angiogenesis, is dependent on endothelial cell proliferation. Using an in vitro approach with rat cardiac endothelial cells, it was shown that angiotensin-II can induce endothelial cell growth (chapter 5). This response however, was only evident at low levels $(5 \%, 7.5 \%)$ of supplemented growth serum. The endothelial growth stimulating effect of angiotensin-II most likely dependend on activation of the $\mathrm{AT}_{1}$ receptor.

Rarefaction in essential hypertension may be due to hampered outgrowth of the microvascular system. To evaluate the contribution of blood-borne factors to microvascular growth, serum was isolated from both normotensive Wistar Kyoto (WKY) rats and spontaneously hypertensive rats (SHR) at 6 and 12 weeks, and tested in the CAM angiogenesis assay (chapter 6). The serum angiogenic capacity was transiently increased during early development in WKY versus SHR. The relative decrease of angiogenic factors in SHR serum might therefore contribute to rarefaction.

Chapter 7 attempts to integrate some of the present hypotheses on the hemodynamic consequences of arteriolar growth. To evaluate the effects of arteriolar growth on resistance to flow, a computer model was constructed (S-model) that could vary addition of new arteriolar segments with the position in the growing tree. Growth of arterioles along existing segments, segmental growth, resulted in slight reduction in resistance. However, growth of arterioles at the terminal part of the arteriolar network, terminal growth, increased resistance.

Based on in vivo vessel length and diameter measurements, resistance to flow of the developing CAM arteriolar tree (day 7 - day 14) could be calculated. The calculated resistance to flow decreased $2 \%$ in the period day $7-10$, and $12 \%$ in the period day 10 14. Topological analysis of the same developing CAM arteriolar tree revealed that the growth process started with segmental growth and within time converged towards terminal growth. Based on these data it was concluded that the change in the calculated resistance to flow during the period day 7-10 may be explained by the topological growth pattern, whereas during the period day 10-14, change in resistance is mainly dependent on an increase in arteriolar lumen diameter. It is postulated that the differential topological patterns of arteriolar growth are determined by a time-varying contribution of transmural pressure (early) and flow or metabolic influences (late') on vascular growth. 
The thesis ends with a discussion about the putative role of the renin-angiotensin system in vascular development (chapter 8 ). The implications of changes in the regulation of vascular development for resistance to flow, and the genesis of essential hypertension are discussed.

\section{Samenvatting}

Essentiële hypertensie wordt gekenmerkt door een verhoogde bloeddruk, een normaal hart-minuut volume en een verhougde perifere weerstand. De permanent verhoogde perifere weerstand wordt gezien als de oorzaak voor het ontstaan en in stand houden van de hoge bloeddruk. Hoofdstuk 1 beschrijft de voornaamste hypotheses ten aanzien van het onstaan essentiële hypertensie. Er wordt gesuggereerd dat zowel functionele als structurele veranderingen in het arteriële vaatbed ten grondslag liggen aan de verhoogde perifere weerstand. Er wordt gepostuleerd dat een afname in het voor perfusie beschikbare aantal bloedvaten (zowel arteriolen als capillairen), rarefaction, mogelijk een rol speelt tijdens de initiële fase in het ontstaan van de verhoogde perifere weerstand. Het vaatbed wordt gevormd tijdens de vroege embryonale fase uit de processen vasculogenese en angiogenese. Na de vorming van het vaatstelsel, kan de architectuur dynamisch aangepast worden afhankelijk van de perfusie-status (druk en flow), metabole vraag, of de aanwezigheid van lokale groeifactoren. Deze processen worden kort bediscussieerd. Herstel van een normale vaatarchitectuur in essentiële hypertensie door het toedienen van groeifactoren voor bloedvaten, is mogelijk klinisch toepasbaar voor het, in een vroege fase, behandelen van essentiële hypertensie. Op basis van de mogelijke rol van het renine-angiotensine systeem in vaatgroei, behoren farmaca die ingrijpen op de werking van dit systeem tot de mogelijke kandidaten.

In hoofdstuk 2 worden de effecten van angiotensine-Il en angiotensine-receptor blokkers op microvasculaire groei beschreven. Angiotensine-II bleek instaat vaatgroei te bevorderen. Dit effekt kon geblokkeerd worden door de peptiderge $\mathrm{AT}_{2}$ blokker CGP42112A. Echter, de non-peptiderge $\mathrm{AT}_{1}$ blokker losartan (DuP753) en $\mathrm{AT}_{2}$ blokker PD123319, waren niet effectief. Additionele biochemische analyse toonde één type angiotensine receptor aan met een bindingsaffiniteit van $2.7 \mathrm{nM}$ voor angiotensine-II en een dichtheid van $1190 \mathrm{fmol} / \mathrm{mg}$ eiwit. De IC $\mathrm{C}_{50}$ voor CGP42112A, losartan, en PD123319 bedroegen respectivelijk 724, >100.000, en 59.000nM. Hieruit wordt geconcludeerd dat het bloedvatgroei stimulerende effect van angiotensine--II berust op activatie van een $A T$ receptor die afwijkt van de $A T_{1}$ en $A_{2}$ receptor.

Het arteriële vertakkingspatroon in de chorio-allantois membraan (CAM) van het kippe-embryo is vrijwel dichotoom. Toediening van angiotensine-II en angiotensine-II in combinatie met losartan resulteerde echter in de vorming van arteriolaire lussen, arcades of anastomoses. Arcades kunnen gevormd worden door het arteriolisatie proces te versnellen. 
Hoofdstuk 3 beschrift een methode om arcade vorming te quantificeren. Er wordt aangetoond dat blokkade van de prostaglandine synthese eenzelfde verandering in arteriolair vertakkingspatroon kan induceren als angiotensine-II en losartan. Er wordt daarom gepostuleerd dat angiotensine-II, door het bevorderen van groei van gladde spiercellen, het opwaarderen van capillairen in arteriolen actief kan stimuleren. Onder normale omstandigheden remmen prostaglandines dit effect. Na blokkade van de prostaglandine synthese valt dit remmende effect weg, en wordt het effect van angiotensine-II op het arteriolisatie proces sterker, resulterende in een verhoogd aantal arcades. Aangezien losartan gevoelige AT receptoren niet aanwezig zijn in het CAM, wordt gepostuleerd dat het effect van losartan het gevolg is van blokkade van prostaglandine synthese of werking.

Hoofdstuk 4 beschrijft een studie waarin, met behulp van autoradiografie, getracht werd de angiotensine receptor in het chorio-allantois membraan van het kippeembryo, te localiseren. De AT receptor kon gelocaliseerd worden in fibroblasten en gladde spiercellen in de vaatwand van maturerende arteriolen. De expressie van de AT receptor was tijdsafhankelijk en liep parallel met de groeisnelheid van de bloedvaten in het CAM. Deze observaties zijn in overeenstemming met de hypothese die stelt dat angiotensine-II, hetzij direct via stimulatie van groei van gladde spiercellen, hetzij indirect door activatie van fibroblasten en vervolgens veranderingen in de extracellulaire matrix, groei van arteriolen kan stimuleren. Groei van capillairen, angiogenese, is afhankelijk van proliferatie van endotheelcellen.

Hoofdstuk 5 beschrijft een in vitro experiment waarbij wordt aangetoond dat angiotensine-II groei van endotheel cellen kan stimuleren. Echter, dit effect was afhankelijk van de gebruikte concentratie ( $5 \%$ en $7.5 \%$ foetaal kalfserum) kweekmedium.

Rarefaction zoals geobserveerd in essentiële hypertensie, is mogelijk het gevolg van een verminderde uitgroei van het vaatstelsel. Om te achterhalen of in het bloed circulerende factoren betrokken zijn bij groei van bloedvaten, werd serum geisoleerd uit normotensieve Wistar Kyoto (WKY) ratten en spontaan hypertensieve ratten (SHR), van respectievelijk 6 en 12 weken oud. De angiogene capaciteit van het serum werd vervolgens getest op het CAM. Hieruit bleek dat de serum angiogene capaciteit van WKY ratten, in vergelijking tot SHR ratten, hoger was. De relatieve afname van circulerende angiogene factoren in SHR serum, draagt mogelijk bij tot het ontwikkelen van rarefaction. 
Hoofdstuk 7 integreert de huidige hypotheses aangaande de interactie tussen hemodynamica en de gevolgen voor arteriolaire groei. Voor het bestuderen van de gevolgen van arteriolaire groei op doorbloedingsweerstand werd een computer model ontwikkeld (S-model). Dit model kan additie (groei) van nieuwe arteriolaire segmenten variëren over de plaats in de vaatboom. Additie van arteriolen langs bestaande arteriolen, segmentale groei, resulteerde in een daling van de weerstand. Additie van nieuwe arteriolen aan het terminale deel van het vaatbed resulteerde in een stijging van de weerstand.

Op basis van de in vivo lengte en diameter metingen in de ontwikkelende arteriolaire vaatboom van het CAM (dag 7-14), kon de weerstand berekend worden. De berekende weerstand van de CAM arteriolaire vaatboom daalde met $2 \%$ in de periode dag $7-10$, en daalde $12 \%$ in de periode dag 10-14. Topologische analyse van deze vaatboom toonde aan dat het groeiproces initieël gedomineerd werd door segmentale groei, maar later in de ontwikkeling door terminale groei. Gebaseerd op deze gegevens werd geconcludeerd dat de veranderingen in weerstand gedurende de periode dag 710 mogelijk verklaard kunnen worden door het topologische groei patroon, terwijl de veranderingen in weerstand gedurende de periode dag 10-14 afhankelijk zijn van een arteriolaire lumen diameter toename. Er wordt gepostuleerd dat de verschillen in topologisch groei patroon veroorzaakt worden door een tijdsafhankelijk bijdrage van transmurale druk (vroege fase) en flow of metabole adaptatie (late fase) aan vaatgroei.

Het proefschrift wordt besloten (hoofdstuk 8) met een algemene beschouwing over de mogelijke betrokkenheid van het renine-angiotensine systeem in vaatgroei. Tevens worden de mogelijke oorzaken en implicaties van een verstoorde vaatgroei voor het ontwikkelen van essentiële hypertensie bediscussieërd. 


\section{Wetenschappelijke Publicaties}

\section{Full papers}

FAC le Noble, IWM Hekking, HWM van Straaten, DW Slaaf, HAJ Struyker Boudier. Angiotensin II stimulates angiogenesis in the chorio-allantoic membrane of the chick embryo. Eur. J. Pharmacol. 195: 305-306, 1991.

FAC le Noble, NHIS Schreurs, HWM van Straaten, DW Slaaf, JFM Smits, H Rogg, HAJ Struyker Boudier. Evidence for a novel angiotensin II receptor involved in angiogenesis in chick embryo chorio-allantoic membrane. Am J. Physiol. 264: R460-R465, 1993.

FAC le Noble, LCGA Kessels van Wylick, WJG Hacking, M oude Egbrink, DW Slaaf, HAJ Struyker Boudier. Pharmacological induction of arcade formation in a developing microvascular network. Journal of Vascular Research, nov. 1996, in press.

FAC le Noble, LCGA Kessels van Wylick, M. Blankesteijn, HAJ Struyker Boudier. Localization and expression of the chick-embryo angiotensin receptor in the developing vasculature of the chorio-allantoic membrane. Submitted for publication.

HAJ Struyker Boudier, JLML le Noble, MWJ Messing, MSP Huyberts, FAC le Noble, H van Essen. The microcirculation in hypertension. J. Hypertension 1992 (suppl 7): S147-S156.

HA] Struyker Boudier, MWJ Messing, HJMG Nelissen, MSP Huijberts, FAC le Noble, JFM Smits. Vascular actions of ACE inhibitors in hypertension: structural and functional consequences. In: Current advances in ACE inhibition 2, 1991, 1st edition. Mac Gregor GA, PS Sever (editor). Churchill Livingstone, Edinburgh; pp. 26-29.

HAJ Struyker Boudier, ILML le Noble, FAC le Noble, MWJ Messing, H van Essen. Hypertension, The microcirculation and Serotonin. Clin. Physiol. Biochem. 1990; 8 (suppl 3): $28-39$

\section{Abstracts}

FAC le Noble, JWM Hekking, HWM van Straaten, HAJ Struyker Boudier. Angiotensin-Il stimulates angiogenesis in the chick chorio-allantoic membrane. Eur. J. Pharmacol. 183(6), 2206, 1990.

FAC le Noble, NHIS Schreurs, DW Slaaf, HAJ Struyker Boudier. Mechanisms of microvascular growth induced by angiotensin II in the chick chorio-allantoic membrane. Pharmaceut. Wkbl. Sci. Ed 13 (suppl H), H7, 1991.

FAC le Noble, NHJS Schreurs, DW Slaaf, HAJ Struyker Boudier. Mechanisms of angiotensin 11 induced microvascular growth in the chick chorio-allantoic membrane. Proceedings 5 th World Congress for Microcirculation, 58 (nr. 794), 1991. 
FAC le Noble, NHJS Schreurs, CGA van Wylick, $H$ Rogg, HAJ Struyker Boudier. Pharmacological identification of a novel angiotensin receptor in the chorio-allantoic membrane of the chick embryo. Pharmaceut. Wkbl. Sci. Ed. 14 (suppl H), H9, 1992.

FAC le Noble, NHIS Schreurs, HWM van Straaten, DW Slaaf, JFM Smits, HAJ Struyker Boudier. Angiotensin II induced angiogenesis is not mediated through the AT1 receptor. The FASEB J. 6, A937, 1992.

FAC le Noble, NHIS Schreurs, HWM van Straaten, DW Slaaf, HAJ Struyker Boudier. Differential effects of angiotensin receptor antagonists on vascular development. Int. ]. Microcirc. Clin. Exp. 11 (suppl 1), S186, 1992.

FAC le Noble, NHJS Schreurs, H Rogg, I Smits, HAJ Struyker Boudier. Evidence for a novel angiotensin receptor involved in angiogenesis in the chorio-allantoic membrane of the chick embryo. The FASEB J. 7(3), A127, 1993.

FAC le Noble, NHJS Schreurs, H Rogg, D Slaaf, HAJ Struyker Boudier. Vascular alterations after modulations of the renin-angiotensin system in the chorio-allantoic membrane of the chick embryo. The FASEB J. 7(4), A892, 1993.

FAC le Noble, L Kessels van Wylick, $\mathrm{H}$ van Straaten, HAJ Struyker Boudier. Prostaglandins control the spatial organization of of blood vessels during angiotensin-II induced angiogenesis in the chick embryo. J. Anatomy 184, 705, 1994.

FAC le Noble, L Kessels van Wylick, M oude Egbrink, D Slaaf, HAJ Struyker Boudier. An important role for prostaglandins in arcade formation in the chick chorio-allantoic membrane. Int. J. Microcirc. Clin Exp. 14, 238, 1994.

FAC le Noble, L Kessels van Wylick, HAJ Struyker Boudier. Pharmacological induction of arteriolar arcade formation in the chick-embryo chorio-allantoic membrane. Pharmaceut. Wkbl. Sci. Ed. 18 (suppl H), H19, 1996.

FAC le Noble, L Kessels van Wylick, W Hacking, D Slaaf, HAJ Struyker Boudier. Topological growth pattern influences resistance during arteriolar development. Int. J. Microcirc. Clin. Exp. 16 (suppl 1), S128, 1996.

FAC le Noble, L Kessels van Wylick, HAl Struyker Boudier. Decreased angiogenic properties of serum from spontaneously hypertensive rats might explain rarefaction. Int. I. Microcirc. Clin. Exp. 16 (suppl 1), S223, 1996. 


\section{Curriculum Vitae}

Ferdinand A.C. le Noble

Geboren te Heerlen, 1 september 1968

1980-1986

Bernardinus college te Heerlen, Atheneum-beta. Afstudeervakken: wiskunde-1, wiskunde-2, natuurkunde, scheikunde, biologie, nederlands, engels.

\section{6-1991}

Gezondheidswetenschappen, afstudeerrichting biologische gezondheidkunde aan de Universiteit Maastricht (U.M.), Faculteit der Gezondheidswetenschappen.

Onderwerp afstudeerstage: farmacologische beïnvloeding van de angiogenese (begeleiders: Prof. dr. H.A.J. Struyker-Boudier, hoofd vakgroep Farmacologie, U.M.; Dr. H.W.M. van Straaten, universitair docent vakgroep Anatomie/Embryologie U.M.).

1991-1996

Assistent in opleiding bij de vakgroep Farmacologie, instituut hart- en vaatziekten

(CARIM), Universiteit Maastricht. Titel onderzoek: "rol van het renine angiotensine systeem in de vasculoneogenese". Project gefinancieerd door de Nederlandse Hartstichting. Titel proefschrift: "The renin-angiotensin system and arteriolar growth: consequences of vascular architecture for the development of hypertension".

In 1992 werd de DuPont losartan (cosaar) travel award gewonnen

(hoofd DuPont research: dr. P. Timmermans),

na een invited lecture voor de American Society for Pathology (FASEB, Los Angeles, USA).

1996-heden

Post-docterale medewerker bij de vakgroep Kindergeneeskunde/Neonatologie, academisch ziekenhuis Maastricht, Universiteit Maastricht. Hoofd: Prof. dr. C. Blanco. Onderzoeksproject: "cardiovascular regulation in neonates". 
$x 84$ 

